\title{
3. Zeiten des Konflikts: Belastungsproben für das deutsch- französische Verhältnis in den 1970er Jahren
}

\subsection{Französische Ängste vor »Großdeutschland»}

Nach Jahren einer sowohl selbst auferlegten als auch durch die Besatzungsmächte erzwungenen außenpolitischen Zurückhaltung Westdeutschlands läutete der Regierungsantritt der von Willy Brandt geführten sozialliberalen Koalition im Jahr 1969 eine Zeit eigenständigeren Handelns der Bonner Diplomatie in der Nachkriegsära ein. Diese Entwicklung schlug sich vor allem in der umfassenden Neuausrichtung der seit langem brach liegenden Ostpolitik nieder, welcher in der anstehenden Legislaturperiode eine herausragende $\mathrm{Be}$ deutung zukam ${ }^{1}$. »Wandel durch Annäherung «" lautete das bald viel zitierte Konzept, mittels dessen die Bundesregierung die eingefrorenen Beziehungen zur Sowjetunion, zu den Staaten Ostmitteleuropas und zur DDR auf eine neue Basis zu stellen suchte. Für die Zeitgenossen unübersehbar begann sich die Bundesrepublik durch ihre groß angelegte außenpolitische Offensive endgültig von der Vormundschaft der einstigen Siegermächte zu befreien.

Bei allem inzwischen gewachsenen Vertrauen in die westdeutsche Demokratie reaktivierte das Eintreten der Bonner Politiker in direkte Verhandlungen mit den sowjetischen Machthabern auf Seiten der westlichen Regierungen, auch in Frankreich, einen weiterhin vorhandenen Restzweifel an der Stoßrichtung der deutschen Außenpolitik ${ }^{3}$. Vor allem standen die Fragen im Raum, wie weit die von den Initiatoren der Ostpolitik propagierte Annäherung an Moskau tatsächlich gehen würde und ob nicht die Bundesregierung bei einer entsprechenden Offerte der Versuchung erliegen könnte, die Wiedervereinigung im Tausch gegen ein neutrales Gesamtdeutschland

1 Vgl. Ulrich LappenküPer, Die Außenpolitik der Bundesrepublik Deutschland 1949 bis 1990, München 2008, S. 27-33 und S. 95-101.

2 Siehe zu diesem von Egon Bahr geprägten Schlagwort Peter Bender, Wandel durch Annäherung. Karriere eines Begriffs, in: Deutschland-Archiv 33 (2000), S. 971-978.

3 Vgl. Gottfried Niedhart, Zustimmung und Irritationen: Die Westmächte und die deutsche Ostpolitik 1969/70, in: Ursula Lehmkuhl, Clemens A. Wurm, Hubert Zimmermann (Hg.), Deutschland, Großbritannien, Amerika. Politik, Gesellschaft und internationale Geschichte im 20. Jahrhundert. Festschrift für Gustav Schmidt zum 65. Geburtstag, Stuttgart 2003, S. 227-246; Gottfried NiedHART, Ost-West-Entspannung aus amerikanischer, deutscher und französischer Sicht, in: Chantal Metzger, Hartmut KaELble (Hg.), Deutschland - Frankreich - Nordamerika: Transfers, Imaginationen, Beziehungen, Stuttgart 2006, S. 35-50. 
$\mathrm{zu}$ realisieren. Ein wiedervereinigter und womöglich unter sowjetischem Einfluss stehender gesamtdeutscher Staat stellte schließlich gerade aus französischer Sicht ein nicht zu kalkulierendes Sicherheitsrisiko dar. Frankreich hätte in diesem Szenario de facto eine direkte Grenze mit dem Machtbereich der UdSSR besessen und wäre zum potenziellen Schlachtfeld eines nuklearen Schlagabtausches zwischen den Bündnissystemen geworden. Die Wiederherstellung der deutschen Einheit konnte somit kaum im französischen Interesse liegen. Ziel der Pariser Regierung musste es vielmehr sein, den status quo in Europa zu wahren. So war es vor allem die Sorge, die bestehenden politischen Verhältnisse könnten sich durch eine Dynamisierung der deutschen Frage zum Nachteil Frankreichs verändern, welche während der 1970er Jahre eine Keimzelle deutsch-französischer Konflikte bildete.

Ebenso stieß die sich zu Beginn der 1980er Jahre entwickelnde westdeutsche Friedensbewegung in Frankreich vielfach auf Unverständnis ${ }^{4}$. Hatte sich die Bundesrepublik aus französischer Sicht bis dahin allzu ergeben in den Dienst der amerikanischen Verbündeten gestellt und war gleichsam als Klassenprimus der atlantischen Allianz wahrgenommen worden, so brachten der nun um sich greifende Pazifismus und die Forderungen nach atomarer Abrüstung dieses Bild gehörig ins Wanken. Der eben noch solide in den westlichen Verteidigungsstrukturen verankerte Nachbar erschien plötzlich als unsicherer Kantonist, auch wenn die Bundesregierung unter Helmut Schmidt ein klares Bekenntnis zur Bündnistreue ihres Landes ablegte. Scherte Westdeutschland unter dem Druck der Friedensdemonstrationen aus der NATO aus, würde es über kurz oder lang, so zumindest die Befürchtung, entweder zu einem Satellitenstaat der Sowjetunion werden oder auf den aggressiv nationalistischen Weg der deutschen Vergangenheit zurückkehren. Ostpolitik, deutsche Frage und Friedensbewegung stellten somit eine große Herausforderung des deutschfranzösischen Verhältnisses dar, welcher sich die erklärten Protagonisten der Annäherung, wie das folgende Kapitel zeigt, mit ihren Möglichkeiten entgegenstemmten.

\subsubsection{Die Bonner Ostpolitik: eine Bedrohung für Frankreich?}

Der französische Staatspräsident Georges Pompidou und die von ihm berufenen Regierungen sicherten zwischen 1969 und 1973 den ostpolitischen Initiativen der Bundesregierung Willy Brandts zwar öffentlich ihre Unterstützung $\mathrm{zu}$ und betonten regelmäßig das gemeinsame Interesse an einer

${ }^{4}$ Vgl. PfeIL, Die »anderen« deutsch-französischen Beziehungen, S. 567-570; GeorgesHenri Soutou, Mitläufer der Allianz? Frankreich und der NATO-Doppelbeschluss, in: Philipp Gassert, Tim Geiger, Hermann Wentker (Hg.), Zweiter Kalter Krieg und Friedensbewegung. Der NATO-Doppelbeschluss in deutsch-deutscher und internationaler Perspektive, München 2011, S. 363-376. 
Entspannungspolitik gegenüber den Staaten des Warschauer Pakts ${ }^{5}$. Dennoch kamen in Frankreich angesichts der engeren Beziehungen, welche die Bundesrepublik seit Amtsantritt der sozialliberalen Koalition zur Sowjetunion aufnahm, immer wieder Zweifel an der Aufrichtigkeit der westdeutschen Beweggründe auf. Diese schlugen sich insbesondere in der französischen Presseberichterstattung über die Bonner Ostpolitik nieder. Ängste vor einer neuerlichen deutsch-russischen Annäherung, einem »zweiten Rapallo « ${ }^{6}$, und Misstrauen gegenüber einem sich hierdurch möglicherweise eröffnenden Weg für eine Wiedervereinigung Deutschlands fanden unterschwellig oder offen Eingang in die französischen Zeitungen. Zu Beginn der 1970er Jahre stellten sie ein latent vorhandenes Konfliktpotenzial in den Beziehungen zwischen beiden Ländern dar $^{7}$. Schließlich berührte die diplomatische Offensive der Bundesrepublik nicht nur das Sicherheitsempfinden, sondern in ebensolchem Maße die Stellung Frankreichs als eine der vier Kontrollmächte und damit auch seine sich aus weltpolitischen Ambitionen speisende Rolle als Vermittler zwischen Ost und West. Dementsprechend wurde im Quai d'Orsay vermerkt: »Quel que soit le jugement d'ensemble que nous pouvons porter sur cette politique d'ouverture vers l'Est du gouvernement fédéral [...], il n'est pas douteux que, telle qu'elle est mise en œuvre aujourd'hui, elle concerne directement nos propres intérêts « ${ }^{8}$.

${ }^{5}$ Vgl. zum Beispiel die Rede Staatspräsident Pompidous anlässlich des deutsch-französischen Gipfeltreffens in Paris am 30. Januar 1970, in: Bulletin des Presse- und Informationsamtes der Bundesregierung 16 (1970), S. 149 sowie Jean SCHWcebel, Paris approuve pleinement la politique d'ouverture à l'Est, in: Le Monde, 01.02.1970, S. 1.

6 Vgl. Andreas Wilkens, Retour à Rapallo. À propos d'un mythe qui vient de loin, in: Pfeil (Hg.), Mythes et tabous des relations franco-allemandes, S. 87-110; vgl. allgemein zu dem 1922 im italienischen Rapallo geschlossenen deutsch-russischen Vertrag Gottfried NIEDHART, Die Außenpolitik der Weimarer Republik, München ${ }^{2} 2006$, S. 15f. und S. 90-97; Eberhard Kolв, Die Weimarer Republik, München ${ }^{6} 2002$, S. 220-223 mit zahlreichen weiterführenden Literaturhinweisen; Heinrich KLÜMPEN, Deutsche Außenpolitik zwischen Versailles und Rapallo. Revisionismus oder Neuorientierung?, Münster, Hamburg 1992; Martin Schulze Wessel, Rapallo, in: Étienne François, Hagen Schulze (Hg.), Deutsche Erinnerungsorte, München 2009, S. 537-551.

7 Vgl. hierzu Christian M. Schmitz, Zwischen Mythos und Aufklärung: Deutschland in der außenpolitischen Berichterstattung der Zeitung Le Monde 1963 bis 1983. Eine Untersuchung zu Kontinuität und Wandel französischer Deutschlandbilder unter Berücksichtigung der Presseorgane L'Express, Le Nouvel Observateur und France-Soir, Frankfurt a.M. u. a. 1990, S. 151-198.

8 AMAE Paris-La Courneuve, Europe, RFA 1961-1970, Bd. 1546, Vermerk betreffend »Politique de M. Brandt à l'égard des pays de l'Est« vom 1. Dezember 1969, S. 6; vgl. allgemein zu den französischen Reaktionen auf die westdeutsche Ostpolitik Werner LINK, Außen- und Deutschlandpolitik in der Ära Brandt 1969-1974, in: Karl-Dietrich Bracher, Wolfgang JäGER, Werner LINK, Geschichte der Bundesrepublik Deutschland, Bd. 5, Teil I: Republik im Wandel 1969-1974. Die Ära Brandt, Stuttgart 1986, S. 163-282, hier S. 238-241; Hans-Peter Schwarz, Willy Brandt, Georges Pompidou und die Ostpolitik, in: Möller, VAÏsse (Hg.), Willy Brandt und Frankreich, S. 155-165; Georges-Henri Soutou, Willy Brandt, Georges Pompidou et l'Ostpolitik, in: Möller, 
Bereits nach den ersten Sondierungsgesprächen zwischen dem deutschen Botschafter Helmut Allardt und dem sowjetischen Außenminister Andrej Gromyko in Moskau Anfang Dezember $1969^{9}$ zeigten sich verschiedene Pariser Presseorgane alarmiert. Die Kommentatoren fragten, ob dies nun der Beginn eines neuen deutsch-sowjetischen Bündnisses sei, im Rahmen dessen die Bonner Regierung in die Position des privilegierten europäischen Verhandlungspartners der Moskauer Machthaber aufrücke und Frankreich ins Abseits des internationalen Geschehens gedrängt werde ${ }^{10}$. Die Wochenzeitschrift »Paris Match« bebilderte ihren Bericht über das Treffen zwischen Allardt und Gromyko gar mit Fotos der Zusammenkunft zwischen Reichsaußenminister Joachim von Ribbentrop und Stalin vom August 1939 und warf die Frage auf, ob die jüngsten Moskauer Gespräche nicht mit einem zweiten Nichtangriffspakt gleichzusetzen seien ${ }^{11}$. »Le Monde« führte die bestehenden Befürchtungen in der Frage zusammen: »Faut-il favoriser résolument une nouvelle version, cette fois pacifique et diplomatique du >Drang nach Osten qui marque si profondément l'histoire allemande ${ }^{12}$ ?

Durch die Unterzeichnung des Moskauer Vertrags am 12. August 1970 sahen sich diejenigen französischen Publizisten, die in der westdeutschen Politik eine Gefahr für Frankreich und Europa ausgemacht hatten, in ihrer Haltung

VAÏsse (Hg.), Willy Brandt und Frankreich, S. 121-154; Soutou, L'alliance incertaine, S. 311-349; Raymond Poidevin, Sur le malaise 1969-1974: questions de l'historien, in: Manfrass (Hg.), Paris-Bonn, S. 236-240; Ernst Weisenfeld, Ostpolitik und deutsche Frage: Französische Initiativen und deutsche Ostpolitik, in: Manfrass (Hg.), Paris-Bonn, S. 247-259; Ernst Weisenfeld, Frankreich und die deutsche Ostpolitik, in: Franz KNIPPING, Ernst WeISENFELD (Hg.), Eine ungewöhnliche Geschichte. Deutschland-Frankreich seit 1870, Bonn 1988, S. 177-186; WiLKens, Der unstete Nachbar, S. 177-188; Michael Meimeth, Frankreichs Entspannungspolitik der 70er Jahre zwischen Status quo und friedlichem Wandel: die Ära Georges Pompidou und Valéry Giscard d'Estaing, BadenBaden 1990.

9 Vgl. Schreiben Botschafter Allardts an Bundesminister Scheel vom 8. Dezember 1969, in: AAPD 1969, Bd. II, Dok. 392; Detlef NaKath, Das Dreieck Bonn - Ost-Berlin - Moskau. Zur sowjetischen Einflußnahme auf die Gestaltung der deutsch-deutschen Beziehungen (1969-1982), in: Ulrich Pfeil (Hg.), Die DDR und der Westen. Transnationale Beziehungen 1949-1989, Berlin 2001, S. 99-115, hier S. $106 f$.

${ }^{10} \mathrm{Vgl}$. Du Rhin à l'Oural. Six semaines après l'arrivée au pouvoir du chancelier Brandt, l'URSS et la RFA engagent des pourparlers sur une déclaration de non-recours à la force, in: Combat, 09.12.1969, S. 1; Frankreich: Letzte Zuflucht, in: Der Spiegel, 15.12.1969, S. 52.

${ }^{11}$ Vgl. William de Bazelaire, Brandt joue et gagne, in: Paris Match, 20.12.1969, S. $18 \mathrm{f}$.

12 Paul-Jean Franceschini, Du bon usage de l'Allemagne, in: Le Monde, 04.07.1970, S. 6; Le Monde berichtete allerdings mehrheitlich wohlwollend über die Bonner Ostpolitik, vgl. hierzu beispielhaft Ders., Les rapports entre Bonn et Berlin-Est: De la réunification à la »nation allemande" ou l'agonie d'un mythe, in: Le Monde, 27.12.1969, S. 4; Maurice Duverger, L'heure de l'Allemagne?, in: Le Monde, 07./08.06.1970, S. 1; Nous ne nous adressons pas à l'Est en francs-tireurs nous déclare le chancelier fédéral, in: Le Monde, 31.01.1970, S. 1. 
nur allzu bestätigt ${ }^{13}$. Die Zeitung »Combat « etwa zog hieraus die Schlussfolgerung, die Bundesrepublik werde künftig der Versuchung nicht widerstehen können, zwischen ihrer Verankerung im Westen und ihren östlichen Hoffnungen nach Gutdünken zu changieren und sich als exklusiven europäischen Dialogpartner der Sowjetunion in Stellung zu bringen ${ }^{14}$. In ähnlicher Weise beschwor »L'Aurore « das französische »Rapallo-Trauma ${ }^{15}$ herauf und wies eindringlich auf die Gefahr hin, welche die deutsch-sowjetische Entente für Frankreichs Sicherheit bedeute ${ }^{16}$. Das Wochenblatt "L'Express « forderte angesichts der vertieften Beziehungen der Bonner Verantwortlichen zur Moskauer Regierung, die Bundesrepublik im Rahmen eines forcierten Integrationsprozesses noch stärker an den Westen zu binden ${ }^{17}$. Ein mit der bangen Frage »L'Europe allemande? « überschriebener Artikel der Wochenzeitschrift »Le Nouvel Observateur« vom Januar 1971 formulierte schließlich symptomatisch:

Ce que les Français craignent obscurément, depuis plus de vingt ans, vient justement d'arriver: l'Allemagne est sortie de son lit, l'Allemagne bouge. Étirant sa force énorme et toute neuve, elle s'ébroue vers l'extérieur [...]. Willy Brandt, pour la première fois depuis la fin de la guerre, traite avec Moscou, joue, hardiment, rapidement, de nouvelles cartes politiques. N'est-ce pas un signe ${ }^{18}$ ?

Weitere Nahrung erhielten die Kommentatoren im September 1971 durch die vertrauliche Zusammenkunft Bundeskanzler Brandts mit dem sowjetischen Staatschef Leonid Breschnew auf der Krim ${ }^{19}$. Hierdurch schien sich der Verdacht eines deutschen Abdriftens nach Osten und einseitiger Verhandlungen der Bundesregierung mit den sowjetischen Führern über die deutsche Frage

13 Vgl. ausführlich zum Abschluss des Vertragswerks Julia von DANNEnBERg, The Foundations of Ostpolitik. The making of the Moscow Treaty between West Germany and the USSR, Oxford 2008.

14 Siehe Bonn et Moscou renoncent à la force. Ils établissent entre eux les prémisses d'une coopération qui fera de la RFA le partenaire occidental privilégié de l'URSS, in: Combat, 08./09.08.1970, S. 1.

15 Vgl. Renata Bournazel, Rapallo. Ein französisches Trauma, Köln 1976.

16 Siehe Paul Stehlin, Les pactes germano-soviétiques. Jamais deux sans trois, in: L'Aurore, 11.08.1970, S. 4.

17 Vgl. Marc Ullmann, Willy Brandt change l'Europe, in: L'Express, 25.01.1971, S. 38-41.

18 Josette Alia, Gérard SAndoz, L'Europe allemande? M. Pompidou reçoit mardi le représentant de la nouvelle Allemagne, devenue la seconde puissance financière mondiale après les États-Unis, in: Le Nouvel Observateur, 25.01.1971, S. 16; vgl. auch Gérard SANDoz, Les nouveaux amis, in: Le Nouvel Observateur, 10.08.1970, S. 17; Michel BosQUET, Une Europe allemande?, in: Le Nouvel Observateur, 24.08.1970, S. 16.

19 Vgl. AAPD 1971, Bd. II, Dok. 310-311 und 314-315; Gottfried NiEDhART, Partnerschaft und Konkurrenz: Deutsche und französische Ostpolitik in der Ära Brandt und Pompidou, in: Ilja Mieck, Pierre Guillen (Hg.), Deutschland, Frankreich, Rußland - La France et l'Allemagne face à la Russie. Begegnungen und Konfrontationen, München 2000, S. 365-367; Ernst Weisenfeld, Welches Deutschland soll es sein? Frankreich und die deutsche Einheit seit 1945, München 1986, S. 116-121. 
weiter zu erhärten ${ }^{20}$. "Le Monde« etwa klagte, die Bundesregierung trete in vermutlich folgenreiche Gespräche mit Moskau ein, ohne auf die Belange ihrer westlichen Verbündeten in angemessener Form Rücksicht zu nehmen ${ }^{21}$. Dass die im Fahrwasser der Bonner ostpolitischen Verhandlungen auftauchende Möglichkeit eines wiedervereinigten Deutschland in Frankreich als Bedrohung wahrgenommen wurde, war neben der medialen Berichterstattung ebenso den Äußerungen verschiedener französischer Spitzenpolitiker geschuldet. Kaum verhohlen unterstellten diese dem Nachbarland und seiner Regierung neutralistische Tendenzen. Insbesondere Landwirtschaftsminister Jacques Chirac, der ehemalige gaullistische Innenminister Christian Fouchet und der Vorsitzende der Sozialistischen Partei, François Mitterrand, schienen das Ziel zu verfolgen, auf diese Weise die unterschwellig vorhandene Furcht vor einer Abkehr der Bundesrepublik von Westeuropa innenpolitisch für ihre Zwecke zu nutzen ${ }^{22}$. Schenkt man dem französischen Soziologen Raymond Aron Glauben, fanden derartige Attacken in Frankreich vor allem deswegen Widerhall, weil die Frage einer künftigen deutschen Einheit für seine Landsleute geradezu eine Obsession war. In einem Interview mit westdeutschen Journalisten vom September 1973 gab er zu Protokoll: »Die Franzosen sind von dem Gedanken an die deutsche Wiedervereinigung besessen - auch wenn diese gar nicht zur Debatte steht -, weil ein wiedervereinigtes Deutschland so viel stärker wäre als Frankreich. Dann kehren eben die jahrhundertealten Befürchtungen wieder « ${ }^{23}$.

Unterdessen blieben das in zahlreichen französischen Pressebeiträgen hervortretende Misstrauen gegenüber der Bonner Ostpolitik und vor allem die Berichterstattung über einen vermeintlichen Allianzwechsel der vielfach bedrohlich und aufgrund ihrer Wirtschaftskraft schier übermächtig dargestellten Bundesrepublik ${ }^{24}$ seitens der westdeutschen Zeitungen nicht

20 Vgl. Paris: Sorge über Bonns Ostpolitik, in: Der Spiegel, 20.09.1971, S. 105-107; auch die deutsche Botschaft Paris vermerkte hierzu, das Treffen des Bundeskanzlers mit Breschnew habe die deutsch-französischen Beziehungen »in gewissem Umfang auf die Probe gestellt«, PA-AA, Auslandsvertretungen, Botschaft Paris, Bd. 5198, Politischer Halbjahresbericht der deutschen Botschaft Paris vom 18. Januar 1972, S. 5.

${ }^{21}$ Siehe Les deux Allemagnes à l'ONU, in: Le Monde, 21.09.1971, S. 1; vgl. hierzu auch De Yalta à Oréanda, in: Le Monde, 17.09.1971, S. 1; Jean WETZ, La République fédérale est devenue une nation majeure, in: Le Monde, 21.09.1971, S. 2.

22 Vgl. hierzu Manuel LuCBERT, Le débat sur la neutralisation de l'Allemagne prend le pas sur le différend agricole entre Paris et Bonn, in: Le Monde, 18.08.1973, S. 1; Ders., Réunifier l'Allemagne ou les Allemands?, in: Le Monde, 05.09.1973, S. 1; Paris, Bonn et l'Europe, in: Le Monde, 14.08.1973, S. 1; François SCHLOSSER, Allemagne »dangereuse». Entre les trois tentations de l'Allemagne (l'Europe, les États-Unis, le rapprochement avec l'URSS), Pompidou comme Mitterrand, redoute que le socialiste Brandt ne choisisse un jour la troisième, in: Le Nouvel Observateur, 27.08.1973, S. 27-29; WILKENs, Der unstete Nachbar, S. 120-122; Schмiтz, Zwischen Mythos und Aufklärung, S. 172-176.

23 »Die Franzosen sind ein seltsames Volk«. Der Soziologe Raymond Aron über die Verstimmung zwischen Bonn und Paris, in: Der Spiegel, 03.09.1973, S. 90.

${ }^{24}$ Vgl. hierzu das in dieser Hinsicht symptomatische Buch des französischen Journalisten 
unkommentiert ${ }^{25}$. Die Anschuldigungen aus dem Nachbarland wurden vielmehr aufmerksam registriert und gaben nicht selten Anlass, um den französischen Partnern mangelndes Vertrauen, Missgunst gegenüber dem selbstbewussteren Auftreten der Bundesrepublik und eine Verkennung der außenpolitischen Intentionen der Regierung Willy Brandts vorzuhalten ${ }^{26}$. Dass der Bundeskanzler ohne gaullistische Vermittlung direkt mit Moskau verhandele, sei in Paris als unangemessener Einbruch in eine französische Domäne aufgefasst worden, schrieb etwa »Der Spiegel« Anfang Dezember 1969: "Bessere Kontakte zwischen Bonn und Moskau weckten sogleich Erinnerungen an den deutsch-sowjetischen Pakt von 1939 - Vorspiel zu Frankreichs letzter Niederlage ${ }^{27}$. Die Franzosen fürchteten angesichts der Bonner Initiativen, dass das Europa der Zukunft nicht mehr, wie von de Gaulle propagiert, vom Atlantik bis zum Ural, sondern nur noch vom Rhein bis zum Ural reichen werde und vermuteten, dass die Deutschen nach 1922 einmal mehr mit östlicher Rückendeckung zu viel Unabhängigkeit gewinnen könnten. Allein die vage Aussicht auf eine politische Entspannung zwischen Westdeutschland und der Sowjetunion schrecke die Nachbarn im Westen ${ }^{28}$. Das in diesen Reaktionen zu erkennende "Inselbewußtsein der Franzosen " mache sie, wie das Blatt den deutschen Lesern berichtete, zu einem äußerst schwierigen Partner für die Bonner Politiker. Die Angst vor der deutschen ökonomischen Stärke habe die Franzosen schon seit Jahren gequält, die Ostbemühungen der Bundesrepublik verstärkten ihren bereits bestehenden Argwohn nun umso mehr ${ }^{29}$. Allenthalben vermute man in Frankreich, dass das heimliche Ziel der westdeutschen Außenpolitik die Vereinigung der beiden deutschen Teilstaaten zu einem neutralen Gesamtdeutschland sei ${ }^{30}$. Über vierzig Prozent der französischen Bevölkerung, so wusste das Nachrich-

Michel Salomon, Faut-il avoir peur de l'Allemagne?, Paris 1969, das in Frankreich auf breite Resonanz stieß; vgl. auch die Einschätzung zum französischen Deutschlandbild Anfang der 1970er Jahre von Henri MéNudier, Viel bewundert, aber mehr gefürchtet. Deutschland mit den Augen der Franzosen gesehen, in: FAZ, 06.10.1973, S. $7 f$.

25 Vgl. Roland Delcour, M. Brandt va tenter de dissiper les réticences françaises sur la politique de l'Est, in: Le Monde, 03.07.1970, S. 1 und 4.

26 Vgl. August von Kageneck, Ostpolitik ohne Frankreich, in: Die Welt, 15.12.1969, S. 2; Allerlei französische Zweifel, in: SZ, 10.12.1969, S. 4; Jan ReIfenberG, Bewunderung und Sorge in Paris über Moskauer Gespräche, in: FAZ, 10.12.1969, S. 3.

27 Frankreich: Deutschenfurcht härter als Gold, in: Der Spiegel, 08.12.1969, S. 143.

${ }^{28}$ Frankreich: Letzte Zuflucht, in: Der Spiegel, 15.12.1969, S. 52; vgl. zu dieser Argumentation auch Ernst WeIsenfeld, Pompidou als Hemmschuh? Brandts Ostpolitik - ein heikles Thema der Bonner Konferenz, in: Die Zeit, 03.07.1970, S. 5.

29 „Sterben, um geliebt zu werden«. Spiegel-Redakteur Dieter Wild über die DeutschenFurcht der Franzosen, in: Der Spiegel, 01.02.1971, S. 76; vgl. auch: Entente cordiale gegen Bonn?, in: Der Spiegel, 17.05.1971, S. 92-94.

${ }^{30}$ Vgl. Europa: »Zum Zusammenraufen verdammt«, in: Der Spiegel, 20.08.1973, S. 17 und 19. 
tenmagazin im September $1971 \mathrm{zu}$ berichten, fürchteten, dass Deutschland eines Tages wieder eine Gefahr für Frankreich werden könnte ${ }^{31}$.

Auch »Die Welt «, namentlich der Pariser Korrespondent der Zeitung, August von Kageneck, stellte fest, die französische Presse reagiere ausnehmend heftig auf die Kontakte zwischen Bonn und Moskau. Die Kommentatoren der französischen Zeitungen hätten, wie von Kageneck schrieb, der Versuchung nicht widerstehen können, »einen gewagten historischen Vergleich mit dem deutsch-sowjetischen Rapallo-Vertrag von 1922 zu ziehen « ${ }^{32}$. Selbst ein so maßvoll urteilendes Blatt wie »Le Monde« habe die Abwendung der Bundesrepublik vom Westen und einen Rückfall der deutschen Diplomatie in klassische Balancepolitik nicht ausgeschlossen. Mit unübersehbarem Misstrauen beobachte man daher in Paris den deutschen Alleingang in Richtung Osten, der aus französischer Perspektive die Gefahr einer dynamischen deutschen Politik in Europa mit sich bringe, welche das "Spiel der Kräfte» stören könnte ${ }^{33}$. In ähnlicher Weise sah schließlich die »Frankfurter Allgemeine Zeitung « das "Rapallo-Gespenst ${ }^{34}$ in Frankreich umgehen. In einem Kommentar vom Januar 1970 wertete das Blatt die Pariser Reaktionen auf die beginnenden Verhandlungen der Bundesregierung mit der sowjetischen Führung als »Eifersucht, von der manchmal die französischen Außenpolitiker [...] bei der wachsamen Beobachtung der bescheidenen Bonner Züge jenseits der Nato-Topographie erfaßt zu sein scheinen ${ }^{35}$. Die Vorstellung, dass am Ende Brandt die Mittlerrolle zwischen Ost und West zufallen könnte, die sich de Gaulle für Frankreich erhofft hatte, sei, wie die Zeitung schrieb, den Planern und Akteuren der französischen Weltpolitik "ganz schrecklich « ${ }^{36}$. Zwar weisen weitere Presseorgane, wie etwa »Die Zeit«, auch Beispiele für einen Berichtsstil auf, der mehr Verständnis für die französischen Sicherheitsinteressen und historisch begründeten Ängste erkennen lässt ${ }^{37}$. Doch deuten die zitierten Zeitungsartikel an, dass zahlreiche westdeutsche Journalisten sich bemüßigt sahen, die in Frankreich angesichts des gewachsenen außenpolitischen Bewegungsradius der Bundesrepublik festzustellenden Besorgnisse

${ }^{31}$ Vgl. Paris: Sorge über Bonns Ostpolitik, in: Der Spiegel, 20.09.1971, S. 106.

32 August von Kageneck, Ostpolitik ohne Frankreich, in: Die Welt, 15.12.1969, S. 2.

33 Siehe Ders., Mit Mißtrauen beobachtet Paris den deutschen Alleingang, in: Die Welt, 16.09.1971, S. 4.

${ }^{34}$ Karlheinz Renfordt, Im Pariser Außenministerium sieht man das Rapallo-Gespenst, in: FAZ, 27.12.1969, S. 2.

35 Jürgen Tern, Paris und Bonn, in: FAZ, 31.01.1970, S. 1.

${ }^{36}$ Ibid.

37 Vgl. Paris unterstützt Bonns Ostpolitik, in: Die Zeit, 06.02.1970, S. 10; Pompidou unterstützt die Ostpolitik. Übereinstimmung in wesentlichen Fragen beim deutsch-französischen Gipfelgespräch, in: Die Zeit, 10.07.1970, S. 10; Ernst WeIsenfeld, „Nicht deutscher als die Deutschen". In der Berlin-Frage hält sich Paris zurück, in: Die Zeit, 06.11.1970, S. 4; Ders., Paris: Sowohl als auch, in: Die Zeit, 24.07.1970, S. 3; Ders., Ja mit stiller Sorge, in: Die Zeit, 18.12.1970, S. 5. 
polemisierend vor ihren Lesern auszubreiten und als übermäßige Sensibilität abzutun.

Das Konfliktpotenzial, welches eine derartige Berichterstattung für das deutsch-französische Verhältnis in sich bergen konnte, wurde von den Regierungen in Paris und Bonn derweil wohl erkannt. Insbesondere die möglichen negativen Auswirkungen auf die Wahrnehmung des jeweiligen Nachbarn galten den politisch Verantwortlichen als Unsicherheitsfaktor für die künftigen Beziehungen zwischen beiden Ländern. Im August 1970 berichtete etwa die deutsche Botschaft an das Auswärtige Amt, die Ostpolitik habe bei aller Unterstützung, die ihr von offizieller französischer Seite zuteil werde, auch stark widersprüchliche Gefühle ausgelöst. Vor allem Erwägungen über Deutschlands künftige Rolle in Europa, mögliche Verschiebungen des Kräftegleichgewichts zu Ungunsten Frankreichs und Furcht vor einer stärker national bestimmten deutschen Politik kämen in der Presse zum Tragen ${ }^{38}$. Bereits einige Monate zuvor hatte Botschafter von Braun in einem Schreiben nach Bonn eindringlich gewarnt: »Im vergangenen Jahr sind die Vorbehalte der Franzosen gegenüber Deutschland in einer nicht unbedenklichen Weise gewachsen. Selbst wohlwollende französische Beobachter sprechen von einer neuerwachsenen >Germanophobie « ${ }^{39}$. Die Franzosen, so die Einschätzung von Brauns, vermuteten eine Gewichtsverlagerung in der europäischen Politik von Frankreich in die Bundesrepublik und entwickelten gegenüber den wirtschaftlichen Kräften, der politischen Selbstständigkeit und den neuen Initiativen der Bundesregierung Argwohn und Befürchtungen. In diesem Prozess tauchten viele alte Ressentiments gegenüber Deutschland wieder auf. Eine »althergebrachte instinktive Angst gegenüber einem übermächtigen Partner im Osten « rege sich, das »Gefühl einer Bedrohung des überkommenen französischen Lebensideals durch einen dynamischeren, weniger geschichtsgebundenen Nachbarn ${ }^{40}$. Um diesem Meinungsstrom entgegentreten und sich zunächst über das Ausmaß der »wieder verstärkten antideutschen Gefühle« klar werden zu können, sei, wie der Botschafter resümierte, eine Untersuchung der öffentlichen Meinung Frankreichs im Hinblick auf das deutsche Image dringend erforderlich ${ }^{41}$.

$\mathrm{Zu}$ gleicher Zeit beobachtete auch die französische Vertretung in der Bundeshauptstadt die öffentlichen Diskussionen um die ostpolitischen Initiativen der Regierung Willy Brandts mit einiger Besorgnis. Hierdurch seien die Franzosen, wie Botschafter François Seydoux im April 1970 urteilte,

38 Siehe BA, B 145, Bd. 9867, Schreiben der deutschen Botschaft Paris an das Auswärtige Amt vom 6. August 1970, S. 1f.

${ }^{39}$ BA, B 145, Bd. 9867, Schreiben des deutschen Botschafters in Paris, Sigismund von Braun, an das Presse- und Informationsamt der Bundesregierung vom 27. Januar 1970, S. 1.

40 Ibid., S. 1f.

${ }^{41}$ Ibid., S. 2; ein Hinweis darauf, dass diese Untersuchung tatsächlich durchgeführt wurde, ist in den Akten allerdings nicht zu finden. 
geradezu in einen Alarmzustand versetzt worden: „Depuis que l'éventualité se présente, apparaît la crainte que [...] nous ne soyons jamais aussi proches de la renaissance d'une grande Allemagne $\aleph^{42}$. Auf westdeutscher Seite wachse hingegen angesichts des Misstrauens, das in den französischen Zeitungen vielfach gegenüber der zurückerlangten Unabhängigkeit der Bundesrepublik bekundet werde, ein Gefühl der Verbitterung. Frankreich werde, wie es in einem Vermerk des Quai d'Orsay vom Dezember 1970 hieß, verdächtigt, eine Entwicklung verhindern zu wollen, die Deutschland einen gewachsenen Einfluss in Europa einbringe. Derartige Positionen würden bedauerlicherweise durch die Haltung verschiedener französischer Presseorgane immer wieder gestärkt ${ }^{43}$. Damit sich, so der Appell des französischen Botschafters, aus diesem medialen Gegeneinander keine veritable "malaise franco-allemand « entwickeln könne, müsse die Politik so rasch als möglich handeln: "Dans le cadre de la grande négociation Est-Ouest, des consultations francoallemandes pourraient empêcher que le malentendu ne se développe et que ne succède à une sorte de dépit amoureux [...] une crise de confiance « ${ }^{44}$.

In der Tat wurden die wechselseitigen Mediendarstellungen seit Beginn des Jahres 1970 mehrfach zum Thema der deutsch-französischen Gipfeltreffen zwischen Staatspräsident und Bundeskanzler. So kam Georges Pompidou etwa im Rahmen der bilateralen Gespräche vom Februar 1972 aus Anlass der nicht abreißenden westdeutschen Presseberichte über die französischen Ängste vor einer vermeintlichen »Finnlandisierung ${ }^{45}$ der Bundesrepublik auf den Zeitungsartikel eines Journalisten zu sprechen, in dem von geheimen Zusicherungen Brandts an Breschnew die Rede gewesen war, nach denen der französische Staatspräsident sein Gegenüber angeblich fragen würde. Pompidou stellte klar: »Je ne le vous demanderai pas car je ne crois pas que vous ayez fait de telles promesses. Il y a certainement un climat dans la presse qui n'est pas excellent et qui cherche à créer l'impression que la France se méfie de l'Allemagne et l'Allemagne de la France ${ }^{46}$. Um derartige atmosphärische Störungen zwischen beiden Ländern zu beseitigen, bekräftigte

42 AMAE Paris-La Courneuve, Europe, RFA 1961-1970, Bd. 1610, Bl. 242, Schreiben des französischen Botschafters in Bonn, François Seydoux de Clausonne, an das französische Außenministerium vom 18. April 1970, S. 3.

43 AMAE Paris-La Courneuve, Europe, RFA 1961-1970, Bd. 1547, Bl. 346, Vermerk betreffend die Position Frankreichs gegenüber der Ostpolitik der Bundesregierung vom 4. Dezember 1970, S. 2.

44 AMAE Paris-La Courneuve, Europe, RFA 1961-1970, Bd. 1610, Bl. 242, Schreiben des französischen Botschafters in Bonn, François Seydoux de Clausonne, an das französische Außenministerium vom 18. April 1970, S. 5.

45 Vgl. Dörte Putensen, Die »Finnlandisierung« Finnlands, in: Robert Bohn, Jürgen ELVERT (Hg.), Kriegsende im Norden, Stuttgart 1995, S. 281-294; Hans Jörg SCHRÖTTER, Das neue Europa. Idee, Politik, Zeitgeschichte in 200 Stichworten, Köln ${ }^{3} 2006$, S. 144.

${ }^{46}$ AN Paris, 5 AG 2, Bd. 106, Protokoll des Gesprächs zwischen Staatspräsident Pompidou und Bundeskanzler Brandt im Rahmen des deutsch-französischen Gipfeltreffens am 10. Februar 1972 in Paris, S. 7. 
der französische Staatspräsident, der allerdings selbst auch nicht immer vollkommen frei von Misstrauen war $^{47}$, in seinen öffentlichen Stellungnahmen vielfach Frankreichs vorbehaltloses Einverständnis mit der Ostpolitik der Bundesregierung ${ }^{48}$. Und auch der deutsche Bundeskanzler war bestrebt, die im Nachbarland bestehenden Zweifel zu zerstreuen, indem er unentwegt die westeuropäische Verankerung der Bundesrepublik betonte: »Das, was man Ostpolitik nennt, fängt im Westen an ${ }^{49}$.

Unterstützung fanden die Staatsmänner hierbei durch die verschiedenen in Politik und Gesellschaft wirkenden Kräfte der Annäherung, die sich angesichts der auf beiden Seiten kursierenden medialen Zerrbilder zum Handeln aufgefordert sahen. Mit großer Empfindlichkeit habe Frankreich, wie es im kulturpolitischen Jahresbericht der deutschen Botschaft vom Januar 1970 hieß, auf die nach dem Amtsantritt der sozialliberalen Regierung eingetretenen Entwicklungen reagiert und diese seitdem mit einer längst für überwunden gehaltenen Befangenheit, größter Unsicherheit und Abwehrbereitschaft verfolgt. Dem hellhörigen Beobachter, so formulierte der Bericht, müsse in den letzten sechs Monaten des vergangenen Jahres klarer geworden sein als zuvor, wie dünn der Boden einer dauerhaften Verständigung, wie gering die Kenntnisse trotz jahrelanger Bemühungen noch immer seien und wie viel harter Arbeit es weiterhin bedürfe ${ }^{50}$. In Anbetracht dieser schwierigen Situation sollte die westdeutsche Kulturdiplomatie insbesondere darauf abzielen, durch die Vermittlung eines objektiven Deutschlandbildes und eine sachliche Darstellung der außenpolitischen Intentionen der Bundesrepublik ein positives Gegengewicht zu Misstrauen und Angstgefühlen zu bilden. Eine solche pädagogisch-kulturelle Arbeit müsse, so der Botschaftsbericht, zunächst bei der im Rahmen des Goethe-Instituts durchgeführten Sprachförderung ansetzen, sei diese doch die Voraussetzung jeglicher fruchtbaren Zusammenarbeit auf wirtschaftlichem, politischen und wissenschaftlichem Gebiet: »Es darf nie außer Acht gelassen werden, daß jeder Franzose, der

47 Vgl. Soutou, L'alliance incertaine, S. 333-338; Schwarz, Willy Brandt, Georges Pompidou und die Ostpolitik; Ziebura, Die deutsch-französischen Beziehungen seit 1945, S. 241-243.

48 Vgl. beispielhaft die Äußerungen Staatspräsident Pompidous im Rahmen einer Pressekonferenz anlässlich des deutsch-französischen Gipfeltreffens am 3. und 4. Juli 1970 in Bonn, in: Kimmel, JaRdin (Hg.), Die deutsch-französischen Beziehungen, S. $160 f$.

49 Presseerklärung Bundeskanzler Brandts nach Abschluss der deutsch-französischen Konsultationen am 11. Februar 1972 in Paris, in: Bulletin des Presse- und Informationsamtes der Bundesregierung 21 (1972), S. 256; vgl. auch AN Paris, 5 AG 2, Bd. 1010, Protokoll des Gesprächs zwischen Staatspräsident Pompidou und Bundeskanzler Brandt im Rahmen des deutsch-französischen Gipfeltreffens am 30. Januar 1970 in Paris, S. 2; AN Paris, 5 AG 2, Bd. 103, Schreiben Bundeskanzler Brandts an Staatspräsident Pompidou vom 7. August und 5. Oktober 1970.

50 Siehe PA-AA, B 97, Bd. 376, Kulturpolitischer Jahresbericht 1969 der deutschen Botschaft Paris vom 26. Januar 1970, S. 3. 
Deutsch lernt, gleichzeitig Deutschlandkunde erfährt und damit ein potentieller Multiplikator wird « ${ }^{51}$.

Sprachkompetenz und damit einhergehende Kenntnisse der deutschen Gegenwart sollten dabei helfen, in der französischen Bevölkerung Verständnis für die Problemlagen des geteilten Nachbarlandes hervorzurufen und die Franzosen gegen Deutschland-Furcht und »Rapallo-Komplex« immunisieren. Auch die verschiedenen bilateralen Programme des DAAD, wie etwa der Austausch von Lektoren, die an französischen und westdeutschen Universitäten sprach- und landeskundlichen Unterricht erteilten, oder die Durchführung von Studienreisen für Hochschullehrer sollten hier$\mathrm{zu}$ beitragen ${ }^{52}$. Die Pariser DAAD-Zweigstelle initiierte etwa anlässlich der Bundestagswahlen im November 1972 in Zusammenarbeit mit dem Ludwigsburger DFI für eine Gruppe französischer Professoren und Deutschlandexperten einen Informationsaufenthalt in der Bundesrepublik. Dieser hatte zum Ziel, den Teilnehmern, darunter auch Pierre Bertaux, einen lebensnahen Eindruck der politischen Verhältnisse zu liefern, sie in ihrer positiven Einstellung zu den deutschen Nachbarn zu bestärken und ihnen nicht zuletzt Argumentationshilfen für die Verbreitung einer ausgewogenen Darstellung Deutschlands in Frankreich zur Verfügung zu stellen ${ }^{53}$.

Im Gegenzug war der französischen Regierung und ihren kulturpolitischen Institutionen vor allem daran gelegen, dass das Bild eines argwöhnisch auf die Bonner Ostpolitik und die zunehmende außenpolitische Unabhängigkeit der Bundesrepublik schielenden Frankreichs keinen dauerhaften Einfluss auf die Menschen in Westdeutschland gewinnen konnte. Bereits vor den ersten großen ostpolitischen Initiativen hatte es in einem Bericht der französischen Botschaft geheißen: "S'il est certain que la population allemande dans son ensemble s'intéresse aux divers aspects de la civilisation de notre pays [...], la politique du gouvernement français n'est pas toujours comprise ${ }^{54}$. Durch die zum Teil von Misstrauen und Anfeindungen geprägten französischen Pressereaktionen auf die sich wandelnden Beziehungen Westdeutschlands zur Sowjetunion und den Staaten Osteuropas konnte dieses Unverständnis aus Sicht der französischen Verantwortlichen nur noch weiter

${ }^{51}$ Ibid., S. 10.

52 Vgl. Jahresbericht 1969, hg. v. DAAD, Bonn 1970, S. 44f.; Jahresbericht 1971, hg. v. DAAD, Bonn 1972, S. 61f.

53 Vgl. BA, B 145, Bd. 9940, Schreiben des Presse- und Informationsamtes der Bundesregierung an die deutsche Botschaft Paris vom 6. Oktober 1972 und Genehmigungsverfügung vom 24. Oktober 1972; DFI-Archiv, Ordner Seminar Bundestagswahlkampf 1972, Verwendungsnachweis zum Bewilligungsbescheid des Presse- und Informationsamtes der Bundesregierung vom 6. November 1972, S. 2 sowie Schreiben Robert Pichts an das Presse- und Informationsamt der Bundesregierung vom 4. Oktober 1972; Jahresbericht 1972, hg. v. DAAD, Bonn 1973, S. 49f.

54 AMAE Paris-La Courneuve, Europe, RFA 1961-1970, Bd. 1697, Bl. 25, Jahresbericht der französischen Botschaft Bonn vom April 1969, Abschnitt: »Attitude générale à l'égard de la France«, S. 2. 
anwachsen. Die Einrichtungen der französischen Kulturpolitik machten es sich daher zur Aufgabe, der westdeutschen Bevölkerung Frankreich, seine Außenpolitik und seine Sicherheitsinteressen zu erklären, um Vorurteilen und Klischeevorstellungen entgegenzuwirken. So sollte im Bereich der Jugendarbeit seit Anfang der 1970er Jahre nicht mehr nur der bloße Austausch zwischen beiden Ländern gefördert, sondern darüber hinaus ein vielfältiges Informationsangebot bereitgestellt werden, mittels dessen junge Deutsche sich profunde Kenntnisse über die realen Gegebenheiten Frankreichs, »le vrai visage actuel de la France«, aneignen konnten ${ }^{55}$. Die Kulturabteilung der französischen Botschaft führte gemeinsam mit den instituts und centres culturels français in der Bundesrepublik Seminar- und Vortragsveranstaltungen zur Frankreichkunde durch, an denen Repräsentanten diverser gesellschaftlicher Gruppen - Gewerkschafter, Offiziere der Bundeswehr sowie Vertreter der Industrie- und Handelskammern - teilnahmen. Zudem ermöglichte es die Botschaft westdeutschen Pädagogen und Verwaltungsbeamten, Informationsreisen nach Frankreich zu unternehmen ${ }^{56}$. Diese verstärkten Bemühungen der Öffentlichkeitsarbeit trugen den durch die Ostpolitik gewandelten Rahmenbedingungen des "tête à tête franco-allemand ${ }^{57}$ Rechnung und zielten darauf ab, vor allem den so genannten Multiplikatoren der bundesdeutschen Gesellschaft, aber auch breiteren Bevölkerungsschichten, ein nicht durch den Filter der Presseberichterstattung vorgegebenes Bild Frankreichs zu vermitteln.

In dem Vorhaben, einen Gegenpol zu den in vielen Fällen einseitig negativen Medienpräsentationen zu schaffen und den Bevölkerungen vorurteilsfreie Informationen über den jeweiligen Nachbarn zur Verfügung zu stellen, fanden sich die Akteure der Auswärtigen Kulturpolitik eng verbunden mit den privaten Verständigungsorganisationen. Gerade »in einer Zeit, in der die deutsch-französischen Beziehungen schwere Stunden erleben ${ }^{58}$, wollte etwa das Pariser BILD einen Beitrag zur öffentlichen Aufklärungsarbeit leisten. Hierzu dienten vorrangig die seitens der Vereinigung herausgegebenen Zeitschriften. Das Ziel der in Frankreich erscheinenden »Documents« bestand

55 AMAE Paris-La Courneuve, Europe, RFA 1971-1976, Bd. 3001, Vermerk bezüglich des deutsch-französischen Austauschs im Jugendbereich vom 11. Juni 1971, S. 2; vgl. hierzu auch AMAE Paris-La Courneuve, DGRCST 1969-1972, Bd. 134, Vermerk bezüglich des deutsch-französischen Austauschs in den Bereichen Jugend und Volksbildung vom 16. Juni 1970.

56 Vgl. ibid. sowie AMAE Nantes, Bonn Service culturel, Bd. 28, Ambassade de France à Bonn, Rapport d'activité des services culturels, année 1971-72, S. 9; Rapport d'activité des services culturels 1972-73, S. 7f.; Rapport d'activités des services culturels, année 1973-74, S. 9f.

57 AN Fontainebleau, ministère de l'Éducation nationale, Bd. 900672/35, Vermerk betreffend die deutsch-französische Zusammenarbeit vom 30. Oktober 1972, S. 2.

${ }^{58}$ BILD-Archiv, Vorläufige Übersicht über die Tätigkeit der GÜZ und des BILD im Jahre 1973, S. 5. 
darin, »Informationen so objektiv wie möglich anzubieten [...] sowie den deutschen Realitäten, selbst wenn diese manchmal schockierend erscheinen ${ }^{59}$, Rechnung zu tragen. Dadurch, dass die Artikel gleichermaßen von deutschen und französischen Autoren verfasst wurden, sollte der Leser die Möglichkeit erhalten, sich ein eigenes Urteil über die Entwicklungen jenseits des Rheins zu bilden. Im Rahmen verschiedener Themenschwerpunkte, die sich mit Ostpolitik und deutscher Frage beschäftigten ${ }^{60}$, versuchte die Zeitschrift auf die seit 1969 immer drängender an sie herangetragenen Leserfragen bezüglich einer möglichen Wiedervereinigung Deutschlands zu antworten ${ }^{61}$. Hierbei war es der Redaktion augenscheinlich ein wesentliches Anliegen, die Franzosen mit der Ostdiplomatie der Bundesregierung auszusöhnen. So betonte der Chefredakteur der "Documents", Antoine Wiss-Verdier, in seinen Beiträgen nachdrücklich, dass Frankreich durch Brandts Politik der Öffnung nach Osten kein zweites Rapallo drohe ${ }^{62}$. Er ließ darüber hinaus an verschiedener Stelle hochrangige SPD-Politiker zu Wort kommen, um seinen Lesern die außenpolitischen Absichten der Bundesrepublik aus erster Hand erläutern zu lassen ${ }^{63}$. Das BILD wollte auf diese Weise im Sinne einer »entente toujours plus approfondie « ${ }^{64}$ auf die französische Bevölkerung einwirken, was der Organisation nicht zuletzt die Unterstützung der Bonner Regierungsstellen sicherte ${ }^{65}$.

Auch das Ludwigsburger DFI war seinerseits bestrebt, dazu beizutragen, die hitzigen öffentlichen Debatten um die ostpolitischen Verhandlungen der Bundesregierung in eine sachliche Diskussion zu überführen und dem Thema das Konfliktpotenzial zu nehmen. Zentrifugale Kräfte seien am Werk, so wurde im DFI Anfang der 1970er Jahre geurteilt, welche die deutsch-französische Zusammenarbeit bedrohten, weshalb eine sorgfältige Bilanz und unvoreingenommene Analyse der beiderseitigen Interessengemeinsamkeiten

${ }^{59}$ BILD-Archiv, Bericht über die Tätigkeit der GÜZ und des BILD in den Jahren 19681969, S. 8.

60 So zum Beispiel »Le traité germano-soviétique«, in: Documents 25/5 (1970), S. 57-95; "Le traité germano-polonais du 7 décembre 1970«, in: Documents 26/1 (1971), S. 59119; "La RFA et la sécurité européenne«, siehe hierzu BILD-Archiv, Rapport d'activités 1973, S. 2.

${ }^{61}$ Vgl. BILD-Archiv, Bericht über die Tätigkeit der GÜZ und des BILD in den Jahren 19681969, S. 7; Rapport d'activités 1972, S. 2f.

${ }^{62}$ Vgl. zum Beispiel Antoine Wiss-Verdier, Le double monologue d'Erfurt, in: Documents 25/2 (1970), S. 114-120.

${ }^{63} \mathrm{Vgl}$. Herbert WeHNer, L'intégration européenne et la question allemande, in: Documents 25/4 (1970), S. 7-12; Carlo SCHMID, Ostpolitik et unification européenne, in: Documents 26/1 (1971), S. 7-11; Erhard EPPLER, Dix thèses sur le problème allemand et l'Ostpolitik, in: Documents 26/2 (1971), S. 6-11.

${ }^{64}$ BILD-Archiv, Aufzeichnung »Conseil d'administration du 19.2.1972, annexe à l'ordre du jour: Projet de réstructuration du BILD«, S. 1.

65 Vgl. BA, B 145, Bd. 9936, Schreiben des Presse- und Informationsamtes der Bundesregierung an das Auswärtige Amt vom 23. Juni 1970; BA, B 122, Bd. 5307, Schreiben des Bundespräsidenten Heinrich Lübke an Bundesaußenminister Willy Brandt vom 20. Oktober 1967. 
und -gegensätze erarbeitet werden müsse ${ }^{66}$. Im Rahmen eines Anfang Juni 1973 anlässlich des zehnjährigen Bestehens des Élysée-Vertrags seitens des Instituts organisierten Kolloquiums, das deutsche und französische Politiker und Regierungsbeamte, Wissenschaftler und Publizisten vereinte, standen daher auch die im Zuge der Ostpolitik aufgetretenen Verstimmungen zwischen beiden Ländern auf der Tagesordnung. Die durch diesen offen geführten Dialog freigesetzten Impulse sollten, wie seine Veranstalter erhofften, Eingang in die öffentliche Meinungsbildung finden und positive Rückwirkungen auf die Wahrnehmung des jeweiligen Nachbarlandes seitens der Medien entfalten ${ }^{67}$.

Ein ähnliches Ansinnen verfolgte zu gleicher Zeit der ADFG. Dessen Verantwortliche sahen die zwischen Frankreich und Westdeutschland entstandenen Unstimmigkeiten insbesondere hervorgerufen »durch die Veröffentlichungen in der Presse, durch das Radio, durch das Fernsehen, die vielfach glauben machen wollen, dass alles zwischen den Franzosen und Deutschen schlecht geht ${ }^{68}{ }^{68}$. Vor diesem Hintergrund sollten die Kongresse der deutsch-französischen Gesellschaften, welche der ADFG jährlich unter Beteiligung namhafter Journalisten, ausgewiesener Wissenschaftler sowie maßgeblicher Diplomaten und Politiker veranstaltete, ein Forum schaffen, um beide Seiten öffentlichkeitswirksam zur Verständigung aufzurufen ${ }^{69}$. »Coopération dans l'amitié« lautete denn auch das Motto der Jahrestagung, die 1969 in Dijon stattfand und im Rahmen derer Pierre Bertaux in seinem Gastvortrag die Notwendigkeit eines gemeinsamen deutsch-französischen Bewusstseins angesichts der Probleme der Gegenwart beschwor ${ }^{70}$. Von Seiten

66 Siehe DFI-Archiv, Ordner Kolloquium 10 Jahre deutsch-französischer Vertrag 1973, Aufzeichnung »Fragestellungen des Kolloquiums«, nicht datiert, S. 1.

67 Vgl. PA-AA, Zwischenarchiv, Nr. 109190, Vermerk betreffend das Deutsch-Französische Institut in Ludwigsburg vom 30. März 1973; Programm und Teilnehmerliste des Kolloquiums 10 Jahre deutsch-französischer Vertrag; Thesenpapier zum Vortrag Alfred Grossers, "Die deutsch-französischen Beziehungen und Europa", S. 2f.; AN Fontainebleau, ministère de l'Éducation nationale, Bd. 840700/26, Schreiben Carlo Schmids an Pierre Garrigue, Chef des Service des relations internationales, vom 23. Mai 1973; BA, B 145, Bd. 9940, Genehmigungsverfügung des Presse- und Informationsamtes der Bundesregierung bezüglich des Kolloquiums 10 Jahre deutsch-französischer Vertrag vom 15. März 1973; DFI-Archiv, Ordner Kolloquium 10 Jahre deutsch-französischer Vertrag 1973, Verwendungsnachweis zum Bewilligungsbescheid des Presse- und Informationsamtes der Bundesregierung vom 18. April 1973.

68 VDFG-Archiv, Ordner Vorstandssitzungen 1972-1973, Protokoll der Mitgliederversammlung des ADFG in Nancy am 6. September 1973, S. 8.

69 Vgl. VDFG-Archiv, Ordner Arbeitskreis e.V. Vorstand, Aufzeichnung der Ehrenpräsidentin des ADFG, Elsie Kühn-Leitz, betreffend die 16. Jahrestagung des ADFG in Caen vom 24. Januar 1971, S. 1.

70 Vgl. hierzu PA-AA, Zwischenarchiv, Nr. 106189, Programm der 14. Jahrestagung des ADFG 1969 in Dijon sowie Schreiben des deutschen Generalkonsulats Lyon an das Auswärtige Amt vom 8. Oktober 1969; VDFG-Archiv, Vortrag Pierre Bertaux' anlässlich der Jahrestagung des ADFG in Dijon 1969, in: Mitteilungsblatt für die Deutsch-Französischen Gesellschaften 32 (1970), S. 78-81. 
des Auswärtigen Amts wurde dem Arbeitskreis und seinen Mitgliedsgesellschaften immerhin »eine nicht unerhebliche Bedeutung im Sinne einer besonders gewünschten privaten Aktivität zur Förderung der deutsch-französischen Beziehungen außerhalb der Regierungsebene « ${ }^{71}$ beigemessen. Sie erfüllten »eine politisch bedeutsame Aufgabe $^{72}$. Gerade die Presse- und Fernsehberichterstattung über die Ereignisse im Nachbarland diene nicht immer der Ausräumung bestehender Missverständnisse und Vorurteile. Hier komme es den Gesellschaften zu, »behutsam, aber mit allem Nachdruck, für ein besseres Verstehen für die Probleme und Eigenarten des Nachbarvolkes einzutreten $\aleph^{73}$.

Die verschiedenen Initiativen der privaten Vereinigungen wurden durch die deutsch-französischen Mittlerpersönlichkeiten immer wieder nach Kräften unterstützt. In einem 1973 gehaltenen Vortrag hatte Pierre Bertaux konstatiert: "La présentation de l'autre pays par les massmédia et les associations qu'ils entretiennent contribuent sans doute à maintenir les préjugés « ${ }^{74}$. Angesichts dessen gehe es jedoch für diejenigen, die zwischen beiden Ländern vermittelten, nicht so sehr darum, negative Bilder lediglich durch positive zu ersetzen. Aufgabe müsse es vielmehr sein, den Menschen kohärente Informationen über die aktuellen Entwicklungen des jeweiligen Partnerlandes zu liefern. Eine von Sachkenntnis geprägte biperspektivische Aufklärungsarbeit sollte dazu dienen, die verhängnisvolle Eigendynamik, welche die konfrontativ geführten Diskussionen um die Ostpolitik entwickelt hatten, zu bremsen. In diesem Sinne versuchte Alfred Grosser einerseits mit seinen in Frankreich publizierten Beiträgen deutlich zu machen, dass die Befürchtungen vor einer Schaukelpolitik der Bundesrepublik zwischen Ost und West unbegründet seien und die Franzosen auch aufgrund der von Vernunft geprägten Entwicklung der Bonner Außenpolitik der vorangegangenen Jahrzehnte allen Grund hätten, der westdeutschen Regierung zu trauen. Andererseits betonte er mit Blick auf ein deutsches Publikum, dass die Bemühungen Willy Brandts um Entspannung von einer Mehrheit der Franzosen sehr wohl gutgeheißen würden. Die historischen Ängste vor einer deutsch-russischen Annäherung seien in Frankreich zwar nicht vollständig verschwunden, hätten aber bereits "phan-

${ }^{71}$ PA-AA, Zwischenarchiv, Nr. 178576, Vermerk bezüglich des Arbeitskreises DeutschFranzösischer Gesellschaften vom 9. Mai 1973, S. 2.

72 PA-AA, Zwischenarchiv, Nr. 109189, Vermerk betreffend die deutsch-französischen Gesellschaften vom 13. Mai 1974, S. 1.

${ }^{73}$ PA-AA, Zwischenarchiv, Nr. 109189, Entwurf für eine Rede des parlamentarischen Staatssekretärs Zander anlässlich der Jahrestagung des ADFG im September 1974 in Kassel, S. If.

${ }^{74}$ AN Fontainebleau, ministère de l'Éducation nationale, Bd. 840700/26, Redemanuskript Pierre Bertaux' für einen am 3. Juni 1973 im Deutsch-Französischen Institut Ludwigsburg gehaltenen Vortrag zum Thema »Les relations culturelles et l'information", S. 2. 
tastisch abgenommen ${ }^{75}$ und würden zudem durch das umsichtige Handeln der Bonner Regierung weiter besänftigt ${ }^{76}$.

Joseph Rovan hatte, wie er gegenüber den Lesern der französischen Wochenzeitschrift »Le Point « im September 1973 bekundete, nach einem Interview mit Bundeskanzler Brandt ebenso den Eindruck gewonnen, dass der Regierungschef selbst wie auch seine Regierung die potenziellen Gefahren der Ostpolitik gründlich erwogen hätten und im Bewusstsein dieser agierten. Daher bestünde hinsichtlich der Grenzen der Ostpolitik eine viel weitreichendere Übereinstimmung zwischen Frankreich und der Bundesrepublik, als dies in Frankreich gemeinhin angenommen werde. Schließlich sei es, wie Rovan ausführte, nicht zuletzt de Gaulle gewesen, der Westdeutschland mehrfach eine Annäherung an den Osten nahegelegt habe. Allein aus diesem Grunde könne man es der Bundesrepublik kaum zur Last legen, dass sie diesen Rat nun tatsächlich befolge. Letztlich hätten doch Frankreich und Westdeutschland dieselben Ziele, unterstellten sich hierbei jedoch gegenseitig unlautere Absichten. Diese für die deutsch-französischen Beziehungen nicht ungefährliche Situation müsse, wie Rovan appellierte, unverzüglich ein Ende finden. Hierzu sollten Deutsche und Franzosen gleichermaßen beitragen ${ }^{77}$.

Mit kulturpolitischen Akteuren, privaten Verständigungsorganisationen und intellektuellen Mittlern standen den öffentlichen Auseinandersetzungen um die Bonner Ostpolitik Kräfte entgegen, die hierin die Gefahr einer unheilvollen Wendung des deutsch-französischen Verhältnisses erblickten. Ausgehend von diesem Befund versuchten sie, den möglichen negativen Folgen der zum Teil stark polemisch gefärbten Berichterstattung beider Seiten entgegenzuwirken. Die Vermittlung von Sprachkenntnissen und landeskundlichen Kompetenzen, die Förderung von persönlichen Begegnungen mit dem jeweiligen Nachbarland und das Einwirken auf die Medien im Sinne eines besseren Verständnisses des anderen erschienen den diversen Protagonisten der Annäherung hierbei als geeignete Maßnahmen. Dem vielfach erklärten Anspruch, sich bei einem drohenden Konfliktfall für die Verständigung zwischen den Bevölkerungen einsetzen zu wollen, wurden sie demzufolge

75 Alfred Grosser, Die Bundesrepublik im Urteil Frankreichs, in: Hans StefFen (Hg.), Die Gesellschaft in der Bundesrepublik. Analysen. Zweiter Teil, Göttingen 1971, S. 178-186, hier S. 183.

76 Vgl. Ders., France and Germany: less divergent outlooks?, in: Foreign Affairs 48/2 (1970), S. 235-244, hier S. 243f.; Ders., Le traité de Varsovie, in: Le Monde, 26.11.1970, S. 1 und 7; Ders., Les traités et les institutions, in: Le Monde, 20.05.1972, S. 1 und 4; Ders., Deutschland von Frankreich aus gesehen, in: Zeitwende 44/3 (1973), S. 169-177.

77 Siehe Joseph Rovan, Brandt m'a convaincu que, in: Le Point, 03.09.1973, S. 26-28; vgl. hierzu BA, B 145, Bd. 9074, Schreiben der deutschen Botschaft Paris an das Auswärtige Amt bezüglich eines Gesprächs zwischen Joseph Rovan und Bundeskanzler Brandt vom 3. September 1973; Vermerk des Presse- und Informationsamtes der Bundesregierung für Bundeskanzler Brandt vom 7. September 1973; BA, B 136, Bd. 41610, Dunkle Absichten unterstellt. Analyse der deutsch-französischen Mißverständnisse, in: Münchner Merkur, 03.09.1972. 
durchaus gerecht. Allein die Wirkungen ihres Tuns sind schwer nachzuweisen. Hielte man die Zahl der im Rahmen der bilateralen Verständigungsarbeit erreichten Deutschen und Franzosen der Masse derer entgegen, die hierdurch entweder gar nicht berührt oder aber durch die Vielzahl tendenziöser Pressebeiträge beeinflusst wurden, so wäre wohl zumindest in Zweifel zu ziehen, ob die wohlmeinenden Bemühungen ihr Ziel tatsächlich erreichen konnten.

\subsection{2 "Que faire de l'Allemagne?" - Spekulationen über die Aktualität der deutschen Frage}

In den Jahren nach Abschluss und Ratifizierung der Ostverträge ${ }^{78}$ wurde auch für misstrauische Beobachter ersichtlich, dass die Bundesregierung nicht die Absicht verfolgte, sich unter Missachtung der alliierten Vorbehaltsrechte mit der sowjetischen Führung über die deutsche Wiedervereinigung $\mathrm{zu}$ verständigen ${ }^{79}$. Folglich flauten die deutsch-französischen Diskussionen um die möglichen Gefahren der Ostpolitik langsam ab. Ab Mitte der 1970er Jahre verschwanden sie, zunehmend überlagert von den drängenden aktuellen Problemen im Zusammenhang mit der Wirtschafts- und Energiekrise und den Fragen der Finanz- und Währungspolitik ${ }^{80}$, nahezu gänzlich aus der medialen Berichterstattung. Die durch das Vertrauensverhältnis zwischen Helmut Schmidt und Valéry Giscard d'Estaing versinnbildlichte neue Zweisamkeit des bilateralen Verhältnisses tat ihr Übriges, um die kontroversen

78 Vgl. 187. Sitzung des Deutschen Bundestages am 17. Mai 1972, in: Verhandlungen des Deutschen Bundestages, 6. Wahlperiode, Stenographische Berichte, Bd. 80, Bonn 1972, S. 10929-10954; weiterführend hierzu Jan KusBER, Ostverträge 1970/72. Überwindung oder Zementierung der Teilung Europas?, in: Andreas RöDder, Wolfgang Elz (Hg.), Deutschland in der Welt. Weichenstellungen in der Geschichte der Bundesrepublik, Göttingen 2010, S. 47-66; Werner Link, Der lange Weg zum "geregelten Nebeneinander«. Die Deutschlandpolitik der Bundesrepublik Mitte der sechziger bis Mitte der siebziger Jahre, in: Christoph Klessmann, Hans Misselwitz, Günter Wichert (Hg.), Deutsche Vergangenheiten - eine gemeinsame Herausforderung. Der schwierige Umgang mit der doppelten Nachkriegsgeschichte, Berlin 1999, S. 97-114.

79 Vgl. hierzu AMAE Paris-La Courneuve, Europe, RFA 1971-1976, Bd. 3006, Schreiben des französischen Botschafters in Bonn, Jean Sauvagnargues, an Außenminister Michel Jobert bezüglich der Außenpolitik der Bundesregierung vom 15. November 1973.

80 Vgl. Serge Berstein, Jean-Claude Casanova, Jean-François Sirinelli (Hg.), Les années Giscard. La politique économique 1974-1981, Paris 2009; Dimitri GrYGOWSKI, La RFA et la France face aux turbulences du système monétaire international. L’Union économique et monétaire (UEM) comme exutoire, instrument de dissuasion et de négociation de 1957 à 1978, in: Eck, Martens, Schirmann (Hg.), L'économie, l'argent et les hommes, S. 339355; Jens Hohensee, Der erste Ölpreisschock 1973/74. Die politischen und gesellschaftlichen Auswirkungen der arabischen Erdölpolitik auf die Bundesrepublik Deutschland und Westeuropa, Stuttgart 1996. 
Debatten zeitweilig zum Verstummen zu bringen ${ }^{81}$. Hintergründig jedoch blieb der östliche Nachbar in den Augen vieler französischer Kommentatoren aufgrund der ungelösten deutschen Frage ein Unsicherheitsfaktor, der schnell wieder zur Bedrohung werden konnte ${ }^{82}$. Nicht viel mehr als ein vager Anfangsverdacht reichte denn auch aus, um in Frankreich die Furcht vor einem wiedervereinigten Deutschland erneut aufbrechen zu lassen.

Einen Anlass hierzu lieferte im November 1978 die Berufung des stellvertretenden sowjetischen Außenministers Wladimir Semjonow zum neuen Botschafter der UdSSR in Bonn ${ }^{83}$. Die Entsendung Semjonows in die Bundeshauptstadt sorgte zunächst in der westdeutschen Presse für einige Aufregung. Hier galt der Diplomat seit den ersten Nachkriegsjahren als erklärter Befürworter einer Traditionslinie sowjetischer Westpolitik, die guten Beziehungen zu Deutschland den Vorrang gegenüber Teilungsstrategie und ideologischer Dominanz einräumte ${ }^{84}$. Vermutungen über eine etwaige Bewegung in der Deutschlandpolitik erhielten hierdurch neue Nahrung ${ }^{85}$. Angesichts dessen ließen beunruhigte Reaktionen aus Frankreich nicht auf sich warten. Bereits im August 1978 war in "Le Monde« über die Möglichkeit der deutschen Einheit spekuliert worden ${ }^{86}$. Mit der Installierung Semjonows in Bonn schienen derartige theoretische Überlegungen plötzlich bedrohlich nahe gerückt. In seinem Leitartikel vom 22. November 1978 fragte der Chefredakteur der Zeitung, André Fontaine: »Que faire de l'Allemagne pour qu'elle ne pèse pas d'un poids trop lourd sur les destins de l'Europe et du monde ${ }^{87}$ ? « Bislang habe die deutsche Teilung, so der Journalist, die Stärke des Nachbarn eingehegt, doch sei dies bei Weitem keine Versicherung für die Ewigkeit, zumal die Deutschen beider Staaten sich derselben Nation zugehörig fühlten. Vor allem deshalb müsse damit gerechnet werden, dass sie sich auf Dauer nicht mit dem augenblicklichen Zustand zufrieden gäben und auf lange Sicht mit den Moskauer Führern über die Frage der Wiedervereinigung verhandelten.

${ }^{81}$ Vgl. Then There Were Two: Valéry and Helmut, in: Time, 07.10.1974, S. 6-12; Rudolf Herlt, Pas de deux in Paris. Entscheidung für die europäische Solidarität, in: Die Zeit, 07.06.1974, S. 1.

82 Bezeichnend für diese Einschätzung Michel Debré, France - Allemagne, in: Le Monde, 06./07.08.1975, S. 1 und 3; Ders., L'Allemagne redevient-elle un danger?, in: Le Monde, 23.07.1976, S. 1f.

83 Vgl. AAPD 1978, Bd. II, Dok. 325; Wladimir S. SEmjonow, Von Stalin bis Gorbatschow. Ein halbes Jahrhundert in diplomatischer Mission 1939-1991, Berlin 1995.

84 Vgl. Heinz HöHne, Wladimir S. Semjonow, der Deutschlandspezialist Moskaus, in: Der europäische Osten 2/7-8 (1955), S. 44f.

85 Vgl. Carl-Christian KaISER, Neuer Sowjetbotschafter: Liebesgrüße aus Moskau?, in: Die Zeit, 27.10.1978, S. 8; Interessante Zeiten. Plant die Sowjet-Union eine neue DeutschlandOffensive?, in: Der Spiegel, 23.10.1978, S. 34; Meimeth, Frankreichs Entspannungspolitik der 70er Jahre, S. 84f.

${ }^{86}$ Vgl. François-Henri Barbé, L’unité allemande: pour quand?, in: Le Monde, 16.08.1978, S. 1 und 3.

${ }^{87}$ André Fontaine, Que faire de l'Allemagne?, in: Le Monde, 22.11.1978, S. 1. 
Wer könne schließlich sagen, ob die Sowjetunion mit der Berufung Semjonows nicht eine spektakuläre Offensive plane, um die Bundesrepublik aus den westlichen Allianzstrukturen herauszulösen. Angesichts eines solchen Risikos seien in Westeuropa Überlegungen anzustellen, was man mit Deutschland tun könne, bevor sich eventuell die Frage stelle, was man gegen Deutschland tun müsse und mit welchen Mitteln ${ }^{88}$. Sekundiert wurde Fontaine in seiner Einschätzung durch den ehemaligen gaullistischen Premierminister Michel Debré, welcher der Bundesregierung in einem tags darauf ebenfalls in "Le Monde" erschienenen Artikel unterstellte, sie arbeite im Rahmen ihrer Sicherheits- und Verteidigungspolitik aktiv an dem einen Ziel: »faciliter par un renforcement de puissance un mouvement favorable à une réunification de l'Allemagne «"

Erstaunt über das plötzliche Wiederaufleben der Debatte um die deutsche Einheit und die Mutmaßungen im Nachbarland veröffentlichte "Die Zeit" Anfang Dezember 1978 aus der Feder Theo Sommers eine Gegenrede, in welcher der Verfasser klarstellte, dass die Spekulationen über ein deutschrussisches Zusammengehen vollständig an den Realitäten vorbeigingen: "Wir schreiben nicht mehr $1922 «^{90}$. Es bestehe weder eine ernstzunehmende sowjetische Offerte, von der irgendeine Verführungskraft ausginge, noch fänden sich in Bonn Partner für eine "Wiederauflage von Rapallo «" ${ }^{91}$. Eine Lösung der deutschen Frage, so bekräftigte Sommer, sei überhaupt nur noch in einem europäischen Rahmen vorstellbar. Derartigen Versicherungen zum Trotz zweifelten Teile der französischen Presse allerdings weiterhin an der Aufrichtigkeit der Bonner Führungsriege und machten insbesondere das linke Spektrum der Sozialdemokraten als Kristallisationspunkt neutralistischer Tendenzen aus. Dieser Eindruck verstärkte sich noch, als der SPDFraktionsvorsitzende Herbert Wehner sich Ende Januar 1979 öffentlich für eine Konföderation zwischen den beiden deutschen Staaten aussprach ${ }^{92}$. Um die hierdurch in Frankreich verursachten Wogen zu glätten, machte Bundeskanzler Schmidt in einem Interview mit der Zeitung "France-Soir" wenige Wochen später deutlich, dass er eine Wiedervereinigung des deutschen Volkes noch im 20. Jahrhundert für schlichtweg unrealistisch halte ${ }^{93}$.

88 Siehe ibid., S. 1 und 6 f.

${ }^{89}$ Michel Debré, Le fond de l'affaire, in: Le Monde, 23.11.1978, S. 1f.

90 Theo Sommer, Deutschland - Traum oder Alptraum? Die nationale Einheit: Visionen und Illusionen einer unerwarteten Debatte, in: Die Zeit, 08.12.1978, S. 1.

91 Ibid.

92 Vgl. Deutschlandpolitik: Herbert Wehner legt nach, in: Der Spiegel, 12.03.1979, S. 28-30; vgl. zu den Reaktionen auf Wehners Äußerungen in Frankreich Jean WeTz, La politique de défense suscite des divergences au sein de la coalition socialiste-libérale, in: Le Monde, 21.02.1979, S. 6; Ders., Bonn s'inquiète du développement du potentiel militaire des pays du pacte de Varsovie, in: Le Monde, 22.02.1979, S. 6.

93 Vgl. Schmidt: »'Allemagne n'a ni la volonté ni le désir de dominer la France«. Une interview exclusive du chancelier allemand par Benoît RAYSKI, in: France-Soir, 16.02.1979, S. 2 . 
Jedoch vermochte auch diese Beschwichtigung von höchster Stelle es kaum, die in der französischen Presse nun wieder in verstärktem Maße zum Ausdruck kommende Besorgnis über den außenpolitischen Weg des Nachbarn aus der Welt zu schaffen ${ }^{94}$. Nicht zuletzt die Verschlechterung der deutschamerikanischen Beziehungen, die sich seit Sommer 1977 abzeichnete ${ }^{95}$, hielt die Befürchtung wach, die Bundesrepublik könne sich von ihren westlichen Bündnispartnern distanzieren, der Sowjetunion gleichzeitig konzessionsbereiter gegenüberstehen und das Wagnis einer durch Neutralität erkauften Wiedervereinigung eingehen ${ }^{96}$. Als schließlich im Frühjahr 1979 in der Pariser Presse kolportiert wurde, dass die Bundesregierung ohne Konsultation ihrer Verbündeten in Verhandlungen mit der sowjetischen Führung getreten sei und Bundeskanzler Schmidt Breschnew zugesagt habe, keine weitere Stationierung von Mittelstreckenraketen auf westdeutschem Boden zuzulassen, hielt »Le Monde « fest: »Le >spectre de Rapallo< est à nouveau présent « ${ }^{97}$.

Auf Seiten der westdeutschen Presse blickte man indessen weiterhin mit Unverständnis auf die neu entfachte Debatte und fragte, aus welchem Grunde die seit langem für erledigt gehaltene deutsche Frage so plötzlich auf die Tagesordnung hatte zurückkehren können. "Der Spiegel « kam im März 1979 zu dem Schluss, die sensiblen Nachbarn hätten wohl früher als die Deutschen selbst erkannt, dass der scheinbar so verfestigte status quo in Mitteleuropa sich aufgrund der zugunsten Westdeutschlands veränderten Machtverhältnisse zu verschieben beginne ${ }^{98}$. Ganz offen, so stellte das Blatt fest, erinnerten seit Jahresfrist Politiker und Kommentatoren in Paris wieder an das Trauma des Paktes von 1922: »Für die Franzosen symbolisiert `Rapallo< die Sorge, Deutschland werde, angelehnt an den Osten und womöglich wiedervereinigt, die Herrschaft über Westeuropa an sich reißen «"99. Diese

94 Vgl. hierzu »Wir sind ein junges, entschlossenes Land «. Der französische Staatspräsident Valéry Giscard d'Estaing über Frankreich und das Europa-Jahr 1979, in: Der Spiegel, 01.01.1979, S. 51f.

95 Vgl. Klaus Wiegrefe, Das Zerwürfnis: Helmut Schmidt, Jimmy Carter und die Krise der deutsch-amerikanischen Beziehungen, Berlin 2005; Matthias Schulz, Vom »Atlantiker« zum »Europäer«? Helmut Schmidt, deutsche Interessen und die europäische Einigung, in: Mareike KöNIG, Matthias Schulz (Hg.), Die Bundesrepublik Deutschland und die europäische Einigung 1949-2000. Politische Akteure, gesellschaftliche Kräfte und internationale Erfahrungen, Stuttgart 2004, S. 185-220; Herbert DitTgen, Deutschamerikanische Sicherheitsbeziehungen in der Ära Helmut Schmidt. Vorgeschichte und Folgen des NATO-Doppelbeschlusses, München 1991, S. 161-176, bes. S. 173; Helmut Schmidt, Menschen und Mächte, Berlin 1987, S. 222-235.

96 Vgl. Michel Colomes, Léo Michel, Guadeloupe: »la bande des quatre« de l'Occident, in: Le Point, 08.01.1979, S. 38f.; Alexandre SAnguinetTi, Risquer l'Europe franco-allemande, in: Le Monde, 10.10.1979, S. 10.

97 Jean WETz, Le chancelier Schmidt entre Washington et Paris, in: Le Monde, 24.03.1979, S. 8.

98 Siehe »Die deutsche Frage ist wieder da«. In Ost und West steht die Zukunft von Bundesrepublik und DDR neu auf der Tagesordnung, in: Der Spiegel, 12.03.1979, S. 31-45.

99 Ibid., S. 38. 
traumatische Angst der Nachbarn vor gemeinsam agierenden Deutschen in Ost und West ziehe sich sowohl durch die französische Presselandschaft als auch durch das gesamte Parteienspektrum. Als Kronzeuge einer solchen Auffassung konnte den westdeutschen Journalisten zum einen der ehemalige Außenminister Michel Jobert gelten, der bereits zu Beginn des Jahres vor einer machtstrotzenden und in gefährlicher Weise zwischen den Bündnissystemen lavierenden Bundesrepublik gewarnt hatte ${ }^{100}$. Zum anderen füllte der Vorsitzende der Sozialistischen Partei, François Mitterrand, diese Rolle aus; in einem Zeitungsinterview hatte er, Anfang Juni 1979 nach der deutschen Wiedervereinigung gefragt, selbige als $»$ ni souhaitable, ni possible « bezeichnet ${ }^{101}$. Wiederum, dieser Eindruck mochte sich in Westdeutschland angesichts der beständig geäußerten Befürchtungen festsetzen, herrschte in Frankreich offenes Misstrauen gegenüber den außenpolitischen Intentionen der Bundesrepublik, die nach den ostpolitischen Initiativen der Regierung Willy Brandts erneut in Verdacht geriet, allzu sehr nach Moskau zu schielen ${ }^{102}$. Auch für französische Berichterstatter, die, wie Raymond Aron, an die Aufrichtigkeit der politisch Verantwortlichen in Bonn glaubten und sie von dem Vorwurf, den Versuchungen des Ostens zu erliegen, freisprachen, blieb eine Unsicherheit bestehen. So formulierte Aron in einem Artikel für »L'Express «: »quelles concessions offrirait le Kremlin pour inciter la RFA à une demi-neutralité, qui, à terme, entraînerait le retrait des troupes américaines? «103

Auf Seiten der offiziellen bundesdeutschen Stellen riefen die Reaktionen der französischen Presseorgane auf die vermeintliche Neuverhandlung der deutschen Frage indessen einige Beunruhigung hervor. Die "zahllosen Pressespekulationen über die künftige Orientierung der deutschen Aussenpolitik «, die, wie die deutsche Botschaft in Paris dem Auswärtigen Amt im Mai 1979 mitteilte, »selbst wohlmeinende und aufgeschlossene Kreise nicht ganz unberührt gelassen haben « ${ }^{104}$, zeigten genauso wie die Auslassungen einer erheblichen Anzahl französischer Politiker, dass in Frankreich gegenwärtig Argumentationen bemüht würden, welche der deutsch-französischen Zusammenarbeit kaum förderlich sein könnten. Dieser Eindruck der westdeutschen Diplomaten hatte sich seit dem Wiedereinsetzen der Diskussionen

100 Siehe Michel Jobert, De l'Allemagne, in: Politique étrangère 44/1 (1979), S. 7-19.

101 André Fontaine, Jean-Marie Colombani, L'enjeu du 10 juin. Socialistes et sociauxdémocrates représentent le plus puissant courant d'opinion de la Communauté nous déclare M. François Mitterrand, in: Le Monde, 01.06.1979, S. 1 und 3, Zitat S. 3.

102 Vgl. François Schlosser, Bonn louche vers l'Est, in: Le Nouvel Observateur, 22.10.1979, S. 62 .

103 Raymond Aron, RFA: La tentation de l'Est, in: L'Express, 21.04.1979, abgedruckt in: Ders., De Giscard à Mitterrand 1977-1983, Paris 2005, S. 251-253, Zitat S. 252f.; vgl. auch Ders., L'unité allemande, in: L'Express, 27.10.1979, abgedruckt in: Ders., De Giscard à Mitterrand, S. 292-295.

104 Siehe PA-AA, Auslandsvertretungen, Botschaft Paris, Bd. 13523, Schreiben der deutschen Botschaft Paris an das Auswärtige Amt betreffend die jüngsten Äußerungen zum deutsch-französischen Verhältnis vom 23. Mai 1979, S. 3. 
um die deutsche Frage zusehends verstärkt. Es seien die alten Unterschiede in der geopolitischen Situation beider Länder, die erneut ins Bewusstsein der französischen Öffentlichkeit rückten, hatte Botschafter Axel Herbst bereits Anfang Dezember 1978 nach Bonn gemeldet ${ }^{105}$. Dem festgefügten Territorium Frankreichs stehe ein Deutschland gegenüber, das mit der Frage belastet sei, welches seine Grenzen im Osten nun eigentlich sein sollten, wodurch das Problem der Wiedervereinigung immer wieder akut werde. Zwar gehe die amtliche Politik überwiegend von der Westverankerung der Bundesrepublik aus, dennoch tauchten auch dort immer wieder »klischeehafte Bedenken auf, die kaum auszurotten sind ${ }^{106}$. Die eigentliche Sorge aber, so die Auffassung Herbsts, ranke sich in Frankreich derzeit um »das wieder einmal missverstandene Stichwort >Rapallo««, das erneut zum Leben erweckt worden sei. Die französische Presse beschäftigten mit wachsender Beunruhigung die Fragen:

Welche Absichten verfolgt Bonn in der ausgehenden Ära Breschnew gegenüber den gesprächiger werdenden Sowjets? Ist nicht Deutschland für die Verlockungen des Ostens immer empfänglich gewesen? [...] Komme es nicht am Ende zu einer allmählich >finnlandisierten B Bundesrepublik Deutschland oder gar zu einem neutralisierten Gesamtdeutschland, das 79 Mio. Deutsche umfasst und Frankreich ohne schützendes Vorfeld ließe $\mathrm{e}^{107}$ ?

Dem Botschafter zufolge verrieten all diese Fragen wieder einmal, wie wenig man in Frankreich wirklich vom jeweiligen Denken der Deutschen wisse. Die französischen Kommentare, welche in der außenpolitischen Richtung der Bundesrepublik die »Gefahr eines Ausbrechens Deutschlands aus der westlichen Gemeinschaft «108 erkennen wollten, schienen die frühere Einschätzung Herbsts zu bestätigen, dass angesichts der "außerordentlichen Verschiedenheit der beiden Völker, ihrer Kultur und ihrer Geschichte und wegen ihrer traditionellen Rivalität « ${ }^{109}$ Missverständnisse zwischen ihnen immer möglich blieben und die unterschiedlichen Mentalitäten sich auch im politischen Bereich auswirkten.

Die hieraus für die Regierungspolitik zu ziehenden Konsequenzen konn-

105 Siehe PA-AA, Zwischenarchiv, Nr. 113562, Schreiben des deutschen Botschafters in Paris, Axel Herbst, an das Auswärtige Amt bezüglich des französischen Deutschlandbildes vom 4. Dezember 1978, S. 1.

106 Ibid.

107 Ibid., S. 2; vgl. zu diesem Abschnitt auch die Memoiren des ehemaligen französischen Botschafters François Seydoux, Botschafter in Deutschland. Meine zweite Mission 1965-1970, Frankfurt a.M. 1978, die Herbst als symptomatisch für die in Frankreich vertretene Auffassung galten, Deutschland sei schon in der Vergangenheit immer wieder geneigt gewesen, seinen östlichen Versuchungen nachzugeben und bleibe daher auch in der Gegenwart ein Unsicherheitsfaktor für seine Nachbarn.

108 PA-AA, Auslandsvertretungen, Botschaft Paris, Bd. 13523, Schreiben der deutschen Botschaft Paris an das Auswärtige Amt betreffend die französischen Äußerungen über Deutschland im Zuge des Europawahlkampfes vom 1. Juni 1979, S. 1.

109 Siehe PA-AA, Auslandsvertretungen, Botschaft Paris, Bd. 13523, Schreiben des deutschen Botschafters in Paris, Axel Herbst, an das Auswärtige Amt betreffend »Deutschland und Frankreich"vom 24. Januar 1978, Zitat S. 2. 
ten, wie ein Botschaftsbericht formulierte, mithin nur sein, »die Basis unserer Gemeinsamkeiten noch mehr zu verbreitern, und zwar auch dann, wenn Interessendifferenzen oder Mentalitätsunterschiede den Weg zu einer gemeinsamen Haltung erschweren ${ }^{110}$. Beruhigend blieb in westdeutscher Perspektive, dass zumindest der französische Staatspräsident und seine Regierung der Bundesrepublik in positiver Weise gegenüberstanden und bestrebt waren, die französischen Debatten um Wiedervereinigung und Neutralität unter Kontrolle zu halten. Wenn auch damit zu rechnen sei, wie Botschafter Herbst urteilte, dass mindestens zu Lebzeiten der gegenwärtigen Generation das Deutschlandbild immer wieder mit negativen Assoziationen verbunden werde, "so können wir doch darauf vertrauen, dass die positiven Akzente von der breiten Bevölkerung vermehrt gesehen und in zunehmendem Maße akzeptiert werden «111. Die weitere Entwicklung der Einstellung der Franzosen zum neuen Deutschland werde zukünftig allerdings entscheidend dadurch bestimmt, in welchem Umfang es den Deutschen gelinge, das bereits bestehende Vertrauen zu pflegen und auszubauen.

Schenkt man den zeitgleich erstellten Berichten der französischen Diplomaten Glauben, so waren angesichts der in Frankreich neu entflammten Ängste vor einem wiedervereinigten Deutschland solcherlei vertrauensbildende Maßnahmen dringlich angezeigt. Bereits Ende November 1978 hatte auch die politische Abteilung des Quai d'Orsay konstatiert, dass die deutsche Frage auf die Titelseiten der französischen Zeitungen zurückgekehrt sei, verbunden mit der vielerorts zu lesenden Vermutung, sie werde sich in einer mehr oder weniger nahen Zukunft auch tatsächlich stellen ${ }^{112}$. Zahlreiche französische Journalisten, so hielten die Diplomaten fest, spekulierten über die Existenz eines deutsch-sowjetischen Plans, der ein wiedervereinigtes und zunächst neutrales Deutschland zum Ziel habe, das sich früher oder später unter das Banner des moskowitischen Kommunismus stelle.

Dieses von Misstrauen geprägte Klima in der Presse führte die Verantwortlichen im Pariser Außenministerium zu dem Urteil: »Ainsi trente ans après la fin de la guerre, quinze ans après la signature du traité de l'Élysée, les réactions de la presse indiquent-elles pour une part de l'opinion, l'ère du soupçon à l'encontre de la République fédérale n'est toujours pas dépassée «113. Wenn auch für einen großen Teil der Franzosen Westdeutschland der beste Verbündete sei, so bleibe doch, wie weiter erläutert wurde, sein Platz in Europa weiterhin zu definieren. In der französischen Presselandschaft werde

110 PA-AA, Auslandsvertretungen, Botschaft Paris, Bd. 13523, Aufzeichnung der deutschen Botschaft Paris betreffend »Deutschland und Frankreich - Herbst 1978«, S. 5.

111 PA-AA, Zwischenarchiv, Nr. 113562, Schreiben des deutschen Botschafters in Paris, Axel Herbst, an das Auswärtige Amt vom 4. Dezember 1978, S. 2 f.

112 AMAE Paris-La Courneuve, Europe, RFA 1976-1980, Bd. 3999, Vermerk betreffend »La presse française et la RFA« vom 25. November 1978, S. 1-4.

113 Ibid., S. 4. 
deshalb, zumal vor dem Hintergrund des wachsenden internationalen Gewichts der Bundesrepublik, regelmäßig die Frage aufgeworfen, ob die Ostpolitik der Bonner Regierung nicht auf lange Sicht darauf ausgerichtet sei, über die Entwicklung von Handelsbeziehungen und menschlichen Kontakten hinaus die beiden deutschen Staaten wieder zu vereinen ${ }^{114}$. Unter der Oberfläche vorhandene Ängste könnten hierdurch immer wieder mobilisiert, deutschfranzösische Konflikte geschürt werden.

Nicht zuletzt diese Einsicht bestärkte die Regierungen in Bonn und Paris in ihrer oftmals gemeinsam bekundeten Absicht, im Sinne eines besseren wechselseitigen Verständnisses auf die Menschen in beiden Ländern einzuwirken. Ziel war es, das in Frankreich durch die Presseberichterstattung genährte Misstrauen gegenüber den wieder bedrohlich erscheinenden »incertitudes allemandes $\aleph^{115}$ abzubauen. In dieser Hinsicht galt beiden Seiten vor allem die gezielte Einladung von Journalisten aus dem jeweiligen Nachbarland als wesentliches Instrument der Verständigungsarbeit. Dem zugrunde lag die Erkenntnis, dass diejenigen, die es vermochten, Einfluss auf die Meinungsbildung von Franzosen und Deutschen auszuüben, in ihrer Einstellung zum Nachbarland günstiger gestimmt werden müssten. "Störungen der `öffentlichen Beziehungen ${ }^{116}$ seien, wie die Diplomaten der deutschen Botschaft formulierten, schließlich immer möglich. Daher müsse man sich versichern, dass im Falle deutsch-französischer Spannungen im Bereich der Medien Persönlichkeiten vorhanden seien, welche durch ihre Berichte, Reportagen und Kommentare für Ausgleich sorgen konnten.

Ausgehend hiervon war die bundesdeutsche Vertretung in Paris in $\mathrm{Zu}-$ sammenarbeit mit den Generalkonsulaten darum bemüht, das Interesse französischer Journalisten an Deutschland, vor allem der in ihrem Deutschlandbild noch nicht gefestigten Nachwuchsredakteure, zu wecken und $\mathrm{zu}$ vertiefen. Durch Botschaft und Bundespresseamt organisierte Informationsreisen nach Westdeutschland würden sich, so hoffte man, "auf die Deutschlandberichterstattung der entsprechenden Medien und damit längerfristig auch auf das Deutschlandbild in der veröffentlichten Meinung

114 Siehe ibid. sowie AMAE Paris-La Courneuve, Europe, RFA 1976-1980, Bd. 3999, Vermerk bezüglich der deutsch-französischen Beziehungen in den Jahren 1977 und 1978 vom 1. Dezember 1978, S. 3.

115 Vgl. hierzu Friedrich W. Husemann, Wolf Siegert, Helmut Schmidt et les incertitudes allemandes, in: Documents 37/1 (1982), S. 38-58; Klaus Otto Nass, Incertitudes allemandes, in: Dokumente 26/5-6 (1970), S. 287-294; zurückzuführen ist dieses Schlagwort auf Pierre VIÉNOT, Incertitudes allemandes. La crise de la civilisation bourgeoise en Allemagne, Paris 1931; der Titel der deutschen Übersetzung lautet: Ungewisses Deutschland. Zur Krise seiner bürgerlichen Kultur, hg. v. Hans Manfred BocK, Bonn 1999.

116 PA-AA, Zwischenarchiv, Nr. 117461, Schreiben der deutschen Botschaft Paris an das Auswärtige Amt vom 10. Juli 1978, Anlage: Stellungnahme zu den Ausführungen Prof. Noacks über die deutsche Kulturpolitik in Frankreich, S. 1. 
Frankreichs positiv auswirken ${ }^{117}$. Indes habe dieses Instrument auch seine Grenzen, da sich, so die Prognose der Botschaft, ideologisch festgelegte Vertreter kritisch zur Bundesrepublik eingestellter Meinungsmedien hierdurch kaum beeinflussen ließen. Eine verzerrte Deutschlandberichterstattung komme schließlich häufig nicht aufgrund mangelnder Information, sondern als bewusster Versuch einer tendenziösen Meinungsbeeinflussung zustande ${ }^{118}$. Dennoch dürfe nichts unversucht gelassen werden, um die unbefriedigende Situation zum Besseren zu wandeln.

$\mathrm{Zu}$ einer ähnlichen Überzeugung gelangten auch die französischen Verantwortlichen. Ein Bericht der Interministeriellen Kommission für die deutschfranzösische Zusammenarbeit vom Januar 1979 stellte etwa fest: "Il n'y a que rarement des réactions instinctives communes de l'opinion face aux événements et aux problèmes actuels. Les préjugés latents remontent vite à la surface. L'information insiste surtout sur l'inattendu qui est souvent le pire ${ }^{119}$. Sowohl die direkte Einladung von Journalisten als auch die Verbesserung ihrer Ausbildung und ihrer Informationsmöglichkeiten könnten hier Abhilfe schaffen. Neben diesen Initiativen zur positiven Einwirkung auf die medialen Meinungsmacher förderten beide Regierungen im Rahmen ihrer kulturellen Verständigungsarbeit weiterhin den Erwerb sprachlicher und landeskundlicher Kompetenzen. Die »weit verbreitete Unkenntnis über das Nachbarland «120 sollte auf diese Weise verringert, »Klischees, die den Blick für die politische, wirtschaftliche, soziale oder kulturelle Realität verstellen «, durch »wirklichkeitsnähere Bilder « ersetzt werden ${ }^{121}$. Vor allem die Kenntnis der Partnersprache stellte, wie immer wieder betont wurde, eine unerlässliche Notwendigkeit für das Verstehen des jeweiligen Nachbarn dar, "pour la compréhension réciproque «122. In den Kursen der Instituts français und des Goethe-Instituts, den Austausch- und Seminarprogrammen des DAAD und des DFJW sowie im Sprachunterricht der allgemeinbildenden

117 BA, B 145, Bd. 13413, Schreiben der deutschen Botschaft Paris an das Presse- und Informationsamt der Bundesregierung vom 1. September 1978, S. 1; vgl. auch ibid., Schreiben der deutschen Botschaft Paris an das Auswärtige Amt vom 4. September 1978, S. If.

118 Siehe PA-AA, Zwischenarchiv, Nr. 117461, Schreiben der deutschen Botschaft Paris an das Auswärtige Amt vom 10. Juli 1978, Anlage: Stellungnahme zu den Punkten 6 und 7 der »Gedanken zur Kulturpolitik in Frankreich" von Prof. Noack, S. 2f., Zitat S. 3.

119 AMAE Paris-La Courneuve, Europe, RFA 1976-1980, Bd. 3999, Bericht der Interministeriellen Kommission für die deutsch-französische Zusammenarbeit bezüglich der öffentlichen Meinungen in Frankreich und der Bundesrepublik vom 29. Januar 1979, S. 2.

120 PA-AA, Auslandsvertretungen, Botschaft Paris, Bd. 13523, Vermerk der deutschen Botschaft Paris betreffend die Möglichkeiten zur Verbesserung der deutsch-französischen Zusammenarbeit vom 24. November 1978, S. 1.

121 PA-AA, Auslandsvertretungen, Botschaft Paris, Bd. 13523, Schreiben des deutschen Botschafters in Paris, Axel Herbst, an das Auswärtige Amt vom 4. Januar 1979, S. 2.

122 AMAE Nantes, Bonn Ambassade, Bd. 322, Schreiben des französischen Botschafters in Bonn, Olivier Wormser, an Außenminister Jean Sauvagnargues vom 21. Juni 1976, S. 2. 
Schulen sollten daher die entscheidenden Grundlagen geschaffen werden, damit Deutsche und Franzosen sich nicht vorschnell die Polemiken und einseitig negativ gefärbten Meinungen der Presseberichterstattung zu eigen machen und hierdurch zu einer kritischen Masse in den deutsch-französischen Beziehungen werden konnten ${ }^{123}$. Eine möglichst enge Verflechtung gerade auf den Gebieten der Bildung und Kultur galt den Regierenden als wesentliche Voraussetzung "für ein friedliches und für alle Seiten gedeihliches Zusammenleben « ${ }^{124}$.

In der Herstellung solch verständigungsfördernder kultureller Verbindungen sahen sich die staatlichen Akteure durch die verschiedenen privaten Kräfte, welche sich für die deutsch-französische Annäherung engagierten, verlässlich unterstützt. Nicht zuletzt die im Rahmen der deutsch-französischen Städtepartnerschaften initiierten Begegnungen und Austauschprozesse verfolgten die Regierungen mit äußerstem Wohlwollen, erblickten sie doch in den Verschwisterungen auf kommunaler Ebene, wie die westdeutschen Diplomaten im Dezember 1978 urteilten, eine tragende Säule der bilateralen Beziehungen ${ }^{125}$. "La plupart des jumelages«, so auch die Einschätzung auf französischer Seite, »constituent des réalités bien vivantes qui, au niveau des populations, contribuent d'une manière heureuse à supprimer les préjugés et les complexes dangereux que l'ignorance des réalités humaines ne manque jamais de susciter « ${ }^{126}$. Eine wesentliche Vermittlungs- und Koordinierungsfunktion bei der Anbahnung und Fortentwicklung der partnerschaftlichen Kontakte zwischen westdeutschen und französischen Städten und Gemein-

123 Vgl. exemplarisch AMAE Nantes, Bonn Service culturel, Bd. 29, Rapport d'activités du Service culturel, année 1977/1978; AMAE Paris-La Courneuve, Europe, RFA 19761980, Bd. 3971, Vermerk bezüglich der Spezialisierung der Kulturinstitute in der Bundesrepublik vom 21. Juni 1979; BA, B 189, Bd. 26334, Schreiben des Bundesministeriums für Jugend, Familie und Gesundheit an den Koordinator für die deutsch-französische Zusammenarbeit vom 29. Januar 1979; AMAE Paris-La Courneuve, Europe, RFA 1976-1980, Bd. 4007, Vermerk bezüglich der deutsch-französischen Zusammenarbeit vom 16. November 1978, S. 6f.; AN Fontainebleau, ministère de l'Éducation nationale, Bd. 900672/38, Protokolle der Sitzungen der Interministeriellen Kommission für die deutsch-französische Zusammenarbeit vom 26. Januar 1978 und 22. Mai 1979; Das Deutsch-Französische Jugendwerk. DFJW-Dokumentation, hg. v. DFJW, Bad Honnef 1979; Jahresbericht 1979, hg. v. DAAD, Bonn 1980, S. 162-175; Znined-Brand, Deutsche und französische auswärtige Kulturpolitik, S. 121-218.

124 PA-AA, Zwischenarchiv, Nr. 106864, Gesamtplan für die auswärtige Kulturpolitik 19771980 vom 15. Juni 1976, S. 3.

125 Siehe PA-AA, Auslandsvertretungen, Botschaft Paris, Bd. 13523, Vermerk der deutschen Botschaft Paris bezüglich einer möglichen Verbesserung der deutsch-französischen Beziehungen vom 18. Dezember 1978, S. 1.

126 AMAE Paris-La Courneuve, Europe, RFA 1971-1976, Bd. 3033, Schreiben des französischen Generalkonsuls in München, G. de la Villesbrunne, an Außenminister Jean Sauvagnargues betreffend die Städtepartnerschaften zwischen bayrischen und französischen Kommunen vom 14. August 1975, S. 6. 
den kam weiterhin der IBU zu${ }^{127}$, die auch am Ende der 1970er Jahre für diesbezügliche Fragen Hauptansprechpartner amtlicher Stellen in beiden Ländern war ${ }^{128}$. Ihre Stellung beabsichtigte die Organisation zu nutzen, um, wie es in einem Memorandum aus dem Jahr 1978 hieß, »die schöpferische Kraft der Gemeinden [...] für die Verständigung zwischen Frankreich und Deutschland zu mobilisieren und einzusetzen, um unabhängig von den wechselnden Situationen der hohen Politik eine kontinuierliche Annäherung beider Länder zu gewährleisten «129. Studienreisen von Bürgermeistern und Verwaltungsbeamten in das jeweilige Nachbarland, mehrtägige Seminare mit deutschen und französischen Jugendlichen zu aktuellen gesellschaftspolitischen Themen und die Veranstaltung öffentlicher Jahreskongresse sollten einen Beitrag dazu leisten, die im Zuge der Diskussionen um die deutsche Frage zu Tage getretenen »alten Schranken des Mißtrauens zwischen den Völkern « zu überwinden ${ }^{130}$. Vor allem wollte die IBU erreichen, dass die Bevölkerungen über die Vorgänge im Partnerland nicht allein »durch die oft tendenziöse Berichterstattung der Presse und anderer öffentlicher Medien « ${ }^{131}$ unterrichtet würden, sondern durch persönliche Begegnungen objektivere Eindrücke erhalten konnten.

Analog zur Bürgermeister-Union im Bereich der Städtepartnerschaften versuchte der ADFG die ihm angehörenden Gesellschaften im Sinne einer intensiveren Förderung der Verständigung zu aktivieren. In einem Rundschreiben vom Dezember 1978 machten die beiden Präsidenten des Arbeitskreises ihren Mitgliedern gegenüber deutlich, dass die Ursache der öffentlichen Verstimmungen, welche die Debatten um die Wiedervereinigung hervorgerufen hatten, insbesondere im mangelnden Informationsfluss zwischen beiden Ländern zu suchen sei. Die Gesellschaften sollten sich daher aufgefordert sehen, den Problemen des Nachbarn mehr Aufmerksamkeit

127 Vgl. PA-AA, Zwischenarchiv, Nr. 178766, Vermerk für Bundesaußenminister HansDietrich Genscher vom 15. März 1978.

128 Vgl. hierzu beispielhaft StASt, Bestand 1020, Bd. 62, Schreiben des DFJW an die IBU vom 5. Juli 1976; ibid., Bd. 69, Schreiben der deutschen Botschaft Paris an die IBU vom 7. Juli 1975 und des Mairie de Villers-sur-Mer an die IBU vom 25. April 1974; ibid., Bd. 71, Schreiben des Abgeordneten der französischen Nationalversammlung, René Radius, an die IBU vom 19. Dezember 1975; ibid., Bd. 81, Schreiben des deutschen Generalkonsulats Marseille an die IBU vom 20. Oktober 1978; ibid., Bd. 482, Schreiben des Präfekten der Region Rhône-Alpes an die IBU vom 28. Februar 1979.

129 StASt, Bestand 1020, Bd. 436, Die Internationale Bürgermeister-Union und ihre Tätigkeiten, 1978, S. 1.

${ }^{130}$ Vgl. Dreißig Jahre deutsch-französische Verständigung, S. 192-224, Zitat S.224; StASt, Bestand 1020, Bd. 67, Studienreise französischer Bürgermeister nach Südwestdeutschland, 27. Mai-2. Juni 1979; ibid., Bd. 17, Protokoll der Sitzung des Verwaltungsausschusses der IBU am 18. April 1977 in Kornwestheim, S. 6; DFI-Archiv, Ordner IBU bis 1993, Programm des 41. deutsch-französischen Jugendleiter-Seminars vom 16.-22.9.1979 in Saint-Jean-de-Monts.

131 Dreißig Jahre deutsch-französische Verständigung, S. 218. 
denn je entgegenzubringen und sie im eigenen Land zu erklären ${ }^{132}$. Ihre Verständigungsarbeit müsse darin bestehen, »unseren Mitbürgern und unseren Freunden « objektive Informationen zu vermitteln ${ }^{133}$. Dabei genüge es nicht, die Herrlichkeiten der Schlösser an der Loire zu besingen, um deutsch-französische Auseinandersetzungen zu verhindern. Vielmehr sei den Deutschen aufzuzeigen, wie sich die politische, wirtschaftliche, soziale und gesellschaftliche Situation in Frankreich gestalte und umgekehrt. Nur auf Grundlage solch fundierter Kenntnisse sei es den Bevölkerungen möglich, die Kommentare der Presse in ihren Zusammenhang einzuordnen. Die Tätigkeit der Gesellschaften müsse daher »neben dem kulturellen Bereich, der notwendig und erforderlich ist «, künftig mehr auf den politischen Bereich ausgedehnt wer$\operatorname{den}^{134}$. Die in diesem Zusammenhang anvisierte »beträchtliche Aktivierung der Verständigungsarbeit « ${ }^{135}$ zielte im Einzelnen darauf ab, die öffentliche Präsenz des Arbeitskreises zu erhöhen ${ }^{136}$, seine Verbindungen zu den Institutionen der Regierungsebene zu vertiefen und auf Konfliktsituationen mit raschen Gegendarstellungen in der Presse zu reagieren. Schließlich sollten die Führungspersönlichkeiten der Mitgliedsgesellschaften durch regelmäßige Seminare geschult werden, damit diese sich an ihrem jeweiligen Standort mit mehr Sachkompetenz in tagesaktuellen Debatten zu Wort melden konnten ${ }^{137}$.

Um eine objektivere Befassung mit den Entwicklungen im Nachbarland ging es auch dem DFI. In Reaktion auf die seit Ende 1978 aufgetauchten medialen Verstimmungen führte es in Kooperation mit dem Institut français des relations internationales ein Kolloquium zum Thema "Entwicklung der französischen und deutschen Außenpolitik seit 1974« durch. Im Rahmen dessen kamen in Paris Ministerialbeamte des Auswärtigen Amts und des Quai d'Orsay, Wissenschaftler, darunter auch Alfred Grosser und Joseph Rovan, sowie Journalisten maßgeblicher Presseorgane aus beiden Ländern

132 Siehe VDFG-Archiv, Ordner Vorstandssitzungen 1974-1976, Rundschreiben der Präsidenten des ADFG, Pierre Martin und Alfred Borgmann, an die Mitgliedsgesellschaften vom 21. Dezember 1978, S. 1.

133 Siehe VDFG-Archiv, Mitteilungsblatt für die Deutsch-Französischen Gesellschaften 44 (1979), S. 23.

134 Siehe ibid.

135 PA-AA, Zwischenarchiv, Nr. 178766, Schreiben des deutschen ADFG-Präsidenten Alfred Borgmann an Bundesaußenminister Hans-Dietrich Genscher vom 4. März 1978, S. 1.

136 So war der ADFG im September 1978 anlässlich des deutsch-französischen Gipfeltreffens etwa bei einem gemeinsam von Bundeskanzler und Staatspräsident gegebenen Abendessen vertreten, vgl. VDFG-Archiv, Ordner Arbeitskreis Korrespondenz 19771979, Jahresbericht des Arbeitskreises Deutsch-Französischer Gesellschaften für das Jahr 1978, S. 4f.

137 Vgl. StAMa, Nl. 96, Bd. 12, Kurzprotokoll der Mitgliederversammlung des ADFG am 26. September 1978, S. 1f. und Kurzprotokoll der gemeinsamen Sitzung von Gesamtvorstand und Kuratorium am 24. August 1978, S. 1. 
zusammen $^{138}$, um über die Ost-West-Beziehungen, die Frage der Wiedervereinigung und das Verhältnis zwischen Frankreich und Westdeutschland zu diskutieren. Da in der Öffentlichkeit immer wieder Krisen entstünden, die kaum aufgearbeitet würden, war es aus Sicht des Instituts erforderlich, die außenpolitische Orientierung der Nachbarländer in Form eines solchen deutsch-französischen Dialogs zu analysieren. Dieser sollte sich nach der Pariser Tagung im besten Falle zwischen den Teilnehmern fortsetzen und helfen, neuerlichen Verstimmungen vorzubeugen ${ }^{139}$.

Demselben Ziel sah sich das BILD verpflichtet. Angesichts der sich in Frankreich manifestierenden Beunruhigung über die engeren Beziehungen der Bundesrepublik zur Sowjetunion wollte die Vereinigung mittels seiner Publikationen öffentliche Aufklärungsarbeit leisten. Wie Joseph Rovan in seiner Eigenschaft als Vize-Präsident des BILD auf einer Mitgliederversammlung im Januar 1979 formulierte, sollte hierbei den Aufgaben »information sur l'Allemagne« und »lutte contre les fausses informations et préjugés « 140 oberste Priorität zukommen ${ }^{141}$. Den Franzosen müsse vor allem ermöglicht werden, die Presseberichterstattung sachlich nachvollziehen und tendenziöse Kommentare als solche erkennen zu können. Rolle der "Documents« war daher: "permettre aux Français de contrôler l'information plus ou moins orientée que leurs journaux leur dispensent, en rétablissant les faits dans leur contexte, en fournissant une information complémentaire sans laquelle l'événement reste parfois incompréhensible « ${ }^{142}$.

Neben den verschiedenen Assoziationen griffen auch die Mittlerpersönlichkeiten in die deutsch-französischen Diskussionen um die Frage der Wiedervereinigung ein. Alfred Grosser erklärte in Pressebeiträgen wiederholt, dass der in Frankreich bekundete Verdacht, die Bundesrepublik schere aus dem westlichen Lager aus, um in exklusiven Verhandlungen mit der Moskauer Führung Bewegung in die deutsche Frage zu bringen, jeglicher Grundlage entbehre. Auch im Rahmen ihrer ostpolitischen Initiativen habe die Bonner Regierung jederzeit erkennen lassen, dass sie die Rechte und Verantwortlichkeiten der Alliierten weiterhin wahre, zumal durch diese der

138 Darunter Raymond Aron, André Fontaine (Le Monde), Paul-M. de la Gorce (Le Figaro), Robert Held (FAZ) und Klaus-Peter Schmid (Die Zeit).

139 Vgl. DFI-Archiv, Ordner Kolloquium Außenpolitik Paris 1979, Skizze betreffend das Kolloquium »Entwicklung der französischen und deutschen Außenpolitik seit 1974« am 9. Juni 1979 in Paris.

140 BILD-Archiv, Compte rendu des travaux de l'assemblée générale du BILD, 20 janvier 1979, annexe 5: Intervention de M. Joseph Rovan.

141 Vgl. BILD-Archiv, Tätigkeitsbericht der Gesellschaft für übernationale Zusammenarbeit und des Bureau international de liaison et de documentation für das Jahr 1979.

142 BILD-Archiv, Compte rendu des travaux de l'assemblée générale du BILD, 20 janvier 1979, annexe 4: Revue "Documents«; vgl. hierzu beispielhaft den Artikel von Alfred FRISCH, L'Allemagne fédérale: partenaire à part entière du directoire occidental, in: Documents 34/1 (1979), S. 131-137. 
Fortbestand einer einheitlichen deutschen Nation gewährleistet werde ${ }^{143}$. Von dem Publizisten Patrick Wajsman nach dem französischen »Schreckgespenst Rapallo « befragt, antwortete Grosser: »Si l'on veut dire que l'Allemagne risque de se jeter dans les bras des Russes, alors, franchement, je ne puis faire mienne cette hypothèse «144. Im Grunde könne Westdeutschland seinen französischen Kritikern gar nicht gerecht werden, vollkommen unabhängig davon, welche Richtung es einschlage: »Depuis trente ans, chaque fois qu'un gouvernement allemand a pratiqué une certaine ouverture vers l'Est, des voix se sont élevées en France pour crier à la désertion; et chaque fois que Bonn a durci son attitude envers Moscou et ses alliés, les mêmes voix se sont stupidement empressées de stigmatiser le >bellicisme allemand $\left\lfloor «^{145}\right.$

Allein der in der Bundesrepublik tief verwurzelte Antikommunismus führe doch, wie Grosser erklärte, Spekulationen über ein deutsches Abdriften nach Osten ad absurdum. Sein Weggefährte Joseph Rovan gab den Franzosen angesichts ihres Misstrauens gegenüber einem möglichen deutschen Einheitsstreben, auch für den Fall, dass dieses nicht vollkommen von der Hand gewiesen werden könne, lediglich den knappen Rat, in den Deutschen endlich normale Nachbarn zu sehen. In einem Beitrag, der in »Le Nouvel Observateur« abgedruckt wurde, schrieb er: »Ce dont nous avons le plus besoin, c'est d'apprendre enfin que les Allemands sont un peuple comme les autres « ${ }^{146}$.

Die in Frankreich seit Ende 1978 erneut zu Tage getretenen Ängste vor einem wiedervereinigten Deutschland ließen auf Seiten der Regierungen die Erkenntnis reifen: »L'histoire de nos deux peuples est trop riche d'affrontements pour que nos relations soient entièrement sorties de l'ère du soupçon « ${ }^{147}$. Als wesentlicher Urheber der fortbestehenden gegenseitigen Verdächtigungen galt den verantwortlichen Stellen in Bonn und Paris die oft tendenziöse Presseberichterstattung, die, ähnlich wie bereits im Zuge der Debatten um die Ostpolitik, als möglicher Ursprung künftiger Konflikte betrachtet wurde. Die politisch Handelnden versuchten daher, Medien und Journalisten zu einer objektiven Kommentierung der Entwicklungen im Nachbarland zu bewegen und breiteren Bevölkerungsschichten Sprach- und Sachkenntnisse zu vermitteln, die unempfänglich für medial transportierte Vorurteile machen sollten. Unterstützung erfuhren sie hierbei durch die deutsch-französischen Mittler,

${ }^{143}$ Vgl. hierzu beispielsweise Alfred Grosser, Semblable et différente, in: L'Express, 24.03.1979, S. 34.

144 Patrick Wajsman, La RFA, la France et les super-grands. Entretien avec Alfred Grosser, in: Politique internationale $9(1979 / 80)$, S. $7-18$, hier S. $7 f$.

145 Ibid., S. 8.

146 Joseph Rovan, Les Allemands, un peuple comme les autres, in: Le Nouvel Observateur, 07.04.1980, S. 28; vgl. dazu auch IMEC, Fonds Joseph Rovan, Schreiben Joseph Rovans an Jean Daniel, Direktor von Le Nouvel Observateur, vom 18. März 1980.

147 AMAE Paris-La Courneuve, Europe, RFA 1976-1980, Bd. 3999, Vermerk bezüglich der deutsch-französischen Beziehungen in den Jahren 1977 und 1978 vom 1. Dezember 1978, S. 1. 
die ihr intellektuelles Gewicht in die Waagschale der Verständigung warfen, sowie durch die verschiedenen privaten Vereinigungen, welche die Menschen beiderseits des Rheins durch ihre Dialog-, Presse- und Austauscharbeit aufklären, informieren und somit einer unvoreingenommenen Beurteilung des Nachbarlandes den Weg bereiten wollten.

An gutem Willen und leidenschaftlichen Einsatz fehlte es nicht bei den Streitern für Ausgleich und Freundschaft, doch war es ihnen, nimmt man die Gesamtheit der Auseinandersetzungen in den Blick, bis auf wenige Ausnahmen kaum möglich, zeitnah auf die öffentlichen Verstimmungen zu reagieren und unmittelbar in Debatten einzugreifen. Viele der beabsichtigten Initiativen blieben in der Planungsphase stecken, wohlmeinende Appelle verhallten ungehört, da ihnen das Publikum fehlte ${ }^{148}$. Die Verständigungsbemühungen, die weite Bevölkerungskreise erreichen sollten, scheinen vielfach fernab öffentlichen Interesses stattgefunden zu haben. Vor diesem Hintergrund konnten sie schwerlich dazu beitragen, Konfliktpotenzial aus den Diskussionen um die deutsche Frage am Ende der 1970er Jahre zu bannen.

\subsubsection{Ein "Strom des Unverständnisses«: Dispute um die Friedensbewegung}

Seit Herbst 1979 klangen die Debatten um die Frage der Wiedervereinigung sukzessive ab. Zur Beruhigung trug unzweifelhaft auch das nach außen demonstrierte deutsch-französische Einvernehmen angesichts der sowjetischen Militärintervention in Afghanistan bei ${ }^{149}$. Dieses kam insbesondere in einer gemeinsamen Erklärung Staatspräsident Giscard d'Estaings und Bundeskanzler Schmidts vom Februar 1980 zum Ausdruck, in welcher beide das Vorgehen der UdSSR als Gefahr für Stabilität und Frieden in den internationalen Bezie-

148 So musste die IBU bereits seit 1973 mehrfach Seminare für deutsche und französische Jugendliche aufgrund mangelnder Beteiligung absagen. Der ADFG konnte, insoweit sich dies anhand der Quellen nachvollziehen lässt, weder sein Vorhaben verwirklichen, Gegendarstellungen in der Presse zu lancieren noch den Plan umsetzen, regelmäßige Seminare zur Schulung der Führungspersönlichkeiten der Mitgliedsgesellschaften einzurichten. Die Verantwortlichen des BILD klagten seit 1975 über die geringe Leserschaft der »Documents", deren Bekanntheitsgrad in Frankreich als höchst unbefriedigend beurteilt wurde, siehe hierzu StASt, Bestand 1020, Bd. 325, Protokoll der Sitzung des Verwaltungsausschusses der IBU am 15. Oktober 1973 in Mâcon; VDFGArchiv, Ordner Arbeitskreis Korrespondenz 1977-1979, Aufzeichnung zu den Tätigkeiten des Arbeitskreises, 1979; BILD-Archiv, Aufzeichnung des Chefredakteurs der »Documents«, Jean-Paul Picaper, betreffend »Documents im Jahre 1975«; Protokoll der erweiterten Präsidiumssitzung des BILD und der GÜZ am 8. November 1978.

149 Vgl. Nicole Gnesotto, Der sicherheitspolitische Dialog 1954 bis 1986, in: Karl KAIsER, Pierre Lellouche (Hg.), Deutsch-französische Sicherheitspolitik. Auf dem Wege zur Gemeinsamkeit?, Bonn 1986, S. 5-26, bes. S. 17; David N. GibBs, Die Hintergründe der sowjetischen Invasion in Afghanistan 1979, in: Bernd Greiner, Christian Th. Müller, Dierk Walter (Hg.), Heiße Kriege im Kalten Krieg, Hamburg 2006, S. 291-314. 
hungen verurteilten ${ }^{150}$. Nicht ohne Genugtuung wurde in der französischen Presse notiert, dass hierdurch die neutralistischen Tendenzen in der Bundesrepublik eingedämmt worden, die vom »rechten Weg« abgekommenen Nachbarn wieder an die Seite ihrer westlichen Alliierten und vor allem Frankreichs zurückgekehrt seien ${ }^{151}$.

Die Beruhigung über den Partner jenseits des Rheins währte indes nicht lange. Die sich als Reaktion auf den NATO-Doppelbeschluss und die daraus resultierende Bestückung Westeuropas mit neuen amerikanischen Raketensystemen in der Bundesrepublik formierende Friedensbewegung sowie die dort erbittert geführten innenpolitischen Kontroversen um die Nachrüstung ließen die französischen Zeitungen erneut fragen, ob Deutschland gen Neutralismus treibe ${ }^{152}$. Bereits im Vorfeld eines Besuchs Helmut Schmidts in Moskau Ende Juni 1980 war in der Pariser Presse darüber gemutmaßt worden, ob der westdeutsche Regierungschef in Anbetracht der stärker werdenden Opposition im eigenen Lande und in der eigenen Partei vom Doppelbeschluss der nordatlantischen Allianz abrücken werde ${ }^{153}$. Zwar galt der Bundeskanzler selbst einer Mehrheit der französischen Beobachter in diesem Sinne als unverdächtig, doch wurde befürchtet, dass er dem Druck des linken SPDFlügels nicht auf Dauer würde standhalten können ${ }^{154}$. In einem Beitrag für »L'Express« hielt Raymond Aron diesbezüglich fest: »La gauche du SPD, un tiers environ du groupe socialiste au Bundestag, incline vers la neutralité, avec la perspective vague d'une réunification allemande dans le cadre d'une Europe

150 Siehe die gemeinsame Erklärung Staatspräsident Giscard d'Estaings und Bundeskanzler Schmidts vom 5. Februar 1980, in: Kimmel, Jardin (Hg.), Die deutsch-französischen Beziehungen, S. 225f.

151 Vgl. Jérôme Dumoulin, Le président, le chancelier et l'ours, in: L'Express, 16.02.1980, S. 54-56.

152 Vgl. hierzu Stephan LaYritz, Der NATO-Doppelbeschluss. Westliche Sicherheitspolitik im Spannungsfeld von Innen-, Bündnis- und Außenpolitik, Frankfurt a.M. u. a. 1992; Michael RoIK, Der NATO-Doppelbeschluss und die Veränderung des antiautoritären Konsenses in der Bundesrepublik Deutschland, in: Karl Dietrich Bracher (Hg.), Politik, Geschichte, Kultur. Wissenschaft in Verantwortung für die »res publica«. Festschrift für Manfred Funke zum 70. Geburtstag, Bonn 2009, S. 65-76; Rüdiger SснмiтT, Die Friedensbewegung in der Bundesrepublik Deutschland. Ursachen und Bedingungen der Mobilisierung einer neuen sozialen Bewegung, Opladen 1990; Andreas Buro, Friedensbewegung, in: Rотн, Rucht (Hg.), Die sozialen Bewegungen in Deutschland seit 1945, S. 267-291; Wolfram Wette, Von der Anti-Atombewegung zur Friedensbewegung (1958-1984), in: Michael SALEwSKI (Hg.), Das nukleare Jahrhundert. Eine Zwischenbilanz, Stuttgart 1998, S. 174-187; Schmitz, Zwischen Mythos und Aufklärung, S. 250-257; Meıмeth, Frankreichs Entspannungspolitik der 70er Jahre, S. 85-91; Miard-DelacroiX, Im Zeichen der europäischen Einigung, S. 89-91.

153 Siehe M. Schmidt et les euromissiles, in: Le Monde, 19.06.1980, S. 1; Incertitudes, in: Le Monde, 03.07.1980, S. 1.

154 Vgl. zu den Auseinandersetzungen innerhalb der Sozialdemokratie Anton Notz, Die SPD und der NATO-Doppelbeschluss. Abkehr von einer Sicherheitspolitik der Vernunft, Baden-Baden 1990. 
orientale socialiste, amie de l'Union soviétique, mais non desservie à elle. Le chancelier ne souscrit pas aux thèses de sa gauche, mais il en tient compte « ${ }^{155}$.

Anfang 1981 schließlich bildeten - in Anbetracht des weiteren Anwachsens der Protestbewegung in der Bundesrepublik - Spekulationen über eventuelle Einschnitte im westdeutschen Verteidigungshaushalt den endgültigen Auslöser für das Wiedererwachen konkreter französischer Ängste vor den Entwicklungen im östlichen Nachbarland ${ }^{156}$. War nicht die Bonner Regierung, massiv beeinflusst durch die pazifistischen Strömungen, im Begriff, dem westlichen Verteidigungsverbund eine offene Wunde zuzufügen und die militärische Kooperation auch mit Frankreich aufzukündigen, um anschließend ihr Heil in der Neutralität zu suchen? So fragten die französischen Kommentatoren. Fern ihres früheren Status' als sicherer Garant des Nordatlantikpaktes sei die Bundesrepublik, wie »Le Monde« schrieb, mittlerweile von einer "fragilité dangereuse « erfasst worden, die sich zu einer ernstlichen Gefahr für Europas Sicherheit entwickeln könne ${ }^{157}$. Vor allem deswegen gerieten die Deutschen immer wieder in neutralistische Versuchungen, weil hierdurch die Hoffnung auf eine schrittweise Wiedervereinigung gestärkt werde. Diese könne für ein Volk, das unter der Teilung mehr gelitten habe, als es zugebe, nicht ohne Anziehungskraft sein ${ }^{158}$.

Vor dem Hintergrund der nun wieder manifest gewordenen Befürchtungen vor einer »dérive allemande ${ }^{159}$ erschien die Friedenskundgebung im Bonner Hofgarten im Oktober $1981^{160}$ französischen Beobachtern als bedrohliches Vorzeichen eines sich im Nachbarland Bahn brechenden

155 Raymond Aron, L'alternative de Schmidt, in: L’Express, 29.11.1980, abgedruckt in: Ders., De Giscard à Mitterrand, S. 452-454, Zitat S. 454; vgl. auch Claire TrÉAN, Le chancelier Schmidt est confronté à une grave crise au sein de son parti, in: Le Monde, 08./09.02.1981, S. 2.

156 Vgl. Rüstung: Sinkendes Schiff, in: Der Spiegel, 02.03.1981, S. 22-24; Wolfgang HoffMANN, Rüstungshaushalt: Gestrichen, gestreckt und gekippt, in: Die Zeit, 13.03.1981, S. 8 .

157 Jean Wetz, Bonn compromet par ses réductions budgétaires la coopération militaire avec Paris et Londres, in: Le Monde, 10.03.1981, S. 1.

158 Siehe Bernard Brigouleix, La tentation du neutralisme en RFA, in: Le Monde, 09.09.1981, S. 1 und 6.

159 Vgl. Jacques BARIÉTy, Les Français craignent-ils une dérive allemande?, in: FranceAllemagne. Perceptions et stratégies nationales, hg. v. der Fondation pour les études de défense nationale, Paris 1988, S. 5-16; Ingo Коцвоом, Im Westen nichts Neues? Frankreichs Sicherheitspolitik, das deutsch-französische Verhältnis und die deutsche Frage, in: Karl KaIser, Pierre Lellouche (Hg.), Deutsch-französische Sicherheitspolitik. Auf dem Wege zur Gemeinsamkeit?, Bonn 1986, S. 68-89.

160 Mehrere hunderttausend Menschen kamen hier am 10. Oktober 1981 zusammen, um gegen die im NATO-Doppelbeschluss vorgesehene Aufstockung des Raketenarsenals auf westdeutschem Boden zu demonstrieren. Die Kundgebung war die bis dahin größte Massendemonstration in der Geschichte der Bundesrepublik, vgl. hierzu Michael Ploetz, Hans-Peter Müller, Ferngelenkte Friedensbewegung? DDR und UdSSR im Kampf gegen den NATO-Doppelbeschluss, Münster 2004, S. 146 und S. 229. 
"Nationalneutralismus«" ${ }^{161}$. Mit der Macht einer Flutwelle hätten sich, wie "Le Monde« formulierte, pazifistische Tendenzen auf allen Ebenen der bundesdeutschen Gesellschaft ausgebreitet ${ }^{162}$. Diese sei, wie es in der Wochenzeitschrift »Le Point« Ende November 1981 hieß, geradezu von einem kollektiven Taumel erfasst worden, der die weiteren Entwicklungen jenseits des Rheins für Außenstehende völlig unkalkulierbar werden lasse ${ }^{163}$. Die Unberechenbarkeit der östlichen Nachbarn, die sich nicht nur mit aller Gewalt gegen die notwendige atomare Nachrüstung stemmten, sondern weiterhin mit dem Gedanken der Wiedervereinigung spielten, stelle angesichts einer aggressiver agierenden sowjetischen Außenpolitik eine reale Gefahr für Frankreichs vitale Sicherheitsinteressen im Rahmen des Ost-West-Gegensatzes dar. So klang dies in einer Reihe von Pressekommentaren an. Nicht zuletzt die in den Augen vieler französischer Berichterstatter zu abwartende, zu neutrale Haltung der Journalisten und der politischen Führungsriege in der Bundesrepublik im Zusammenhang mit der Verhängung des Kriegsrechts in Polen im Dezember 1981 schien schließlich die Einschätzung zu bestätigen, dass Deutschland der westlichen Welt mehr und mehr den Rücken kehrte ${ }^{164}$. Nicht die Elbe, sondern den Rhein sehe mancher Franzose bereits als Grenze zwischen Ost und West, wie der westdeutsche Journalist Klaus-Peter Schmid formulierte. Das derzeitige Unbehagen der Nachbarn spiegele Ängste, die das künftige deutsch-französische Verhältnis unweigerlich belasten würden ${ }^{165}$.

Den bundesdeutschen Presseorganen war, so wird in diesem Kommentar deutlich, die neuerliche Beunruhigung in Frankreich nicht verborgen geblieben. Ganz im Gegenteil: Aufgrund der anhaltenden Diskussionen um

161 Vgl. Karl-Heinz Janssen, Deutsche aus der Front?, in: Die Zeit, 13.11.1981, S. 3f.; hierzu ausführlich Alexander Gallus, Für ein vereintes Deutschland zwischen Ost und West: Neutralistischer Protest in der Bundesrepublik Deutschland, in: Dominik GEPPert, Udo Wengst (Hg.), Neutralität - Chance oder Chimäre? Konzepte des Dritten Weges für Deutschland und die Welt 1945-1990, München 2005, S. 59-78; Alexander GaLlus, Die Neutralisten. Verfechter eines vereinten Deutschland zwischen Ost und West 1945-1990, Düsseldorf 2001; Dong-Ki LEE, Option oder Illusion? Die Idee einer nationalen Konföderation im geteilten Deutschland 1949-1990, Berlin 2010.

162 Siehe Claire TrÉAN, Le pacifisme en Europe I. - Allemagne fédérale: la vague de fond, in: Le Monde, 20.10.1981, S. 7; Dies., Entre le neutralisme et la peur. Les limites du pacifisme allemand, in: Le Monde, 06.02.1982, S. 1 und 3.

163 Vgl. Le vertige allemand, in: Le Point, 23.11.1981, S. 74-79; weiterführend hierzu André Glucksmann, La force du vertige, Paris 1983 und Brigitte SAuZAY, Le vertige allemand, Paris 1985.

164 Siehe »Bonn hält ohne Scham Fiktionen aufrecht«. Französische Pressestimmen zur Polen-Haltung der Deutschen, in: Der Spiegel, 04.01.1982, S. 63; vgl. hierzu Mark KramER, Die Sowjetunion, der Warschauer Pakt und blockinterne Krisen während der BrežnevÄra, in: Torsten Diedrich, Winfried Heinemann, Christan F. Ostermann (Hg.), Der Warschauer Pakt von der Gründung bis zum Zusammenbruch 1955 bis 1991, Berlin 2009, S. 273-336.

165 Siehe Klaus-Peter Schmid, Im Zerrspiegel der Franzosen. An der Seine wächst das Mißtrauen: Reagieren die Deutschen richtig auf Polen?, in: Die Zeit, 08.01.1982, S. 5. 
Friedensbewegung und Neutralismus rechneten manche Beobachter gar mit einer Abkühlung des persönlichen Kontakts zwischen Bundeskanzler und französischem Staatspräsidenten ${ }^{166}$. Vor allem das völlige Unverständnis für die Ereignisse in der Bundesrepublik habe, wie »Die Zeit» schrieb, in Frankreich einmal mehr Misstrauen und Zweifel gegenüber den deutschen Partnern geweckt. Zuvor hätten die Franzosen sich in einem langwierigen Prozess mit der zwar nicht immer angenehmen, aber berechenbaren Vorstellung arrangiert, Westdeutschland sei der amerikanischen Führungsmacht in blinder Loyalität verpflichtet und damit fest im atlantischen Bündnis verankert. Mit der Existenz eines abwehrbereiten Pufferstaates zwischen dem eigenen Territorium und den Staaten des Warschauer Paktes sei in diesem Szenario zumindest ein wesentliches französisches Grundbedürfnis gedeckt gewesen. Der westdeutsche Pazifismus, der in Frankreich nahezu automatisch mit neutralistischem Streben gleichgesetzt würde, bringe nun hingegen das gesamte französische Sicherheitskonzept ins Wanken. Darüber hinaus schüre er die Ängste davor, dass die Sowjetunion einer neutralen Bundesrepublik eines Tages doch die Wiedervereinigung anbieten könnte. Ein wie auch immer konzipiertes Großdeutschland, so kommentierte die Zeitung, wünsche sich in Frankreich schließlich niemand zum Nachbarn, auch wenn dies selten offen ausgesprochen werde ${ }^{167}$. Ähnlich urteilte auch »Der Spiegel«. Die Franzosen ängstige nach allen historischen Erfahrungen mit den »Boches« nicht nur der nie überwundene Alptraum von einem mächtigen, wiedervereinigten Deutschland. »Sie haben auch aus geographischen Gründen ein ausgeprägtes Eigeninteresse, daß die Bundesrepublik [...] Vorfeld eines möglichen nuklearen Schlagabtausches in Europa bleibt « ${ }^{168}$.

Waren die französischen Sicherheitsinteressen für eine Mehrheit der bundesdeutschen Beobachter zumindest noch nachvollziehbar, so grenzte aus ihrer Sicht die in zahlreichen französischen Zeitungen vertretene Auffas-

166 Vgl. August von Kageneck, Paris macht sich Sorgen über »deutschen Neutralismus«, in: Die Welt, 07.01.1981, S. 1; Bernt Conrad, Persönlicher Kontakt zwischen Schmidt und Giscard abgekühlt, in: Die Welt, 09.01.1981, S. 1; Rudolph Chimelli, In Paris spricht man nicht mehr von Détente. Vor dem Treffen Giscards mit Schmidt eine leichte Abkühlung im deutsch-französischen Verhältnis, in: SZ, 05.02.1981, S. 4.

167 Siehe zu diesem Abschnitt Klaus-Peter Schmid, Was ist bloß mit den Deutschen los? Pazifisten oder Nationalisten - ein großes Rätsel für Frankreich, in: Die Zeit, 11.12.1981, S. 5.

168 „Unser Haus, unser Kiez, unser Bauch«. Gibt es einen neuen deutschen Nationalismus?, in: Der Spiegel, 01.02.1982, S. 36 und S. 38; vgl. auch: Paris denkt nach, in: Der Spiegel, 05.10.1981, S. 14f.; vgl. weiterführend zu diesem Abschnitt Pierre Hassner, Was geht in Deutschland vor? Wiederbelebung der deutschen Frage durch Friedensbewegung und alternative Gruppe, in: Europa-Archiv 37/17 (1982), S. 517-526; Harald BAUER, Frankreichs Sicherheitspolitik und das geteilte Deutschland 1980-1985: Zwischen Kontrolle, Kooperation und Abhängigkeiten, Berlin 1987; Eckhard Jesse, DDR und deutsche Frage, in: Ders., Demokratie in Deutschland. Diagnosen und Analysen, hg. v. Uwe BACKeS und Alexander Gallus, Köln u. a. 2008, S. 99-165. 
sung, die Friedensbewegung verkörpere einen typisch deutschen Hang zum Extremen und sei als Wegbereiterin eines neuen deutschen Nationalismus zu interpretieren, an den Rand des Absurden: »Dieser Spuk wird zwar nur von einigen Journalisten angezettelt. Doch er ist ernst zu nehmen, weil er auf nicht auszurottenden Klischees beruht. Diese Klischees haben ein langes Leben, weil die französische Haltung zum deutschen Nachbarn nach wie vor widersprüchlich ist « ${ }^{169}$.

Angesichts der nunmehr in Fülle zwischen beiden Ländern kursierenden medialen Zerrbilder sahen sich die Regierenden in Bonn und Paris mehrfach zum Einschreiten genötigt. So sollte etwa eine gemeinsame Erklärung Helmut Schmidts und Valéry Giscard d'Estaings vom Februar 1981, in welcher beide die Treue Frankreichs und der Bundesrepublik zu den Verpflichtungen des atlantischen Bündnisses sowie ihre Entschlossenheit zur Aufrechterhaltung der Verteidigungsanstrengungen bekräftigten, zweifellos beruhigend auf die in Frankreich aufgekommenen Befürchtungen einwirken ${ }^{170}$. Auch eine Ansprache des Bundeskanzlers im Rahmen des Gipfeltreffens vom Februar 1982 in Paris, in welcher Schmidt den versammelten französischen Journalisten die Bonner Reaktion auf die Ausrufung des Kriegszustandes in Polen erläuterte, war dazu angetan, den Nachbarn zu verdeutlichen, dass ihre Sorgen unbegründet seien. Der westdeutsche Regierungschef, der, wie er angab, irritiert über manches gewesen sei, was er in der Pariser Presse über die deutsche Politik gelesen habe, zeigte sich hier zufrieden darüber, dass in Frankreich inzwischen gesehen werde, »daß wir weder in die Fußstapfen Hitlers oder Stalins treten wollten noch daß wir zu denjenigen gehören, die Herrn Breschnew die Füße küssen «171.

Dennoch waren die medialen Dispute aus Sicht der Regierungsstellen Grund genug, um sich in Wachsamkeit zu üben. Den Diplomaten des Quai d'Orsay galten etwa die neu entflammten Debatten um die deutsche Wiedervereinigung und den Dialog zwischen Bonn und Moskau als beunruhigendes Anzeichen einer weiterhin nicht gefestigten Freundschaft zwischen beiden Ländern: »'amitié entre la France et la RFA n'est pas définitivement acquise comme on le croirait trop facilement. Certes, les sondages indiquent que la RFA est considérée comme le pays le plus ami du nôtre mais

169 Klaus-Peter Schmid, Was ist bloß mit den Deutschen los? Pazifisten oder Nationalisten - ein großes Rätsel für Frankreich, in: Die Zeit, 11.12.1981, S. 5; vgl. des Weiteren Mathias Greffrath, Albert Sellner, Lothar Baier, Pazifisten sind keine Nationalisten, in: Die Zeit, 13.11.1981, S. 37f.

170 Vgl. die gemeinsame Erklärung Bundeskanzler Schmidts und Staatspräsident Giscard d'Estaings anlässlich der deutsch-französischen Konsultationen am 5. und 6. Februar 1981 in Paris, in: Bulletin des Presse- und Informationsamtes der Bundesregierung 12 (1981), S. 101f.

171 Ansprache von Bundeskanzler Schmidt am 25. Februar 1982, in: Kimmel, Jardin (Hg.), Die deutsch-französischen Beziehungen, S. 242. 
l'incompréhension d'une large partie de l'opinion à l'égard du pays voisin ne s'est guère atténuée « ${ }^{172}$.

Die westdeutsche wie auch die französische Presse zeichne vom jeweiligen Nachbarland noch immer stereotype Bilder, welche die Bemühungen um Verständigung konterkarierten. Die in der Bundesrepublik an die Oberfläche tretenden anti-militaristischen Tendenzen, so das Urteil im Pariser Außenministerium, ließen in der französischen Öffentlichkeit den Verdacht wieder wach werden, Westdeutschland gleite nach Osten $a b^{173}$. Ähnlich beunruhigt zeigten sich auch die politisch Verantwortlichen in Bonn. So stellte ein Bericht der Interministeriellen Kommission der Bundesregierung vom März 1982 fest, dass die seitens der Pariser Presse in ihrer Bedeutung überzeichnete deutsche Friedensbewegung alte Befürchtungen vor einem außerhalb der NATO und zwischen den Blöcken agierenden Deutschland geweckt habe, das Frankreich seines strategischen Glacis beraube ${ }^{174}$. Es sei daher, wie die deutsche Botschaft befand, »bei den Medien, besonders bei den tonangebenden privaten Zeitungen", noch viel Raum für aufklärende Öffentlichkeitsarbeit gegeben ${ }^{175}$.

Die verständigungspolitischen Anstrengungen beider Regierungen konzentrierten sich in Konsequenz dessen vor allem auf den Bereich des Informationswesens. Aussicht auf Erfolg hätten, wie man hier der Ansicht war, insbesondere Initiativen, die sich direkt auf die öffentliche Meinungsbildung auswirkten. Sie würden das gegenseitige Verständnis der Bevölkerungen auf lange Sicht vertiefen und damit Konflikte bereits im Ansatz entschärfen: »Pour correspondre à une réalité, c'est-à-dire pour résister aux crises éventuelles, la compréhension entre deux peuples doit à la fois être profonde et s'étendre aux couches les plus vastes des populations ${ }^{176}$, wie der Kulturrat der französischen Botschaft im Januar 1981 betonte. Dem Rechnung tragend, wurde in bilateralen Gesprächen etwa die Möglichkeit erörtert, ein regelmäßiges Austauschprogramm für Journalisten einzurichten, die im Rahmen

172 AMAE Nantes, Bonn Ambassade, Bd. 326, Vermerk betreffend "La République fédérale d'Allemagne au milieu de l'année 1980« vom 2. Juli 1980, S. 12; vgl. auch AMAE Paris-La Courneuve, Europe, RFA 1976-1980, Bd. 3999, Schreiben des französischen Außenministeriums an die französische Botschaft Bonn vom 27. Februar 1980, Anlage: Vertraulicher Bericht über die deutsch-französische Zusammenarbeit vom 25. Februar 1980, S. $13 f$.

173 Vgl. AMAE Nantes, Bonn Ambassade, Bd. 327, Vermerk betreffend »La République fédérale d'Allemagne au début de l'année 1981 « vom 28. Januar 1981.

174 Siehe DFI-Archiv, Ordner Büro des Koordinators 1975-1988, 24. Bericht der Interministeriellen Kommission für die deutsch-französische Zusammenarbeit vom März 1982, S. 5f., Zitat S. 5.

175 AMAE Paris-La Courneuve, Europe, RFA 1976-1980, Bd. 4007, Schreiben der deutschen Botschaft Paris an das Büro des Koordinators für die deutsch-französische Zusammenarbeit im Auswärtigen Amt vom 24. Juni 1980, S. 2.

176 AMAE Nantes, Bonn Ambassade, Bd. 366, Vermerk des Kulturrats der französischen Botschaft Bonn vom 5. Januar 1981, S. 1. 
dessen zwei oder drei Monate im jeweiligen Nachbarland zubringen konnten, um das dortige Leben besser kennenzulernen und persönliche Beziehungen zu knüpfen ${ }^{177}$. Beide Seiten zogen ebenso eine verstärkte Zusammenarbeit zwischen den öffentlich-rechtlichen Fernsehanstalten in Betracht, aus welcher deutsch-französische Koproduktionen hervorgehen sollten, die Gelegenheit geben würden, einem größeren Publikum aktuelle politische Fragen aus einer gleichermaßen westdeutschen wie französischen Perspektive zu präsentieren ${ }^{178}$. Daneben fassten die politisch Verantwortlichen ins Auge, die als unbefriedigend geltende Bilanz des Sprachunterrichts an allgemeinbildenden Schulen in beiden Ländern aufzubessern ${ }^{179}$. Anfang 1980 waren der französische Bildungsminister Christian Beullac und sein westdeutscher Ansprechpartner Bernhard Vogel einhellig zu dem Schluss gekommen: »Für die deutsch-französischen Beziehungen ist nichts wichtiger, als daß mehr Franzosen besser Deutsch lernen und mehr Deutsche besser Französisch. Wir müssen also in beiden Ländern die Stellung der Partnersprache stärken « ${ }^{180}$. Um dies zu erreichen, verständigten sich beide Seiten darauf, Schülern und Eltern zusätzliche Anreize zu geben, die Sprache des Nachbarn als erste oder zweite Fremdsprache zu wählen. Die Mobilität von Schülern und Lehrern zwischen beiden Ländern sollte durch eine verstärkte Förderung entsprechender Austauschangebote erhöht und die bereits existierenden bilingualen Sektionen an westdeutschen Gymnasien und französischen lycées weiter ausgebaut werden ${ }^{181}$. Wesentliche Träger der kulturellen Verständigungspolitik im außerschulischen Bereich blieben darüber hinaus die Kulturinstitute, welche beide Regierungen im jeweiligen Nachbarland unterhielten. Ihre Aufgabe war auch jetzt klar umrissen: »'approfondissement des connaissances qu'ont

177 Aus den Akten ist zu schließen, dass die Bemühungen zur Einladung von Journalisten im Jahr 1978 (siehe hierzu Kap. 3.1.2) ohne messbaren Erfolg blieben.

178 Vgl. AMAE Nantes, Bonn Ambassade, Bd. 366, Schreiben der französischen Botschaft Bonn an das französische Außenministerium vom 16. September und 10. Dezember 1980.

179 Vgl. hierzu AN Paris, 5 AG 3, Bd. 939, Aufzeichnung bezüglich des Staatsbesuchs Valéry Giscard d'Estaings in der Bundesrepublik und der deutsch-französischen Konsultationen am 10. und 11. Juli 1980, S. 1, wo es heißt: "Il apparait indispensable que soit exprimée clairement, à l'occasion du sommet, la volonté politique des deux pays de promouvoir la langue du partenaire".

180 BA, B 304, Bd. 2877, Bericht des Bevollmächtigten der Bundesrepublik Deutschland für kulturelle Angelegenheiten im Rahmen des Vertrages über die deutsch-französische Zusammenarbeit, Bernhard Vogel, anlässlich der 197. Kultusministerkonferenz am 21. und 22. März 1980 in Bonn, S. 4.

${ }^{181}$ Vgl. AN Fontainebleau, ministère de l'Éducation nationale, Bd. 900672/38, Vermerk über die deutsch-französische Zusammenarbeit im Bildungsbereich vom 18. Juni 1980; AMAE Paris-La Courneuve, Europe, RFA 1976-1980, Bd. 4007, Protokoll der Sitzung der Interministeriellen Kommission für die deutsch-französische Zusammenarbeit vom 18. Juni 1980; AMAE Nantes, Bonn Ambassade, Bd. 366, Vermerk für den französischen Botschafter betreffend »Possibilités de développer les relations culturelles francoallemandes« vom 25. August 1980. 
les deux peuples de leurs voisins, de leur langue et de leur civilisation ${ }^{182}$. Denn nur eine bessere Kenntnis des anderen, so die immer wiederkehrende Argumentation, würde die Annäherung zwischen Deutschen und Franzosen $\mathrm{zu}$ einem unumkehrbaren Prozess machen.

In der Verfolgung dieses Ziels sahen auch die verschiedenen Verständigungsorganisationen ihre hauptsächliche Bestimmung. Mit wachsender Unruhe waren etwa beim ADFG die erneuten öffentlich hervorgetretenen Spannungen beobachtet worden. In einem Rundschreiben an die Mitglieder vom Dezember 1981 ist zu lesen: »Une certaine tendance de politique intérieure s'est développée dans nos deux pays, qui pourrait contribuer à créer entre les Français et les Allemands, une nouvelle méfiance et de nouvelles incompréhensions « ${ }^{183}$. Die Gesellschaften in beiden Ländern seien in Anbetracht dieser schwierigen Zeit dazu aufgefordert, durch ihre Tätigkeit den Willen der Bevölkerungen zu einer wirklichen Kooperation zu stärken ${ }^{184}$. Den einzelnen Vereinigungen komme somit die verantwortungsvolle gesellschaftspolitische Aufgabe "als Stabilisierungsfaktoren im Rahmen der offiziellen deutsch-französischen Beziehungen " $\mathrm{zu}^{185}$. In dieser Funktion sei es ihre Pflicht, durch unermüdliche Informationsarbeit auf die Öffentlichkeit einzuwirken und vor allem mehr Menschen, nicht zuletzt die immer weniger interessierten Jugendlichen, für den deutsch-französischen Gedanken zu gewinnen ${ }^{186}$. Seitens der amtlichen Stellen wurden die Aktivitäten der Gesellschaften als durchaus wichtige Ergänzung der politischen Initiativen angesehen. So bewertete der französische Botschafter in Bonn, Henri Froment-Meurice, ihre Rolle als "non négligeable dans l'élimination des clichés et des préjugés que l'on rencontre encore dans notre pays « ${ }^{187}$.

Ähnlich wie der ADFG sah sich auch das seit Ende der 1970er Jahre wesentlich durch seinen Vize-Präsidenten Joseph Rovan geprägte BILD einmal

182 AMAE Nantes, Bonn Ambassade, Bd. 367, Vermerk des Kulturrats der französischen Botschaft in Bonn bezüglich der deutsch-französischen Zusammenarbeit im kulturellen Bereich vom 22. Mai 1981, S. 1.

183 VDFG-Archiv, Ordner Vorstandssitzungen 1979-1982, Rundschreiben der Präsidenten des ADFG, Pierre Martin und Siegfried Troch, an die Mitgliedsgesellschaften vom Dezember 1981.

184 Siehe ibid.

185 VDFG-Archiv, Ordner Vorstandssitzungen 1979-1982, Grundsatzrede des deutschen Präsidenten des ADFG, Siegfried Troch, im Rahmen der 25. Jahrestagung des Arbeitskreises am 28. September 1980 in Donaueschingen, S. 1f.

186 Vgl. VDFG-Archiv, Ordner Vorstandssitzungen 1979-1982, Ergebnisprotokoll über die Sitzung des geschäftsführenden Vorstands des ADFG am 26. November 1982 in Wiesbaden, S. 3; Bericht des deutschen Präsidenten betreffend die 26. Jahrestagung des ADFG in Contrexéville, August 1981; Aufzeichnung des deutschen Präsidenten bezüglich der 27. Jahrestagung der VDFG in Mainz vom 10. August 1982.

187 AMAE Nantes, Bonn Ambassade, Bd. 314, Schreiben des französischen Botschafters in Bonn, Henri Froment-Meurice, an das französische Außenministerium vom 10. September 1982, S. 3. 
mehr zu verstärktem Handeln angehalten, um den krisenhaften Entwicklungen zwischen Frankreich und der Bundesrepublik entgegenzusteuern. Auch wenn das große Wort der deutsch-französischen Freundschaft oftmals bemüht werde, so hieß es im Tätigkeitsbericht des BILD für das Jahr 1980, stießen doch immer noch Äußerungen in der Presse auf das Misstrauen des Partners. Aufgrund unterschiedlicher Sprache und Mentalität, unterschiedlichen Denkens und divergierender geschichtlicher wie politischer Hintergründe würden bestimmtes Handeln und bestimmte Ereignisse im Nachbarland nicht verstanden. Diese Missverständnisse und Spannungen zu überwinden, sei weiterhin eine vordringliche Aufgabe. Die Vereinigung wolle gegenseitiges Vertrauen schaffen durch das Zusammenführen der Menschen aus allen sozialen Schichten, aus zahlreichen Berufs- und Interessengruppen und vor allem der Jugend. Diese praktische Arbeit werde intensiv durch die Informationsarbeit unterstützt, besonders durch die Zeitschriften $»$ Dokumente « und »Documents«. »Sie sollen das Wissen um die Probleme des anderen Partners ergänzen und so auch für mehr Verständnis wirken « ${ }^{188}$.

Neben Jugendbegegnungen, Studienreisen, sprach- und landeskundlichen Seminaren ${ }^{189}$ organisierte das BILD auf Initiative Rovans zudem ab 1979 unter dem Titel "Rencontre avec une personnalité dirigeante allemande" regelmäßige Gesprächsrunden. Diese brachten westdeutsche Politiker, Industrielle oder Publizisten mit französischen Medienvertretern und weiteren Personen des öffentlichen Lebens in Paris zusammen und sollten in einen offenen Austausch auch über deutsch-französische Probleme einmünden. Dank seiner vielfältigen Verbindungen nach Westdeutschland konnte Rovan Bundespräsident Karl Carstens, die Bundesminister Hans Matthöfer und Hans-Jürgen Wischnewski sowie den Regierenden Bürgermeister von Berlin, Dietrich Stobbe, als Redner gewinnen. Dem offiziellen Teil einer solchen Veranstaltung folgte zumeist ein Empfang in der deutschen Botschaft, in dessen Rahmen ein engerer Kreis der Gäste die Möglichkeit hatte, begonnene Diskussionen zu vertiefen. Gerade in den informellen Kontakten, deren Entstehung und Pflege hierdurch gefördert werden sollte, sah Rovan essentielle Bedingungsfaktoren der deutsch-französischen Annäherung ${ }^{190}$.

188 BILD-Archiv, Tätigkeitsbericht 1980 der Gesellschaft für übernationale Zusammenarbeit und des Bureau international de liaison et de documentation, April 1981, S. 1f., Zitat S. 2 .

189 Vgl. BILD-Archiv, Tätigkeitsbericht der GÜZ und des BILD für das Jahr 1981, Juli 1982, S. 8-21.

190 Vgl. zu diesem Abschnitt IMEC, Fonds Joseph Rovan, Schreiben des geschäftsführenden Vize-Präsidenten des BILD, Joseph Rovan, an Bundeswirtschaftsminister Otto Graf Lambsdorff vom 16. Februar 1979, an Bundesfinanzminister Hans Matthöfer vom 4. Dezember 1979, an Hans Friedrichs, Vorstandssprecher der Dresdner Bank, vom 28. Februar 1979 und an den Herausgeber des Nachrichtenmagazins »Der Spiegel «, Rudolf Augstein, vom 8. Oktober 1979; Vermerk zur Ansprache von Bundespräsident a.D. Walter Scheel beim BILD am 4. Dezember 1981. 
Auch das DFI in Ludwigsburg erblickte wie das BILD und der ADFG seine Aufgabe darin, den scheinbar ins Stocken geratenen Verständigungsprozess von unten her zu stützen. So hielt Institutsleiter Robert Picht in einer Aufzeichnung vom November 1980 fest, dass die bereits von den Gründungsvätern des DFI ausgegebene Zielsetzung, das Gemeinsame zwischen Franzosen und Deutschen »langsam herausschälen« zu wollen, als dringlicher denn je angesehen werden könne. Vor allem die weiterhin oft unterschiedlichen Interessen beider Länder gelte es wissenschaftlich und politisch aufzuarbeiten. Präzise Kenntnisse des Partnerlandes seien ebenso erforderlich wie die Fähigkeit zur Verständigung auch über schwierige fachliche und politische Probleme. Hierzu reichten jedoch, wie Picht urteilte, in Anbetracht der aktuellen schwierigen Situation weder kurzfristige Begegnungen noch die im Élysée-Vertrag institutionalisierten Kontakte zwischen den Regierungen aus. Vielmehr könne die mühsame Arbeit gegenseitigen Informierens und Erklärens erst dann gelingen, wenn neben den bestehenden Verbindungen "auf neutraler Ebene ein vertiefter Dialog zwischen Wissenschaft, hoher Verwaltung, Politik, Wirtschaft, Verbänden und Massenmedien « geführt werde ${ }^{191}$. Diesen Dialog auch in Phasen des Konflikts beständig aufrecht und lebendig zu halten, betrachtete man im DFI als eine prioritäre Aufgabe. Die weiterhin veranstalteten deutsch-französischen Kolloquien und Expertengespräche ${ }^{192}$ sollten hierzu ebenso dienen wie die Durchführung binationaler Forschungsprojekte, die daraus hervorgehende Publikation von Informationsschriften über Frankreich ${ }^{193}$ sowie die Organisation landeskundlicher Seminare, etwa für Studierende an französischen grandes écoles und Universitäten ${ }^{194}$. Aus offizieller französischer Sicht kam dem Ludwigsburger Institut damit eine wichtige Funktion für die Überbrückung von öffentlich zu Tage tretenden Gegensätzen zwischen beiden Ländern zu. Botschafter Brunet urteilte im Oktober 1980:

Certaines institutions se donnent ouvertement et prioritairement pour but de favoriser le rapprochement entre les deux opinions publiques. Exemplaire est ainsi l'action menée, dans le domaine de la recherche et de l'établissement de contacts, par l'Institut franco-allemand

191 DFI-Archiv, Ordner Tätigkeitsberichte 1978-1989, Aufzeichnung "Das Deutsch-Französische Institut Ludwigsburg« vom 7. November 1980, S. 1f., hier die Zitate; vgl. hierzu auch ibid., Bericht über die mittelfristige Planung des DFI vom 13. März 1981.

192 Das im Dezember 1980 seitens des DFI organisierte 8. Deutsch-Französische Kolloquium befasste sich etwa mit dem Thema "Das Partnerland in Kultur, Wissenschaft und Medien«, vgl. DFI-Archiv, Ordner Deutsch-Französisches Kolloquium 1980, Bericht über die Ergebnisse des Kolloquiums vom 8. Dezember 1980.

193 Vgl. beispielsweise Deutschland-Frankreich: Bausteine zum Systemvergleich, 2 Bde., hg. v. d. Robert-Bosch-Stiftung, Gerlingen 1980-1981; Robert Picht (Hg.), Deutschland, Frankreich, Europa. Bilanz einer schwierigen Partnerschaft, München 1978; René LasSERRE (Hg.), La France contemporaine. Guide bibliographique et thématique, Tübingen ${ }^{2} 1980$.

194 Siehe DFI-Archiv, Ordner Tätigkeitsberichte 1978-1989, Sachlicher Bericht zum Verwendungsnachweis 1981, S. 2. 
de Ludwigsburg [...] qui par ses publications, par les colloques et rencontres qu'il organise, travaille en profondeur sur l'analyse des structures et des problèmes français ${ }^{195}$.

Neben den Verständigungsorganisationen wurden auch die deutsch-französischen Mittlerfiguren nicht müde, in den Debatten um die westdeutsche Friedensbewegung ihre Stimme zu erheben. In »Le Monde« versuchte Alfred Grosser bei den Franzosen Verständnis für die Entwicklungen in der Bundesrepublik zu wecken, indem er betonte, dass die Deutschen vor allem deswegen für die Friedensidee demonstrierten, weil sie einst dazu gebracht worden seien, den Krieg zu bejubeln. Anders als in Frankreich, wo die force de frappe als Versicherung der nationalen Unabhängigkeit gelte und somit positiv gesehen werde, dominiere zudem in Westdeutschland, dem potenziellen Hauptkriegsschauplatz im Falle eines nuklearen Konflikts, hauptsächlich die negative Symbolwirkung der Atomwaffen. Zwar seien durch die Friedensbewegung, wie Grosser einräumte, destabilisierende Tendenzen entstanden, doch zu behaupten, diese hätten die über dreißig Jahre währende Stabilität in der Bundesrepublik bereits abgelöst, sei verfrüht ${ }^{196}$. Den Deutschen wollte Grosser andererseits $\mathrm{zu}$ verstehen geben, dass das Misstrauen der französischen Nachbarn gegenüber den Ereignissen jenseits des Rheins nicht gar so groß sei, wie teilweise in den Medien dargestellt. Es fiele in Frankreich zwar manchem schwer, den plötzlichen Gesinnungswandel der jüngst noch als übertrieben pro-amerikanisch wahrgenommenen Bundesrepublik nachzuvollziehen, doch seien diejenigen, die antideutsche Traditionen fortsetzten und die Bedrohung eines nationalistisch eingefärbten Neutralismus in Deutschland beschwörten, Repräsentanten einer Minderheit ${ }^{197}$.

Joseph Rovan schätzte die möglichen Bedrohungen durch die Friedensbewegung und die in ihrem Gefolge mobilisierten Kräfte weitaus kritischer ein als Grosser und war daher bestrebt, in beiden Ländern hiervor zu warnen. Seinen französischen Lesern gegenüber, denen Rovan, wie er schrieb, helfen wolle, die in Deutschland vor sich gehenden Wandlungsprozesse besser verstehen und die hieraus eventuell resultierenden Konsequenzen schärfer

195 AMAE Paris-La Courneuve, Europe, RFA 1976-1980, Bd. 3999, Schreiben des französischen Botschafters in Bonn, Jean-Pierre Brunet, an Jean Laloy, Präsident der Interministeriellen Kommission für die deutsch-französische Zusammenarbeit, vom 10. Oktober 1980, S. 3.

196 Vgl. »Diese Krise ist die schwerste«. Alfred Grosser über Tendenzen zur Destabilisierung der Bundesrepublik, in: Der Spiegel, 19.10.1981, S. 32-35, hier Abdruck des Artikels aus Le Monde in deutscher Übersetzung.

197 Siehe »Frankreichs Trauma: die Niederlage von 1940«. Der französische Politologe Alfred Grosser über die Beziehungen zwischen Franzosen und Deutschen, in: Der Spiegel, 28.11.1983, S. 154-165; vgl. auch Alfred Grosser, Das Recht auf ein offenes Wort. Ein Gespräch mit Bernard Brigouleix und Rupert Neudeck, in: Dokumente 39 (1983), Sonderheft, S. 107-117, hier S. 114-116; Ders., Was heißt Verständigung?, in: Robert PICHT (Hg.), Das Bündnis im Bündnis: deutsch-französische Beziehungen im internationalen Spannungsfeld, Berlin 1982, S. 233-239. 
sehen zu können ${ }^{198}$, machte er deutlich: »Aujourd'hui, confus, contradictoire, pareil à un fleuve aux cent bras et aux mille méandres le >mouvement de paix débouche sur une neutralisation ${ }^{199}$. Die Massenproteste in der Bundesrepublik zielten auf die Erschütterung der Fundamente Bonner Außen- und Sicherheitspolitik seit 1949 und spielten letztlich der Sowjetunion in die Hände, die es darauf abgesehen habe, Westdeutschland von den USA und seinen europäischen Verbündeten zu entfernen. Angesichts der Entwicklungen im Partnerland sei es, so Rovan, nicht verwunderlich, dass die Franzosen in Unruhe versetzt worden seien. Doch dürfe diese Beunruhigung nicht in eine "vieille méfiance antigermanique ${ }^{200}$ münden, welche die deutsch-französische Zusammenarbeit unweigerlich gefährde. Gerade aufgrund der Schwere der Lage seien Deutsche und Franzosen dazu aufgerufen, fester zusammenzustehen denn je, um der um sich greifenden Destabilisierung die Stirn zu bieten. Insbesondere von den politisch Verantwortlichen in beiden Ländern forderte Rovan ein, »ihre Völker zu mobilisieren, um diese Bedrohungen zu bekämpfen «201. Nur auf diesem Wege des gemeinsamen Handelns sei die so notwendige Festigung der Beziehungen zwischen beiden Ländern und Bevölkerungen, eine tatsächliche »deutsch-französische Union«, zu erreichen ${ }^{202}$.

Wie schon im Zuge der Debatten um die ostpolitischen Initiativen der Bundesregierung Willy Brandts und der Diskussionen über die deutsche Frage 1978 und 1979 war auch in den deutsch-französischen Auseinandersetzungen um Friedensbewegung und Neutralismus zu Beginn der 1980er Jahre eine Reihe der Kräfte aktiv, die sich dem Ziel verschrieben hatten, für Ausgleich und Freundschaft zwischen beiden Ländern und Bevölkerungen einzutreten. Wiederum sei nach den Auswirkungen ihrer Verständigungsarbeit gefragt: War es ihnen möglich, das in Frankreich medial geschürte Misstrauen gegenüber den »deutschen Ungewissheiten « einzudämmen, das auf westdeutscher Seite öffentlich zum Ausdruck kommende Gefühl, nicht verstanden und vor allem auch nach dreißig Jahren verlässlicher Zusammenarbeit noch immer argwöhnisch belauert zu werden, zu besänftigen? Gewiss: Die staatlichen Kulturinstitute füllten in beiden Ländern weiterhin eine wichtige Funktion aus, vermittelten Sprachkenntnisse, weckten Interesse für das Nachbarland. Die deutsch-französischen Gesellschaften warben lokal und

198 Siehe Joseph Rovan, L'Allemagne du changement, Paris 1983, S. 9.

199 Ders., Deux anniversaires, in: Espoir 42 (1982), S. 62-66, hier S. 64.

200 Ders., L'Allemagne du changement, S. 9.

201 Ders., Keine selbstzufriedenen Gedenkfeiern! Ein Wort zur Krisengefahr für Institutionen und Werte, in: Dokumente 39 (1983), Sonderheft, S. 5-10, hier S. 9.

202 Siehe Ders., Dreißig Argumente für eine deutsch-französische Union, in: Ders., Werner WeIDENFELD (Hg.), Europäische Zeitzeichen. Elemente eines deutsch-französischen Dialogs, Bonn 1982, S. 13-21; vgl. zu diesem Abschnitt auch Joseph Rovan, Wiedervereinigung Deutschlands - weder aktuell noch utopisch?, in: Deutschland-Archiv 14/9 (1981), S. 1000-1006; Ders., Vom Nächsten schlecht zu denken, liegt näher als das Gegenteil, in: Dokumente 38/1 (1982), S. 4f. 
regional um Verständnis für den anderen, das BILD und das DFI brachten führende Persönlichkeiten zu offenen Gesprächen zusammen und betrieben mit ihren Publikationen Informationsarbeit. Und auch geistige Mittler wie Alfred Grosser oder Joseph Rovan taten ihren Teil, um zu erklären, zu beschwichtigen und zu ermutigen. Doch stand diesen steten Bemühungen ein Ende der 1970er Jahre bereits deutlich sichtbares und weiter zunehmendes Desinteresse an deutsch-französischen Aktivitäten seitens der Bevölkerungen gegenüber. Anzeichen hierfür waren etwa die sinkenden Schülerzahlen im Deutsch- und Französischunterricht, der schleichende Mitgliederschwund bei den verschiedenen privaten Vereinigungen und auch die Feststellung, dass Jugendliche auf beiden Seiten kaum noch für ein Engagement im Dienste der Aussöhnung zu begeistern waren. Wie konnte angesichts der Tatsache, dass der hierfür potenziell empfängliche Adressatenkreis sich zusehends reduzierte, die Verständigungsarbeit auf breitere Bevölkerungskreise einwirken und dazu beitragen, Spannungen zu beenden? Dass Alfred Grosser in einem Interview Ende 1983 bekannte, er habe nur selten gegen einen »so starken Strom des Unverständnisses anzuschwimmen ${ }^{203}$ gehabt wie in den Kontroversen um die Friedensbewegung, erscheint in dieser Hinsicht geradezu symptomatisch. Es erhärtet sich der Eindruck, dass die Protagonisten der deutsch-französischen Annäherung es trotz all ihrer Anstrengungen nicht vermochten, entscheidend auf die aus den französischen Ängsten vor einem neutralen und möglicherweise wiedervereinigten Deutschland gespeisten und öffentlich ausgetragenen Konflikte in der Zeitspanne zwischen beginnender Ostpolitik und Friedensbewegung einzuwirken.

\section{2 »Unheimliche Nachbarn«: Frankreich und die starke Bundesrepublik}

Dank eines rasanten Wachstums in den 1950er und 1960er Jahren gehörte die Bundesrepublik nur wenige Jahrzehnte nach der bedingungslosen Kapitulation von $1945 \mathrm{zu}$ den wirtschaftsstärksten westlichen Industriestaaten ${ }^{204}$. In Westdeutschland produzierte Waren konnten schon bald wieder auf dem Weltmarkt konkurrieren, wurden, wie etwa der VW Käfer, gar zu veritablen Exportschlagern ${ }^{205}$. Auch die D-Mark etablierte sich neben dem US-Dollar

$203 »$ Frankreichs Trauma: die Niederlage von 1940«. Der französische Politologe Alfred Grosser über die Beziehungen zwischen Franzosen und Deutschen, in: Der Spiegel, 28.11.1983, S. 165.

204 Vgl. Werner Abelshauser, Deutsche Wirtschaftsgeschichte von 1945 bis zur Gegenwart, München ${ }^{2} 2011$.

205 Siehe Gerhard Volz, Die Organisationen der Weltwirtschaft, München 2000, S. 62; vgl. auch Christopher Kopper, Handel und Verkehr im 20. Jahrhundert, München 2002, S. 58. 
als eine weltweit nachgefragte und äußerst stabile Währung ${ }^{206}$. Inmitten der Weltwirtschaftskrise, der Zeit nach dem Boom ${ }^{207}$, galt Westdeutschland weiterhin als Hort des Wohlstands.

Darüber hinaus gewann die Bundesrepublik seit Initiierung der sozialliberalen Ostpolitik erheblich an außenpolitischem Format. Hatte Willy Brandt den gewachsenen ökonomischen und politischen Einfluss der Bundesrepublik noch durch ein moderates internationales Auftreten und das offen formulierte Bekenntnis zur deutschen Schuld an den Verbrechen des Zweiten Weltkriegs abgemildert und damit auch für die europäischen Nachbarländer erträglicher gemacht ${ }^{208}$, so schien nach dem Amtsantritt Helmut Schmidts im Mai 1974 ein veränderter Tonfall in der Bonner Politik zu herrschen. Im Bewusstsein der Rolle, die das von ihm geführte Land inzwischen einnahm und auch eingedenk des Beitrags, den die Bundesrepublik etwa zur Finanzierung der Europäischen Gemeinschaft leistete, formulierte Schmidt gegenüber seinen Partnern nüchtern deutsche Interessen. Westdeutschland sollte nicht nur als gleichberechtigtes Mitglied der westlichen Staatenwelt handeln, sondern eigene Positionen auch in Dissens zu anderen vertreten dürfen ${ }^{209}$.

Das forsche Auftreten des Bonner Regierungschefs rief bei den westeuropäischen Nachbarn stellenweise Missfallen hervor, hatten diese sich doch an einen bundesdeutschen Staat gewöhnt, der eigene Ansprüche nur mit Zurückhaltung anmeldete. Schmidts Habitus, der in klarem Gegensatz zu den Verhaltensmustern seines Amtsvorgängers zu stehen schien, wurde bald mit einem vermeintlich typisch deutschen Hang zum zackig Militärischen in Verbindung gebracht ${ }^{210}$. Sei es im Streit um den europäischen Agrarmarkt, angesichts der erdrückend wirkenden Wirtschaftskraft der Bundesrepublik oder anlässlich der ersten Direktwahl zum Europa-Parlament - viele ausländische Beobachter, so auch in Frankreich, gelangten zu der Auffassung, die wiedererstarkten Deutschen schickten sich unter Führung des ehemaligen Wehrmachtsoffiziers Schmidt an, Europa wieder unter ihre Kuratel zu stellen.

206 Vgl. Harold James, Die D-Mark, in: Étienne Françors, Hagen Schulze (Hg.), Deutsche Erinnerungsorte. Eine Auswahl, München 2005, S. 369-384.

207 Vgl. hierzu Anselm Doering Manteuffel, Lutz Raphael, Nach dem Boom. Perspektiven auf die Zeitgeschichte seit 1970, Göttingen ${ }^{2} 2010$.

208 Als Sinnbild für Brandts internationales Agieren kann der berühmt gewordene Kniefall des Bundeskanzlers vor dem Denkmal des Warschauer Ghetto-Aufstandes im Dezember 1970 gewertet werden, vgl. hierzu Christoph SchneIder, Der Warschauer Kniefall. Ritual, Ereignis und Erzählung, Konstanz 2006; Klaus Dieter Hein-Mooren, Spontan oder geplant? Bemerkungen zu Willy Brandts Kniefall in Warschau, in: Geschichte in Wissenschaft und Unterricht 55 (2004), S. 744-753.

209 Vgl. HaскE, 60 Jahre Außenpolitik der Bundesrepublik Deutschland, S. 497f.; Helga Haftendorn, Deutsche Außenpolitik zwischen Selbstbeschränkung und Selbstbehauptung 1945-2000, Stuttgart 2011, S. 439.

${ }^{210}$ Vgl. Martin Rupps, Helmut Schmidt. Politikverständnis und geistige Grundlagen, Bonn 1997, S. 34 f. 
In den Konflikten, die hieraus erwuchsen, kam den Akteuren, die sich der deutsch-französischen Freundschaft verpflichtet sahen, die in mancher Hinsicht Ernüchterung hervorrufende Aufgabe zu, Brücken des Verständnisses zwischen beiden Ländern zu schlagen. Diesen Prozess nachzuvollziehen, setzten sich die folgenden Abschnitte zum Ziel.

\subsubsection{Das »Diktat» Helmut Schmidts und der Streit um den europäischen Agrarmarkt}

Hatten französische Befürchtungen, Westdeutschland könne aufgrund seiner ökonomischen Stärke danach trachten, Europa wirtschaftlich und politisch zu dominieren, bis 1974 weitgehend im Schatten der Kontroversen um die Bonner Ostpolitik gestanden ${ }^{211}$, so traten sie nach dem Rücktritt Willy Brandts und befördert durch den Kontext der Weltwirtschaftskrise stärker in den Vordergrund. Das internationale Auftreten des neuen Bundeskanzlers Helmut Schmidt galt vielen französischen Beobachtern im Vergleich mit seinem Vorgänger bald als zu selbstbewusst, bisweilen arrogant und rechthaberisch. Sein außenpolitisches Agieren ließ in Paris den Eindruck eines seiner Schuldgefühle mehr und mehr entledigten Nachbarlandes entstehen, das mit seinen internationalen Partnern fortan mindestens auf Augenhöhe verhandeln wollte. Würde Westdeutschland, frei der Fesseln seiner Vergangenheit, wirtschaftlich und nun auch politisch wiedererstarkt, über kurz oder lang nicht zwangsläufig danach streben, den europäischen Nachbarn seinen Willen aufzuzwingen? Frankreich, so die Ängste, die auch durch das betont enge Einvernehmen zwischen Schmidt und Giscard d'Estaing kaum zu besänftigen waren, würde in diesem Falle endgültig auf den Platz eines deutschen Juniorpartners verwiesen.

Dabei war die Wahl Schmidts zum Bundeskanzler im Mai 1974 seitens der französischen Presse zunächst mehrheitlich begrüßt worden. Im Gegensatz zu dem zuletzt verbraucht wirkenden Visionär Brandt schien dessen tat- und willenskräftiger Nachfolger, wie »Le Monde« urteilte, der rechte Mann zu sein, um das angesichts der drohenden Rezession erforderliche Krisenmanagement zu leisten, wovon Frankreich doch nur profitieren konnte ${ }^{212}$. In das insgesamt

211 Vgl. beispielsweise »Die germanische Seele ist geblieben«. Französische Zeitungen über die Wirtschaftskraft der Bundesrepublik, in: Der Spiegel, 08.12.1969, S. 145; Une parenthèse, in: Le Monde, 12.05.1971, S. 1; Paul-Jean Franceschini, Bonn et la manière forte, in: Le Monde, 21.08.1971, S. 2; Michael Jungblut, Deutschland, Deutschland über alles?, in: Die Zeit, 09.01.1970, S. 22.

212 Siehe À la recherche de l'efficacité, in: Le Monde, 16.05.1974, S. 1; vgl. auch Le rude langage d'un homme du Nord, in: Le Monde, 08.05.1974, S. 3; Michel TATU, »Sommet « franco-allemand: Vers un renforcement de la concertation, in: Le Monde, 01.06.1974, S. 1 und S. 4; André Fontaine, Un entretien avec le chancelier Helmut Schmidt, in: Le Monde, 11.06.1974, S. 1 und S. 12. 
positive Echo auf den Amtsantritt Schmidts mischten sich jedoch auch kritische Stimmen. Diese verwiesen insbesondere auf dessen soldatische Laufbahn während der NS-Zeit und hoben hervor, wie etwa "Le Nouvel Observateur«, dass das Deutschland des Wehrmachtsoffiziers Schmidt wohl kaum mehr dasselbe wie das des Exilanten Brandt sein könne. Vielmehr halte mit dem neuen Regierungschef unweigerlich ein autoritäres Moment in die Bonner Politik Einzug: "Schmidt est un socialiste impérial< et, dans le fond, très peu socialiste. Cela non plus, il ne le cache pas. Les Allemands veulent être gouvernés? Eh bien, ils le seront. Schmidt aime la loi et l'ordre. Il déteste les contradicteurs ${ }^{213}$. In Bonn habe man es, wie die Zeitschrift andeutete, künftig mit für französische Belange wenig verständnisvollen Gesprächspartnern zu tun.

Diese Einschätzung schien sich nur einige Monate später durch das Verhalten der Bundesregierung in der schon früher oftmals kontrovers diskutierten Frage der Finanzierung des europäischen Agrarmarktes zu bestätigen ${ }^{214}$. Der Brüsseler Ministerrat hatte zunächst unter Zustimmung des westdeutschen Landwirtschaftsministers Josef Ertl für die Jahre 1975 und 1976 eine Anhebung der gemeinsamen Agrarpreise um fünf Prozent beschlossen. Für die Bundesrepublik bedeutete dies jedoch gleichzeitig Kürzungen der so genannten Grenzausgleichsbeträge, welche die Folgen der Währungsschwankungen für das Einkommen der Landwirte kompensieren sollten. So hätte Westdeutschland bei größerer Nettoeinzahlung weitaus weniger von der Preisanhebung profitieren können als etwa Frankreich, einer der hauptsächlichen Nutznießer. In Erkenntnis dessen verweigerte Helmut Schmidt Ende September 1974 dem Beschluss nachträglich seine Zustimmung ${ }^{215}$. Das Veto des deutschen Bundeskanzlers gegen eine Entwicklung, welche die Bundesrepublik in seinen Augen immer mehr in die Rolle eines »Zahlmeisters der Gemeinschaft « ${ }^{216}$ drängte, entfachte in der französischen Presse einen Sturm der Entrüstung. Allenthalben sprossen nun Vermutungen über ein rauer werdendes Klima in den Beziehungen zwischen beiden Ländern ${ }^{217}$.

213 Gérard Sandoz, François Schlosser, Schmidt à la barre. À Bonn, des interlocuteurs peu compréhensifs pour la France, in: Le Nouvel Observateur, 21.05.1974, S. 39.

214 Vgl. hierzu ausführlich Kiran Klaus Patel, Europäisierung wider Willen. Die Bundesrepublik Deutschland in der Agrarintegration der EWG 1955-1973, München 2009.

215 Vgl. Nicole Leuchtweis, Deutsche Europapolitik zwischen Aufbruchstimmung und Weltwirtschaftskrise: Willy Brandt und Helmut Schmidt, in: Gisela MülLER-BranDECK-Bocquet u.a. (Hg.), Deutsche Europapolitik von Adenauer bis Merkel, Wiesbaden ${ }^{2} 2010$, S. 67-117, hier S. 106f.; Winfried von URFF, Agrarpolitik und Währungsentwicklung, in: Hermann PrIEBE (Hg.), Die agrarwirtschaftliche Integration Europas, Baden-Baden 1979, S. 41-67; Ziebura, Die deutsch-französischen Beziehungen seit 1945, S. $253 f$.

216 Siehe Klaus Otto NAss, Der "Zahlmeister« als Schrittmacher? Die Bundesrepublik Deutschland in der Europäischen Gemeinschaft, in: Europa-Archiv 31/10 (1976), S. 325-336.

217 Vgl. Alfred Grosser, Frankreich und seine Außenpolitik 1944 bis heute, München, Wien 1986, S. 346-348; Schmitz, Zwischen Mythos und Aufklärung, S. 202-207; »Wer 
Hatte Westdeutschland in der Perspektive vieler Kommentatoren bereits zuvor seine ökonomische Vormachstellung in Europa trotz Wirtschaftskrise ausbauen und seine Nachbarländer, insbesondere Frankreich, weit überflügeln können ${ }^{218}$, so schickte es sich nun offenbar an, die erlangte Stellung zu nutzen, um den europäischen Partnern seine Politik der neu gewonnenen Stärke brutal aufzuzwingen. Gar das Schlagwort des »deutschen Diktats« ging nun $\mathrm{um}^{219}$.

Mit preußischer Härte wolle Schmidt das wirtschaftliche Europa in deutschem Rhythmus marschieren lassen, schrieb etwa das Wochenmagazin "Le Point«. Die Tageszeitungen »Le Figaro« und »L'Humanité« sahen durch das außenpolitische Agieren des Bundeskanzlers bereits eine Rückkehr zu dem Deutschland Bismarcks und Hitlers drohen und bemühten abschreckende historische Vergleiche mit Emser Depesche und Münchener Abkommen ${ }^{220}$. In einem zwei Tage nach der Intervention des westdeutschen Regierungschefs in »Le Monde« veröffentlichten Kommentar fragte der Autor: »La brutalité avec laquelle le chancelier allemand cherche à ımettre au pas ses partenaires européens, annonce-t-elle que la snouvelle Allemagne retrouve par une pente naturelle certains caractères de la `mauvaise Allemagne ‘ de naguère? M. Schmidt se veut-il un nouveau >chancelier de fer « ${ }^{221}$ ?

Wenn die deutschen Nachbarn es auch nicht mit einem neuen eisernen Kanzler zu tun bekämen, so räumte der Kommentator anschließend ein, zeuge Schmidts Vorgehen doch von einer Tendenz zu autoritärem Verhalten und von einem neuen politischen Klima in der Bundesrepublik. Letztlich, dies das Fazit des Beitrags, werde vor allem deutlich, dass für Deutschland die Zeit einer demütig akzeptierten Schuld, die Zeit der Kniefälle von Warschau, endgültig vorbei sei. »Un peuple qui s'est toujours senti `mal aimé< [...] et las d'avoir mauvaise conscience se trouve flatté par le coup de poing sur la table de Bruxelles « ${ }^{222}$. Ähnlich äußerte auch »Le Nouvel Observateur «, dass der Bonner Regierungschef sich nunmehr ohne Komplexe und im vollen Bewusstsein der nationalen Interessen seines Landes der neuen deutschen Machtfülle bediene. Die Krise um die Finanzierung des Gemeinsamen Agrarmarktes müsse daher den Nachbarländern der Bundesrepublik in Westeuropa eine Tatsache eindrücklich vor Augen führen: "Trente ans après la plus grande catastrophe de son histoire, l'Allemagne met non seulement en question les structures de

reich ist, muß zahlen«. Bundeskanzler Schmidts Politik der Stärke - letzte Chance für Europa?, in: Der Spiegel, 30.09.1974, S. 29-39.

218 Vgl. Le réalisme allemand, in: Le Monde, 03.09.1974, S. 1.

219 Vgl. Philippe Moreau, Image de l'Allemagne. La presse française et le »véto« allemand à la hausse des prix agricoles, Lille 1975, S. 26.

220 Siehe zu den Reaktionen in "Le Point «, "Le Figaro« und »L'Humanité« Henri MÉnuDIER, La politique d'Helmut Schmidt vue par la presse française, in: Études. Revue de culture contemporaine 341/12 (1974), S. 703-725, hier S. $716 f$.

${ }^{221}$ Une nouvelle Allemagne, in: Le Monde, 27.09.1974, S. 1.

222 Ibid. 
l'Europe verte mais formule clairement sa candidature au leadership en Europe occidentale $\aleph^{223}$.

In der westdeutschen Presselandschaft wurden die harschen französischen Reaktionen mit Unverständnis und zum Teil unverhohlener Verärgerung aufgenommen ${ }^{224}$. Schließlich sei der deutsche Bundeskanzler, so eine hier vielfach vertretene Auffassung, mit seiner Entscheidung gegen eine Erhöhung der Agrarpreise für eine solide europäische Haushaltspolitik eingetreten, die allen EWG-Partnern gut anstünde. Diese blickten jedoch neiderfüllt auf den ökonomischen Klassenprimus Westdeutschland, dessen Geld zwar gerne genommen, dem aber aufgrund der historischen Schuld keine eigene interessengeleitete Außenpolitik zugestanden werde. Fast ein Vierteljahrhundert lang hätten die Europäer, wie »Der Spiegel « formulierte, deutsche Regierungen erlebt, die sich nationale Interessen ebenso schamhaft versagten wie den Versuch, die ökonomische Macht ihres Landes politisch aufzuwiegen. Nun schrecke die Bundesrepublik ihre Nachbarn plötzlich mit Selbstbewusstsein und unverhüllten Machtpositionen, die deutlich machten, dass die Ära der handzahmen Deutschen zu Ende gehe. Fassungslos sei in Frankreich registriert worden, dass die Vergangenheit der Bundesregierung nicht länger im Wege stehe: »Und sogleich werden, wie nicht anders zu erwarten, die alten Ressentiments wach ${ }^{225}$.

In dieselbe Richtung wies ein Artikel Theo Sommers, den »Die Zeit» Anfang Oktober 1974 veröffentlichte. Dieser stellte zunächst klar, dass die Bundesregierung ihre Zustimmung in Brüssel nicht kategorisch verweigert, sondern sie vielmehr an eine Reihe durchaus vernünftiger Voraussetzungen geknüpft habe. Den französischen Blättern sei daraufhin nichts Besseres eingefallen, als »die >rüden Eselstritte aus Bonn zu beklagen, das >Diktat eines neuen `Eisernen Kanzlers`, das `Mit-der-Faust-auf-den-Tisch-Schlagen eines rautoritären Spielmachers`. Von Emser Depesche war gar die Rede, als rüste sich der preußische Generalstab zur Mobilisierung «226. Daher drängten sich die Fragen auf, ob fast dreißig Nachkriegsjahre und sechzehn Jahre Partnerschaft in der Europäischen Gemeinschaft nicht ausgereicht hätten, um die Nachbarn davon zu überzeugen, dass Westdeutschland nicht mehr

${ }^{223}$ Gérard SANDOZ, »Le `boche« ne paiera plus«. Comment et pourquoi le chancelier Schmidt a provoqué le »coup de tonnerre « du 25 septembre, in: Le Nouvel Observateur, 30.09.1974, S. 71-73, Zitat S. 73.

224 Siehe hierzu Raymond Poidevin, Die Vernunftehe 1945-1975, in: Ders., Jacques BARIÉTY, Frankreich und Deutschland. Die Geschichte ihrer Beziehungen 1815-1975, München 1982, S. 423-464, hier S. 443f.; vgl. auch BAums, Die deutsch-französischen Beziehungen von 1969-1982, S. 311; F. Roy WiLlis, Deutschland, Frankreich und Europa, in: Wolfram F. HANRIEder, Hans RüHLE (Hg.), Im Spannungsfeld der Weltpolitik. 30 Jahre deutsche Außenpolitik (1949-1979), Stuttgart 1981, S. 159-181.

225 „Wer reich ist, muß zahlen«. Bundeskanzler Schmidts Politik der Stärke - letzte Chance für Europa?, in: Der Spiegel, 30.09.1974, S. 29.

226 Theo Sommer, Das Diktat der Vernunft. Schmidts Faustschlag hat den Nebel über Europa gelichtet, in: Die Zeit, 04.10.1974, S. 1. 
das »Dritte Reich « Adolf Hitlers sei, ob zudem für die Bundesrepublik andere Maßstäbe angelegt würden als für die übrigen Partner und ob schließlich die Deutschen wider bessere Einsicht sachgerechte Forderungen fallen lassen sollten, bloß weil andere hierdurch dazu gebracht werden könnten, »in der Reminiszenzenkiste unserer Vergangenheit $\mathrm{zu}$ wühlen «227. Konfrontiert mit diesen Fragestellungen, so klingt in Sommers Artikel an, müssten die europäischen Nachbarländer der Bundesrepublik, auch Frankreich, endlich begreifen, dass der Bonner Außenpolitik weder Gegnerschaft zu Brüssel, noch »teutonische Lust zur Vorherrschaft» Pate stehe ${ }^{228}$.

In den sich ausgehend von der Frage der Agrarpreise entwickelnden medialen Gefechten um ein vermeintliches Hegemonialstreben Westdeutschlands wurde seitens der amtlichen bundesdeutschen Stellen seit Herbst 1974 eine nicht unerhebliche Gefahr für das freundschaftliche Verhältnis zwischen Frankreich und der Bundesrepublik gesehen. In ihrem politischen Halbjahresbericht vom Januar 1975 gelangte die deutsche Botschaft in Paris zu der Einschätzung, dass sich Giscards Frankreich dem Nachbarn gegenwärtig unterlegen fühle und konstant bemüht sei, den westdeutschen Vorsprung aufzuholen. Die stabilitätspolitischen Erfolge, das Selbstbewusstsein und »ein in Frankreich oft unterstellter europäischer Führungsanspruch der neuen Bundesregierung «229 reichten vor diesem Hintergrund aus, um die französische Öffentlichkeit tiefgehend zu beunruhigen. So seien durch den Streit um die Agrarpreiserhöhung, wie der Bericht konstatierte, "viele der überkommenen antideutschen Klischees $^{230}$ wieder aufgedeckt worden. Botschafter Sigismund von Braun hielt es, wie er an das Auswärtige Amt schrieb, für wichtig zu wissen, dass derartige Befürchtungen in Frankreich trotz aller festzustellenden positiven Entwicklungen unterschwellig weiter vorhanden seien und plötzlich durchbrechen könnten, wenn Bonn und Paris aneinandergerieten ${ }^{231}$. Die Kontroverse um die Preisanhebung hätte, wie von Braun urteilte, nicht nur zu einer Reserviertheit in der Zusammenarbeit der beiden Regierungen bei Agrarfragen geführt ${ }^{232}$ - zumal die Unwilligkeit der Bundesrepublik, Zahlmeister zu sein, Frankreich am Geldbeutel treffe -,

227 Ibid.

228 Ibid.

229 PA-AA, Zwischenarchiv, Nr. 109188, Politischer Halbjahresbericht der deutschen Botschaft Paris vom 14. Januar 1975, S. 5.

230 Ibid.

231 Siehe PA-AA, Auslandsvertretungen, Botschaft Paris, Bd. 13524, Schreiben des deutschen Botschafters in Paris, Sigismund von Braun, an das Auswärtige Amt betreffend »Deutsch-französische Beziehungen nach anderthalb Jahren Präsidentschaft Giscard d'Estaing « vom 27. Oktober 1975, S. 5.

232 Siehe PA-AA, Zwischenarchiv, Nr. 109189, Schreiben des deutschen Botschafters in Paris, Sigismund von Braun, an das Auswärtige Amt vom 30. Oktober 1975, S. 2 f. 
sondern stellten auch auf lange Sicht eine »ernste potentielle Belastung des deutsch-frz. Verhältnisses« dar ${ }^{233}$.

Für die französische Vertretung in Bonn, deren Hauptaugenmerk den Reaktionen der westdeutschen Zeitungen galt, kam in den Debatten um den Agrarmarkt vor allem ein seit dem Amtsantritt Helmut Schmidts in der Presselandschaft der Bundesrepublik beständig lauter werdender Ruf nach außenpolitischer Gleichberechtigung zum Ausdruck: »les porte-parole de l'opinion revendiquent le droit d'être enfin traités sur le même pied que les autres peuples, celui de pouvoir adopter les mêmes attitudes que les voisins pour défendre les intérêts nationaux de l'Allemagne « ${ }^{234}$. Darüber hinaus werde in der Berichterstattung des Nachbarlandes immer häufiger mit dem Gedanken gespielt, dass Westdeutschland aufgrund seines ökonomischen Gewichts und seiner "rôle de spayeur« eine führende Stellung in Europa einnehmen müsse ${ }^{235}$. Vor diesem Hintergrund werde die gemeinsame europäische Agrarpolitik, wie es in einem späteren Botschaftsbericht heißt, in der Bundesrepublik vornehmlich betrachtet als eine "absurdité ruineuse imposée par la France à ses partenaires, pour son seul profit « ${ }^{236}$. Dieses Bild, an dessen Verbreitung die westdeutschen Presseorgane aus Sicht der französischen Diplomaten wesentlichen Anteil hatten, konnte den Beziehungen zwischen beiden Ländern nur abträglich sein.

In Anbetracht der in Frankreich um sich greifenden Befürchtungen vor deutschen hegemonialen Ambitionen sowie der sich gleichzeitig in Westdeutschland verbreitenden Auffassung, die schlecht wirtschaftenden französischen Nachbarn alimentieren zu müssen, dafür aber keine dem angemessenen politischen Einflussmöglichkeiten gewährt zu bekommen, stand die Informations- und Kulturarbeit der Regierungen vor schwierigen Aufgaben: "Das Bild vom Partnerland bleibt in beiden Staaten noch verbesserungsbedürftig «, wie die Koordinatoren für die deutsch-französische Zusammenarbeit, Carlo Schmid und Pierre-Olivier Lapie, mit Blick auf die öffentlich zum Tragen gekommenen Auseinandersetzungen konstatierten ${ }^{237}$. Allerdings finde, so betonte das Bundespresseamt im Oktober 1974, die Ab-

233 PA-AA, Zwischenarchiv, Nr. 109189, Aufzeichnung des deutschen Botschafters in Paris, Sigismund von Braun, für das Auswärtige Amt vom 4. November 1975, S. 4 und S. 12.

234 AMAE Paris-La Courneuve, Europe, RFA 1971-1976, Bd. 2998, Schreiben der französischen Botschaft Bonn an das französische Außenministerium betreffend »La France vue à travers la presse allemande« vom 30. Oktober 1974, S. 5.

235 Siehe ibid.; vgl. hierzu auch, AMAE Paris-La Courneuve, Europe, RFA 1971-1976, Bd. 3007, Vermerk betreffend »Position allemande avant la rencontre entre M. Giscard d'Estaing et M. Schmidt« vom 27. Mai 1974, S. 2 f.

236 AMAE Nantes, Bonn Ambassade, Bd. 318, Bericht des französischen Botschafters in Bonn, Jean-Pierre Brunet, über das Frankreichbild in der Bundesrepublik vom 26. September 1980, S. 11.

237 PA-AA, Zwischenarchiv, Nr. 111200, Auszug aus der Ergebnisniederschrift der Koordinatorengespräche im Rahmen der deutsch-französischen Gipfelkonsultationen am 25./26. Juli 1975 in Bonn, S. 10. 
sicht, die gegenseitige Darstellung in den Massenmedien von Ressentiments und historischen Reminiszenzen zu befreien, ihre Begrenzung in der demokratischen Meinungsfreiheit der Publizistik. Paris und Bonn sollten dennoch gemeinsam versuchen, alle vorhandenen Möglichkeiten auszuschöpfen, die zu einer Versachlichung der Berichterstattung beitragen könnten ${ }^{238}$. Diesbezügliche Beratungen fanden vor allem im Rahmen regelmäßiger Gespräche zwischen den Regierungssprechern statt. Hier wurden Medienbeiträge thematisiert, welche das Nachbarland in ein ungünstiges Licht rückten, Überlegungen angestellt, in welcher Form etwa auf bestimmte Presseorgane mäßigend eingewirkt und mit welchen Maßnahmen ein »impact psychologique ${ }^{239}$ bei den Bevölkerungen erzielt werden konnte. Es sei schließlich verfehlt, wie die deutsche Botschaft im März 1975 urteilte, zu viel von der bloßen Berufung auf die deutsch-französische Freundschaft zu erwarten. Im Sinne der Völkerverständigung und der Stabilität der Beziehungen zwischen beiden Ländern sollte die kulturelle Verständigungsarbeit vielmehr aktiv versuchen, die Menschen zu erreichen. Insbesondere durch die Vermittlung der Sprache und der civilisation des Partnerlandes könne man Unkenntnisse abbauen, Reibungsrisiken in einer enger werdenden Nachbarschaft mindern und den Rückfall in nationale Selbstbezogenheit verhindern. Nur durch eine solche »erzieherische Kleinarbeit« sei politischer Nutzen für Generationen zu erzielen $^{240}$.

Die bewährten Instrumente dieser Bemühungen waren aus westdeutscher Sicht vor allem die Stipendien- und Lektorenprogramme des DAAD, mit denen »die Erzieher von heute und die Multiplikatoren von morgen" erreicht würden, sowie die Sprachkurse und landeskundlichen Seminare der Goethe-Institute $^{241}$. In französischer Perspektive fielen hierunter insbesondere die Initiativen zur Förderung des schulischen wie außerschulischen Französischunterrichts in der Bundesrepublik, die Informationsarbeit der Instituts français und die deutsch-französischen Begegnungen im Rahmen von Schüler- und Studentenaustausch ${ }^{242}$. Beide Seiten kooperierten darüber hinaus bei der Einrichtung bilingualer Sektionen an westdeutschen und französischen Schulen und dem Aufbau weiterer deutsch-französischer Gymnasien, die jeweils als Foren grenzüberschreitenden Austauschs, so

238 Siehe BA, B 145, Bd. 11421, Schreiben des Presse- und Informationsamtes der Bundesregierung an den Koordinator für die deutsch-französische Zusammenarbeit, Carlo Schmid, vom 3. Oktober 1974.

239 AMAE Paris-La Courneuve, Europe, RFA 1971-1976, Bd. 3025, Vermerk bezüglich der deutsch-französischen Zusammenarbeit im Bereich des Informationswesens vom 9. Oktober 1974, S. 2.

240 Siehe PA-AA, Zwischenarchiv, Nr. 107749, Kulturpolitischer Jahresbericht 1974 der deutschen Botschaft Paris vom 19. März 1975, S. 4-8, Zitate S. 8.

241 Siehe ibid., S. 9f.

242 Siehe AMAE Nantes, Bonn Service culturel, Bd. 28, Rapport d'activités des services culturels, année 1973/74. 
hoffte man, dazu beitragen würden, ein auf zwischenmenschlichen Beziehungen basierendes Fundament der Annäherung zu schaffen ${ }^{243}$. Letztlich sollten die verschiedenen Mittel der Auswärtigen Kulturpolitik dafür sorgen, dies zumindest die Vorgabe der Bonner Verantwortlichen, die bilateralen Beziehungen "gegen politisch bedingte Störungen abzusichern und ihnen über Krisen hinwegzuhelfen«, sie zudem »auf der Ebene menschlichen Verständnisses, menschlicher Interessenverflechtungen und positiv getönter Emotionen zu verankern « ${ }^{244}$.

Helfer bei der Realisierung dieser ambitionierten Zielsetzungen konnten die staatlichen Stellen einmal mehr in den Reihen der Verständigungsorganisationen finden. Insbesondere ein Mitte Oktober 1974 durch das DFI veranstaltetes Kolloquium diente in dieser Hinsicht als Plattform einer offenen Diskussion über die jüngsten Verstimmungen des deutsch-französischen Verhältnisses. Unter dem Thema »Frankreich, Deutschland und die europäische Krise« kamen in Ludwigsburg über vierzig Politiker, Ministerialbeamte, Wissenschaftler und Journalisten aus beiden Ländern zusammen, darunter Vertreter der Außenministerien und Botschaften, verschiedener politischer Parteien, der französischen Rundfunk- und Fernsehanstalt ORTF und die Bonner beziehungsweise Pariser Korrespondenten von "Le Monde", "Le Point« und »Die Zeit» ${ }^{245}$. Neben dem Aufzeigen von Möglichkeiten und Grenzen der bilateralen Regierungskooperation, welche Alfred Grosser in seinem Impulsvortrag als "völlig unzureichend, um die gemeinsamen Probleme zu lösen ${ }^{246}$, bezeichnete, ging es hierbei vor allem darum, nach den "Ursachen gegenseitigen Mißtrauens in der öffentlichen Meinung beider

243 Vgl. AN Fontainebleau, ministère de l'Éducation nationale, Bd. 800486/1, Protokoll der Zusammenkunft des französischen Bildungsministers René Haby mit dem Bevollmächtigten der Bundesrepublik Deutschland für kulturelle Angelegenheiten im Rahmen des Vertrages über die deutsch-französische Zusammenarbeit, Hans Filbinger, am 7./8. Oktober 1974 in Paris, S. 4f.; PA-AA, Zwischenarchiv, Nr. 104053, Schreiben des Auswärtigen Amts an den Koordinator für die deutsch-französische Zusammenarbeit vom 20. Februar 1974, Anlage: Sechzehnter Bericht der Interministeriellen Kommission der Bundesregierung für die deutsch-französische Zusammenarbeit, S. 46-48.

244 PA-AA, Zwischenarchiv, Nr. 104636, Ministervorlage der Kulturabteilung des Auswärtigen Amts bezüglich der Reform der Auswärtigen Kulturpolitik vom 22. November 1974, S. 4.

245 Siehe DFI-Archiv, Ordner Tätigkeitsberichte 1968-1977, Sachlicher Bericht zum Verwendungsnachweis für 1974, S. 3f.; DFI-Archiv, Ordner Deutsch-Französisches Kolloquium 1974, Teilnehmerliste des Kolloquiums »Frankreich, Deutschland und die europäische Krise" vom 10.-13. Oktober 1974; vgl. auch BA, B 122, Bd. 12628, Vermerk bezüglich des Kolloquiums zum 25jährigen Bestehen des DFI Ludwigsburg vom 11. Oktober 1974.

246 DFI-Archiv, Ordner Deutsch-Französisches Kolloquium 1974, Referat Alfred Grossers zum Thema "Möglichkeiten und Grenzen des deutsch-französischen Bilateralismus", S.3. 
Länder « ${ }^{247}$ zu suchen. Der Romanist Roland Höhne bescheinigte der westdeutschen Presse im Zusammenhang mit dem Streit um die Agrarpreise etwa »Egozentrismus « und »Selbstgefälligkeit « ${ }^{248}$. Alte Interpretationsmuster bestimmten die Frankreichberichterstattung weiterhin. Die Bundesrepublik werde den Nachbarn in überheblicher Weise als Vorbild hingestellt, dem nachzueifern sei, wollten die Franzosen gleichen wirtschaftlichen Erfolg haben $^{249}$. Ähnlich ernüchternd fiel das Urteil aus, das der Politikwissenschaftler Henri Ménudier über die französischen Medien fällte. Sowohl die Kommentare, die Ängste vor einem machtlüsternen Deutschland schürten, das Europa seinen Willen aufzwingen wolle, als auch die Emotionen, welche das angebliche Diktat Helmut Schmidts geweckt hätten, zeugten, wie Ménudier ausführte, von medialen Überreaktionen, die die realen Verhältnisse des Nachbarlandes völlig aus den Augen verloren hätten: "L'image d'une `Allemagne repue, puissante, obsédée de Realpolitik`, [...] >libérée de ses complexes et servie par un nouveau >chancelier de fer prend des contours de plus en plus nets ${ }^{250}$.

Dass die im Rahmen der Tagung durchgeführte Konfliktanalyse zu äußerst kontroversen Gesprächen unter den Anwesenden, und vor allem zwischen deutschen und französischen Teilnehmern führte, belegen die im Auswärtigen Amt und im Quai d'Orsay angefertigten Diplomatenberichte wie auch die Reaktionen der Presse. "Wie bei einem Versöhnungstermin vor dem Scheidungsrichter « ${ }^{251}$ sei es in Ludwigsburg zugegangen, titelte etwa die »Frankfurter Allgemeine Zeitung«. Die aus französischer Sicht »unzulässigen deutschen Pressionen « in der Agrarfrage und der in Frankreich so wahrgenommene Hang der Deutschen, das in ökonomischen Schwierigkeiten befindliche Nachbarland in arroganter Weise zu belehren, seien, wie ein Bericht des Auswärtigen Amts festhielt, ohne falsche Rücksichtnahme zur Sprache gekommen. Ebenso intensiv habe man über die vermeintliche »Renationalisierung der öffentlichen Meinung und der Politik « in Westdeutschland, über den Vorwurf der deutschen Seite, den industriellen Rückstand Frankreichs finanzieren zu müssen und das sich in der Bundesrepublik ausbreitende Gefühl, dass die Deutschen »jahrelang Frankreichs Launen ertragen hätten«, debattiert $^{252}$. Ein in dieser Weise offen geführter deutsch-französischer

247 PA-AA, Zwischenarchiv, Nr. 109189, Schreiben des Leiters des DFI, Robert Picht, an das Presse- und Informationsamt der Bundesregierung vom 28. Februar 1974, S. 1.

248 DFI-Archiv, Ordner Deutsch-Französisches Kolloquium 1974, Referat Roland Höhnes zum Thema »Die deutsch-französischen Beziehungen in der deutschen Presse«, S. 2.

249 Siehe ibid., S. 3

250 PA-AA, Zwischenarchiv, Nr. 109189, Referat Henri Ménudiers zum Thema "L'Allemagne d'Helmut Schmidt vue par la presse française«, S. 3.

251 Heinz Stadlmann, »Wie bei einem Versöhnungstermin vor dem Scheidungsrichter«, in: FAZ, 16.10.1974, S. 12; vgl. auch Daniel VERNET, L'Institut franco-allemand de Ludwigsburg a fêté son $25^{\mathrm{e}}$ anniversaire, in: Le Monde, 19.10.1974, S. 2.

252 Siehe zu diesem Abschnitt PA-AA, Zwischenarchiv, Nr. 109189, Vermerk betreffend die 
Schlagabtausch sollte, so das erklärte Ziel des DFI, sich auf lange Sicht positiv sowohl auf die mediale Präsentation des Nachbarlandes als auch den politischen Umgang mit der anderen Seite und damit indirekt auf die Einstellung der Bevölkerungen zueinander auswirken. Ob aus der in Ludwigsburg geweckten Unruhe tatsächlich heilsame Kräfte würden hervorgehen können, so resümierte die "Stuttgarter Zeitung«, werde allerdings davon abhängen, wie diese sich über den kleinen Zirkel der Teilnehmer hinaus in Regierungen, Parlamente und Öffentlichkeit in beiden Ländern fortzusetzen vermöge ${ }^{253}$. Zumindest im Auswärtigen Amt wurde konstatiert, dass die Gespräche deutlich gemacht hätten, "wie stark emotionell [!] das Verhältnis zwischen beiden Ländern bestimmt ist « und sich hieraus der Schluss ziehen ließe, dass die Beziehungen »in der öffentlichen Darstellung nicht ohne den Einsatz positiver Emotionen gepflegt werden können ${ }^{254}$. Ob die aus den Diskussionen resultierende Anregung, »die Vertretung unserer Interessen gegenüber Frankreich etwas anders zu artikulieren $\aleph^{255}$, Eingang in weitere politische Überlegungen fand, ist jedoch nicht zweifelsfrei festzustellen.

Das Ziel, in Anbetracht der zwischen beiden Ländern aufgetretenen Spannungen den Gedanken der Verständigung in Politik, Medien und Bevölkerungen zu festigen, wurde zu gleicher Zeit auch von Paris aus verfolgt. Das BILD wollte, wie sein Präsidium festgehalten hatte, im Angesicht der Krise nicht nur als ruhender Pol objektiver Informationsvermittlung fungieren, sondern gleichermaßen als Austauschstelle geistige Eliten zusammenbringen ${ }^{256}$. Hiervon ausgehend führte die Organisation zwischen 1974 und 1976 regelmäßig Fortbildungsseminare für Journalisten durch, die mit den politischen, wirtschaftlichen und gesellschaftlichen Verhältnissen des Partnerlandes vertraut gemacht und somit zu Multiplikatoren positiver Deutschland- und Frankreichbilder in den Medien werden sollten ${ }^{257}$. Darüber hinaus machte es sich die seitens der Vereinigung herausgegebene

»Deutsch-Französische Tagung in Ludwigsburg zum Thema Frankreich/Deutschland und die europäische Krise" vom 15. Oktober 1974, S. 2-4, hier alle angeführten Zitate; vgl. auch AMAE Paris-La Courneuve, Europe, RFA 1971-1976, Bd. 3032, Schreiben des französischen Generalkonsuls in Stuttgart an den französischen Botschafter in Bonn vom 25. Oktober 1974.

253 Siehe Heinz Mörsberger, Michel und Marianne vor dem Scheidungsrichter. Bilanz eines Kolloquiums zum 25jährigen Bestehen des Deutsch-Französischen Instituts, in: StZ, 14.10.1974, S.2.

254 PA-AA, Zwischenarchiv, Nr. 109189, Vermerk betreffend die »Deutsch-Französische Tagung in Ludwigsburg zum Thema Frankreich/Deutschland und die europäische Krise« vom 15. Oktober 1974, S. 5 f.

255 Ibid., S. 6.

256 Siehe BILD-Archiv, Protokoll der Präsidiumssitzung der GÜZ und des BILD am 8. und 9. Juni 1974 in Paris, S. 4.

257 Siehe BILD-Archiv, Übersicht über die Tätigkeit der Gesellschaft für übernationale Zusammenarbeit und des BILD im Jahre 1974, S. 4; Tätigkeitsbericht 1974-1976 der GÜZ und des BILD, S. 27. 
Zeitschrift "Documents« zur Aufgabe, auf medial verursachte Fehlwahrnehmungen und Vorurteile hinzuweisen und die französischen Leser über die außenpolitischen Orientierungen und die ökonomische Entwicklung Westdeutschlands aufzuklären ${ }^{258}$, denn: „Die Beziehungen zwischen unseren beiden Ländern können erst dann fruchtbar sein, wenn ein möglichst exaktes Wissen über die deutschen Gegebenheiten vorhanden ist « ${ }^{259}$. Auch der ADFG, dessen Vorstand in den öffentlich ausgetragenen Auseinandersetzungen des Jahres 1974 eine Infragestellung der deutsch-französischen Freundschaft erkannte, sah sich zum Handeln herausgefordert. Vor allem die fast einhundert Mitgliedsvereinigungen in Frankreich und der Bundesrepublik verschafften dem Zusammenschluss die Möglichkeit, mit allen gesellschaftlichen Gruppen zu kommunizieren und auf weite Bevölkerungskreise auszustrahlen, wie der Präsident des ADFG formulierte. Dieser Weg müsse indes noch mehr genutzt werden als zuvor, die Tätigkeit auf regionaler Ebene stärker vorangetrieben und seitens der einzelnen Gesellschaften eine kontinuierliche Presse- und Informationsarbeit geleistet werden ${ }^{260}$. Schenkt man dem Urteil der offiziellen bundesdeutschen Stellen Glauben, war diese Strategie durchaus erfolgreich. Der Koordinator der Bundesregierung für die deutsch-französische Zusammenarbeit gelangte etwa zu der Einschätzung, dass die »Gesellschaften in beiden Ländern eine sehr wesentliche Funktion als Unterbau unserer deutsch-französischen Politik der Verständigung und Zusammenarbeit haben $\aleph^{261}$.

Flankiert wurden die Anstrengungen der kulturpolitischen Akteure und privaten Vereinigungen für eine Stabilisierung des deutsch-französischen Verhältnisses zudem durch die publizistischen Interventionen der geistigen Mittler. Pierre Bertaux hatte bereits seit 1973 in Frankreich darauf hingewiesen, dass die deutschen Nachbarn auf dem Wege seien, die Traumata der Vergangenheit hinter sich zu lassen, sich von der alliierten Vormundschaft sukzessive zu emanzipieren, die Nachkriegszeit somit zu überwinden: »Les représentants du gouvernement français trouveront devant eux des partenaires désormais sans complexes et n'ayant plus envers la France les motifs de

258 Vgl. beispielhaft Robert PICHT, La perception de l'information par l'opinion publique, in: Documents 29/1 (1974), S. 75-82; Robert HAERDTER, Le vingt-cinquième anniversaire de la RFA, in: Documents 29/3 (1974), S. 6-10; Alfred FrISCH, Puissance et fragilité, in: Documents 29/4 (1974), S. 6-16; Dossier: L'Allemagne et l'Europe, in: Documents 30/1 (1975), S. 39-88.

259 BILD-Archiv, Tätigkeitsbericht 1974-1976 der GÜZ und des BILD, S. 12.

260 Siehe VDFG-Archiv, Ordner Vorstandssitzungen 1974-1976, Kurzprotokoll der Mitgliederversammlung des ADFG im September 1974 in Kassel; Protokoll der Vorstandssitzung des ADFG am 30. November 1974 in Mainz; Kurzprotokoll der Gesamtvorstandssitzung am 4. September 1975 in Amiens.

261 PA-AA, Zwischenarchiv, Nr. 109189, Aufzeichnung des Koordinators für die deutschfranzösische Zusammenarbeit, Carlo Schmid, bezüglich des Arbeitskreises DeutschFranzösischer Gesellschaften vom 12. September 1975, S. 2. 
complaisance qu'ils pouvaient encore avoir eus naguère ${ }^{262}$. In Konsequenz dieses gleichsam natürlichen Entwicklungsprozesses verschaffe die Bundesrepublik ihrem ökonomischen Gewicht auf europäischer Ebene und auch Frankreich gegenüber in stärkerem Maße Geltung als zuvor. Die Verfolgung ökonomischer Interessen sei jedoch ihr gutes Recht. Daraus den Schluss zu ziehen, die Deutschen strebten nach einer Vormachtstellung in Westeuropa, so klingt es bei Bertaux an, zeuge von einer Verkennung der Realität.

Joseph Rovan zog aus den seit 1974 zu Tage getretenen Konflikten den Schluss, dass die Zusammenarbeit zwischen Frankreich und Westdeutschland auf öffentlicher und staatlicher Ebene aufgrund von »psychologisch-soziologisch bestimmten Kommunikationsschwierigkeiten ${ }^{263}$ weiterhin gehemmt bleibe. Die Schuld daran war seiner Auffassung nach zu gleichen Teilen auf westdeutscher wie auf französischer Seite zu suchen. In Frankreich werde die ökonomische Stärke der Bundesrepublik regelmäßig überschätzt, was in der Öffentlichkeit allzu oft empfindliche Reaktionen und Ängste vor einem deutsch dominierten Europa auslöse, zumal in Anbetracht eines selbstbewusst auftretenden Bundeskanzlers ${ }^{264}$. Umgekehrt sei in Westdeutschland "ein Wiederanwachsen der Strömung festzustellen, die in Frankreich ein unordentliches Gemeinwesen sieht, das seine eigenen Probleme nicht lösen kann und diese Unfähigkeit mit politisch/diplomatischen Prätentionen verbindet, die in keinem Verhältnis zu den wirklichen Kräften und Möglichkeiten Frankreichs stehen ${ }^{265}$. Dabei seien durch die neue französische Regierung und den Staatspräsidenten viele wirtschaftliche und soziale Problemlagen erkannt und angegangen worden und auch die Europa-Politik Frankreichs zeichne sich durch ein neues Klima aus, durch inhaltlich und formell gemäßigte Positionen und eine konziliante Haltung gerade auch in der Frage der Agrarpreise ${ }^{266}$. Den Deutschen empfahl Rovan mithin ein weniger selbstgefälliges Auftreten sowie eine ernsthafte und unvoreingenommene Auseinandersetzung mit der Situation des Nachbarlandes, den Franzosen mehr Vertrauen in die deutschen Partner und insgesamt mehr Gelassenheit beim Blick nach Osten.

In ähnlicher Weise wie Rovan galt schließlich auch Alfred Grosser die Krise um die Agrarpreiserhöhung als deutliches Anzeichen dafür, wie leicht einerseits bei einem nicht unerheblichen Teil der französischen Bevölkerung

262 Pierre Bertaux, Les élections du 19 novembre et les rapports franco-allemands, in: Allemagne d'aujourd'hui 36 (1973), S. 57-62, hier S. 59.

${ }^{263}$ Joseph Rovan, Dreißig Jahre Gesellschaft für übernationale Zusammenarbeit, in: Dokumente 32/4 (1976), S. 263-268, hier S. 264.

264 Vgl. Ders., Histoire de la social-démocratie allemande, S. 456-463, bes. S. 462.

265 Ders., Dreißig Jahre Gesellschaft für übernationale Zusammenarbeit, S. 265.

266 Siehe Ders., Frankreichs Außenpolitik nach dem 19. Mai, in: Dokumente 30/3 (1974), S. 195-199; Ders., Frankreichs neues Regime, in: Frankfurter Hefte 29/9 (1974), S. $625-$ 634. 
das Bild des »ewigen Deutschland $\aleph^{267}$ mobilisiert werden konnte, wenn ein Unterlegenheitsgefühl gegenüber dem östlichen Nachbarn vorhanden sei. Andererseits habe sie gezeigt, wie viel "unerfreuliche Überheblichkeit» die deutsche Wirtschaftsmacht in der Bundesrepublik hervorrufe, wenn dort über Frankreich geurteilt werde ${ }^{268}$. Ein nahezu vollkommenes Missverstehen des anderen sei es daher, welches das Verhältnis zwischen Deutschen und Franzosen noch immer präge. Ende Dezember 1974 äußerte Grosser in einem Beitrag in "Le Monde " gar besorgt, dass die Entwicklung so sehr auseinander gehe, dass sich die Gefahr einer "Mauer des Unverständnisses« zwischen beiden Ländern abzeichne und selbst die Regierungsbeziehungen hierdurch negativ beeinflusst werden könnten ${ }^{269}$. Nicht ohne einen Anflug von Resignation klagte er: "Si seulement chacun consentait à vouloir comprendre les raisons et les aspects positifs de l'orientation du pays voisin! Ce simple effort le conduirait à mettre en perspective sa propre attitude et à en découvrir les limitations et les partis pris ${ }^{270}$. Hatten denn all die deutsch-französischen Vermittlungsversuche der vorangegangenen Jahre keinerlei Früchte getragen?

Wenn der Klageruf Grossers auch auf die Enttäuschung des Moments zurückgeführt werden kann, war er dennoch bezeichnend für die Rückschläge, welche diejenigen, die sich während der 1970er Jahre für die Verständigung zwischen Frankreich und der Bundesrepublik engagierten, in ihrer Arbeit immer wieder hinnehmen mussten. Der politische Wille, die Beziehungen zwischen beiden Ländern durch die Intensivierung von sprach- und landeskundlichen Kenntnissen, durch das Einwirken auf die Medien oder den Austausch von Journalisten zu fördern, war zweifellos stark ausgeprägt. Beharrlich brachten die privaten Vereinigungen Deutsche und Franzosen zusammen oder lancierten Informations- und Aufklärungskampagnen. Unermüdlich erhoben weithin anerkannte Persönlichkeiten ihre Stimme

267 Siehe zu diesem Schlagwort Charles Maurras, Devant l'Allemagne éternelle. Gaulois, Germains, Latins. Chronique d'une résistance, Paris 1937; vgl. weiterführend Michel GRUNEWALD, De Luther à Hitler. Maurras et l'»Allemagne éternelle«, in: Olivier DARD, Michel Grunewald (Hg.), Charles Maurras et l'étranger. L'étranger et Charles Maurras, Bern 2009, S. 339-358; Michel Grunewald, Face à l'»Allemagne éternelle«. Maurras et l'Allemagne de la naissance de l'Action française à la Première Guerre mondiale, in: Dagmar Bussıek, Simona GöBel (Hg.), Kultur, Politik und Öffentlichkeit. Festschrift für Jens Flemming, Kassel 2009, S. 244-265; Strickmann, L'Allemagne nouvelle; Frano ILIĆ, Frankreich und Deutschland. Das Deutschlandbild im französischen Parlament 1919-1933, Münster 2004.

268 Siehe Alfred Grosser, Germany: a European and World Power, in: David S. LaNDES (Hg.), Western Europe: the Trials of Partnership, Lexington 1977, S. 173-207, hier S. 174f.; Alfred Grosser, Die kulturelle Identität der Bundesrepublik Deutschland. Probleme und Perspektiven, in: Ders. u. a., Wirtschaft, Gesellschaft, Geschichte, Stuttgart 1974, S. 202-221, hier S. 220.

269 Ders., L'incompréhension franco-allemande, in: Le Monde, 11.12.1974, S. 1, Abdruck des Artikels in deutscher Fassung in Ders., Gegen den Strom. Aufklärung als Friedenspolitik, München 1975, S. 77-79.

270 Ders., L'incompréhension franco-allemande, in: Le Monde, 11.12.1974, S. 5. 
zugunsten der Freundschaft. Dennoch: Einige polemische Zeitungsartikel genügten offenbar - dieser Eindruck mochte sich bei den verschiedenen Protagonisten der Annäherung einschleichen -, um die Geister deutschfranzösischer Feindseligkeiten unversehens zu neuem Leben zu erwecken. Die Debatte, welche auf das Veto Helmut Schmidts gegen eine Anhebung der Agrarpreise folgte, und die hierdurch an die Oberfläche quellenden Bilder alter Gegnerschaft hatten weder verhindert noch in ihrer Aggressivität wesentlich entschärft werden können. Sicher, so kann man einräumen, wird ein groß angelegter und von einflussreichen Persönlichkeiten gestalteter deutschfranzösischer Dialog, wie im Rahmen des Kolloquiums im Ludwigsburger Institut durchgeführt, nicht völlig ohne Wirkung geblieben sein. Doch Effekte in entgegengesetzter Richtung erzielte das polemische Heraufbeschwören von »Emser Depesche « und »eisernem Kanzler « auf der einen und das selbstgefällig vorgetragene Diktum vom »deutschen Zahlmeister « auf der anderen Seite allemal. Ein exaktes Bemessen ist in beiden Fällen kaum möglich; die Polemiken, nicht der Dialog, erreichten allerdings ein breiteres Publikum.

\subsection{2 „Wettlauf mit einem Riesen«: die deutsche Wirtschaftskraft weckt Befürchtungen}

Waren die Wogen, welche die Auseinandersetzungen um den europäischen Agrarmarkt im Herbst 1974 verursacht hatten, auch nach einiger Zeit geglättet, die Ängste, dass Westdeutschland seine ökonomische Kraft auf lange Sicht als Instrument einer neuen Machtpolitik einsetzen könnte, schwelten in Frankreich unter der Oberfläche fort. Vor allem schien der bundesdeutsche Wirtschaftsvorsprung aus französischer Sicht weiter anzuwachsen, das eigene Land hingegen immer mehr ins Hintertreffen zu geraten und trotz äußerster Anstrengungen über die Position eines "éternel second de l'Allemagne «71 nicht hinauszukommen. Der beständige Vergleich mit einem vielfach übermäßig effizient und leistungsstark wahrgenommenen »deutschen Modell«, das in der Perspektive vieler französischer Beobachter das Nachbarland zu einem Hort von Wohlstand und Wachstum inmitten des von Rezession geplagten Westeuropa gemacht hatte, wirkte hierbei schon fast bedrohlich $^{272}$. Wie konnte Staatspräsident Giscard d'Estaing, »cousin pauvre« ${ }^{273}$

${ }^{271}$ La France, éternel second de l'Allemagne, in: Le Monde, 22./23.12.1974, S. 4.

272 Vgl. Bernard Keizer, Le modèle économique allemand. Mythes et réalités, Paris 1979; J. Bozzi, Suivre le »modèle allemand«?, in: Perspectives, Nr. 1531, 20.07.1978, Teil II, S. 17-26; Georges Delange, La spécificité du »modèle« allemand. Trois études sur la RFA, Paris 1980; hierzu weiterführend Jean-Charles Asselain, La conduite de la politique économique, in: Berstein, Casanova, Sirinelli (Hg.), Les années Giscard. La politique économique, S. 9-52.

273 François Schlosser, Allemagne: un trop beau parti, in: Le Nouvel Observateur, 03.02.1975, S. 25 . 
des deutschen Bundeskanzlers, Bonn vor diesem Hintergrund noch in einer gleichberechtigten Partnerschaft mit Paris halten? Was konnte Frankreich, so die oftmals in der französischen Presse hervortretende Frage, dem übermächtigen Nachbarn noch entgegensetzen, sollte dieser beginnen, offene machtpolitische Ansprüche zu formulieren ${ }^{274}$ ?

Den westdeutschen Zeitungen galten hingegen derartige französische Sorgen mehrheitlich als Zeugnis eines völligen Unverständnisses des Nachbarn und seines ökonomischen Potenzials. Wenn die Franzosen ihren großen Bruder nicht mehr verstünden, so schrieb »Die Zeit« im März 1975, nähmen sie Zuflucht zu alten Klischees, den »typisch deutschen « Tugenden. Schnell sei in Frankreich vom dynamischen deutschen Volk die Rede, von der Mobilisierung aller Kräfte für ein gemeinsames Ziel, von emsigem Fleiß und eiserner Disziplin, gar die "germanische Seele« werde bemüht, um die Wirtschaftskraft der »unheimlichen Nachbarn« zu erklären. Ein lähmendes Gefühl der Unterlegenheit gehe derzeit in Paris gegenüber der Bundesrepublik um, die den Franzosen immer noch suspekt sei: »das Vertrauen in den deutschen Partner steht nach wie vor auf schwachen Füßen $\aleph^{275}$.

Angesichts einer solch spannungsgeladenen Konstellation zwischen beiden Ländern genügte im Sommer 1975 eine Polemik des französischen Generals François Binoche über die deutschen Nachbarn, um erneut Irritationen im deutsch-französischen Verhältnis hervorzurufen ${ }^{276}$. In der gaullistischen Zeitschrift "L'Appel « ${ }^{277}$ hatte Binoche, von 1964 bis 1967 Militärgouverneur des französischen Sektors von Berlin, die These vertreten, Deutschland habe sich seit den Zeiten Bismarcks nicht geändert und habe die europäische Nachkriegsordnung von 1945 nie akzeptiert. Gleichsam getrieben von den zwanghaft wiederkehrenden nationalistischen Aufwallungen seiner Vergangenheit, strebe es nicht nur nach einer Revision der Grenzen, sondern nach Vorherrschaft in Europa ${ }^{278}$ :

Chaque jour qui passe nous confirme: d'une part, le désir de l'Allemagne d'annuler progressivement, mais totalement, les conséquences politiques de sa défaite et de repartir vers de

274 Vgl. Pierre Drouin, Le deuxième »miracle« allemand, in: Le Monde, 22.01.1975, S. 1 und 34.

275 Klaus-Peter Schmid, Unheimliche Nachbarn. Warum die deutsche Wirtschaftsmacht jenseits des Rheins so gefürchtet wird, in: Die Zeit, 14.03.1975, S. 38.

276 Vgl. hierzu Meimeth, Frankreichs Entspannungspolitik der 70er Jahre, S. $79 f$.

277 Siehe François Bınoche, Le rôle véritable de notre armée, in: L’Appel 18 (Juli/August 1975), S. 9-17.

278 Siehe Ders., Un retour en arrière, in: Le Monde, 26.07.1975, S. 2, hier findet sich eine knappe Zusammenfassung der Thesen Binoches; vgl. auch Roland HöHNE, Der Fall Binoche: antideutscher Nationalismus in Frankreich?, in: Frankfurter Hefte 31/2 (1976), S. 2f.; weiterführend hierzu Wolf D. GrunER, Deutschland mitten in Europa. Aspekte und Perspektiven der deutschen Frage in Geschichte und Gegenwart, Hamburg 1992, S. 401 und Gabriele Weber, Die europapolitische Rolle der Bundesrepublik Deutschland aus Sicht ihrer EG-Partner: deutscher Sonderweg oder europäische Musterrolle?, Bonn 1984, S. 55-100. 
nouveaux rêves de grandeur plus en rapport avec ses mérites; d'autre part, la volonté quasi absolue, en France, de dissimuler le danger évident que nous fait courir cette Allemagne toujours si semblable à elle-même à travers le temps ${ }^{279}$.

Verstärkte öffentliche Aufmerksamkeit erhielt der »non-konformistische General «, wie »Le Monde« Binoche betitelte ${ }^{280}$, vor allem dadurch, dass er aufgrund seiner Äußerungen Anfang August 1975 in den Ruhestand versetzt wurde. Er habe es, so die Begründung des französischen Verteidigungsministeriums, an der seiner Position angemessenen Zurückhaltung fehlen lassen und das von Adenauer und de Gaulle begründete Werk der deutsch-französischen Aussöhnung kompromittiert ${ }^{281}$. Dieser einmalige Vorgang ließ Binoche in den Fokus der westdeutschen Presse rücken. In einem Interview, das »Der Spiegel « Ende September 1975 veröffentlichte, bekräftigte der nunmehr demobilisierte General, dass Frankreich auch in der Gegenwart noch vor den Deutschen auf der Hut sein müsse. Denn wenn Deutschland erst einmal wiedervereinigt sei und seine alte Machtstellung zurückerlangt habe, dann würde es zwangsläufig danach trachten, seine Macht auch anzuwenden. Selbst einen erneuten deutschen Angriffskrieg gegen Frankreich wollte Binoche nicht ausschließen. »Es gibt viele Franzosen, die so denken wie ich: Diese Deutschen sind gefährlich mit ihrer Macht und ihrer Kraft « ${ }^{282}$. Die Ansicht Binoches sei, wie daraufhin »Die Zeit« urteilte, zwar keinesfalls mit der in Frankreich vorherrschenden Meinung gleichzusetzen, doch dürfe man solche Stimmen nicht ignorieren, zumal sie es immer wieder schafften, ein im Ganzen positives Deutschlandbild plötzlich ins Wanken zu bringen. Möglich sei dies vor allem deswegen, weil trotz aller offiziell bekundeter Freundschaft angesichts der engen Bindung Bonns an Washington und des wirtschaftlichen Übergewichts der Bundesrepublik auch bei den Durchschnitts-Franzosen ein Rest von Skepsis über den deutschen Partner weiterhin vorhanden bleibe ${ }^{283}$.

Dass diese Skepsis nicht viel Nahrung brauchte, um in offenes Misstrauen umzuschlagen, zeigte sich nur wenige Monate später, als Helmut Schmidt nach den Streitigkeiten um den Agrarmarkt im Frühjahr 1976 einmal mehr in Verdacht geriet, seine Nachbarn auf den Weg eines »deutschen Europas « zwingen zu wollen. Bereits zuvor war die »diplomatie musclée « ${ }^{284}$ der Bundesregierung seitens der französischen Presse mit Argusaugen verfolgt

279 Le général Binoche nous écrit, in: Le Nouvel Observateur, 13.10.1975, S. 5.

${ }^{280}$ Vgl. Un non-conformiste, in: Le Monde, 08.08.1975, S. 5.

281 Vgl. Un général au trou, in: Le Nouvel Observateur, 11.08.1975, S. 27; Le général François Binoche est mis d'office à la retraite, in: Le Monde, 08.08.1975, S. 5.

282 Siehe "Diese Deutschen sind gefährlich«. Der französische General François Binoche über die Bundesrepublik und Frankreich, in: Der Spiegel, 22.09.1975, S. 89-94, Zitat S. 90.

283 Siehe Klaus-Peter Schmid, Vor Deutschen auf der Hut. Propheten von gestern rühren an heimliche Ängste, in: Die Zeit, 14.11.1975, S. 7.

${ }^{284}$ Gérard SANDOZ, La diplomatie musclée de Helmut Schmidt, in: Le Nouvel Observateur, 28.07.1975, S. 30 . 
worden. Für "Le Nouvel Observateur « stand etwa fest, dass Westdeutschland unter der Kanzlerschaft Schmidts endgültig aufgehört hatte, der "politische Zwerg « von einst zu sein. Der Komplexe ihrer Vergangenheit vollständig entledigt, bediene sich die Bundesrepublik nunmehr ihrer ökonomischen Stärke, um Europa und die Welt zur Ordnung aufzurufen und zu solidem Wirtschaften anzuhalten ${ }^{285}$. Das Ungleichgewicht in den deutsch-französischen Finanz- und Wirtschaftsbeziehungen wachse indes unaufhaltsam weiter: "Dans le tandem franco-allemand, dont l'harmonie et l'efficacité sont tant vantés par l'Élysée, ce sera de plus en plus l'Allemagne qui détiendra les commandes «286. Frankreich sehe sich, wie in den bundesdeutschen Medien konstatiert wurde, im permanenten Wettlauf mit einem vor Gesundheit strotzenden ökonomischen »Riesen", gegen den es nichts zu bestellen habe $^{287}$. Ein westdeutscher Regierungschef, der vor dem Hintergrund dieses auf französischer Seite zunehmenden Gefühls der Unterlegenheit dazu neigte, dem Nachbarland Ratschläge zu erteilen und gelegentlich offene Kritik an ihm übte, konnte dort kaum auf Sympathie treffen.

Als Schmidt sich im beginnenden Bundestagswahlkampf 1976 seitens der christdemokratischen Opposition mit dem Vorwurf konfrontiert sah, die SPD fördere mit ihrer politischen Zielsetzung die Entstehung einer sozialistischkommunistischen Volksfront in Westeuropa ${ }^{288}$, holte er zu einem verbalen Gegenschlag aus. Dieser galt allem Anschein nach dem Gegner im eigenen Lande. Die französischen Nachbarn fühlten sich hiervon jedoch nicht minder getroffen. In einem Interview mit dem Bayerischen Rundfunk verkündete der Bundeskanzler, dass vor allem dort kommunistische Parteien von Gewicht existierten, »wo mit Gewalt und Kraft auf Jahrzehnte hinaus die alten Verhältnisse festgeschrieben worden sind: in Portugal, in Spanien, in Italien, in einem gewissen Maße in Frankreich, das durch den Gaullismus geprägt war « ${ }^{289}$. In

285 Siehe ibid.

286 Jacques MoRnAnd, L'échappée du mark, in: Le Nouvel Observateur, 16.02.1976, S. 35.

287 Siehe Klaus-Peter Schmid, Der Wettlauf mit dem »Riesen«, in: Die Zeit, 16.04.1976, S. $25 f$.

288 Vgl. zum Bundestagswahlkampf von 1976 Werner Kaltefleiter, Vorspiel zum Wechsel. Eine Analyse der Bundestagswahl 1976, Bonn 1977; Christiane Wild, Der Bundestagswahlkampf 1976, Mannheim 1980; Hans Kremendahl, Die Freiheit-Sozialismus-Diskussion im Bundestagswahlkampf 1976 und das Verhältnis von Konsens und Konflikt im Parteiensystem der Bundesrepublik Deutschland, in: Gerhard GöHLER (Hg.), Politische Theorie: Begründungszusammenhänge in der Politikwissenschaft, Stuttgart 1978, S. 109-135; Michael Koss, Scheitern als Chance. Helmut Kohl und die Bundestagswahl 1976, in: Daniela Forkmann, Saskia Richter (Hg.), Gescheiterte Kanzlerkandidaten. Von Kurt Schumacher bis Edmund Stoiber, Wiesbaden 2007, S. 174-201.

289 Zitiert nach Heinz-Jürgen Axt, Das »Europa der Bürger« - Ideologie und Wirklichkeit. Zum Tindemans-Bericht über die »Europäische Union« und zur gegenwärtigen Lage der EG, in: Blätter für deutsche und internationale Politik 21/8 (1976), S. 849-866, hier S. 865 . 
Paris wurde die Tatsache, dass Schmidt das gaullistische Frankreich in einem Atemzug mit den Diktaturen Portugals und Spaniens genannt hatte, mit einiger Entrüstung zur Kenntnis genommen ${ }^{290}$. Premierminister Jacques Chirac, selbst Gaullist, nahm die öffentliche Empörung als willkommene Gelegenheit, um mit einer markigen Gegenrede Front nicht nur gegen den deutschen Bundeskanzler, sondern auch gegen dessen Vertrauten Giscard d'Estaing zu machen:

Les déclarations [...] ont suscité chez les autorités françaises de l'étonnement - j'emploie ce mot pour des raisons diplomatiques. [...] Il ne faut pas oublier que c'est à l'initiative du général de Gaulle que furent engagées, en 1963, les conversations qui aboutirent à l'accord franco-allemand auquel l'Allemagne doit d'être sortie de l'isolement où elle était plongée. Cela montrait l'estime, l'amitié, la considération que le grand chancelier allemand de l'époque témoignait au chef de la France libre. Il n'appartient donc pas à M. Schmidt de faire des déclarations aussi irréfléchies ${ }^{291}$.

In der hierdurch um ein Vielfaches verstärkten Aufregung wurde Helmut Schmidt seinem in der französischen Presselandschaft inzwischen verbreiteten Ruf als »le Feldwebel « ${ }^{292}$ einmal mehr gerecht. Kraft seiner Stellung als Regierungschef der stärksten Industrienation Westeuropas, so eine von vielen französischen Kommentatoren vertretene Auffassung, lese der deutsche "Lehrmeister « Schmidt den disziplinlosen und ökonomisch zurückgefallenen Nachbarländern in arroganter Weise die Leviten. In »Le Nouvel Observateur « hieß es Anfang Mai 1976: "Beaucoup sont tentés d'opposer à cette Allemagne soucieuse d'autorité, et où règne l'ordre social et économique, une

290 Auch auf Regierungsebene lösten die Äußerungen Schmidts kurzzeitig Verstimmungen aus, die insbesondere in einer französischen Demarche beim Auswärtigen Amt Ende April 1976 zum Ausdruck kamen. In diesem Rahmen wies Botschafter Wormser die Kritik des Bundeskanzlers zurück und betonte, dass diese dem Geist, der die deutschfranzösischen Beziehungen ansonsten charakterisiere, in keiner Weise entspreche: "je me suis exprimé avec modération, mais avec netteté. J'ai dit: qu'à Paris on avait été étonné en prenant connaissance d'une critique peu compatible avecl'esprit qui caractérise les relations franco-allemandes [...] que l'énumération Salazar - Franco - de Gaulle était de nature de choquer profondément les Français; que l'expression Gewalt und Kraft, qu'elle qu'en soit la bonne traduction, pouvait être mal interprétée, que le Général était venu régulièrement au pouvoir, qu'il s'y était maintenu avec l'appui librement accordé des électeurs et qu'il s'était retiré lorsque cet appui lui avait manqué«, AN Paris, 5 AG 3, Bd. 935, Schreiben des französischen Botschafters in Bonn, Olivier Wormser, an das französische Außenministerium vom 21. April 1976; vgl. auch AMAE Paris-La Courneuve, Europe, RFA 1971-1976, Bd. 2999, Schreiben der französischen Botschaft Bonn an das französische Außenministerium vom 17. April 1976; Schreiben des französischen Außenministeriums an die französische Botschaft Bonn vom 20. April 1976.

291 Stellungnahme Jacques Chiracs, zitiert nach Maurice Delarue, Les déclarations »irréfléchies« de M. Schmidt sur le gaullisme »étonnent« M. Chirac, in: Le Monde, 07.05.1976, S. 1 und S. 6.

292 Jean Dutourd, Le Feldwebel Helmut, in: France-Soir, 12.05.1975, S. 3; vgl. hierzu Marion Gräfin Dönhoff u. a. (Hg.), Hart am Wind. Helmut Schmidts politische Laufbahn, Hamburg 1978, S. 180f. und 231f.; Eugen Kogon, Der »häßliche Deutsche«, in: Frankfurter Hefte 31/11 (1976), S. 11-14, hier S. 14. 
Europe sans discipline, menacée par le désordre, qu'incarneraient des fronts populaires ${ }^{293}$. In Frankreich fragten sich viele, so formulierte der Autor des Artikels, ob es für einen deutschen Regierungschef angemessen sei, sich in Europa als Hüter einer Ordnung zu präsentieren, welche auf der Modellhaftigkeit der Bundesrepublik beruhe. Der Bundeskanzler habe mit seinem Verhalten, wie "Le Monde« anklingen ließ, einen wesentlichen Teil dazu beigetragen, dass die deutsch-französischen Beziehungen eine merkliche Abkühlung erfahren hätten ${ }^{294}$. Auch für »France-Soir « war der Vorfall deutliches Anzeichen dafür, dass der Grad gegenseitiger Wertschätzung zwischen Bonn und Paris nicht mehr ausreiche, um Irritationen zu verhindern. Beide Seiten verstünden einander einfach nicht mehr: "Effectivement, Français et Allemands ne parlent plus le même langage « ${ }^{295}$.

Letztere Einschätzung wurde seitens der westdeutschen Presse weitgehend geteilt ${ }^{296}$. Das deutsch-französische Verhältnis werde gegenwärtig von Misstrauen und Unverständnis beherrscht, wie »Die Zeit« Mitte Mai 1976 schrieb. Die Ursachen für die verfahrene Situation sah das Blatt jedoch weniger in den Äußerungen des Bundeskanzlers, als vielmehr in einem nach wie vor nicht normalisierten Deutschlandbild in Frankreich, gepaart mit einem französischen "Minderwertigkeitskomplex" gegenüber der Bundesrepublik. Vor allem die Stabilität der deutschen Wirtschaft werde den Franzosen unheimlich. Durch die erdrückend empfundene Konkurrenz mit den Deutschen fühlten sie sich zunehmend bedroht und ängstigten sich vor einem Ausverkauf ihres Landes an den mächtigen Nachbarn, der das europäische Geschehen schon bald diktieren könnte. »Die französische Überempfindlichkeit verträgt vor allem keine Belehrung. Wenn Kritik von außen kommt, schließen sich sogar politische Gegner zur Abwehrfront zusammen. Gerade die Deutschen, so heißt es dann, haben es nicht nötig, uns Lektionen zu erteilen ${ }^{297}$. Das Echo auf die Äußerungen Helmut Schmidts sei daher nicht verwunderlich. Es zeige vielmehr erneut, wo die Grenzen der Freundschaft lägen.

In ähnlicher Argumentation gelangte auch die "Süddeutsche Zeitung« zu dem Schluss, dass es den Deutschen eben nicht gedankt werde, dass sie innerhalb Europas zum Modell geworden seien. »Für weniger erfolgreiche Völker,

293 Gérard SANDoz, Le gendarme de l'Europe, in: Le Nouvel Observateur, 03.05.1976, S. 50.

294 Siehe Maurice Delarue, Les déclarations »irréfléchies« de M. Schmidt sur le gaullisme »étonnent« M. Chirac, in: Le Monde, 07.05.1976, S. 1 und S. 6.

295 AMAE, Paris-La Courneuve, Europe, RFA 1971-1976, Bd. 2980, Benoît RaYski, Dérapage des relations franco-allemandes, in: France-Soir, 29.04.1976.

296 Vgl. zum Beispiel den Artikel Angst vor den häßlichen Deutschen, in: Der Spiegel, 26.04.1976, S. 25-27.

297 Klaus-Peter Schmid, Weh dem, der kritisiert. Warum die Franzosen so empfindlich auf Kanzlers Schelte reagieren, in: Die Zeit, 14.05.1976, S. 4; ähnlich argumentierend auch August von Kageneck, Den Franzosen steckt deutsche Kritik im Hals, in: Die Welt, 22.11.1976, S. 1 . 
zumal für vergleichbar große und hoch entwickelte wie die Briten, Franzosen und Italiener«, so die dortige Einschätzung, sei es schwer erträglich, ausgerechnet die Deutschen als Musterknaben neben sich zu haben, noch dazu, wenn sie arrogant wirkende Lehren erteilten ${ }^{298}$. Für die »Frankfurter Allgemeine Zeitung" schließlich offenbarte der Wirbel um das Interview des Bundeskanzlers, dass die Annahme, Giscard und Schmidt könnten im »kurzgeschlossenen Verfahren « deutsch-französische Missverständnisse von oben her aus der Welt schaffen, nur in begrenztem Maße zutreffe. Realpolitischer Pragmatismus allein genüge nicht für die Verständigung zwischen beiden Ländern; emotionale Brücken, wie sie durch private Bemühungen entstünden, würden ebenso gebraucht. Zwar sei die deutsch-französische Aussöhnung, wie der Artikel resümierte, ein säkularer Vorgang, der kaum binnen weniger Wochen umgekehrt werden könne, doch bleibe die Aufgabe an sich noch für lange Zeit bestehen ${ }^{299}$.

Auch aus Sicht der bundesdeutschen Regierungsstellen verdichteten sich in den seit Sommer 1975 zwischen Frankreich und Westdeutschland geführten Kontroversen um die polemischen Einlassungen General Binoches zur »deutschen Gefahr" und die Äußerungen Helmut Schmidts über das gaullistische Frankreich Tendenzen, die auf eine Abkühlung des deutschfranzösischen Verhältnisses hindeuteten. Zu Beginn seiner Amtszeit hätte sich Staatspräsident Giscard d'Estaing, wie im Auswärtigen Amt festgehalten wurde, noch über die Reserven in der französischen Öffentlichkeit hinwegsetzen können. In Anbetracht der immer kräftiger ins Kraut schießenden französischen Furchtgefühle vor der deutschen wirtschaftlichen Überlegenheit sei er jedoch mittlerweile dazu gezwungen, auf diese Rücksicht zu nehmen. Hierdurch orientierte sich die Politik des Nachbarlandes stärker dahin, den gewachsenen deutschen Einfluss auszubalancieren ${ }^{300}$. »Im bilateralen deutsch-französischen Verhältnis«, so das Urteil der Bonner Diplomaten im Mai 1976, "scheint die Tendenz zunehmender Qualität der Beziehungen, die sich seit dem Amtsantritt Giscard d'Estaings vor zwei Jahren gezeigt hatte, zum Stillstand gekommen zu sein « ${ }^{301}$. Als Tiefpunkt dieser Entwicklung galten die französischen Reaktionen auf die Äußerungen des Bundeskanzlers und die öffentliche Fehde zwischen Schmidt und Chi$\mathrm{rac}^{302}$. Nach Ansicht der deutschen Botschaft in Paris warf das Verhalten des französischen Premierministers ein Schlaglicht auf »die französischen Empfindlichkeiten gegenüber dem oft als übermächtig empfundenen Nachbarn

\footnotetext{
298 Siehe Hans Heigert, Der häßliche Deutsche, in: SZ, 29./30.05.1976, S. 4.

299 Siehe Robert HeLd, Deutsch-französische Mißverständnisse?, in: FAZ, 22.05.1976, S. 1.

300 Siehe hierzu PA-AA, Zwischenarchiv, Nr. 113544, Vermerk betreffend "Deutsch-französische Beziehungen in der Giscardschen Außenpolitik« vom 8. November 1976.

301 PA-AA, Zwischenarchiv, Nr. 113544, Vermerk für Bundesaußenminister Hans-Dietrich Genscher betreffend »Frankreich und die deutsch-französischen Beziehungen im Frühjahr 1976«vom 12. Mai 1976, S. 3.

302 Siehe ibid.
} 
Deutschland « ${ }^{303}$. Den Franzosen sei, wie der politische Halbjahresbericht der Vertretung vom Juli 1976 festhielt, die deutsche Bereitschaft, in Europa und der Welt eine der Wirtschaftskraft entsprechende politische Verantwortung zu tragen, zunehmend bewusst geworden ${ }^{304}$. Botschafter Sigismund von Braun schließlich hielt den Denkansatz für »erwägenswert«, dass deutsche Stärke, gleichgültig auf welchem Gebiet, für Frankreich problematisch sei: »Alles was nach deutschem Führungsanspruch aussieht, ist inakzeptabel und muß aus französischer Sicht zumindestens durch französische Vorrangstellung auf anderen Gebieten sichtbar ausgeglichen werden « ${ }^{305}$. Diese französische Haltung könne, so die Auffassung von Brauns, als nahezu feste Größe in die deutsch-französischen Beziehungen eingesetzt werden. Französische Reaktionen auf ein deutsches Vorbild, sei es im Wirtschaftlichen, Sozialen oder Politischen, würden umso heftiger ausfallen, je weniger man in Frankreich das deutsche Vorbild erreichen könne oder wolle. Die wieder anwachsende französische Sorge vor einer wirtschaftlichen Übermacht des deutschen Partners und der auch seitens der Pariser Regierung bekundete Wille, in Europa von niemandem dominiert zu werden, habe letztlich dazu geführt, so berichtete die deutsche Botschaft Anfang 1977, dass befreundete europäische Gesprächspartner in französischen Amtsstuben zu hören bekommen hätten, »die Flitterwochen französisch-deutschen Einvernehmens der Ära Giscard/ Schmidt seien vorbei $\aleph^{306}$.

Auch die französischen Regierungsstellen sahen in den Auseinandersetzungen der Jahre 1975 und 1976 untrügliche Zeichen einer fortbestehenden Krisenanfälligkeit des deutsch-französischen Verhältnisses. Die westdeutschen Reaktionen auf die Thesen General Binoches unterstrichen, wie im Quai d'Orsay geurteilt wurde, das Wort, welches Staatssekretär Paul Frank anlässlich der Friedenspreisverleihung an Alfred Grosser über die Beziehungen zwischen beiden Ländern gesprochen habe: "Nous n'en sommes qu'au début d'une entente [...] une infinité de choses nous séparent encore « ${ }^{307}$. Ebenso zeugten die Debatten um die Äußerungen Helmut Schmidts, so die Einschätzung des französischen Botschafters Olivier Wormser, von einer immer noch vorhandenen Instabilität deutsch-französischen Miteinanders:

303 PA-AA, Zwischenarchiv, Nr. 113544, Politischer Halbjahresbericht der deutschen Botschaft Paris vom 19. Juli 1976, S. 8.

304 Siehe ibid., S. 8f.

305 PA-AA, Zwischenarchiv, Nr. 113544, Schreiben des deutschen Botschafters in Paris, Sigismund von Braun, an das Auswärtige Amt vom 10. Mai 1976, S. 2.

306 PA-AA, Zwischenarchiv, Nr. 113544, Politischer Halbjahresbericht der deutschen Botschaft Paris vom 19. Januar 1977, S. 7.

307 AMAE Paris-La Courneuve, Europe, RFA 1971-1976, Bd. 2948, Vermerk betreffend »La RFA au début de 1976« vom 5. Februar 1976, S. 11; vgl. hierzu auch ibid., Bd. 2999, Schreiben der französischen Botschaft Bonn an das französische Außenministerium vom 17. Juli 1975. 
Les controverses franco-allemandes qui se sont élevées à la suite des déclarations du chancelier Schmidt montrent, me semble-t-il, combien sont encore fragiles les relations franco-allemandes. [...] Il suffit de pas grand-chose pour que se réveillent les vieux démons. [...] Il ne reste donc, en ce moment, pour étayer véritablement le rapprochement francoallemand que la raison. Nous sommes voisins. Et nous ne devons pas retomber dans la désastreuse ornière ${ }^{308}$.

Angefacht wurden die Konflikte nach Auffassung der offiziellen französischen Stellen in beiden Fällen durch eine hüben wie drüben tendenziöse und streckenweise feindselige Medienberichterstattung. Auf deutscher Seite regierten ein Gefühl des Hochmuts und ein »triomphalisme sans vergogne « 309 der Journalisten gegenüber Frankreich: »les moyens d'information allemands font volontiers apparaître la République fédérale comme une sorte de modèle pour l'Europe et s'érigent en donneurs de leçons « ${ }^{310}$. Die westdeutschen Zeitungen gefielen sich nach Erachten der Pariser Diplomaten vor allem darin, Frankreich angesichts des ökonomischen Erfolgs der Bundesrepublik einen Minderwertigkeitskomplex zuzuschreiben. Dieser sei zwar nicht vollständig von der Hand zu weisen, werde aber durch das Verhalten der Presse, welche die französischen Wirtschaftsschwierigkeiten mit Genugtuung und Schadenfreude ausschlachte, wesentlich verstärkt: "Sans doute faudra-t-il encore du temps pour que la France et l'Allemagne soient réconciliées dans leurs profondeurs comme la France et l'Angleterre ont pu l'être par la guerre de 1914-1918 «11, lautete angesichts dessen eine Einschätzung des Quai d'Orsay vom Juni 1976.

In den französischen Medien bestimmte demgegenüber, wie in Paris konstatiert wurde, häufig ein historisch bedingter antideutscher Reflex weite Teile der Berichterstattung, welcher durch die wachsende internationale Rolle sowie die Wirtschaftsstärke der Bundesrepublik ausgelöst werde. Westdeutschland habe, so notierte Gabriel Robin, außenpolitischer Berater Staatspräsident Giscards, auf politischer und wirtschaftlicher Ebene in Europa inzwischen den Platz eingenommen, der seinem spezifischen Gewicht entspreche. Habe sich die Bundesrepublik in der Vergangenheit für lange Zeit in diplomatischer Zurückhaltung geübt, zögere sie heute nicht mehr, mit lauter und fester Stimme und manches Mal mit brutaler Offenheit zu sprechen, wenn ihre Interessen im Spiel seien. Der hierdurch in Frankreich geweckten Befürchtungen vor deutschen Dominanzabsichten sei sich die westdeutsche

308 AMAE Paris-La Courneuve, Europe, RFA 1971-1976, Bd. 2999, Schreiben des französischen Botschafters in Bonn, Olivier Wormser, an das französische Außenministerium vom 31. Mai 1976, S. 1 und S. 3.

309 AMAE Nantes, Bonn Ambassade, Bd. 322, Vermerk betreffend »La République fédérale d'Allemagne et sa politique extérieure au milieu de 1976« vom 29. Juni 1976, S. 4.

310 AN Paris, 5 AG 3, Bd. 935, Vermerk des außenpolitischen Beraters des französischen Staatspräsidenten, Gabriel Robin, vom 2. Juli 1976, S. 7.

311 AMAE Nantes, Bonn Ambassade, Bd. 322, Vermerk betreffend »La République fédérale d'Allemagne et sa politique extérieure au milieu de 1976« vom 29. Juni 1976, S. 10. 
Regierung unter Bundeskanzler Schmidt jedoch wohl bewusst und wirke durch die beständige Beteuerung, dass sie solcherlei Intentionen zu keinem Zeitpunkt hege, darauf hin, die Unruhe im Nachbarland zu besänftigen ${ }^{312}$. Aus den jüngsten Verstimmungen ließen sich, wie Robin betonte, zwei Feststellungen ableiten: »la première est la révélation d'une sensibilité très vive des opinions publiques des deux pays, l'une par rapport à l'autre; la seconde est la volonté des deux gouvernements d'empêcher que ces réactions instinctives n'affectent sérieusement les relations des deux pays « ${ }^{313}$. Eine Konsolidierung der »zerbrechlichen « deutsch-französischen Beziehungen - dies das Fazit, das man im Quai d'Orsay zog - erfordere angesichts der hervorgetretenen Zerwürfnisse und des wenig partnerschaftlichen Konkurrenzdenkens allerdings einen langen $\mathrm{Atem}^{314}$. »Si l'on veut éviter que la compétition ne dégénère en rivalité, la seule issue est l'amitié des deux peuples et des deux États à l'image de celle qui unit leurs plus hauts dirigeants « ${ }^{315}$.

Die Auffassung, dass die freundschaftlichen Bande, die zwischen Bundeskanzler und Staatspräsident bestünden, auch auf die Bevölkerungen auszuweiten seien, wollte man eine gefährliche Zuspitzung der augenblicklichen negativen Tendenzen des bilateralen Verhältnisses verhindern, deckte sich weitgehend mit der auf deutscher Seite vertretenen Ansicht. In seinem Jahresbericht 1975 hatte etwa der Koordinator der Bundesregierung für die deutsch-französische Zusammenarbeit mit Blick auf die in Frankreich durch General Binoche geschürten Ressentiments sowie die "Sorgen der französischen Industrie vor dem Dominieren der deutschen « eindringlich darauf hingewiesen, dass die westdeutsche Kultur-, Öffentlichkeits- und Informationsarbeit im Nachbarland mit Geduld und Nachdruck weiter gefördert werden müsse. Nur auf diese Weise könnten die »strukturell und mentalitätsbedingten >Differenzen « z zwischen den Bevölkerungen abgebaut werden, die »heute noch Fortschritte in politischen und wirtschaftlichen Bereichen hemmen « ${ }^{316}$. Ein "geistiger Dialog « zwischen beiden Ländern, Kontakte zwischen Politikern, Wissenschaftlern, Publizisten, seien vonnöten, wie in einem Vermerk des Auswärtigen Amts vom April 1976 festgehalten wurde, um die Defizite des wechselseitigen Unverständnisses zu überwinden. Träger eines

312 Siehe AN Paris, 5 AG 3, Bd. 935, Vermerk des außenpolitischen Beraters des französischen Staatspräsidenten, Gabriel Robin, vom 9. Februar 1976, S. 3; vgl. hierzu auch AMAE Paris-La Courneuve, Europe, RFA 1971-1976, Bd. 3009, „Note de synthèse « bezüglich des deutsch-französischen Gipfeltreffens im Juli 1975, S. 9f.

313 AN Paris, 5 AG 3, Bd. 935, Vermerk des außenpolitischen Beraters des französischen Staatspräsidenten, Gabriel Robin, vom 2. Juli 1976, S. 7.

314 Siehe AMAE Nantes, Bonn Ambassade, Bd. 322, Vermerk betreffend »La République fédérale d'Allemagne et sa politique extérieure au milieu de 1976« vom 29. Juni 1976, S. 10.

315 AMAE Paris-La Courneuve, Europe, RFA 1971-1976, Bd. 2948, Vermerk betreffend »La RFA au début de 1976« vom 5. Februar 1976, S. 12.

316 BA, B 189, Bd. 18641, Aufzeichnung »Die deutsch-französische Zusammenarbeit im Jahre 1975 - Bewertung des Koordinators" vom 18. März 1976, Zitate S. 2 und S. 4. 
solchen Dialogs seien unter anderem Institutionen wie das DFI, die deutschfranzösischen Gesellschaften oder Begegnungszeitschriften wie »Dokumente $\aleph^{317}$. Sie trügen dazu bei, die Basis des deutsch-französischen Verhältnisses bei den »führenden politischen und gesellschaftlichen Kräften unserer Länder ${ }^{318}$ zu festigen. Daneben sei es Aufgabe der offiziellen Auswärtigen Kulturpolitik, »durch umfassende Information, Landeskunde, Sprachwerbung und gezielte Austauschprogramme « ${ }^{319}$ Interesse an Deutschland zu wecken und zu vertiefen, und zwar nicht nur, um die Gefahr eines oberflächlichen Nebeneinanders zu bannen, sondern auch, so betonte die deutsche Botschaft, um das auf politischem und wirtschaftlichem Gebiet Erreichte abzusichern ${ }^{320}$. »Die Kenntnis der Sprache und des Landes des Partners" müsse, wie Koordinator Carlo Schmid bekräftigte, als »eine unabdingbare, grundlegende Voraussetzung für das bessere Verständnis beider Völker und die deutsch-französische Zusammenarbeit insgesamt « ${ }^{321}$ betrachtet werden. Umso notwendiger sei daher die in Frankreich mit großer Intensität betriebene "sprach-pädagogische Verbindungsarbeit" der Goethe-Institute und der ins Nachbarland entsandten DAAD-Lektoren und Sprachassistenten. Darüber hinaus komme dem Deutschunterricht an französischen Schulen eine eminente Bedeutung für die langfristige Verankerung der Freundschaft auf Ebene der Bevölkerungen zu. In dieser Hinsicht könne es als Erfolg der Bemühungen der letzten Jahre gewertet werden, dass 1975 mehr als eine Million junger Franzosen die deutsche Sprache erlernt hätten. Ein intensives Werben für das Deutsche sei in Frankreich jedoch weiterhin erforderlich, um diese Tendenz zu bestärken. Desgleichen sollte, wie ein Botschaftsbericht empfahl, die westdeutsche Kulturarbeit etwa durch Fortbildungsprogramme für französische Deutschlehrer oder direktes Intervenieren bei den Pariser Stellen darauf hinwirken, dass die vielfach unbefriedigende Qualität des Deutschunterrichts verbessert werde ${ }^{322}$.

Die Situation des Sprachunterrichts im Nachbarland hatten zu gleicher Zeit auch die Verantwortlichen auf französischer Seite fest im Blick. Ihnen galt das Erlernen der Partnersprache, so wurde immer wieder bekräftigt, in ebensolchem Maße als Voraussetzung für die Verständigung in konflikt-

317 Siehe PA-AA, Zwischenarchiv, Nr. 113563, Vermerk betreffend »Deutsch-französische Konferenzen « vom 2. April 1976, S. 1f.

318 PA-AA, Zwischenarchiv, Nr. 113563, Schreiben des deutschen Botschafters in Paris, Sigismund von Braun, an Bundesaußenminister Genscher vom 25. Februar 1976, S. 2.

319 PA-AA, Zwischenarchiv, Nr. 117461, Themenliste für den Staatsbesuch des Bundespräsidenten in Frankreich vom 21.-25. April 1975, Anlage: Kulturbeziehungen, S. 1.

320 Siehe PA-AA, Zwischenarchiv, Nr. 107749, Kulturpolitischer Jahresbericht 1975 der deutschen Botschaft Paris vom 28. Januar 1976, S. 3 und 12.

${ }^{321}$ BA, B 189, Bd. 26334, Schreiben des Koordinators für die deutsch-französische Zusammenarbeit, Carlo Schmid, an die Bundesministerin für Jugend, Familie und Gesundheit, Katharina Focke, vom 25. April 1976, S. 10.

322 Vgl. PA-AA, Zwischenarchiv, Nr. 107749, Kulturpolitischer Jahresbericht 1975 der deutschen Botschaft Paris vom 28. Januar 1976, S. 12-17. 
reichen Phasen, als Voraussetzung für ein »resserrement des liens francoallemands $«^{323}$. Neben dem Angebot von Sprachkursen und Seminarveranstaltungen ${ }^{324}$ waren die offiziellen französischen Stellen daher bestrebt, bei Bundesregierung und Ländern eine Ausweitung des Französischunterrichts an westdeutschen Schulen zu erreichen ${ }^{325}$. Mit Erfolg: Veranlasst durch die wiederholten französischen Interventionen kamen Mitte 1975 auf Einladung des Bevollmächtigten für kulturelle deutsch-französische Angelegenheiten, Klaus Schütz, Vertreter der Kultusministerkonferenz, der Westdeutschen Rektorenkonferenz und der öffentlich-rechtlichen Rundfunk- und Fernsehanstalten in West-Berlin zusammen, um Maßnahmen zur Förderung des Französischen in der Bundesrepublik zu erörtern ${ }^{326}$. Ergebnis der Zusammenkunft war eine "9-Punkte-Empfehlung «. Diese sah unter anderem vor, Französisch an allen westdeutschen Gymnasien und Realschulen anzubieten, die Mindestanzahl von Schülern für die Eröffnung von Französisch-Klassen zu senken, Landeskunde stärker in das universitäre Französischstudium zu integrieren und Hörfunk und Fernsehen dazu anzuhalten, das Interesse der Deutschen am Erlernen der französischen Sprache intensiver zu fördern ${ }^{327}$. In einem Schreiben vom August 1975 bat Bundeskanzler Schmidt den Präsidenten der Kultusministerkonferenz, alles ihm Mögliche zu tun, damit die Empfehlungen umgesetzt werden könnten. Es bedürfe keiner Begründung, wie Schmidt formulierte, dass »die sprachliche Verständigung mit unserem Nachbarn eine wesentliche Voraussetzung für das Verständnis beider Staaten und ihrer Menschen [...] ist. Dies zu fördern, ist mir als Bundeskanzler, aber auch persönlich ein Anliegen « ${ }^{328}$.

323 AN Fontainebleau, ministère de l'Éducation nationale, Bd. 900672/36, Vermerk betreffend »Situation du français en République fédérale d'Allemagne« vom 1. Juni 1976, S. 5.

${ }^{324}$ Siehe AMAE Nantes, Bonn Service culturel, Bd. 28, Rapport d'activités des services culturels, année 1975/1976; ibid., Bd. 29, Rapport d'activités des services culturels, année 1976/1977, 21. März 1977.

325 Siehe AMAE Nantes, Bonn Service culturel, Bd. 49, Vermerk betreffend »Position de la langue française dans l'enseignement officiel en République fédérale d'Allemagne « vom 7. Juli 1975; Schreiben der französischen Botschaft Bonn an Außenminister de Guiringaud vom 13. Oktober 1976; AMAE Nantes, Bonn Ambassade, Bd. 368, Vermerk betreffend »Situation de la langue française dans l'enseignement allemand « vom 15. Januar 1975; ibid., Bd. 340, »Fiche opérationnelle« der Sous-direction d'Europe centrale vom 23. November 1976.

326 Vgl. BA, B 304, Bd. 2562, Ergebnisprotokoll der Besprechung am 19. Juni 1975 in Berlin auf Einladung des Bevollmächtigten bezüglich des Erlernens der französischen Sprache.

327 Siehe BA, B 304, Bd. 6174, Empfehlung zur Förderung der französischen Sprache im Rahmen des Vertrages über die deutsch-französische Zusammenarbeit, Anlage II zur Niederschrift über die 172. Plenarsitzung der KMK am 11./12. September 1975 in Berlin; vgl. hierzu BA, B 145, Bd. 11423, Schreiben des Koordinators für die deutsch-französische Zusammenarbeit, Carlo Schmid, an Bundeskanzler Schmidt vom 26. Juni 1975.

328 BA, B 304, Bd. 6174, Schreiben Bundeskanzler Schmidts an den Präsidenten der Kultusministerkonferenz, Joist Grolle, vom 25. August 1975. 
Sprache und Landeskunde, kultureller Austausch und persönliche Begegnungen mit dem Nachbarland galten den Bonner wie den Pariser Verantwortlichen einmal mehr als geeignete Instrumente, um die Verbindungen zwischen Franzosen und Deutschen zu stärken und um ein positives Gegengewicht zu den im deutsch-französischen Verhältnis immer wieder auftretenden Krisenerscheinungen zu schaffen. Selbige Ziele motivierten auch die privaten Verständigungsorganisationen, welche ihre Hauptaufgabe weiterhin darin erblickten, die Politik der Regierungen von unten her zu stützen. Denn, wie Joseph Rovan in seiner Funktion als Vize-Präsident des BILD anlässlich des dreißigjährigen Bestehens der Vereinigung im August 1976 betonte, hätten die jüngsten Auseinandersetzungen verdeutlicht, dass die zwischengesellschaftliche Annäherungsarbeit des BILD und der GÜZ notwendiger sei denn je: »Malgré tous les efforts [...] la grande majorité des Français et des Allemands ne se connaissent pas. Dans la mesure où cette connaissance réciproque existe, elle n'est que superficielle. Les incompréhensions, les suspicions, les désenchantements réciproques continuent à planer « ${ }^{329}$.

In Frankreich gehe, so Rovan, die Angst vor einer deutschen ökonomischen und politischen Übermacht um, in der Bundesrepublik betrachte man das Nachbarland vielfach im Innern als unorganisiert, nach außen als großtuerisch. Den aus diesen Vorurteilen resultierenden Spannungen müsse das BILD weiterhin energisch entgegentreten: »La nécessité de surmonter les tensions, les irritations, les conflits d'intérêt et les problèmes de langue tels qu'ils se multiplient dans les contacts intensifs quotidiens est plus urgent que jamais « ${ }^{330}$. Um dies zu erreichen, führte die Vereinigung in den Jahren 1975 und 1976 junge Deutsche und Franzosen im Rahmen von Austauschprogrammen zusammen, veranstaltete deutsch-französische Dolmetscherseminare, organisierte Studienreisen für deutsche Journalisten und Verwaltungsbeamte nach Frankreich und intervenierte vor allem mittels der »Documents « immer wieder in den öffentlichen Debatten ${ }^{331}$. In einem Mitte 1976 erschienenen Beitrag machte etwa der Journalist Alfred Frisch, Bezug nehmend auf die Debatte um die Äußerungen Helmut Schmidts vom April, darauf aufmerksam, wie essentiell es für die deutsch-französischen Beziehungen sei, die Ursachen derartiger Auseinandersetzungen zu ergründen und den mangelhaften Informationsfluss zwischen beiden Ländern zu verbessern. Um gemeinsam voran zu schreiten, müsse man sich, wie Frisch schrieb, schließlich verstehen. Um sich zu verstehen, sei jedoch die Kenntnis des anderen eine unerlässliche Voraus-

329 BILD-Archiv, Rede des Vize-Präsidenten des Bureau international de liaison et de documentation, Joseph Rovan, anlässlich der Feier zum dreißigjährigen Bestehen des BILD und der GÜZ am 20./21. August 1976 in Stuttgart, S. 1; vgl. hierzu auch »Deutschfranzösische Dienste für Europa«. Dreißig Jahre »Gesellschaft für übernationale Zusammenarbeit«, in: FAZ, 23.08.1976, S. 3.

330 Ibid., S. 6.

331 Siehe BILD-Archiv, Note sur la situation, 1975, S. 1; Aufzeichnung "Activités 1976«, S. 1f.; Tätigkeitsbericht 1974-1976 der GÜZ und des BILD. 
setzung. »Les opinions fausses, les schémas préétablis, les préjugés tenaces et l'insuffisance des informations doivent donc être pris au sérieux, avec la ferme intention d'empêcher que ces fissures dans la construction franco-allemande s'élargissent «332.

Der ADFG wollte derweil vor allem durch seinen im September 1976 in Braunschweig abgehaltenen Jahreskongress die Bevölkerungen beiderseits des Rheins zur Verständigung aufrufen. Angesichts der Belastungen, denen das deutsch-französische Verhältnis ausgesetzt sei, bestehe, wie der Präsident der Organisation in seiner Eröffnungsansprache formulierte, die vorrangige Aufgabe darin, das Verständnis zwischen Deutschen und Franzosen zu vertiefen und eine dauerhafte Freundschaft zu gewährleisten: »Wir werden unbeirrbar unsere Ziele einer für beide Nationen erspriesslichen Zusammenarbeit verfolgen. Ich meine, gerade wir sind [...] dazu berufen, auch wenn der Himmel einmal verhangen ist, die uns so hochwertige Partnerschaft so überzeugend wie möglich darzustellen « ${ }^{333}$. In dieser Hinsicht erhofften sich die Organisatoren von der Braunschweiger Tagung eine Signalwirkung, welche durch die Mithilfe verantwortlicher Politiker entscheidend verstärkt werden sollte. In einer Grußbotschaft teilte Bundespräsident Scheel den Teilnehmern des Kongresses mit: »Ihrer aktiven Mitarbeit verdanken wir, daß das Werk der deutsch-französischen Verständigung in unserem Volk Wurzeln geschlagen hat ${ }^{334}$. Die politische Zusammenarbeit der Regierungen hätte, wie Scheel urteilte, nicht ihre Wirkung entfalten können ohne das Bemühen der Gesellschaften, ein "Band der Freundschaft « zwischen den Menschen in Frankreich und Deutschland zu knüpfen. Ebenso dankte Bundesaußenminister Genscher in seiner Rede den Teilnehmern des Kongresses für ihr stetes Engagement. Die Politik könne schließlich für die deutsch-französischen Beziehungen lediglich die Konstruktionen liefern, das Fundament jedoch, auf dem das Verhältnis der beiden Völker beruhe, seien die Menschen. Indem sie diese zusammenführten, handelten die deutsch-französischen Gesellschaften, wie Genscher ausführte, zum Wohle beider Länder ${ }^{335}$. Eine in dieser Form zum Ausdruck kommende Unterstützung der privaten Verständigungsarbeit seitens der Regierenden zielte, wie im Auswärtigen Amt vermerkt wurde, zuvorderst darauf ab, »der wertvollen und aus politischen Gründen wichtigen Arbeit der

332 Alfred Frisch, Les relations franco-allemandes, une amitié solide et fragile à la fois, in: Documents 31/4-5 (1976), S. 5-17, hier S. 16.

333 VDFG-Archiv, Ansprache von ADFG-Präsident Helmut Paetzold anlässlich der Eröffnung des Jahreskongresses der deutsch-französischen Gesellschaften am 2. September 1976, in: Mitteilungsblatt für die Deutsch-Französischen Gesellschaften 41 (1977), S. 17-19, Zitat S. 19.

334 PA-AA, Zwischenarchiv, Nr. 113563, Grußbotschaft Bundespräsident Scheels für die 21. Jahrestagung des ADFG in Braunschweig vom 13. August 1976.

335 VDFG-Archiv, Rede Bundesaußenminister Hans-Dietrich Genschers in Braunschweig am 5. September 1976, in: Mitteilungsblatt für die Deutsch-Französischen Gesellschaften 41 (1977), S. 121. 
deutsch-französischen Gesellschaften im ganzen Lande Impulse zu geben « ${ }^{336}$. Beflügelt durch die lobenden offiziellen Worte würden die zahlreichen Vereinigungen ihre Tätigkeit intensivieren und dazu beitragen, durch kulturellen Austausch und menschliche Begegnungen die politisch gewünschte Freundschaft auf gesellschaftlicher Ebene zu verankern.

Aus ähnlichen Überlegungen heraus unterstützten die staatlichen Stellen auch die Aktivitäten der IBU im Bereich der Städtepartnerschaften, galten doch auch die jumelages, so eine Einschätzung des Bundesinnenministeriums vom August 1975, als »bedeutende Grundlage für die deutsch-französische Zusammenarbeit auf Regierungsebene $«^{337}$. Den Mitte der 1970er Jahre zwischen beiden Ländern aufgetretenen Spannungen wollte die IBU, wie ihr Präsident formulierte, ein »dauerhaftes Netz menschlicher Kontakte «338 entgegensetzen. Vorurteile bestünden trotz des bereits zurückgelegten Weges der Versöhnung weiterhin fort, insbesondere wirtschaftliche Konflikte könnten jederzeit aufbrechen ${ }^{339}$. Vor diesem Hintergrund müsse die Freundschaft zwischen Deutschen und Franzosen, so forderte es eine Resolution der Mitgliederversammlung der IBU vom Oktober 1975, täglich neu gefördert und gefestigt werden. ${ }^{340}$ Hierzu sollten die seitens der Vereinigung veranstalteten Jugendaustauschprogramme und landeskundlichen Seminare ebenso dienen wie die jährlichen Bürgermeister-Kongresse und vor allem die Vermittlung von kommunalen Partnerschaften ${ }^{341}$. Letztere hätten, wie die »Frankfurter Allgemeine Zeitung " in Reaktion auf ein durch das DFI und die IBU im Herbst 1975 organisiertes Kolloquium bekräftigte, auch dreißig Jahre nach Kriegsende nicht an Bedeutung eingebüßt, im Gegenteil: Die kommunale Ebene mit ihrer Nähe zum Bürger sei auch gegenwärtig noch besonders geeignet, nationale Grenzen aufzulockern und zur Völkerverständigung beizutragen. Vorurteile ließen sich schließlich kaum durch die oberflächlichen Kontakte des internationalen Tourismus aus der Welt schaffen ${ }^{342}$. Zu einem

336 PA-AA, Zwischenarchiv, Nr. 113563, Vermerk bezüglich des Arbeitskreises DeutschFranzösischer Gesellschaften vom 24. März 1976, S. 1f.

337 StASt, Bestand 1020, Bd. 71, Schreiben des Bundesministeriums des Innern an das Bundespräsidialamt vom 1. August 1975, S. 2.

338 Ansprache des Präsidenten der IBU, Urs Widmer, im Rahmen des Internationalen Bürgermeister-Kongresses im Oktober 1975 in West-Berlin, in: Dreißig Jahre deutschfranzösische Verständigung, S. 167.

339 Siehe StASt, Bestand 1020, Bd. 35, Bericht über das Kolloquium der IBU und des DFI zum Thema »Möglichkeiten und Grenzen deutsch-französischer Städtepartnerschaften « am 19./20. September 1975 in Ludwigsburg, S. 2.

340 Siehe Dreißig Jahre deutsch-französische Verständigung, S. 172.

341 Vgl. zu den Aktivitäten der IBU exemplarisch StASt, Bestand 1020, Bd. 321, Protokoll der Sitzung des Verwaltungsausschusses der IBU am 29. März 1976 in Zürich; ibid., Bd. 433, Protokoll der Mitgliederversammlung der deutschen Sektion am 9. November 1976 in Mâcon.

342 Siehe Nikolaus BenCKiser, Die glückliche Ehe der Mundelsheimer, in: FAZ, 25.09.1975, S. 7; vgl. hierzu auch DFI-Archiv, Ordner Kolloquium Städtepartnerschaften 1975, Pro- 
ähnlichen Schluss kam auch der deutsche Botschafter in Paris, Sigismund von Braun, dessen Ansicht zufolge »zahlreiche dieser Partnerschaftsunternehmen zu den besten und erfolgreichsten Zeugnissen der deutsch-französischen Freundschaft « ${ }^{343}$ gehörten. Sie gäben nicht nur Anlass zu gegenseitigen Besuchen der Stadtverwaltungen, sondern führten auch zu einem regen und freundschaftlichen Austausch zwischen Vereinen, Schulen, Berufsgruppen und Familien der Partnerstädte ${ }^{344}$. Von einem solch engen Geflecht, innerhalb dessen die IBU die Rolle eines deutsch-französischen Maklers einnahm, konnten die Beziehungen zwischen beiden Ländern doch nur profitieren.

Unterstützt wurden die Bemühungen der Verständigungsorganisationen weiterhin nicht nur von Seiten der amtlichen Politik, sondern auch durch die deutsch-französischen Mittler, welche, wie Joseph Rovan beim BILD, zum Teil selbst als Funktionsträger in privaten Vereinigungen wirkten. Wie könne es möglich sein, so die Frage, die Rovan seit 1976 zunehmend umtrieb, dass man in beiden Ländern oft und leichtfertig das "große Interesse der deutschfranzösischen Übereinstimmung durch kleine alltägliche Dinge $\aleph^{345}$ aufs Spiel setze, um Vorteile und Genugtuung zu erlangen, die am nächsten Tag vergessen seien? "Gewiß sind sie vergessen von den Interessierten, aber nicht von der Masse der Leser, Zuhörer und Zuschauer, bei denen man wieder einmal die Erinnerungen an alte Mißverständnisse, alte Ressentiments und an alte Greuel wachruft « ${ }^{346}$. Schwierigkeiten entstünden im deutsch-französischen Verhältnis immer wieder aufs Neue. Gleichzeitig seien aber, wie Rovan konstatierte, die "aus der jüngsten Vergangenheit entstandenen Impulse zur Verständigung und zum Neubeginn $\aleph^{347}$ aufgrund des zeitlichen Abstands zum Weltkrieg und aufgrund des Generationenwandels um vieles schwächer geworden. Geistige Vermittlungsarbeit zwischen Deutschen und Franzosen war daher seiner Ansicht nach geradezu unabdingbar. Seine vornehmliche Aufgabe sah Rovan darin, den Franzosen zu verdeutlichen, dass der in den Zeitungen heraufbeschworene Verdacht, die Bundesrepublik Schmidts rüste sich, Europa unter deutsche Vorherrschaft zu zwingen und eine von seinen Partnern unabhängige und an deutsche Interessen gebundene Weltpolitik ins Werk zu setzen, in keiner Weise den Realitäten entspreche: »Schmidt ne cesse de rappeler à l'opinion allemande que la République fédérale n'est pas de taille à jouer un rôle indépendant dans la politique mondiale « ${ }^{348}$. Mit Bestimmtheit

gramm und Themenplanung für das Kolloquium »Möglichkeiten und Grenzen deutschfranzösischer Städtepartnerschaften « im September 1975 in Ludwigsburg.

343 PA-AA, Auslandsvertretungen, Botschaft Paris, Bd. 13533, Schreiben des deutschen Botschafters in Paris, Sigismund von Braun, an das Auswärtige Amt vom 6. Mai 1975, S. 1.

${ }^{344}$ Siehe ibid.

${ }^{345}$ Rovan, Hauptziel - dauerhafte Verständigung, S. 14.

346 Ibid.

347 Rovan, Deutsch-französische Zusammenarbeit, S. 275.

348 Ders., Histoire de la social-démocratie allemande, S. 462f. 
weise der westdeutsche Regierungschef die Rolle der »Weltmacht wider Willen $\aleph^{349}$ für die Bundesrepublik zurück. Illusionslos und pragmatisch beurteile er vielmehr die internationale Situation seines Landes, welche gleichermaßen durch ökonomische Stärke und politische Unsicherheit gekennzeichnet sei. Man mache sich in Frankreich, so Rovan in der Zeitschrift »Études«, noch immer ein falsches Bild des deutschen Bundeskanzlers, der vielfach als autoritär, taktlos und herrschsüchtig gesehen werde. "Il est temps d'y faire connaittre un Schmidt subtil, modéré, interrogatif et désireux de rendre plus solide la solidarité franco-allemande $\ll^{350}$.

Für Alfred Grosser zeigten die Entwicklungen der Jahre 1975 und 1976 zweierlei: Einerseits könne festgestellt werden, dass die offiziellen Beziehungen zwischen Frankreich und Westdeutschland weitgehend "entkrampft" seien, auf französischer Seite Interesse für den deutschen Nachbarn in den unterschiedlichsten Bereichen bestehe und zunehmende Interdependenzen die Nachbarländer immer enger miteinander verknüpften. Andererseits weise eine Reihe von Anzeichen darauf hin, dass zwischen den Bevölkerungen eine Phase neuen Misstrauens begonnen habe: »tout un ensemble d'indices montrent que les soupçons et les procès d'intention sont de retour. Alors que la volonté de connaître semblait avoir remplacé le goût pour le cliché, [...] on ressent aujourd'hui comme une sorte de renouveau de l' antigermanisme « ${ }^{351}$. Diese Tendenz erkläre sich zum einen aus einer diffusen Feindseligkeit, welche die Angst vor der deutschen Wirtschaftskraft in Frankreich auslöse, zum anderen durch die Furcht vor einem künftigen Europa, in dem Frankreich in die politische Abhängigkeit von »Allemagne éternelle gerate $^{352}$. Bevor die Franzosen das Nachbarland jedoch vorschnell verdächtigten und verurteilten, sollten sie zunächst versuchen, es in seinen wesentlichen Zügen kennenzulernen. Dies würde ihnen, wie Grosser in »Le Monde« ausführte, vor Augen führen, dass das ökonomische Übergewicht der Bundesrepublik gar nicht derart erdrückend sei, wie in Frankreich weithin angenommen. Vielmehr seien beide Länder gegenwärtig mit denselben sozialen und wirtschaftlichen Problemen konfrontiert. Die politisch Verantwortlichen in Westdeutschland

349 Siehe zu diesem Schlagwort das Titelthema "Deutschland. Weltmacht wider Willen", in: Der Spiegel, 06.01.1975, S. 22-34, hier Abdruck eines Interviews mit Bundeskanzler Schmidt, auf das Rovan Bezug nimmt; vgl. hierzu des Weiteren Alfred Grosser, Les politiques extérieures européennes dans la crise, Paris 1976, S. 136; Christian HACKE, Weltmacht wider Willen. Die Außenpolitik der Bundesrepublik Deutschland, Stuttgart 1988.

${ }^{350}$ Joseph Rovan, Le chancelier Helmut Schmidt, in: Études. Revue de culture contemporaine 350/5 (1979), S. 599-606, hier S. 606, deutsche Fassung "Le chancelier " Helmut Schmidt, in: Frankfurter Hefte 35/5 (1980), S. 21-26.

351 Alfred Grosser, Préface, in: Henri Ménudier, L’Allemagne selon Willy Brandt. Entretiens et enquêtes 1969-1976, Paris 1976, S. 7-12, hier S. 7f.

352 Siehe ibid., S. 8f.; vgl. hierzu auch Alfred Grosser, Was ist deutsche Außenpolitik?, Kon$\operatorname{stanz} 1975$, S. $26 f$. 
visierten zudem mitnichten eine europäische Hegemonialstellung an ${ }^{353}$. Es bestehe, so Grosser in einem Vortrag in Straßburg im Jahr 1977, eine Vielzahl deutsch-französischer Konvergenzen. Allerdings bedürfe es weiterhin beträchlicher pädagogischer Anstrengungen, um diese den Bevölkerungen zu vermitteln ${ }^{354}$.

Nach den Debatten um die Agrarpreisanhebung von 1974, dies mochten die öffentlichen Auseinandersetzungen der beiden darauffolgenden Jahre den verschiedenen Protagonisten der Annäherung deutlich gemacht haben, war das französische Misstrauen gegenüber einer vermeintlich hegemonialen Träumen nachhängenden Bundesrepublik ebenso geblieben wie die deutsche Überheblichkeit gegenüber einem scheinbar schlecht organisierten und nationalistischen Frankreich. Ja, es ließ sich angesichts der Heftigkeit der Dispute um die Thesen Binoches und die Äußerungen Helmut Schmidts vom Frühjahr 1976 sogar der Eindruck gewinnen, die wechselseitig vorhandene Verständigungsbereitschaft sei weiter gesunken. Diesen ernüchternden Befund hatten allem Anschein nach weder die Verständigungspolitik der Regierungen noch die konstanten Bemühungen der privaten Kräfte und Mittlerfiguren zum Positiven wandeln können. Ob Ausbau des Französischunterrichts in der Bundesrepublik, Intensivierung von Informations- und Aufklärungsarbeit, Verstärkung persönlicher Kontakte im Rahmen von Städtepartnerschaften oder Mobilisierung der Bevölkerungen zugunsten der Partnerschaft mit dem Nachbarland - an wohlmeinenden und bisweilen kämpferisch vorgetragenen Absichtserklärungen aus den Reihen der Verständigungsakteure, gegen die deutsch-französischen Spannungen vorzugehen, fehlte es nicht, auch nicht an konkreten Vorschlägen, die Willensbekundungen zu realisieren.

Der tatsächlichen Umsetzung der Verständigungsinitiativen waren indes enge Grenzen gesetzt, nicht zuletzt monetäre. Die mit dem Ölpreisschock von 1973 einsetzende Wirtschaftskrise hatte für die Kulturhaushalte des Auswärtigen Amts und des Quai d'Orsay tiefe Einschnitte bedeutet, was sich nicht nur in einer Einschränkung des kulturpolitischen Handelns der Regierungen selbst, sondern auch in einer Reduzierung der Förderung privaten Engagements auswirkte. Ökonomische Zwänge diktierten nun allenthalben eine Kultur des finanziellen Maßhaltens. Die IBU hatte etwa seit $1974 \mathrm{zu}$ nehmende Austritte ihrer Mitglieder und damit das schrittweise Wegbrechen ihrer Existenzgrundlage zu beklagen ${ }^{355}$, der ADFG fürchtete Anfang 1976, seine Aktivitäten aufgrund fehlender Finanzmittel vollständig einstellen zu müssen ${ }^{356}$, über dem BILD schwebte bereits seit Jahresbeginn 1975 das

353 Siehe Ders., La comparaison allemande, in: Le Monde, 07.04.1976, S. 1 und S. 6.

354 Ders., Convergences et divergences franco-allemandes, in: Jürgen OlbERT (Hg.), Le colloque de Strasbourg 1977. Die erste Begegnung deutscher Französischlehrer und französischer Deutschlehrer, Frankfurt a.M. u. a. 1979, S. 26-36.

355 Vgl. beispielhaft StASt, Bestand 1020, Bd. 321, Protokoll der Sitzung des Verwaltungsausschusses der IBU in Zürich am 29. März 1976, S. 1.

356 Vgl. PA-AA, Zwischenarchiv, Nr. 113563, Schreiben des deutschen Botschafters in Paris, 
Damoklesschwert des Konkursverfahrens ${ }^{357}$. In allen drei Fällen konnte das Schlimmste zwar zunächst verhindert werden, doch veranschaulichen diese Beispiele, wie sehr sich die Grundkoordinaten des organisierten Verständigungsengagements im Vergleich zu den 1950er und 1960er Jahren inzwischen verschoben hatten: Der finanzielle Spielraum war zunehmend schmaler geworden, die Austausch- und Kulturarbeit bescheidender. Angesichts dessen konnte eine Verständigungsarbeit, die Wirkungen auf weite Kreise der Bevölkerungen entfalten und damit Konflikte verhindern sollte, ihren Ansprüchen kaum mehr gerecht werden.

\subsubsection{Wird Europa deutsch? Diskussionen um die erste Direktwahl zum Europäischen Parlament}

Einen neuerlichen Anlass zu kontroversen Diskussionen über die Stellung der Bundesrepublik in Westeuropa und vermutete deutsche Hegemonialabsichten bildete die erste Direktwahl zum Europäischen Parlament im Jahr 1979. Bereits seit Herbst 1978 war im Zuge des beginnenden Wahlkampfes in der französischen Presse eine intensive Debatte um die Kompetenzen der künftigen Volksvertretung Europas geführt worden, welche insbesondere durch die Einlassungen der Gaullisten auf der Rechten und der Kommunisten auf der Linken eine polemische Färbung erhielt. Eine Ausweitung der Vollmachten des Europa-Parlaments, so die weitgehend übereinstimmende Meinung der beiden konträren politischen Lager, bedeute für Frankreich vor allem eine Einschränkung seiner staatlichen Souveränität und einen schrittweisen Verlust seiner nationalen Unabhängigkeit. Dies führe schließlich zu dem unvermeidlichen Fall unter die Vorherrschaft Westdeutschlands, das vor allen anderen von einem Machtzuwachs des europäischen Hohen Hauses profitiere und seine bereits vorhandene Dominanz gegenüber seinen Partnern weiter ausbauen würde ${ }^{358}$.

Sigismund von Braun, an den Koordinator für die deutsch-französische Zusammenarbeit, Carlo Schmid, vom 25. Februar 1976.

357 Vgl. BILD-Archiv, Protokoll der Präsidiumssitzung des BILD und der GÜZ am 8. MärZ 1975, S. 7f.

358 Vgl. zu den deutsch-französischen Diskussionen im Vorfeld der Europa-Wahlen Henri MÉNudier, Deutschfeindlichkeit im französischen Wahlkampf zum Europäischen Parlament, in: Ders., Das Deutschlandbild der Franzosen in den 70er Jahren. Gesammelte Aufsätze 1973-1980, Bonn 1981, S. 218-234; Ders., Die Deutschlandbilder der Franzosen, in: Dieter Tiemann (Hg.), Die deutsche Frage im 19. und 20. Jahrhundert als west- und osteuropäisches Problem. Fachliche und didaktische Aspekte, Wiesbaden 1994, S. 123-163, hier S. 142-145; Henri Ménudier, Die Deutschlandbilder der Franzosen 1974-1985, in: Hans Süssmuth (Hg.), Deutschlandbilder in Dänemark und England, in Frankreich und den Niederlanden, Baden-Baden 1996, S. 303-336, hier S. 319-321; Gerhard Kiersch, Die Außenpolitik Frankreichs, in: Wichard Woyke (Hg.), Netzwerk Weltpolitik. Großmächte, Mittelmächte und Regionen und ihre Außenpo- 
Als Bundeskanzler Helmut Schmidt vor diesem Hintergrund Mitte November $1978 \mathrm{im}$ Gespräch mit westdeutschen Journalisten erwähnte, ein direkt gewähltes Parlament werde sich seiner Ansicht nach nicht mit den bisherigen Rechten zufrieden geben, erntete er scharfe Reaktionen in der französischen Presse ${ }^{359}$. Der Verdacht, dass mit den Direktwahlen eine Kompetenzerweiterung des Europa-Parlaments einhergehe, welche der Bundesrepublik zugute komme, schien sich zu bestätigen. Schmidt habe bewiesen, wie die gaullistische Zeitung »La Lettre de la nation « verkündete, dass Bonn nun doch nach europäischer Hegemonie strebe ${ }^{360}$. Durch die Verbindung zwischen dem wachsenden politischen Gewicht Westdeutschlands auf der einen und seiner Dominanz auf ökonomischem Gebiet auf der anderen Seite, welche mittels der Einrichtung des Europäischen Währungssystems zusätzlich gestärkt werde, sah »Le Monde diplomatique« Europa bereits zum »deutschen Modell« verurteilt. Frankreich, so die pessimistische Vision, könne dagegen in der künftigen Finanz- und Wirtschaftspolitik des Kontinents neben dem mächtigen Nachbarn kaum mehr eine einflussreiche Rolle spielen und würde schließlich in den deutschen Wirtschaftsraum eingegliedert ${ }^{361}$. Die Furcht davor, dass das schwache Frankreich auf lange Sicht zu einem »Vasallen« des politisch und wirtschaftlich übermächtigen Deutschland degradiert werden könnte, wurde in der französischen Presse nun merklich lauter vorgetragen ${ }^{362}$. Wer hätte denn $\mathrm{zu}$ Beginn des westeuropäischen Einigungsprozesses auch ahnen können, so die mit einem Anklang von Resignation und Verbitterung oftmals formulierte Frage, dass die so sorgsam in supranationale Strukturen eingebettete Bundesrepublik eines Tages wieder zu einer solchen Machtfülle gelangen würde, dass die Gefahr deutscher Vorherrschaft zu neuem Leben erwachte? In dieser Hinsicht ist bezeichnend, was in »Le Monde« dazu formuliert wurde:

litik nach dem Zweiten Weltkrieg, Opladen 1989, S. 193-215, hier S. 204f.; Gerhard KIERSCH, Nationalismus, nationale Ideen und Interessen als Bestimmungsfaktoren der französischen Europapolitik, in: Politische Grundströmungen im europäischen Integrationsprozeß. Jahreskolloquium 1981, hg. v. Arbeitskreis Europäische Integration, Baden-Baden 1982, S. 153-176, hier S. 172f.; Renata Fritsch-Bournazel, Deutsche und Franzosen. Schicksalsgemeinschaft in Europa, in: Deutschland. Porträt einer Nation, Bd. 10: Deutschland, Europa und die Welt, Gütersloh 1986, S. 144-155, hier S. 151; Roland HöHNE, Europawahlkampf in Frankreich, in: Die Neue Gesellschaft 26/4 (1979), S. 294-298; Henrik Uterwedde, Europa-Wahl und nationale Politik. Die Wahlen zum Europäischen Parlament im Juni 1979, Bad Honnef 1979; Meimeth, Frankreichs Entspannungspolitik der 70er Jahre, S. 76f.

359 Vgl. Markus Stanat, Die französische Nationalversammlung und die Europäische Union. Zwischen parlamentarischer Tradition und europäischer Integration, Wiesbaden 2006, S. 148.

360 Siehe Saison des Nebels, in: Der Spiegel, 27.11.1978, S. 164.

361 Siehe Daniel Biron, Alexandre Faire, Le mark souverain, in: Le Monde diplomatique, November 1978, S. 1 und S. 16.

362 Vgl. André Boyer, La France ne rattrapera pas la RFA, in: Le Monde, 23.11.1978, S. 2; Benoît RAYsKI, Faut-il avoir peur de l'Allemagne?, in: France-Soir, 16.02.1979, S. 1f. 
Pour un Robert Schuman ou pour un Jean Monnet, par exemple, il ne faisait pas de doute que l'intégration européenne constituait le meilleur rempart possible contre un retour de flamme de l'esprit de domination germanique. Ce qu'ils n'avaient pas prévu, c'est que le moment viendrait où l'on redouterait de voir l'Allemagne fédérale, >contenuer dans l'organisation européenne, acquérir une telle puissance qu'elle risquerait de la dominer ${ }^{363}$.

Zwar versuchte Staatspräsident Giscard d'Estaing im Rahmen einer Pressekonferenz Ende November 1978 die Situation zu beruhigen, indem er klarstellte, dass weder er selbst noch seine Regierung noch die Franzosen in ihrer Gesamtheit den deutschen Partnern misstrauten oder Ängste vor westdeutscher Dominanz hegten, doch der Schaden war bereits angerichtet ${ }^{364}$. Die künftigen Vollmachten des Europäischen Parlaments und das drohende wirtschaftlich-monetäre Übergewicht der Bundesrepublik in der geplanten Währungsunion sorge in Frankreich für innenpolitischen Zündstoff, der sich auch auf das deutsch-französische Verhältnis auswirken könne, urteilte etwa die »Frankfurter Allgemeine Zeitung « ${ }^{365}$. "Die Abneigung gegen die Deutschen «, so die Auffassung des Autors, »scheint mit der Härte ihrer Mark, mit dem Gewicht ihrer Wirtschaft in der Welt zuzunehmen « ${ }^{366}$. Ähnlich auch die Einschätzung, welche »Der Spiegel« den deutschen Lesern darbrachte: Die anti-europäischen Argumente des französischen Wahlkampfes seien vorwiegend von der Angst vor der Übermacht der Deutschen getragen. Die in der Bundesrepublik bei höherem Bruttosozialprodukt geringere Arbeitslosigkeit und Inflation, aber auch das von Bonn projektierte europäische Währungssystem gebe den Franzosen ein Gefühl der Unterlegenheit, gar der Abhängigkeit gegenüber dem Nachbarn. In Frankreich gehe die Angst um, das Vaterland werde »einem germanischen Europa ausgeliefert ${ }^{367}$, wie das Nachrichtenmagazin den früheren gaullistischen Premierminister Michel Debré zitierte.

Im fortschreitenden französischen Wahlkampf der ersten Jahreshälfte 1979 war es neben den Zeitungen, die dem Gaullismus nahestanden, vor allem das Presseorgan der Kommunistischen Partei, »L'Humanité«, das gezielt versuchte, antideutsche Dispositionen in der französischen Bevölkerung zu mobilisieren, um Attacken gegen Staatspräsident und Regierung zu führen ${ }^{368}$. Frankreichs nationale Eigenständigkeit wolle das Blatt wahren und wende

363 André Fontaine, Que faire de l'Allemagne?, in: Le Monde, 22.11.1978, S. 7.

364 Vgl. Pressekonferenz des französischen Staatspräsidenten Valéry Giscard d'Estaing am 21. November 1978, in: Jürgen Schwarz (Hg.), Der Aufbau Europas. Pläne und Dokumente 1945-1980, Bonn 1980, S. 601-606, bes. S. 603.

365 Siehe Giscard gegen Mutmaßungen über deutsche Dominanz-Absichten, in: FAZ, 23.11.1978, S. 1.

366 Karl Jetter, Die Franzosen fürchten die Herrschaft der Mark. Kann sich Paris im neuen Europäischen Währungssystem behaupten?, in: FAZ, 24.11.1978, S. 6.

367 Saison des Nebels, in: Der Spiegel, 27.11.1978, S. 164.

368 Vgl. hierzu Henri MÉnUdier, L’antigermanisme et la campagne française pour l'élection du Parlement européen, in: Études internationales 11/1 (1980), S. 97-131. 
sich daher gegen ein deutsches Europa, gegen das Europa Helmut Schmidts, gegen die Abdankung Frankreichs vor einem übermächtigen Nachbarn: »Même si le monde n'est plus celui de 1930 et si l'Allemagne est effectivement bien différente de cette époque, n'est-ce pas dans la tradition de Munich et de Vichy que s'inscrit la politique giscardienne de collaboration avec les Konzern d'outre-Rhin, les plus puissants d'Europe occidentale? «369

Jenseits derartig offen formulierter Polemiken waren allerdings auch gemäBigte Zeitungen wie "Le Monde « nicht immer davon frei, das ewige Leitmotiv deutscher Stärke in einer Weise zu bemühen, welche Westdeutschland als Gefahr für Frankreich erscheinen ließ. So veröffentlichte das Blatt unter dem Titel »Vingt ans de réussite allemande « ${ }^{370}$ Anfang 1979 eine Artikelserie, die zu dem Ergebnis kam, Frankreich werde die deutsche Wirtschaftsstärke auch in fernerer Zukunft und mit größten Anstrengungen nicht erreichen. Das »deutsche Modell« sei dem französischen eben weit überlegen. Anderslautende Hoffnungen qualifizierten die Autoren als bloße Illusion ${ }^{371}$. Darüber hinaus bot die Zeitung dem von Jean-Paul Sartre, dem Physiker Jean-Pierre Vigier, dem ehemaligen Brigadegeneral Jacques Pâris de la Bollardière und weiteren Ikonen der politischen Linken gegründeten Comité d'action contre l'hégémonie germano-américaine en Europe ${ }^{372}$ eine Meinungsplattform, welche diesem dazu diente, in eindeutiger Zielrichtung vor einem "pangermanischen « Ausgreifen der Bundesrepublik nach Europa zu warnen: »Tous les pays sont en déficit croissant [...] vis-à-vis de la RFA. [...] Dirigée par une social-démocratie qui a repris à son compte les rêves d'hégémonie de la bourgeoisie pangermaniste, la RFA dominera, en fait, la vie économique et politique de l'Europe ${ }^{373}$.

Die anhaltenden medialen Attacken gegen die Bundesrepublik und die Tatsache, dass Staatspräsident Giscard d'Estaing sich im Februar 1979 erneut genötigt gesehen hatte, selbst in die Debatte einzugreifen und die Parolen seiner politischen Gegner aufs Schärfste zu verurteilen ${ }^{374}$, stimmte die Kommentatoren auf Seiten der westdeutschen Presse zunehmend nachdenklich. Zwar

369 Yves Moreau, Giscard plaide pour l'Europe d'Helmut Schmidt. Et n'a pas un seul mot pour l'indépendance nationale, in: L'Humanité, 16.02.1979, zitiert nach MéNUdiER, L'antigermanisme, S. 102.

370 Vgl. Vingt ans de réussite allemande. Une enquête du Monde, Paris 1979.

371 Siehe Gilbert Mathieu, Vingt ans de réussite allemande I. - Un écart qui va croissant entre la RFA et la France, in: Le Monde, 13.03.1979, S. 1 und S. 40; eine Ausnahme stellte in dieser Hinsicht allerdings der Artikel Alfred Grossers vom 17. März 1979 dar.

372 Vgl. hierzu Bernard BruneteAu, La mémoire de l'anti-européisme, des années 1950 à 2005, in: Les Cahiers Irice 2/4 (2009), S. 147-156; Michael KreILE, Die Bundesrepublik Deutschland - eine »Économie dominante« in Westeuropa?, in: Udo Bermbach (Hg.), Politische Wissenschaft und politische Praxis, Opladen 1978, S. 236-256.

373 Sortir de l'Europe pour sortir de la crise, in: Le Monde, 20./21.05.1979, S. 6; vgl. hierzu auch Claude Bourdet, Comme en 1940, in: Le Monde, 12./13.06.1977, S. 5.

374 Siehe Pressekonferenz des französischen Staatspräsidenten Valéry Giscard d'Estaing am 15. Februar 1979 (Auszüge zu europa- und außenpolitischen Fragen), in: Europa-Archiv 
lasse vorerst nichts darauf schließen, dass sich unter den Franzosen tatsächlich eine neue Welle deutschfeindlicher Gefühle ausbreite, wie die »Süddeutsche Zeitung « schrieb, zumal der wahre Adressat eines Großteils der polemischen Äußerungen der französische Staatspräsident und nicht die Bundesrepublik sei, die hier lediglich als Mittel zum Zweck diene. Dennoch stimme es bedenklich, dass Wahlen zum Europäischen Parlament und die sich verschärfende Arbeitslosigkeit in der Industriearbeiterschaft ausreichten, um Kommunisten und Gaullisten von der deutschen Gefahr reden zu lassen. Gefährlich würde es aber erst, wenn alle Franzosen solche Reden tatsächlich ernst nähmen ${ }^{375}$.

Neben den westdeutschen Medien hatte auch die deutsche Botschaft in Paris die Diskussionen im Vorfeld der europäischen Wahlen aufmerksam beobachtet und mit Beunruhigung festgestellt, dass die von Gaullisten und Kommunisten initiierte Kampagne gegen ein deutsch dominiertes Europa in der französischen Presse "alte unterschwellige Sorgen vor Deutschlands künftiger Entwicklung « ${ }^{376}$ zum Vorschein gebracht habe. Die beständigen Behauptungen, »Deutschland wolle auf wirtschaftlichem Wege die Herrschaft über Europa und damit über Frankreich ausüben und strebe dessen politische Unterwerfung an ${ }^{377}$, seien zwar, so die Ansicht der Diplomaten, nicht repräsentativ für die Meinung einer Mehrheit der französischen Bevölkerung. Dennoch müsse man sie ernst nehmen, da sie im Falle größerer Krisen politisch ins Gewicht fallen und negative Auswirkungen auf das deutschfranzösische Verhältnis entfalten könnten. Erfreulich war aus westdeutscher Perspektive, dass Staatspräsident und Regierung in Frankreich der »Furcht vor einem deutschen Hegemoniestreben im künftigen Europa «378 entschieden entgegentraten und von den Medien wie den betreffenden politischen Parteien mit Nachdruck mehr Objektivität in der Berichterstattung über Deutschland einforderten ${ }^{379}$. Dass jedoch »die Repräsentanten von einem guten Drittel der französischen Wählerschaft zu Argumenten Zuflucht nehmen, die die deutsch-französische Kooperation nicht fördern können « ${ }^{380}$, wirkte auf die Beobachter in der deutschen Vertretung trotz aller positiven Signale von offizieller Stelle beunruhigend.

34/7 (1979), Dokumente, S. 177-186, hier S. 179; vgl. hierzu auch August von KagenECK, Giscard warnt vor antideutschen Parolen, in: Die Welt, 17.02.1979, S. 7.

375 Siehe Giscard warnt die Franzosen, in: SZ, 17./18.02.1979, S. 4.

376 PA-AA, Zwischenarchiv, Nr. 113562, Schreiben des deutschen Botschafters in Paris, Axel Herbst, an das Auswärtige Amt vom 4. Dezember 1978, S. 1.

377 Siehe PA-AA, Auslandsvertretungen, Botschaft Paris, Bd. 13523, Schreiben der deutschen Botschaft Paris an das Auswärtige Amt vom 14. Februar 1979, S. 2.

378 BA, B 189, Bd. 26334, 21. Bericht der Interministeriellen Kommission der Bundesregierung für die deutsch-französische Zusammenarbeit, April 1979, S. 38f.

379 Siehe PA-AA, Auslandsvertretungen, Botschaft Paris, Bd. 13523, Schreiben des deutschen Botschafters in Paris, Axel Herbst, an das Auswärtige Amt vom 16. Februar 1979 und Schreiben der deutschen Botschaft Paris an das Auswärtige Amt vom 23. Mai 1979.

${ }^{380}$ PA-AA, Auslandsvertretungen, Botschaft Paris, Bd. 13523, Schreiben der deutschen Botschaft Paris an das Auswärtige Amt vom 1. Juni 1979, S. 4. 
Ähnlich sorgenvoll klangen auch die Einschätzungen auf französischer Seite. In der Presse seien, so wurde im Quai d'Orsay bereits Ende November 1978 konstatiert, in jüngster Zeit erneut Befürchtungen laut geworden, Frankreich könne auf lange Sicht in wirtschaftliche und politische Abhängigkeit des mächtigen Nachbarn im Osten geraten: »Pour l'ensemble de la presse en effet, le déséquilibre qui se creuse entre les deux pays [...] risque fort de déboucher sur une vassalisation de la France. Le spectre de l'Europe allemande hante de nouveau une partie des consciences $\aleph^{381}$. Die Ängste vor der deutschen Stärke erklärten nach Ansicht der Pariser Diplomaten auch die Heftigkeit, mit der die Kontroversen um die Europa-Wahl und die Kompetenzen des künftigen Europäischen Parlaments geführt wurden. Die Intensität sei durch die Wahlkampagnen der Kommunistischen Partei und der Gaullisten, welche die Furcht vor einem übermächtigen Deutschland bewusst geschürt hätten, anschließend weiter gesteigert worden, so dass der Wahlkampf streckenweise einen antideutschen Tonfall erhalten habe. "Les élections européennes ont favorisé en France«, so urteilte Botschafter Brunet Mitte 1979, »sinon la résurgence d'un sentiment anti-allemand, tout au moins la réapparition d'une crainte devant les menaces d'une hégémonie allemande sur l'Europe « ${ }^{382}$.

Neben den polemischen Einlassungen französischer Politiker und der französischen Presse war jedoch nach Auffassung der Bonner Botschaft auch die Berichterstattung der westdeutschen Medien mitverantwortlich dafür, dass die deutsch-französischen Auseinandersetzungen eine unerfreuliche Dynamik entwickeln konnten. Insbesondere die vorurteilsbehaftete und teilweise äußerst herablassende Kommentierung der ökonomischen Situation Frankreichs habe bei den Franzosen Verärgerung hervorgerufen und den Konflikt genährt. In den deutschen Zeitungen seien die alten Klischees über Frankreich und die Franzosen wieder aufgetaucht: » Manque d'organisation<, >dynamisme commercial insuffisant $\iota$, les Français sont `futiles`, pas assez >accrocheurs`, ils `manquent de réalisme` et, en définitive, sont peu doués pour l'industrie et le commerce ${ }^{383}$.

Misstrauen, Ängsten und verzerrten Wahrnehmungen, welche die Debatten um die Wahlen zum Europäischen Parlament in den deutschfranzösischen Beziehungen freigesetzt hatten, versuchten die politisch Verantwortlichen beider Länder durch eine verstärkte Öffentlichkeitsarbeit zu begegnen. Diese zielte vor allem darauf ab, mittels massenmedialer Kommunikationsforen einen direkteren Kontakt zwischen Regierenden und

381 AMAE Paris-La Courneuve, Europe, RFA 1976-1980, Bd. 3999, Vermerk betreffend »La presse française et la RFA« vom 25. November 1978, S. 2.

382 AMAE Nantes, Bonn Ambassade, Bd. 318, Schreiben des französischen Botschafters in Bonn, Jean-Pierre Brunet, an das französische Außenministerium vom 19. Juli 1979, S. 4.

383 AMAE Nantes, Bonn Ambassade, Bd. 324, Schreiben der französischen Botschaft Bonn an das französische Außenministerium vom 24. September 1979, S. 3 f. 
Bevölkerungen herzustellen. Im Februar 1979 etwa kam Bundeskanzler Schmidt eigens nach Paris, um sich im Rahmen einer Livesendung den Fragen französischer Bürger zu stellen, was auch dazu dienen sollte, das Bild vom deutschen »Feldwebel « gerade zu rücken und den Argwohn gegenüber einer hegemonialen Gelüsten anheim gefallenen Bundesrepublik zu entkräften ${ }^{384}$. Zumindest aus Sicht der französischen Botschaft ging von dem Gespräch eine positive Signalwirkung für das Miteinander von Deutschen und Franzosen aus: »Que le chancelier n'ait pas hésité [...] à se rendre personellement à Paris pour dialoguer avec des téléspectateurs français dans le cadre d'une émission de la deuxième chaîne allemande, prouve [...] que Paris et Bonn deviennent peu à peu plus que des voisins ou des partenaires « ${ }^{385}$.

Anfang Oktober 1979 tat Staatspräsident Giscard d'Estaing es dem westdeutschen Regierungschef nach, indem er in der ebenfalls live im deutschen Fernsehen ausgestrahlten Sendung »Bürger fragen, Politiker antworten « während einer guten Stunde zu den Fragen acht junger Deutscher Stellung nahm. Schenkt man dem überaus wohlwollenden westdeutschen Presseecho Glauben, so halfen vor allem die Offenheit und die Souveränität, mit welcher das französische Staatsoberhaupt das Gespräch bestritt, die Sympathie des deutschen Publikums zu gewinnen. Die Diskussion habe ein für allemal den Beweis erbracht, dass die Rede von der deutsch-französischen "Erbfeindschaft" ins Reich der Legenden gehöre und vielmehr von einer »Erbfreundschaft « zu sprechen sei. Sendungen dieser Art, so das Fazit der Kommentatoren, trügen erheblich zu einer Annäherung beider Länder bei ${ }^{386}$. Derselben Ansicht war auch Bundeskanzler Schmidt, der Giscard in einem persönlichen Schreiben zwei Tage nach der Sendung mitteilte:

Ihre Fernsehunterhaltung mit überwiegend jungen deutschen Bürgern hat bei uns eine gute Resonanz gefunden. Ich selber habe mir die Sendung in meinem Arbeitszimmer angesehen und fand im Gespräch mit etlichen Bonner Journalisten meinen Eindruck bestätigt, dass Ihre offenen, gradlinigen Antworten ein eindringlicher Beweis für den authentisch freundschaftlichen Umgang zwischen Deutschen und Franzosen waren. [...] Mir scheint, dass die

${ }^{384}$ Vgl. Le chancelier interrogé par des citoyens français, in: Pariser Kurier, 15.-28.02.1979, S. 7-10; Henri Ménudier, L’Allemagne à la télévision française en 1978 et 1979, in: Revue administrative de l'Est de la France 18 (1980), S. 49-74; Gut Deutsch, in: Der Spiegel, 17.09.1979, S. 16; Josef Müller-Marein, Schade!, in: Die Zeit, 09.03.1979, S. 84; Von Europa hören und sehen, in: EG-Magazin 1 (1979), S. 31.

385 AMAE Nantes, Bonn Ambassade, Bd. 318, Schreiben des französischen Botschafters in Bonn, Jean-Pierre Brunet, an das französische Außenministerium vom 10. Februar 1979, S. 5.

386 Siehe AMAE Nantes, Bonn Ambassade, Bd. 324, Schreiben der französischen Botschaft Bonn an das französische Außenministerium betreffend "Réactions de la presse allemande à l'émission du ZDF avec le président de la République« vom 4. Oktober 1979; vgl. hierzu auch Eberhard NiтschкE, Napoleon in der Bonner Beethovenhalle. Bürger nicken - ein Politiker glänzt, in: Die Welt, 04.10.1979, S. 3. 
politisch-psychologische Wirkung der ganzen Sendung auf unsere deutschen Bürger sehr günstig geworden ist ${ }^{387}$.

Neben solch punktuellen Initiativen zur deutsch-französischen Annäherung, die vor allem das öffentliche Gewicht von Bundeskanzler und Staatspräsident nutzten, um positive Effekte auf die Wahrnehmung des jeweiligen Nachbarn $\mathrm{zu}$ erzielen, waren beide Regierungen auch weiterhin bestrebt, langfristig angelegte Verständigungsmaßnahmen und kontinuierlichen Austausch zu fördern. Die DAAD-Zweigstelle in Paris etwa führte am Ende der 1970er Jahre regelmäßig Informationsreisen für westdeutsche Hochschulrektoren nach Frankreich und für französische Germanisten in die Bundesrepublik durch. Im Rahmen derer besuchten die Professoren Bildungs- und Wissenschaftseinrichtungen, trafen mit Politikern zusammen und nahmen an sprach- und landeskundlichen Seminaren teil. 1979 standen dort insbesondere die Europa-Wahl und die hierdurch in beiden Ländern ausgelösten öffentlichen Diskussionen auf dem Programm. Das Prinzip, welches derartigen Veranstaltungen zugrunde lag, war es, ausgewählte Multiplikatoren auf beiden Seiten des Rheins für konfliktbehaftete Thematiken der deutschfranzösischen Beziehungen zu sensibilisieren und ihnen Anstöße zu geben, in ihrem jeweiligen Umfeld auf die Etablierung eines ausgewogenen Deutschland- beziehungsweise Frankreichbildes hinzuwirken ${ }^{388}$.

Auf die Beeinflussung weiter Bevölkerungskreise zielten auch die zahlreichen Austauschaktivitäten des DFJW ab. Das Jugendwerk, »institution vivace qui continue à jouer un rôle irremplaçable ${ }^{389}$, wie im französischen Außenministerium Ende November 1978 geurteilt wurde, leiste mit seiner Arbeit einen entscheidenden Beitrag dazu, die Jugendlichen beider Länder in dauerhaften freundschaftlichen Kontakt zu bringen, der auch durch die immer wieder auftauchenden medialen Polemiken nicht erschüttert werden könne. Immerhin rund 200000 jungen Deutschen und Franzosen ermöglichten es die verschiedenen Austauschangebote Jahr für Jahr, das Nachbarland nicht nur aus der eingeschränkten Perspektive des Touristen zu erleben. Und auch die

387 AN Paris, 5 AG 3, Bd. 938, Schreiben Bundeskanzler Schmidts an Staatspräsident Giscard d'Estaing vom 4. Oktober 1979.

388 Vgl. hierzu DAAD-Archiv, B 212, Bd. 91758/1, Programm für die Informationsreise französischer Institutsdirektoren der Germanistik in die Bundesrepublik Deutschland vom 27. Mai bis 3. Juni 1979; Vermerk der Leiterin der DAAD-Zweigstelle Paris, Alexandra Hauck, vom 29. März 1979 sowie Schreiben Haucks an das Büro des Bevollmächtigten für kulturelle Angelegenheiten im Rahmen des Vertrages über die deutschfranzösische Zusammenarbeit vom 10. April 1979; DAAD-Archiv, B 212, Bd. 91517/2, Programm des Hochschul-Informationsseminars in Frankreich vom 4.-17. März 1979; Vermerk des Leiters der DAAD-Zweigstelle Paris, Theo Buck, betreffend »HochschulInformationsseminar in Frankreich" vom 10. September 1979; Jahresbericht 1979, hg. v. DAAD, Bonn 1980, S. 162-175.

389 AMAE Paris-La Courneuve, Europe, RFA 1976-1980, Bd. 4007, Vermerk bezüglich der deutsch-französischen Zusammenarbeit vom 16. November 1978, S. 7. 
am Ende der 1970er Jahre durch das DFJW verstärkt geförderten Schulpartnerschaften brachten eine wachsende Anzahl an Jugendlichen beider Länder zusammen. 1978 konnten auf diese Weise 30000 Schüler das Leben in französischen oder deutschen Familien kennenlernen ${ }^{390}$. Ähnlich der Einschätzung auf französischer Seite war man auch im zuständigen Bonner Ministerium der Ansicht, dass derartige Begegnungen in erheblichem Umfang zum Abbau von Vorurteilen und zur Toleranz gegenüber den Nachbarn beitrügen ${ }^{391}$.

Regierungsamtliche Öffentlichkeitsarbeit und die staatlich protegierten Austausch- und Begegnungsprogramme wurden schließlich ergänzt durch die Verständigungsaktivitäten der verschiedenen privaten Organisationen, die sich angesichts der im Kontext der Europa-Wahlen aufgetretenen Spannungen angehalten sahen, die deutsch-französische Freundschaft vor zerstörerischen Tendenzen $\mathrm{zu}$ bewahren. In einem Rundschreiben vom Dezember 1978 rief etwa der ADFG seine Mitglieder dazu auf, die Bevölkerungen in beiden Ländern objektiv über Bedeutung und Folgen der ersten Direktwahl zum Europäischen Parlament zu unterrichten ${ }^{392}$. Den westdeutschen Vereinigungen müsse hierbei vor allem die Aufgabe zukommen, in Frankreich um Vertrauen für die Bundesrepublik zu werben. Für die französischen Gesellschaften sei es oberstes Ziel, der »bewußt hochgespielten These von der >drohenden Gefahr einer deutschen Vorherrschaft in Europa«" energisch entgegenzutreten ${ }^{393}$.

Über Möglichkeiten, diese Ziele zu realisieren, debattierte der Vorstand des ADFG anlässlich einer Sitzung in Dijon im Frühjahr 1979. Was könne konkret getan werden, so lautete hier die zentrale Frage, wenn die französische Presse weiterhin tendenziöse Artikel über das Nachbarland veröffentliche? Gemäß den Vorschlägen aus den Reihen der Verantwortlichen des Arbeitskreises sollten die Gesellschaften in Frankreich hierauf rasch durch Leserbriefe und Gegendarstellungen in den Lokalzeitungen reagieren, Journalisten dafür gewinnen, positiv über Deutschland zu berichten und Vortragsveranstaltungen mit ausgewiesenen Experten organisieren, welche den Franzosen unvoreingenommen die Orientierungen der bundesdeutschen Politik erläutern könnten. Vor allem der nächste Jahreskongress der deutsch-französischen Gesellschaften müsse dazu genutzt werden, die in dieser Hinsicht bislang

390 Vgl. AMAE Paris-La Courneuve, Europe, RFA 1976-1980, Bd. 3999, Vermerk bezüglich der deutsch-französischen Zusammenarbeit vom 25. Februar 1980, S. $12 \mathrm{f}$.

391 Vgl. BA, B 189, Bd. 26336, Vermerk betreffend das VN-Jugendprogramm vom 14. April 1980.

392 Siehe VDFG-Archiv, Ordner Vorstandssitzungen 1974-1976, Rundschreiben der Präsidenten des ADFG, Pierre Martin und Alfred Borgmann, an die Mitgliedsgesellschaften des ADFG vom 21. Dezember 1978, S. 1f.

393 VDFG-Archiv, Ordner Arbeitskreis Korrespondenz 1977-1979, Schreiben des Vorstandsmitglieds Siegfried Troch an den Präsidenten des ADFG, Alfred Borgmann, vom 6. Februar 1979, Zitat S. 1. 
wenig aktiven Vereinigungen zu verstärktem Handeln anzuregen ${ }^{394}$. Denn für den ADFG, so die Einschätzung der beiden Präsidenten, sei es nur dann möglich, seinen Zielsetzungen gerecht zu werden, wenn er einerseits seine Mitglieder zu Verständigungsinitiativen motiviere und andererseits die Öffentlichkeit in beiden Ländern von der unbedingten Notwendigkeit enger deutsch-französischer Beziehungen überzeuge ${ }^{395}$.

In dieselbe Richtung wies das Engagement der IBU, die bereits seit dem Direktwahlakt des Rates der Europäischen Gemeinschaften im Jahr $1976^{396}$ bei ihren Mitgliedern - Städten, Kommunen und Bürgermeistern - dafür warb, die Öffentlichkeit beider Länder über die tatsächlichen Folgen der EuropaWahl aufzuklären. Insbesondere denjenigen, die in Frankreich alte Ängste vor deutscher Dominanz heraufbeschworen, wollte die IBU durch gezielte Informationsarbeit Paroli bieten ${ }^{397}$. Daneben versuchte die Vereinigung zum einen durch die Veranstaltung von Studienseminaren für junge Deutsche und Franzosen, in welchen auch die politischen Auswirkungen des europäischen Wahlganges für Frankreich und die Bundesrepublik zur Sprache kamen, einen Beitrag für ein besseres Verständnis des Nachbarn zu leisten ${ }^{398}$. Zum anderen organisierte sie Informationsaufenthalte für westdeutsche und französische Bürgermeister im jeweils anderen Land, die den Repräsentanten der Städte eine vorurteilsfreie Perspektive vermitteln sollten, welche sie, so zumindest die Hoffnung, anschließend auch an die Bürger ihrer Heimatgemeinde weitergeben würden ${ }^{399}$.

Die Verantwortlichen des BILD schließlich brachten die im deutschfranzösischen Verhältnis aufgekommenen Missstimmungen anlässlich einer Mitgliederversammlung im Januar 1979 zur Sprache. Das Protokoll der Zusammenkunft hielt fest: »L'assemblée s'inquiète en particulier de la campagne

${ }^{394}$ VDFG-Archiv, Ordner Vorstandssitzungen 1979-1982, Kurzprotokoll der Gesamtvorstandssitzung des ADFG am 1. April 1979 in Dijon, S. 4f.

395 VDFG-Archiv, Ordner Vorstandssitzungen 1979-1982, Rundschreiben der Präsidenten des ADFG an die Mitgliedsgesellschaften vom 17. Dezember 1979.

396 Vgl. Klaus PoIER, Die Wahl des Europäischen Parlaments - auf dem Weg zu einem einheitlichen Wahlverfahren, in: Erhard Busek, Waldemar Hummer (Hg.), Etappen auf dem Weg zu einer europäischen Verfassung, Wien u. a. 2004, S. 341-358, hier S. 347f.; Christine Holeschovsky, Art. "Direktwahl zum Europäischen Parlament", in: Wolfgang W. Mickel, Jan M. Bergmann (Hg.), Handlexikon der Europäischen Union, Baden-Baden ${ }^{3} 2005$, S. $156 f$.

397 Vgl. StASt, Bestand 1020, Bd. 321, Resolution der Internationalen Bürgermeister-Union vom 29. März 1976; ibid., Bd. 332, Protokoll über die Sitzung des Verwaltungsausschusses der IBU in Basel am 16. Oktober 1978.

398 Vgl. DFI-Archiv, Ordner IBU bis 1993, Programm des deutsch-französischen Jugendleiter-Seminars vom 16.-22. September 1979 in Saint-Jean-de-Monts; StASt, Bestand 1020, Bd. 332, Protokolle über die Sitzungen des Verwaltungsausschusses der IBU am 23. April 1979 in Berlin und am 5. November 1979 in Nantes.

399 Vgl. StASt, Bestand 1020, Bd. 67, Programm der Studienreise französischer Bürgermeister nach Südwestdeutschland vom 27. Mai bis 2. Juni 1979. 
anti-allemande qui va se développer autour des élections européennes « ${ }^{400}$. Die sich hier manifestierende Beunruhigung führte zur Einberufung einer réunion spéciale, die dem Ziel gewidmet war, sich über konkrete Gegenmaßnahmen zu verständigen, welche das BILD nunmehr einleiten könnte ${ }^{401}$. Neben einer ausführlichen Thematisierung der europäischen Wahl in den beiden Publikationsorganen der Vereinigung ${ }^{402}$ gehörte hierzu vor allem die Veranstaltung von Informationsreisen für Jugendliche zur Beobachtung des westdeutschen und französischen Wahlkampfes und die Mitwirkung an der Vorbereitung des Fernsehgesprächs zwischen Bundeskanzler Schmidt und französischen Bürgern im Februar 1979403. Die verschiedenen Aktivitäten verfolgten, wie in einer Aufzeichnung der Organisation zu lesen ist, hauptsächlich den Zweck, durch die Vermittlung von Kenntnissen über das jeweilige Nachbarland und die dortigen aktuellen Entwicklungen »Verständnis und Sympathie zu wecken « und zugleich deutlich zu machen, »daß die Angelegenheiten in der europäischen Dimension « Deutsche und Franzosen gleichermaßen beträfen. Sie dürften nicht dahin führen, neue Gräben der Feindseligkeit zwischen ihnen entstehen zu lassen ${ }^{404}$.

Begleitet wurden die vielfältigen Aktivitäten der Verständigungsorganisationen einmal mehr durch die Stimmen von Mittlerpersönlichkeiten wie Alfred Grosser und Joseph Rovan, die wiederholt in die deutsch-französischen Debatten um die Direktwahl zum Europäischen Parlament eingriffen. Grosser etwa ließ es sich vor dem Hintergrund der in Frankreich immer wieder anklingenden Furcht, unter die ökonomische und politische Vormundschaft einer übermächtigen Bundesrepublik geraten zu können, angelegen sein, das Potenzial der vermeintlich so erdrückenden westdeutschen Wirtschaftskraft in realistischerer Weise darzustellen, als dies die Mehrheit der französischen Medien tat. Gewiss, so räumte er in Beiträgen für »Le Monde« und "L'Express« ein, sei das Wirtschaftswachstum in Westdeutschland größer als in Frankreich, die D-Mark eine stabilere Währung als der Franc. Doch habe auch die Bundesrepublik ganz erheblich unter den Folgen der Weltwirtschaftskrise zu leiden, seien wachsende Jugendarbeitslosigkeit, eine steigende Anzahl von Unternehmensinsolvenzen und höhere Sozi-

400 BILD-Archiv, Compte rendu des travaux de l'assemblée générale du BILD, 20. Januar 1979, S. 1.

401 Siehe ibid.

402 Vgl. Dossier: L'élection du parlement européen au suffrage universel, in: Documents 34/1 (1979), S. 14-100, darin bes. Hélène Riffault, Français et Allemands se comprennent-ils et veulent-ils la même chose?, in: Documents 34/1 (1979), S. 29-42; Daniel Colard, Die Europa-Wahl und ihre Folgen für Frankreich, in: Dokumente 35/3 (1979), S. 203-211; Dossier: Frankreich vor der Europa-Wahl, in: Dokumente 35/1 (1979), S. $7-$ 36.

403 Vgl. BILD-Archiv, Tätigkeitsbericht 1979 der GÜZ und des BILD, S. 2-6 und S. 13-15.

404 BILD-Archiv, Aufzeichnung zur Arbeitsplanung des BILD für das Jahr 1979, S. 2. 
alausgaben auch dort ein Problem ${ }^{405}$. Die augenblickliche Situation der Nachbarländer gleiche sich daher weitaus mehr, als die Presseberichterstattung es erkennen lasse: "L'ennui, c'est que l'information quotidienne préfère le sensationnel, le surprenant et privilégie donc les différences « ${ }^{406}$. Statt in übermäßiger Frequenz die zweifellos bestehenden Unterschiede zu betonen, sollten nach Ansicht Grossers vielmehr die Interdependenzen und Ähnlichkeiten zwischen Frankreich und Westdeutschland öffentlich stärker hervorgehoben werden. Dann würde für jedermann ersichtlich, dass sich Deutsche und Franzosen insgesamt auf einem guten gemeinsamen Weg befänden ${ }^{407}$.

Joseph Rovan zufolge konnten die auch in seinen Augen vollkommen unbegründeten französischen Ängste vor einer deutschen Vormachtstellung und das hierdurch latent vorhandene Konfliktpotenzial nur dann überwunden werden, wenn zwischen beiden Ländern und getragen von Regierungen wie Bevölkerungen ein neues Bewusstsein für die Notwendigkeit einvernehmlichen Miteinanders entstünden:

Les craintes que soulève parfois en France, sans raison véritable, la trop grande puissance économique et commerciale de la République fédérale [...] pourront être évoquées et vaincus par un nouveau progrès décisif et public vers davantage de réflexions, de discussions et de décisions communes, dans des réunions où nous nous interpellerions mutuellement au grand jour ${ }^{408}$.

Als mögliche Schritte zur Erreichung dieser Ziele schlug Rovan unter anderem die Einführung regelmäßiger gemeinsamer Sitzungen der beiden Parlamente und Kabinette vor, den wechselseitigen Zugang zum öffentlichen Dienst und die Einrichtung weiterer binationaler Institutionen, wie etwa eines deutsch-französischen Amtes für Informationsangelegenheiten. Diese Maßnahmen seien schließlich - so die Vorstellung, die Rovan bereits in einem 1978 erschienenen Aufsatz entfaltet hatte -, durch eine »entreprise ambitieuse et difficile, qui frappe l'imagination et mobilise les engagements « $^{409} \mathrm{zu}$ krönen, die Schaffung einer gemeinsamen Staatsangehörigkeit, mit welcher

405 Siehe Alfred Grosser, Semblable et différente, in: L’Express, 24.03.1979, S. 34-36; DERs., Vingt ans de réussite allemande V. - Certitudes et incertitudes politiques, in: Le Monde, 17.03.1979, S. 37; vgl. hierzu auch Ders., L'Allemagne de notre temps 19451978, Paris 1978, S. 691f.

406 Ders., Conclusion: sur la route commune, in: L'Express, 24.03.1979, S. 73.

407 Siehe ibid.

408 Joseph Rovan, Au service de l'Europe: l'union franco-allemande, in: Documents 33 (1978), Sonderheft, S. 192-200, hier S. 199; vgl. auch die deutsche Fassung Was bringt die Zukunft?, in: Dokumente 34 (1978), Sonderheft, S. 147-155.

409 Ders., Au service de l'Europe, S. 198. 
die so dringlich gebotene deutsch-französische »Fusion« im Dienste Europas Wirklichkeit werden könne ${ }^{410}$.

So visionär ein derartiger Vorschlag auch sein mochte, so wenig schienen Deutsche und Franzosen am Ende der 1970er Jahre darauf vorbereitet und gewillt, eine deutsch-französische Nationalität zu akzeptieren. Nicht zuletzt die konfrontativen Debatten im Vorfeld der Wahlen zum Europäischen Parlament zeigen, wie rasch Argwohn, Vorurteile und überkommene FreundFeind-Schemata im deutsch-französischen Verhältnis immer noch mobilisiert werden konnten. Diese Auseinandersetzungen im Zaum zu halten, hatten sich die verschiedenen Protagonisten der Annäherung nach Kräften bemüht, doch nehmen sich die sichtbaren Erfolge ihrer Anstrengungen insgesamt bescheiden aus. Die Fernsehauftritte von Staatspräsident und Bundeskanzler zu Beginn des Jahres 1979 mögen zu einer positiven öffentlichen Wahrnehmung des jeweiligen Nachbarlandes beigetragen haben. Dies lässt zumindest das wohlwollende Presseecho vermuten. Ob Gleiches für die seitens des DAAD und des DFJW durchgeführten Austauschprogramme angenommen werden darf, ist nicht letztgültig zu beantworten, da die Auswirkungen auf die Betroffenen im Einzelnen kaum zu bemessen sind. Die Appelle der privaten Verständigungsorganisationen riefen zumeist ebenso wenig Resonanz hervor wie ihr Angebot an landeskundlichen Seminaren und Informationsreisen. Zum Teil mussten geplante Veranstaltungen aufgrund mangelnden Interesses sogar abgesagt werden ${ }^{411}$. Das vermittelnde Einschreiten Grossers und Rovans schließlich erfolgte zwar vielfach in auflagenstarken Publikationsorganen wie »Le Monde« oder »L'Express «112, doch ist es fraglich, ob ihre Stimmen es angesichts des lauten polemischen Getöses schafften, zu breiteren Bevölkerungsschichten durchzudringen. Die Diskussionen um die Direktwahl des Europa-Parlaments 1978 und 1979 führten letztlich zu ähnlich heftigen öffentlichen Zerwürfnissen in den deutsch-französischen Beziehungen wie Helmut Schmidts Äußerungen zum Gaullismus 1976, die Thesen General Binoches über Deutschland 1975 und der Streit um die Agrarpreiserhöhung im Jahr 1974. Die vermeintliche ökonomische Übermacht im Verbund mit der außenpolitischen Emanzipation der Bundesrepublik bildete bereits Mitte der 1970er Jahre den Hintergrund für die französischen Befürchtungen vor einem »deutschen Europa«. Sie tat es auch noch am Ende des Jahrzehnts. Daran hatten die zahlreichen deutsch-französischen Verständigungsinitiativen, die auf den Weg gebracht worden waren,

410 Siehe ibid., S. 200; vgl. hierzu auch Ders., Dreißig Argumente für eine deutsch-französische Union, S. 15-21; weiterführend Ders., Zwei Völker - eine Zukunft. Deutsche und Franzosen an der Schwelle des 21. Jahrhunderts, München u. a. 1986.

411 Vgl. BILD-Archiv, Tabellarische Übersicht »Activités réalisées en 1978-1979«; VDFGArchiv, Schreiben des Deutschen Generalsekretärs Hermann Paul an den Präsidenten des ADFG, Alfred Borgmann, vom 10. Februar 1979.

412 Zur Auflagenhöhe von »Le Monde« und »L'Express« in der zweiten Hälfte der 1970er Jahre siehe Kap. 1., Anm. 91. 
um Misstrauen, Ängste und stereotype Wahrnehmungsmuster zwischen beiden Ländern aus der Welt zu schaffen, kaum etwas ändern können.

\subsection{Die Schatten der Kriegserfahrungen}

Trotz vieler positiver Entwicklungen der ersten Nachkriegsjahrzehnte blieb in der Erlebnisgeneration die Erinnerung an die nationalsozialistische Gewaltherrschaft auch während der 1970er Jahre weiterhin präsent. Konnte sich die Geschichte wiederholen? Waren die Deutschen frei von den Einflüssen der NS-Ideologie? Ein Vierteljahrhundert nach dem Ende des Krieges hatten diese Fragen für einen Großteil der Menschen im geteilten Europa keineswegs an Aktualität eingebüßt $\mathrm{t}^{413}$. Nicht zuletzt die Aktivitäten von Opfer- oder Veteranenverbänden und die alljährlich zelebrierten Gedenkfeiern zum Kriegsende hielten das Thema in der Öffentlichkeit wach ${ }^{414}$. Die politischen Verhältnisse in der Bundesrepublik wurden derweil von ihren Nachbarn aufmerksam beobachtet, um bei den ersten Anzeichen eines Rückfalls der Deutschen in braunes Gedankengut Alarm schlagen zu können ${ }^{415}$. Nicht nur die Auseinandersetzung mit der NS-Vergangenheit gelangte so in den Fokus des internationalen Interesses, auch rückwärtsgewandte Tendenzen in der bundesdeutschen Gesellschaft galt es aufzuspüren, bevor diese eine Gefahr für das friedliche $\mathrm{Zu}$ sammenleben in Europa darstellen konnten.

Eine Frage, welche die Gemüter noch immer erhitzte, war die Strafverfolgung von NS-Kriegsverbrechern und insbesondere die in diesem Zusammenhang ans Licht tretenden Mängel und Versäumnisse ${ }^{416}$. Dass viele

413 Vgl. Jost DüLFFER, Europa im Ost-West-Konflikt 1945-1990, München 2004, S. 7-18; Arnd BAUERKäMPER, Das umstrittene Gedächtnis. Die Erinnerung an Nationalsozialismus, Faschismus und Krieg in Europa seit 1945, Paderborn u. a. 2012.

414 Vgl. Rudolf von Thadden, Steffen KaudelKa (Hg.), Erinnerung und Geschichte 60 Jahre nach dem 8. Mai 1945, Göttingen 2006; Brigitte SAUZAY (Hg.), Vom Vergessen vom Gedenken. Erinnerungen und Erwartungen in Europa zum 8. Mai 1945, Göttingen 1995.

${ }^{415}$ So schon im Zusammenhang mit den im gesamten Bundesgebiet auftauchenden Hakenkreuzschmierereien im Jahr 1958 oder vor dem Hintergrund des Einzuges der NPD in mehrere westdeutsche Landesparlamente in den 1960er Jahren, vgl. hierzu Peter ReicheL, Vergangenheitsbewältigung in Deutschland. Die Auseinandersetzung mit der NS-Diktatur in Politik und Justiz, München ${ }^{2} 2007$, S. 125-157; Rainer ErB, Michael KoHLSTRUCK, Rechtsextremismus in Deutschland nach 1945, in: Wolfgang Benz (Hg.), Handbuch des Antisemitismus. Judenfeindschaft in Geschichte und Gegenwart, Bd. 3: Begriffe, Theorien, Ideologien, Berlin, New York 2010, S. 282-285.

416 Vgl. hierzu Torben Fischer, Matthias N. Lorenz (Hg.), Lexikon der »Vergangenheitsbewältigung « in Deutschland. Debatten- und Diskursgeschichte des Nationalsozialismus nach 1945, Bielefeld 2007, S. 92-106 und S. 199-210; Michael Greve, Der justitielle und rechtspolitische Umgang mit den NS-Gewaltverbrechen in den sechziger Jahren, Frankfurt a.M. 2001; Norbert FrEI, Vergangenheitspolitik. Die Anfänge der Bundesrepublik 
der Täter für ihre unmenschlichen Vergehen nicht belangt worden waren und in der Bundesrepublik vollkommen unbehelligt ein bürgerliches Leben führten, dass gar Forderungen nach Erteilung einer Generalamnestie laut geworden waren und das Wort vom "Schlussstrich « die Runde machte ${ }^{417}$, all dies konnte bei ausländischen Beobachtern, zumal bei den Opfern, kaum auf Verständnis treffen. Symptomatisch war in dieser Hinsicht der Protest, der 1974 in Frankreich gegen die Verurteilung der Journalistin Beate Klarsfeld aufkam, die mit ihrem Ehemann versucht hatte, einen straflos gebliebenen ehemaligen SS-Offizier zu entführen und der französischen Justiz zu übergeben $^{418}$. In ähnlicher Weise sorgten die Aktivitäten von Verbänden ehemaliger SS-Angehöriger und vor allem die Tatsache, dass diese in der Bundesrepublik legal existieren konnten, seit Mitte der 1970er Jahre auf französischer Seite für verstärkte Unmutsbekundungen ${ }^{419}$. Diese reichten so weit, dass Joachim Fests Film »Hitler - Eine Karriere« sowie die Entscheidung der Bundesregierung, den aus italienischer Haft entkommenen Kriegsverbrecher Herbert Kappler nicht auszuliefern, im Sommer 1977 als Belege für ein in Westdeutschland zunehmend praktiziertes Verharmlosen und Beschweigen der NS-Zeit dienten ${ }^{420}$. Dass der von verschiedenen Printmedien in beiden Ländern beschriebene Vertrauensverlust in den deutsch-französischen Beziehungen nicht real werde und die auch nach Jahrzehnten fortbestehenden Schatten der Kriegserfahrungen vertrieben würden, machten sich die beiderseits des Rheins agierenden Akteure der Verständigung zur Aufgabe. Die Konflikte, die aus den Belastungen der Vergangenheit resultierten, und die ihnen entgegengesetzten Versöhnungsstrategien stehen somit im Mittelpunkt der folgenden Kapitel.

und die NS-Vergangenheit, München ${ }^{2}$ 1997; Rüdiger FLEITER, Die Ludwigsburger Zentrale Stelle - eine Strafverfolgungsbehörde als Legitimationsinstrument, in: Kritische Justiz 35/2 (2002), S. 253-272.

417 Vgl. Ulrich Herbert, NS-Eliten in der Bundesrepublik, in: Wilfried Loth, Bernd A. RusineK (Hg.), Verwandlungspolitik. NS-Eliten in der westdeutschen Nachkriegsgesellschaft, Frankfurt a.M., New York 1998, S. 93-115; Jörg FrIEDRICH, Die kalte Amnestie. NS-Täter in der Bundesrepublik, Berlin 2007; Maria WIRTH, Christian Broda. Eine politische Biographie, Göttingen 2011, S. 456-458.

418 Vgl. Carsten Dams, Michael Stolle, Die Gestapo. Herrschaft und Terror im Dritten Reich, München ${ }^{3}$ 2012, S. 188.

419 Vgl. zu den in der Bundesrepublik existierenden Vereinigungen ehemaliger SS-Angehöriger Karsten WILKE, Die »Hilfsgemeinschaft auf Gegenseitigkeit« (HIAG) 1950-1990. Veteranen der Waffen-SS in der Bundesrepublik, Paderborn u. a. 2011.

420 Vgl. Werner Bergmann, Antisemitismus in öffentlichen Konflikten. Kollektives Lernen in der politischen Kultur der Bundesrepublik 1949-1989, Frankfurt a.M., New York 1997, S. 314f.; Wichard WoYKe, Frankreichs Außenpolitik von de Gaulle bis Mitterrand, Opladen 1987, S. 102. 


\subsection{1 „L'Allemagne de Kurt Lischka et celle de Willy Brandtu: der Klarsfeld-Prozess}

Am 9. Juli 1974 wurde die Deutsch-Französin Beate Klarsfeld ${ }^{421}$ durch das Kölner Landgericht zu einer Freiheitsstrafe von zwei Monaten ohne Bewährung verurteilt. Die in Paris lebende Journalistin hatte sich in dem sieben Verhandlungstage andauernden Strafprozess dafür zu verantworten, im März 1971 gemeinsam mit ihrem Ehemann, dem französischen Anwalt Serge Klarsfeld, versucht zu haben, den ehemaligen SS-Obersturmbannführer Kurt Lischka zu entführen ${ }^{422}$. Plan der Klarsfelds war es in der Tat gewesen, Lischka ${ }^{423}$, der zwischen 1940 und 1943 als stellvertretender Kommandeur der Sicherheitspolizei und des Sicherheitsdienstes im besetzten Paris maßgeblich an der Deportation der französischen Juden beteiligt war, aus der Bundesrepublik nach Frankreich zu verbringen und ihn in die Hände der dortigen Justiz zu übergeben. Ein französisches Militärgericht hatte Lischka im Herbst 1950 für seine Taten während des Zweiten Weltkriegs bereits zu lebenslänglicher Zwangsarbeit verurteilt, der Richterspruch war jedoch in Abwesenheit erfolgt, da die französischen Behörden des Angeklagten nicht hatten habhaft werden können. In der Bundesrepublik war im Rahmen der Entnazifizierung zwar gegen Lischka ermittelt worden, ein seitens der Staatsanwaltschaft Bielefeld angestrengtes Spruchkammerverfahren wurde jedoch im November 1950 eingestellt und später nicht wieder aufgenommen ${ }^{424}$. Lischka hatte seitdem unbehelligt in Köln gelebt, wo er als Prokurist eines Getreidegroßhändlers tätig war. Der Entführungsversuch in Köln diente, wie schon eine Reihe anderer öffentlicher Aktionen Beate und Serge Klarsfelds gegen strafrechtlich nicht belangte NS-Täter in den Jahren zuvor $^{425}$, dazu, die

421 Biografische Angaben zu Beate Klarsfeld finden sich in Claudia FröHLICH, Rückkehr zur Demokratie - Wandel der politischen Kultur in der Bundesrepublik, in: Peter Reichel, Harald Schmid, Peter Steinbach (Hg.), Der Nationalsozialismus - die zweite Geschichte: Überwindung, Deutung, Erinnerung, München 2009, S. 105-126, hier S. $117 f$.

422 Vgl. hierzu Bernhard Brunner, Der Frankreich-Komplex. Die nationalsozialistischen Verbrechen in Frankreich und die Justiz der Bundesrepublik Deutschland, Göttingen 2004, S. 287-291.

423 Zur Biografie und zu den Funktionen Kurt Lischkas während der NS-Zeit vgl. Robert S. Wistrich, Who's Who in Nazi Germany, London 2002, S. 157f.; Klaus Drobisch, Die Judenreferate des Geheimen Staatspolizeiamtes und des Sicherheitsdienstes der SS 1933 bis 1939, in: Jahrbuch für Antisemitismusforschung 2 (1993), S. 230-254, hier S. 234 und 249.

${ }^{424}$ Vgl. hierzu Claudia MoISEL, Frankreich und die deutschen Kriegsverbrecher. Politik und Praxis der Strafverfolgung nach dem Zweiten Weltkrieg, Göttingen 2004, S. 109-112; Bernhard BRUNNER, Lebenswege der deutschen Sipo-Chefs in Frankreich nach 1945, in: Ulrich Herbert (Hg.), Wandlungsprozesse in Westdeutschland. Belastung, Integration, Liberalisierung 1945-1980, Göttingen ${ }^{2} 2003$, S. 214-242.

425 Vgl. den Eintrag zu Beate Klarsfeld in Fischer, Lorenz (Hg.), Lexikon der »Vergangenheitsbewältigung« in Deutschland, S. 186f. sowie Beate KLARSFEld, Die Geschichte des 
Medien auf die Straflosigkeit des ehemaligen SS-Offiziers aufmerksam zu machen. Vor allem sollte das öffentliche Interesse auf ein zwischen Frankreich und der Bundesrepublik in der Schwebe befindliches Abkommen gelenkt werden, welches der bis dahin nicht möglichen Strafverfolgung von in Frankreich nach 1945 in absentia verurteilten deutschen Kriegsverbrechern eine juristische Verfahrensgrundlage verschafft hätte ${ }^{426}$.

Wie war es zu der Rechtssituation gekommen, gegen die das Ehepaar Klarsfeld protestierte? Durch den so genannten Überleitungsvertrag von $1955^{427}$ waren diejenigen Strafverfahren gegen NS-Täter, welche die alliierten Behörden endgültig abgeschlossen hatten, der bundesdeutschen Gerichtsbarkeit entzogen worden. Die entsprechende Vertragsklausel, deren eigentlicher Zweck es war, nachträgliche Strafmilderungen durch deutsche Gerichte zu verhindern, galt jedoch auch für Strafprozesse, die aus Mangel an Beweisen eingestellt worden waren und, wie der Bundesgerichtshof entschieden hatte, im Falle von Verurteilungen in Abwesenheit. Da das Grundgesetz der Bundesrepublik zudem die Auslieferung von Deutschen an das Ausland verbot, konnten sich in Frankreich verurteilte NS-Täter wie Kurt Lischka in Westdeutschland in Sicherheit wiegen. Weder waren die in absentia gefällten Urteile vollstreckbar, noch konnten die Betreffenden von der westdeutschen Justiz belangt oder an das Nachbarland ausgeliefert werden $^{428}$. Das im Februar 1971 zwischen Frankreich und der Bundesrepublik geschlossene "Zusatzabkommen zum Überleitungsvertrag « ${ }^{429}$ sollte daher den westdeutschen Strafverfolgungsbehörden eine rechtliche Handhabe liefern, um Ermittlungsverfahren gegen den entsprechenden Personenkreis eröffnen zu können. Damit das Abkommen in Kraft treten konnte, musste es jedoch zunächst durch den Bundestag ratifiziert werden, wo die nachträgliche Strafverfolgung von NS-Kriegsverbrechern vor allem in den Reihen der

PG 2633930 Kiesinger. Dokumentation, Darmstadt 1969; Dies., Partout où ils seront, Paris 1972.

426 Vgl. Kerstin Freudiger, Die juristische Aufarbeitung von NS-Verbrechen, Tübingen 2002, S. 24f.; Brunner, Der Frankreich-Komplex, S. 262-279.

427 Siehe den Vertrag zur Regelung aus Krieg und Besatzung entstandener Fragen, in: Bundesgesetzblatt 1955, Teil II, S. 405-468.

${ }^{428}$ Vgl. Joachim Perels, Das juristische Erbe des »Dritten Reiches«. Beschädigungen der demokratischen Rechtsordnung, Frankfurt a.M., New York 1999, S. 209f.; Annette WeINKE, »Alliierter Angriff auf die nationale Souveränität«? Die Strafverfolgung von NS-Verbrechen in der Bundesrepublik, der DDR und Österreich, in: Norbert FrEI (Hg.), Transnationale Vergangenheitspolitik. Der Umgang mit den deutschen Kriegsverbrechern in Europa nach dem Zweiten Weltkrieg, Göttingen 2006, S. 37-93, hier S. 56; Fritz BAUER, Im Namen des Volkes: Die strafrechtliche Bewältigung der Vergangenheit, in: Ders., Die Humanität der Rechtsordnung. Ausgewählte Schriften, hg. v. Joachim Perels und Irmtrud WoJAK, Frankfurt a.M., New York 1998, S. 77-90, hier S. 84.

${ }^{429}$ Siehe das Abkommen zwischen der Regierung der Bundesrepublik Deutschland und der Regierung der Französischen Republik über die deutsche Gerichtsbarkeit für die Verfolgung bestimmter Verbrechen vom 2. Februar 1971, in: Bundesgesetzblatt 1975, Teil II, S. 432f. 
liberalen und konservativen Abgeordneten zahlreiche Gegner hatte ${ }^{430}$. Insbesondere der FDP-Politiker Ernst Achenbach ${ }^{431}$, der als Leiter der politischen Abteilung der deutschen Botschaft in Paris zwischen 1940 und 1943 selbst für die Deportation der französischen Juden mitverantwortlich gewesen war ${ }^{432}$, weigerte sich in seiner Funktion als Berichterstatter des Auswärtigen Ausschusses, das deutsch-französischen Abkommen auf die Tagesordnung zu setzen. Dessen Ratifizierung verzögerte sich hierdurch noch bis $1975^{433}$. Der Kölner Prozess gegen Beate Klarsfeld führte dazu, dass diese Situation in das Bewusstsein weiter gesellschaftlicher Kreise gelangte.

In Frankreich rief nicht nur die Verurteilung Klarsfelds an sich Empörung hervor, sondern vor allem die Tatsache, dass Kurt Lischka vor Gericht als Zeuge auftrat. Der Täter, derjenige, der mitverantwortlich für das Leid Tausender gewesen war, fand sich nicht auf der Anklagebank wieder, sondern trug mit seiner Aussage dazu bei, diejenige ins Gefängnis zu bringen, die seine Verbrechen hatte aufdecken wollen. Hier wurde doch, so schien es vielen französischen Beobachtern, das Recht der Opfer mit Füßen getreten: »Il s'appelle Kurt Lischka, Obersturmbannführer SS, collaborateur direct d'Eichmann, chargé de la ‘police de sécurité ‘ nazie en France occupée, il est responsable de milliers de morts. [...] Cet homme-là est libre. Et Beate Klarsfeld est aujourd'hui au banc des accusés « ${ }^{434}$.

Um ihrer Entrüstung über die Haftstrafe für Beate Klarsfeld Ausdruck zu verleihen, organisierten verschiedene französische Opferverbände in den Tagen nach der Urteilsverkündung öffentliche Protestkundgebungen, so vor den Generalkonsulaten der Bundesrepublik in Lyon und Marseille. Vor der deutschen Botschaft in Paris kamen gar eintausend Menschen zusammen und skandierten »Justice allemande, justice fasciste « ${ }^{435}$. Die Vereinigung

430 Vgl. hierzu MoIsel, Frankreich und die deutschen Kriegsverbrecher, S. 211-228 sowie weiterführend ReIcheL, Vergangenheitsbewältigung in Deutschland, S. 182-198; Marc von MiQuel, Ahnden oder amnestieren? Westdeutsche Justiz und Vergangenheitspolitik in den sechziger Jahren, Göttingen 2004.

431 Vgl. Ernst KLEE, Das Personenlexikon zum Dritten Reich. Wer war was vor und nach 1945, Frankfurt a.M. 2003, S. 10; Biographisches Handbuch des deutschen Auswärtigen Dienstes 1871-1945, Bd. 1, hg. v. Historischen Dienst des Auswärtigen Amtes, Paderborn u. a. 2000, S. 3f.

432 Vgl. hierzu Eckart Conze u. a., Das Amt und die Vergangenheit. Deutsche Diplomaten im Dritten Reich und in der Bundesrepublik, München 2010, S. 19.

433 Vgl. Bernhard Brunner, Deutsche NS-Täter vor französischen Gerichten, in: Heimo Halbrainer, Claudia Kuretsidis-Haider (Hg.), Kriegsverbrechen, NS-Gewaltverbrechen und die europäische Strafjustiz von Nürnberg bis Den Haag, Graz 2007, S. 148157.

${ }^{434}$ Les nazis d'aujourd'hui, in: Le Nouvel Observateur, 08.07.1974, S. 31f.; vgl. auch Daniel VERNET, Après de nouveaux incidents le président du tribunal de Cologne interrompt l'audition de témoins français au procès de Mme Klarsfeld, in: Le Monde, 05.07.1974, S. 3 .

435 Vgl. BA, B 122, Bd. 16408, Schreiben des deutschen Generalkonsulats Marseille an das Auswärtige Amt vom 15. Juli 1974; Devant l'ambassade de la RFA: pour Beate Klarsfeld, 
L'Amicale des déportés d'Auschwitz bezeichnete in einer Presseerklärung das Kölner Verdikt als »insulte envers toutes les victimes du nazisme«, für die Ligue internationale contre le racisme et l'antisémitisme kam es einer »revanche de l'Allemagne nazie " gleich $^{436}$. Ein weiterer Verband ehemaliger Verfolgter forderte von Bundespräsident Scheel: »Les membres [...] estiment le jugement rendu contraire à l'honneur de votre pays et demandent purement et simplement l'annulation de celui-ci, incompréhensible pour nous victimes du terreur nazi de 1940 à 1945 « $^{437}$. In einem Telegramm der Association française Buchenwald Dora an Staatspräsident Giscard d'Estaing ist schließlich zu lesen: »Demandons instamment votre intervention pour faire casser scandaleuse condamnation Beate Klarsfeld STOP Tribunal Cologne montre racines profondes nazisme dans la justice ouest-allemande « ${ }^{438}$. Auch dreißig Jahre nach Kriegsende war das westdeutsche Rechtswesen, dieser Eindruck entstand bei den französischen Opfern der nationalsozialistischen Verfolgungen, noch immer durchsetzt mit »furchtbaren Juristen « ${ }^{439}$, die Täter schützten und über die Qualen der Opfer schwiegen.

Die Empörung der Opferverbände aufgreifend, zeigte sich die Mehrheit der französischen Pressekommentatoren nicht minder schockiert über das Urteil der Kölner Richter. Die Bestrafung Beate Klarsfelds sei, wie »Le Figaro" schrieb, eine Ohrfeige für all diejenigen, die unter der nationalsozialistischen Besatzungs- und Repressionspolitik gelitten hätten: »L'Allemagne actuelle ne veut pas avoir d'antécédents, ce qui lui permet de se croire une démocratie modèle tout en protégeant ceux des siens qui commirent des crimes contre l'humanité. Si c'est là l'humanisme allemand, la condamnation de Beate Klarsfeld est juste et logique ${ }^{440}$.

Der Leiter des Außenpolitik-Ressorts von »Le Monde«, Maurice Delarue, urteilte: »il est franchement choquant que des juges allemands, non contents d'ignorer les agissements d'un bourreau, prétendent emprisonner celle qui

in: Le Figaro, 11.07.1974, S. 1; Plusieurs associations organisent une manifestation de protestation devant l'ambassade d'Allemagne à Paris, in: Le Monde, 11.07.1974, S. 2; Après la condamnation de Mme Klarsfeld, in: Le Monde, 12.07.1974, S. 2; Robert SolÉ, Des fleurs pour la condamné, in: Le Monde, 12.07.1974, S. 2, hier das Zitat.

436 Beide Erklärungen sind zitiert nach: Plusieurs associations organisent une manifestation de protestation devant l'ambassade d'Allemagne à Paris, in: Le Monde, 11.07.1974, S. 2.

437 BA, B 122, Bd. 16408, Schreiben der Fédération nationale des déportés, internés, résistants et patriotes, association départementale du Haut-Rhin, an Bundespräsident Walter Scheel vom 26. Juli 1974.

438 AMAE Paris-La Courneuve, Europe, RFA 1971-1976, Bd. 3034, Telegramm der Association française Buchenwald Dora an Staatspräsident Valéry Giscard d'Estaing vom 10. Juli 1974.

439 Siehe Ingo MüLLER, Furchtbare Juristen. Die unbewältigte Vergangenheit unserer Justiz, München 1987.

440 Pierre Emmanuel, Une gifle, in: Le Figaro, 10.07.1974, S. 1. 
les dénonce ${ }^{441}$. Die bundesdeutschen Richter sollten der Tatsache gewahr werden, dass durch ihr Urteil die deutsch-französische Aussöhnung Schaden nehmen könne, da es den französischen Nachbarn das Bild eines Deutschland vermittele, in dem Männer wie Lischka und ihr unmenschliches Handeln während des Zweiten Weltkriegs nicht nur straflos blieben, sondern sogar gesellschaftliche Akzeptanz erführen. Es sei aber, wie Delarue seinen Artikel beschloss, nicht das Deutschland Kurt Lischkas, mit dem die Franzosen eng zusammenarbeiten und die europäische Einigung gestalten wollten, sondern das Deutschland Willy Brandts und Beate Klarsfelds ${ }^{42}$. In einem noch stärker anklagenden Tonfall hieß es in der kommunistischen Zeitung "L'Humanité«: "Des centaines de criminels nazis mènent une existence confortable en $\mathrm{Al}$ lemagne de l'Ouest. Le général Lammerding, bourreau d'Oradour, est mort dans son lit. D'autres, comme Barbie, ont eu tout loisir de se ménager un exil doré «443. Angesichts dieser unhaltbaren Lage seien auch die Versicherungen Helmut Schmidts, das deutsch-französische Zusatzabkommen so schnell als möglich zur Ratifizierung zu bringen, nicht hinreichend. Die französischwestdeutschen Beziehungen würden vielmehr erst dann wieder durch einen zufriedenstellenden Charakter gekennzeichnet sein, wenn auf beiden Seiten ein fester Wille zur Demokratie und zu einer friedlichen Kooperation bestünde ${ }^{444}$.

Die Auffassung, Beate Klarsfeld habe mit ihren öffentlichen Aktionen zu Recht auf nicht hinnehmbare Versäumnisse bei der Strafverfolgung von NSTätern und die skandalöse Verschleppung der Ratifizierung des deutschfranzösischen Zusatzabkommens hingewiesen, wurde von der westdeutschen Presse weitgehend geteilt ${ }^{445}$. Ihrem »hochtrabenden Sühnerigorismus « ${ }^{446}$ und ihren als anmaßend empfundenen Bekundungen, die "Ehre Deutschlands" retten und als personifiziertes schlechtes Gewissen den Deutschen ihre aus der NS-Zeit herrührenden Obliegenheiten vor Augen führen zu wollen ${ }^{447}$, standen viele Kommentatoren allerdings ablehnend gegenüber.

${ }^{441}$ Maurice Delarue, L'Allemagne de Kurt Lischka et celle de Willy Brandt, in: Le Monde, 11.07.1974, S. 2.

442 Siehe ibid.

443 Yves Moreau, Les »juges« de Cologne, in: L'Humanité, 10.07.1974, S. 2.

${ }^{444}$ Siehe ibid.

445 Vgl. exemplarisch Günter BöDDEKER, Die Rechtslage, gegen die Beate Klarsfeld anrannte, in: Die Welt, 10.07.1974, S. 5; Der Welt Lohn, in: Der Spiegel, 22.07.1974, S. 29f.; Dettmar Cramer, Nach dem Urteil gegen Beate Klarsfeld hat es der Bundestag sehr eilig, in: FAZ, 17.07.1974, S. 4; Dietrich Strothmann, Die Schatten des Ernst Achenbach, in: Die Zeit, 19.07.1974, S. 4.

446 Ders., Ein bißchen heilige Johanna. Beate Klarsfelds moralische Kreuzzüge, in: Die Zeit, 12.07.1974, S. 6.

447 Vgl. hierzu »Die Ohrfeige war ein symbolischer Akt «. Spiegel-Interview mit Beate Klarsfeld, in: Der Spiegel, 18.11.1968, S. 34; Willi WINKLER, Die Geschichte der RAF, Berlin 2007, S. 132; Gerd Koenen, Das rote Jahrzehnt. Unsere kleine deutsche Kulturrevolution 1967-1977, Köln ${ }^{2} 2001$, S. $119 f$. 
Nicht ohne sarkastischen Unterton berichtete etwa »Der Spiegel« am 15. Juli 1974, Beate Klarsfeld habe den Gipfel ihrer Laufbahn als »Vertreterin eines >besseren Deutschlands $\triangleleft,[. .$.$] als >$ Fackel des Widerstands $\triangleleft$ und als die Frau erreicht, die >dem deutschen Volk seine Verpflichtungen zeigt « ${ }^{448}$. Die Welt, so hieß es in dem Artikel, halle wider von den Greueln, die Frau Klarsfeld offenbart habe und von dem Greuel, der Frau Klarsfeld ob ihrer Offenbarung widerfahren sei.

Indes ließen sich in den bundesdeutschen Zeitungen auch Stimmen vernehmen, die in eindeutiger Weise das Vorgehen Beate Klarsfelds nicht nur im Hinblick auf den Stil, sondern auch der Sache nach als ungerechtfertigt kritisierten. So erschien Anfang August 1974 in der »Frankfurter Allgemeinen Zeitung " ein Artikel von Bundesrichter Günther Willms, der die mangelhafte Strafverfolgung von in Frankreich verurteilten NS-Tätern der französischen Rechtsprechung anlastete und Beate Klarsfeld und ihren "Gesinnungsfreunden « empfahl, ihren Protest nicht in Köln oder Bonn, sondern doch in Paris kund zu tun. "Die Bundesrepublik«, wie Willms formulierte, "die sich wie kein anderer der drei deutschen Staaten um Wiedergutmachung und Sühne nationalsozialistischer Schandtaten bemüht hat, bleibt eben doch der beste Prügelknabe, und ihre Justiz zumal ${ }^{449}$. Einlassungen dieser Art, welche aus Sicht der ohnehin alarmierten französischen Presse und Opferverbände allein dem Zweck dienen konnten, die offenen Fragen einer immer noch unbewältigten Vergangenheit zu verschleiern und die deutsche Gerichtsbarkeit von Schuld rein zu waschen, noch dazu aus der Feder eines Richters, konnten in Frankreich kaum auf Verständnis treffen.

Neben der Kritik, die an der Person Beate Klarsfelds und ihren öffentlichen Demonstrationen Anstoß nahm, wurde Unmut in den westdeutschen Zeitungen auch darüber laut, dass die französische Botschaft und Staatspräsident Giscard d'Estaing persönlich in der Sache Klarsfeld interveniert hatten, um auf ein maßvolles Urteil hinzuwirken ${ }^{450}$. Schließlich gehe es, wie die Journalisten argumentierten, um ein deutsches Gerichtsverfahren. Einmischungen von außen seien schon aufgrund des Unabhängigkeitsgrundsatzes, der für die Richter gelte, unzulässig. ${ }^{451}$ Die »Frankfurter Allgemeine Zeitung« fragte

448 Gerhard Mauz, »Ach, ach, der Achenbach...«, in: Der Spiegel, 15.07.1974, S. 31; vgl. auch Ders., Verfolgen - für ein besseres Deutschland?, in: Der Spiegel, 01.07.1974, S. 48f.

449 Günther WiLLMS, Späte Aufregung in Paris. Strafverfolgung von Kriegsverbrechern hätte sich auch ohne Vertrag mit Bonn erreichen lassen, in: FAZ, 02.08.1974, S. 10.

450 Vgl. hierzu PA-AA, Zwischenarchiv, Nr. 109198, Eilbrief des Bereitschaftsdienstes des Auswärtigen Amts an den Bundesminister der Justiz betreffend »Verfahren gegen Frau Klarsfeld« vom 29. Juni 1974; AMAE Paris-La Courneuve, Europe, RFA 1971-1976, Bd. 3034, Schreiben des französischen Außenministers Jean Sauvagnargues an die französische Botschaft Bonn vom 28. Juni 1974; Morsel, Frankreich und die deutschen Kriegsverbrecher, S. 226.

451 Siehe AMAE Paris-La Courneuve, Europe, RFA 1971-1976, Bd. 3034, Schreiben der französischen Botschaft Bonn an das französische Außenministerium betreffend »Procès de madame Klarsfeld« vom 2. Juli 1974. 
denn auch: »Der Bundeskanzler hat dem französischen Präsidenten zugesichert, das Abkommen solle nun rasch in Kraft gesetzt werden. Hat er ihm auch gesagt, daß unser Staat Versuche, in seine Justiz einzugreifen, befremdlich finde - von wem sie auch kommen ${ }^{452}$ ? «

Nicht zuletzt das Einschreiten von höchster französischer Stelle verdeutlicht, dass der Prozess gegen Beate Klarsfeld und die damit verbundene Frage der strafrechtlichen Verfolgung von bis dahin nicht belangten deutschen Kriegsverbrechern auch in der Wahrnehmung der politisch Verantwortlichen Gefährdungspotenzial für das deutsch-französische Verhältnis in sich barg. Bereits seit der Unterzeichnung des deutsch-französischen Zusatzabkommens im Februar 1971 hatte die seitens des Quai d'Orsay instruierte französische Botschaft ihre westdeutschen Gesprächspartner im Auswärtigen Amt wiederholt und nachdrücklich darauf hingewiesen, wie sensibel eine Mehrheit der Franzosen auf die Verzögerungen bei der Ratifizierung reagiere. Insbesondere die beständigen Appelle der zahlreichen Verfolgtenorganisationen schüfen eine Atmosphäre, in der ein Wiederaufbrechen deutschfeindlicher Stimmungen in der französischen Bevölkerung jederzeit möglich sei ${ }^{453}$. Einem Schreiben des französischen Außenministeriums an die Bonner Botschaft vom Januar 1972 ist die ernüchtert klingende Feststellung zu entnehmen, dass der Ratifizierungsprozess des deutsch-französischen Abkommens vom 2. Februar 1971 in der Bundesrepublik binnen eines Jahres in keiner Weise vorangekommen sei. Die Gefahr, die hieraus erwachse, sei indes evident: »Faute du règlement dont les deux gouvernements sont convenus, on peut toujours craindre un réveil de polémiques qui risquerait de porter préjudice à l'atmosphère dans laquelle se développent les relations franco-allemandes « ${ }^{454}$.

Das Strafverfahren gegen Beate Klarsfeld schien die befürchteten Polemiken tatsächlich auszulösen. Kurz nach Eröffnung der Gerichtsverhandlung in Köln teilte Außenminister Jean Sauvagnargues der Botschaft mit, der Prozess habe in Frankreich und vor allem im Milieu der ehemaligen Deportierten und bei den Familien von Vermissten »une grande émotion « hervorgerufen. Die Vorsitzenden zahlreicher Opfervereinigungen seien an Staatspräsident Giscard d'Estaing herangetreten, um ihre Empörung zu bekunden und um eine

452 Johann Georg ReIssmüller, Zweimal Achenbach, in: FAZ, 13.07.1974, S. 1.

453 Vgl. AMAE Paris-La Courneuve, Europe, RFA 1971-1976, Bd. 3120, Schreiben des französischen Justizministers René Pleven an Außenminister Maurice Schumann vom 29. Juni 1971; »Note pour la direction d'Europe« vom 9. Juli 1971; Vermerk betreffend "Démarche d'associations d'anciens déportés « vom 22. Januar 1973; Vermerk betreffend "Ratification de l'accord franco-allemand du 2 février 1971 sur la poursuite des criminels de guerre" vom 6. Juni 1973; AMAE Nantes, Bonn Ambassade, Bd. 27, Schreiben des französischen Botschafters in Bonn, Jean Sauvagnargues, betreffend »Criminels de guerre allemands condamnés par contumace« an das französische Außenministerium vom 17. März 1973.

454 AMAE Nantes, Bonn Ambassade, Bd. 27, Schreiben des französischen Außenministeriums an die französische Botschaft Bonn betreffend "Criminels de guerre allemands condamnés par contumace« vom 19. Januar 1972, S. If. 
französische Intervention zugunsten der Angeklagten zu fordern. Diese Entwicklung müsse den westdeutschen Stellen im Rahmen einer Demarche zur Kenntnis gebracht und ihnen ferner verdeutlicht werden, welch negative Folgen aus einer strengen Verurteilung Beate Klarsfelds erwachsen könnten ${ }^{455}$. Darüber hinaus sei es angezeigt, dass Staatspräsident Giscard d'Estaing, wie die französische Botschaft anregte, die »Affäre Klarsfeld«, welche das Klima der bilateralen Beziehungen belaste, im Rahmen der Gipfelkonsultationen am 8. und 9. Juli 1974 in Bonn mit Bundeskanzler Schmidt erörtere und dort den französischen Wunsch nach einer raschen Ratifizierung des Zusatzabkommens zum Ausdruck bringe ${ }^{456}$. Den Hinweis der Botschaft aufgreifend, empfahl der außenpolitische Berater des französischen Staatspräsidenten, Gabriel Robin, seinem obersten Dienstherren drei Tage vor Beginn der Gipfelgespräche:

Or, s'il est vrai que le gouvernement de $\mathrm{M}$. Brandt a bien soumis sans retard cet accord à la ratification du parlement fédéral, celui-ci refuse en fait, sous divers prétextes, à l'examiner et à se prononcer à son sujet. Cette attitude du Bundestag est due à la mauvaise volonté publiquement affichée de quelques membres de la Commission des affaires juridiques de cette assemblée et plus précisément d'un député libéral, M. Achenbach, dont le passé est assez chargé. Le moment paraît donc venu pour rappeler au gouvernement fédéral qu'il est dangereux, pour le climat des bonnes relations franco-allemandes, de laisser ainsi un député bloquer une procédure parlementaire sur une affaire à laquelle l'opinion française est très sensible ${ }^{457}$.

Der Gefahren, die aus den öffentlichen Auseinandersetzungen um KlarsfeldProzess und Zusatzabkommen für die deutsch-französischen Beziehungen entstehen konnten, war man sich auf Seiten der westdeutschen Regierungsstellen derweil wohl bewusst. Die Kölner Verhandlung habe in Frankreich, wie das Bonner Presse- und Informationsamt vermerkte, »viele alte Wunden wieder aufgerissen «. Man könne im Nachbarland einfach nicht verstehen, »daß eine Frau verurteilt wird, die, wie man hier meint, für eine gerechte und berechtigte Sache kämpft, während andererseits ein Mann wie Lischka in Freiheit ist, den man hier in Frankreich immerhin für den Tod von über

455 Siehe AMAE Paris-La Courneuve, Europe, RFA 1971-1976, Bd. 3034, Schreiben des französischen Außenministers Jean Sauvagnargues an die französische Botschaft Bonn betreffend »Affaire Klarsfeld « vom 28. Juni 1974; Schreiben der französischen Botschaft Bonn, Morizet, an das französische Außenministerium vom 29. Juni 1974; BA, B 122, Bd. 16408, Schreiben des Auswärtigen Amts an den Bundesminister der Justiz vom 29. Juni 1974.

456 Siehe AMAE Paris-La Courneuve, Europe, RFA 1971-1976, Bd. 3007, Schreiben der französischen Botschaft Bonn, Morizet, an das französische Außenministerium vom 1. Juli 1974, S. 2f.

457 AN Paris, 5 AG 3, Bd. 933, Vermerk des außenpolitischen Beraters des französischen Staatspräsidenten, Gabriel Robin, betreffend »Affaire Klarsfeld et ratification de l'accord de février 1971« vom 5. Juli 1974. 
100000 Juden verantwortlich macht « ${ }^{458}$. In Anbetracht der emotionalen Aufwallungen im Partnerland sei, so die Ansicht der politischen Abteilung des Auswärtigen Amts, die Zustimmung des Bundestags zum Abkommen vom 2. Februar 1971 »für das deutsch-französische Verhältnis von erheblicher politischer Bedeutung « ${ }^{459}$. Nicht zuletzt, weil in den französischen Parteien starke Tendenzen existierten, die Erinnerung an die Leiden der deutschen Besatzungszeit und den Mythos der Résistance wachzuhalten und in der Presse eine große Empfindlichkeit in Fragen der deutschen Okkupation vorherrsche, sehe sich die Pariser Regierung aus innenpolitischen Gründen gezwungen, eine zügige Ratifizierung mit allem Nachdruck zu verlangen. Eine Ablehnung des Abkommens würde jedoch, wie die westdeutschen Diplomaten warnten, $\mathrm{zu}$ einem psychologischen Schock führen und die deutsch-französischen Beziehungen einer schweren politischen Belastung aussetzen. »Die ohnehin bestehenden französischen Befürchtungen vor einem deutschen wirtschaftlichen und politischen Übergewicht [...] würden sich erheblich verstärken. Das Thema nationalsozialistischen Unrechts würde in der französischen Presse nicht mehr zur Ruhe kommen ${ }^{460}$.

Das Auswärtige Amt trat daher für eine beschleunigte Ratifizierung ein. Diese werde dazu beitragen, einen Schlussstrich unter einen leidvollen Abschnitt deutsch-französischer Vergangenheit zu ziehen ${ }^{461}$. In diesem Sinne handelte Bundeskanzler Schmidt, als er im Rahmen des deutsch-französischen Gipfeltreffens vom Juli 1974 dem französischen Staatspräsidenten zusagte, sich persönlich dafür einzusetzen, dass das Zusatzabkommen dem Parlament so bald als möglich zur Ratifizierung vorgelegt werde ${ }^{462}$. Zu einer weiteren Beruhigung der im Anschluss an das Urteil gegen Beate Klarsfeld in Frankreich laut gewordenen Proteste führte zudem der Rücktritt Ernst Achenbachs von seinem Amt als Berichterstatter des Auswärtigen Ausschusses nur wenige Wochen später ${ }^{463}$. Erst die Ratifizierung des Abkommens durch den

458 PA-AA, Zwischenarchiv, Nr. 109198, Vermerk des Presse- und Informationsamtes der Bundesregierung bezüglich des Klarsfeld-Prozesses vom 9. Juli 1974.

459 PA-AA, Zwischenarchiv, Nr. 109198, Vermerk betreffend »Deutsch-französisches Abkommen vom 2. Februar 1971 über die deutsche Gerichtsbarkeit für die Verfolgung bestimmter Verbrechen« vom 12. November 1974, S. 1.

460 Ibid.

461 Siehe ibid., S. 1f.

462 Vgl. BA, B 145, Bd. 11420, Protokoll der Pressekonferenz anlässlich der deutsch-französischen Gipfelkonsultationen am 9. Juli 1974, S. 13.

463 Vgl. hierzu Brunner, Der Frankreich-Komplex, S. 279; Kritik an Achenbach: Rücktritt verlangt, in: Die Zeit, 19.07.1974, S. 12; L'affaire Klarsfeld (suites), in: Le Nouvel Observateur, 22.07.1974, S.31; Stenographisches Protokoll der 32. Sitzung des Auswärtigen Ausschusses des Deutschen Bundestages am 18. September 1974, in: Winfried BECKER u. a. (Hg.), Quellen zur Geschichte des Parlamentarismus und der politischen Parteien. Vierte Reihe: Deutschland seit 1945, Bd. 13/VII: Der Auswärtige Ausschuss des Deutschen Bundestages. Sitzungsprotokolle 1972-1976. Erster Halbband Januar 1973 bis November 1974, Düsseldorf 2010, S. 790. 
Bundestag Ende Januar 1975 konnte jedoch, wie "Le Monde" formulierte, endgültig den dunklen Schatten vertreiben, der sich über die deutsch-französischen Beziehungen gelegt hatte ${ }^{464}$. Mit Dankesworten schrieb denn auch Staatspräsident Giscard d'Estaing an den Bundeskanzler: „Cette décision a été accueillie avec une grande satisfaction en France et je suis convaincu qu'elle aura contribué à raffermir l'esprit d'amitié et de confiance qui inspire les relations entre nos deux peuples « ${ }^{465}$.

Zur Festigung des hier beschworenen freundschaftlichen Geistes sollten auch verschiedene öffentlichkeitswirksame Gesten beitragen, welche zum Ziel hatten, den Bevölkerungen in beiden Ländern vor Augen zu führen, dass die konfliktreiche Vergangenheit zwischen Deutschen und Franzosen überwunden und vor allem Frankreich mit seinen einstigen Peinigern ausgesöhnt sei. Hierzu zählte die erstmalige Einladung eines deutschen Botschafters zu den französischen Feierlichkeiten am 11. November 1974 anlässlich der Beendigung des Ersten Weltkriegs ${ }^{466}$ sowie die Ankündigung des französischen Staatspräsidenten vom Mai 1975, den Jahrestag des Kriegsendes 1945 und die deutsche Kapitulation künftig nicht mehr offiziell feiern zu wollen ${ }^{467}$. Seinerseits war es nun an Helmut Schmidt, seinem Gegenüber zu danken:

Ihr Schreiben vom 8. Mai 1975 hat meine Mitbürger und mich selber tief bewegt. [...] Auch dreißig Jahre nach dem Ende des Weltkriegs erinnern wir uns noch mit Schmerz der Leiden, die er über die Welt gebracht hat. In Ehrfurcht gedenken wir aller Opfer des Krieges, darunter der Franzosen und Französinnen, die von seinen Schrecken hart getroffen wurden und deren Kreis bis in Ihre eigene Familie reicht. Umso stärker hat uns Ihre Entscheidung berührt, daß die französische Regierung in Zukunft den Jahrestag des Kriegsendes nicht mehr in offizieller Form feiern wird. Wir begreifen diesen Beschluss nicht als Ausdruck der Absicht zu vergessen, wir betrachten ihn als Äußerung des französischen Vertrauens in die einigende Kraft der europäischen Idee und des durch sie bewirkten immer engeren Zusammenschlusses unserer Völker ${ }^{468}$.

${ }^{464}$ Siehe Une ombre dissipée entre Paris et Bonn, in: Le Monde, 01.02.1975, S. 1; vgl. hierzu AMAE Paris-La Courneuve, Europe, RFA 1971-1976, Bd. 3120, Schreiben des französischen Botschafters in Bonn, Olivier Wormser, an das französische Außenministerium vom 31. Januar 1975.

465 AMAE Nantes, Bonn Ambassade, Bd. 27, Schreiben des französischen Staatspräsidenten Valéry Giscard d'Estaing an Bundeskanzler Helmut Schmidt vom 24. März 1975.

466 Vgl. PA-AA, Zwischenarchiv, Nr. 109198, Schreiben des deutschen Botschafters in Paris, Sigismund von Braun, an das Auswärtige Amt vom 11. und 13. November 1974.

467 Vgl. AMAE Paris-La Courneuve, Europe, RFA 1971-1976, Bd. 2952, AFP-Meldungen »La presse ouest-allemande et la suppression de l'anniversaire du 8 mai 1945 « vom 10. Mai 1975 und »Bonn se félicite de la décision de Paris de ne plus célébrer l'anniversaire du 8 mai« vom 9. Mai 1975; Feier des 8. Mai in Frankreich zum letzten Male, in: FAZ, 09.05.1975, S. 2; Vera Caroline Simon, Gefeierte Nation. Erinnerungskultur und Nationalfeiertag in Deutschland und Frankreich seit 1990, Frankfurt a.M., New York 2010, S. 334.

468 AN Paris, 5 AG 3, Bd. 934, Schreiben Bundeskanzler Helmut Schmidts an den französischen Staatspräsidenten Valéry Giscard d'Estaing vom 2. Juni 1975. 
Jenseits der staatsmännischen Freundschaftssymbolik, welche bei französischen Veteranenverbänden und ehemaligen Widerstandskämpfern allerdings auf starke Ablehnung stieß und ihren Zweck somit kaum erfüllen konnte ${ }^{469}$, zielte vor allem die kulturpolitische Verständigungsarbeit beider Regierungen darauf $a b$, zur Bewältigung der nachwirkenden Kriegserfahrungen beizutragen. Da die Tragweite der Diskussionen vom Sommer 1974, wie die westdeutschen Stellen urteilten, die Gefahr heraufbeschworen habe, »alles das infrage zu stellen, was so mühsam in so vielen Jahren an innerem Frieden und äusserem Vertrauen aufgebaut worden ist ${ }^{470}$, sei, um diese »böse Vergangenheit« endgültig aus den Beziehungen zwischen beiden Ländern zu bannen, vor allem eine Festigung der kulturellen Bande zwischen Franzosen und Deutschen vonnöten ${ }^{471}$. Dies umso mehr, als die politische Zusammenarbeit, welche ausnehmend gut sei, in eklatantem »Kontrast zu der in den Völkern weitverbreiteten Unkenntnis der Mentalität des Nachbarlandes « 472 stehe. Hier, auf der Ebene der Bevölkerungen, sei daher der größte Handlungsbedarf zur Förderung der Verständigung vorhanden. Denn das aus der wechselseitigen Ignoranz resultierende Misstrauen könne dazu führen, dass das im deutsch-französischen Verhältnis Erreichte immer wieder in Frage gestellt werde ${ }^{473}$.

Die Vermittlung von Informationen über das Partnerland, wissenschaftliche Forschung und die konsequente Entwicklung der gesellschaftlichen Beziehungen galten den amtlichen Stellen vor diesem Hintergrund als probate Mittel, um die Spuren, die die Vergangenheit hinterlassen hatte, zu tilgen. Die Regierungen in Paris und Bonn konnten hierfür durch ihre Kulturarbeit im Nachbarland, ihre Kooperation im Erziehungs- und Bildungswesen oder die Finanzierung des DFJW Rahmenbedingungen festlegen und Impulse setzen. Die Aufgabe, diesen staatlicherseits errichteten Überbau durch menschliche Begegnungen mit Leben zu erfüllen, kam jedoch ihrer Auffassung nach in besonderem Maße den regierungsunmittelbaren Kräften in den deutsch-französischen Beziehungen zu: Austauschorganisationen, Forschungseinrichtungen oder deutsch-französischen Gesellschaften ${ }^{474}$. Sie

469 Vgl. Robert Frank, Der Élysée-Vertrag: Ein deutsch-französischer Erinnerungsort?, in: Defrance, Pfeil (Hg.), Der Élysée-Vertrag, S. 237-247, hier S.242; Helga BoRIEs-Sawala, Un passé qui ne passe pas. Täter, Opfer und Erinnerungskonflikte in Frankreich, in: Wolfgang Stephan Kissel, Ulrike Liebert (Hg.), Perspektiven einer europäischen Erinnerungsgemeinschaft. Nationale Narrative und transnationale Dynamiken seit 1989, Berlin 2010, S. 105-126, hier S. 119.

470 BA, B 122, Bd. 16408, Entwurf für eine Presseerklärung des Bundespräsidenten, Juli 1974.

471 Siehe ibid.

472 PA-AA, Zwischenarchiv, Nr. 104059, Vermerk betreffend »Projektbezogene Förderung deutsch-französischer Beziehungen" vom 20. März 1974, S. 5.

473 Ibid.

${ }^{474}$ Vgl. ibid.; PA-AA, Zwischenarchiv, Nr. 106926, Vermerk betreffend »Reorganisation der Mittlerorganisationen« vom 3. April 1974; PA-AA, Zwischenarchiv, Nr. 104053, Bericht 
sollten in erster Linie die Verbindungen schaffen, mit Hilfe derer es gelingen würde, die Schatten des Zweiten Weltkriegs zu vertreiben.

In der Tat sahen die privaten Vereinigungen es als eine ihrer wesentlichen Aufgaben an, auch nach dreißig Jahren im deutsch-französischen Verhältnis den immer wieder erkennbar werdenden Nachwehen von Krieg und Besatzungszeit entgegenzutreten, wie im Verlauf des Klarsfeld-Prozesses geschehen. Mit ihren Verständigungsbemühungen wollten sie darauf hinwirken, dass hieraus keine schwerwiegenden Störungen der bilateralen Beziehungen entstehen konnten. Das BILD machte den Prozess gegen Beate Klarsfeld in den »Documents« zum Thema, wo der Chefredakteur der Zeitschrift, Antoine Wiss-Verdier, den französischen Lesern die Hintergründe des deutsch-französischen Zusatzabkommens erläuterte. Die Verantwortung für die mangelhafte Entnazifizierung und somit dafür, dass ein Mann wie Kurt Lischka nicht zur Rechenschaft gezogen worden war, sei, wie WissVerdier ausführte, nicht allein auf Seiten der Bundesrepublik, sondern in ebensolchem Maße bei den Alliierten zu suchen. Ein großer Teil der Westdeutschen, und vor allem die Jugendlichen, sähen die Verzögerung bei der Ratifizierung und die Rolle Achenbachs zudem in gleicher Weise kritisch wie die französische Öffentlichkeit. Französische Vermutungen, die Deutschen seien zu großen Teilen noch immer nationalsozialistischem Gedankengut verhaftet, entsprächen daher in keiner Weise der Realität ${ }^{475}$.

Beim DFI in Ludwigsburg kam der »Fall Klarsfeld" im Rahmen des Deutsch-Französischen Kolloquiums vom Oktober 1974 zur Sprache. In mehreren Beiträgen wurde hier darauf hingewiesen, dass die Vergangenheit noch immer einen maßgeblichen Einflussfaktor für die deutsch-französischen Beziehungen darstelle, der auch in der Analyse tagespolitischer Vorgänge nicht vernachlässigt werden dürfe. Ganz im Gegenteil: Deutschfranzösische Konflikte entstünden vielfach "par la brusque réapparition du passé [...] comme l'a rappelé la dernière affaire Klarsfeld avec tout son contexte émotionnel « ${ }^{476}$. In dieselbe Richtung weisend hatte ein Grußwort Bundesprä-

über die Zusammenkunft des Bevollmächtigten, Ministerpräsident Filbinger, mit dem französischen Bildungsminister René Haby und dem französischen Staatssekretär für das Hochschulwesen, Pierre Soisson, am 7. und 8. Oktober 1974; AMAE Paris-La Courneuve, Europe, RFA 1971-1976, Bd. 3025, "Note à l'attention de M. l'Ambassadeur: Réalisations franco-allemandes dans le domaine culturel« vom 30. September 1974; AN Fontainebleau, ministère de l'Éducation nationale, Bd. 900672/38, Vermerk betreffend »Coopération franco-allemande en matière d'enseignement« vom 11. Juni 1974.

475 Siehe Antoine Wiss-Verdier, Beate Klarsfeld ou la chasse aux nazis, in: Documents 29/5 (1974), S. 6-13.

476 PA-AA, Zwischenarchiv, Nr. 109189, Referat Henri Ménudiers anlässlich des DeutschFranzösischen Kolloquiums »Frankreich, Deutschland und die europäische Krise« vom 10.-13. Oktober 1974 in Ludwigsburg zum Thema "L'Allemagne d'Helmut Schmidt vue par la presse française«, S. 1; vgl. hierzu auch DFI-Archiv, Ordner DeutschFranzösisches Kolloquium 1974, Referat Roland Höhnes zum Thema »Die deutschfranzösischen Beziehungen in der deutschen Presse«, S. 1. 
sident Gustav Heinemanns an das DFI formuliert: »Manches bleibt angesichts der Schatten der Vergangenheit und unterschiedlicher Denkkategorien im Verhältnis beider Völker allerdings noch zu tun ${ }^{477}$. Nach drei verlustreichen Kriegen habe sich das deutsch-französische Verhältnis zwar nunmehr gebessert, dennoch werde immer wieder deutlich, dass »in den Völkern verwurzelte Ressentiments" ein längeres Leben hätten, als politische Verstimmungen oder wirtschaftliche Hindernisse. Die auf ein »besseres deutschfranzösisches Verstehen gerichtete Arbeit« des Ludwigsburger Instituts trage erfreulicherweise zu einem »Abbau solcher nationalen Vorurteile und damit auch zur europäischen Verständigung bei, deren Kernstück die Freundschaft zwischen Deutschland und Frankreich bildet ${ }^{478}$. Diesen Zielen sah sich das DFI in der Tat verpflichtet, dessen Verantwortliche, wie immer wieder betont wurde, dafür sorgen wollten, Kommunikationsstrukturen zwischen Frankreich und der Bundesrepublik in unterschiedlichen gesellschaftlichen Bereichen herzustellen. Diese würden im besten Falle verhindern, dass die Nachwirkungen der Vergangenheit, verstärkt durch mangelnden bilateralen Austausch, Fehlinformationen oder tendenziöse Medienberichte, $\mathrm{zu}$ einer ernsten Gefährdung der deutsch-französischen Beziehungen führen konnten ${ }^{479}$.

Leuchttürme in diesen unterhalb der Regierungsebene angesiedelten Kommunikationsstrukturen zwischen beiden Ländern stellten Mittlerpersönlichkeiten wie Alfred Grosser dar, der nach der Verurteilung Beate Klarsfelds in einem Kommentar in "Le Monde « in eindeutiger Weise Stellung bezog. Die Blockierung des deutsch-französischen Abkommens durch den Bundestag war in seinen Augen ebenso skandalös wie die verhältnismäßig harte Haftstrafe, welche das Kölner Landgericht gegen Klarsfeld verhängt hatte. Der Richter habe, wie Grosser in sarkastischem Ton schrieb, alles getan, um zu beweisen, dass die abfällige Meinung, die vielerorts über die deutsche Justiz und ihren Umgang mit der nationalsozialistischen Vergangenheit herrsche, vollkommen zu Recht bestehe. Dennoch dürfe das Urteil, so unverständlich und ungerecht es auch sein möge, in Frankreich nicht dazu führen, alle Deutschen unter Generalverdacht zu stellen. Allzu gern ergriffen heute diejenigen, die schon 1945 die Nachbarn auf immer hätten verdammen wollen, jede sich bietende Gelegenheit "pour assimiler la République fédérale à l'Allemagne éternelle de leurs ressentiments ¿ $^{480}$. Indessen falle es leicht, sich darüber zu empören, dass die Schuldigen ein ruhiges Leben führten, wenn

477 PA-AA, Zwischenarchiv, Nr. 109189, Grußwort Bundespräsident Gustav Heinemanns anlässlich des fünfundzwanzigjährigen Bestehens des Deutsch-Französischen Instituts Ludwigsburg vom 25. April 1974.

478 Ibid.

479 Siehe DFI-Archiv, Ordner Tätigkeitsberichte 1968-1977, Sachlicher Bericht zum Verwendungsnachweis 1974; Aufzeichnung »Tätigkeiten des Deutsch-Französischen Instituts in den Jahren 1974-1977«.

480 Alfred Grosser, De Beate Klarsfeld à Soljenitsyne, in: Le Monde, 13.07.1974, S. 3. 
man selbst Franzose sei und die Schuldigen Deutsche: »Nous, nous amnistions. Et si une Beate Klarsfeld algérienne venait nous interpeller sur le sort de tel homme politique, de tel ancien ministre, de tel chef militaire? Avec quelle facilité on évoque les victimes françaises et pas celles des autres pays! « ${ }^{481}$ Der Vergleich mit dem Algerienkrieg diente Alfred Grosser als Mittel, um das seinem Empfinden nach auf französischer Seite verloren gegangene Augenmaß bei der Beurteilung des Nachbarlandes anzumahnen und vor vorschnellen und generalisierenden Verurteilungen zu warnen. In einem Essay, den »Der Spiegel« Ende 1974 unter dem Titel »Die neuen Deutschen« veröffentlichte, führte Grosser seine Position weiter aus. Zwar seien zweifelsohne in Teilen der deutschen Bevölkerung noch immer Einstellungen vorhanden, »die den Sieg Hitlers ermöglicht haben", doch habe sich die bundesdeutsche Gesellschaft nach 1945 grundlegend gewandelt. Mit »neu« meine die Welt immer noch allzu oft die Frage, ob die Deutschen dem Nazismus abgeschworen hätten, ob sie gegen eine neue Fieberwelle gefeit seien. »Die Erneuerung ist tiefgreifend, muß die ermutigende Antwort heißen. Wie tief? Beate Klarsfeld in allen Ehren, aber die Deutschen von heute, das sind nicht die paar Lischkas, die noch ruhig umherlaufen ${ }^{482}$. Sie alle zusammengenommen wögen, wie Grosser bekräftigte, nicht viel, wenn man auf die andere Seite der Waagschale das jüngste Wahlergebnis zum Bundestag lege, welches zeigte, dass die Parteien, die sich auf die freiheitlich-demokratische Grundordnung beriefen, nahezu einhundert Prozent der Wählerstimmen erhalten hätten ${ }^{483}$. Ähnlich hatte zuvor bereits Pierre Bertaux argumentiert. Auch ihm galt das Abstimmungsverhalten der bundesdeutschen Bürger bei den zurückliegenden Parlamentswahlen als eindeutiger Ausweis für den demokratischen Geist, der in der Bundesrepublik der 1970er Jahre vorherrschte. "La RFA«, so das Urteil Bertaux', "vient de faire la preuve de sa maturité politique et de son esprit démocratique; elle n'a, sur ce point, de leçons de civisme à recevoir de personne «484. Das Demokratiebewusstsein der Deutschen - dies die versichernde Botschaft an seine Landsleute - sei in einer Weise ausgeprägt, dass rechtsextremistische Parteien oder Strömungen auch in Zukunft nicht mehr als eine marginale Rolle in der politischen Landschaft Westdeutschlands spielen würden.

Der Gerichtsprozess gegen Beate Klarsfeld und die stark verzögerte Ratifizierung des Zusatzabkommens hatten bei Opferverbänden und Presse in Frankreich Unverständnis, Empörung und Wut über das "Deutschland Kurt Lischkas« hervorgerufen. Nachweisliche NS-Täter konnten dort dem Anschein nach als unbescholtene Bürger gelten, Richter ein Recht sprechen, das sie als Gefangene einer unbewältigten Vergangenheit auswies. Selbst die

481 Ibid.

482 Ders., Die neuen Deutschen, in: Der Spiegel, 23.12.1974, S. 90.

483 Siehe ibid.

${ }^{484}$ Bertaux, Les élections du 19 novembre, S. 58. 
gewählten Vertreter des Volkes schienen Teil eines gesellschaftlichen Konsenses zu sein, nicht gesühntes Unrecht zu beschweigen und zu vergessen. Demgegenüber stand die öffentlichkeitswirksam in Szene gesetzte Entente zwischen Staatspräsident Giscard d'Estaing und Bundeskanzler Schmidt, die, nicht selten garniert mit symbolischen Versöhnungsgesten, über alle Zweifel an der deutsch-französischen Freundschaft erhaben schien. Demgegenüber standen auch die staatlicherseits angestoßenen Begegnungen zwischen jungen Deutschen und Franzosen im Rahmen der Austauschprogramme des DFJW oder der zahlreichen Schulpartnerschaften, die sich aus privater Initiative speisende Informations- und Kontaktarbeit des BILD oder des DFI und die geistige Vermittlungstätigkeit Alfred Grossers. Die Debatten um den »Fall Klarsfeld " nahmen nach der Ratifizierung des so viel diskutierten deutschfranzösischen Abkommens Anfang 1975 ein Ende. Dass sich jedoch Grossers Entwurf der "neuen Deutschen " gegen die Negativfolie des "Deutschlands der Lischkas" trotz aller verständigungsfördernden Bemühungen zunächst nicht durchsetzen konnte, macht die Tatsache deutlich, dass bis zum Ende der 1970er Jahre immer neue Konflikte hervortraten, in denen Krieg und Besatzungszeit nachwirkten und alte Feindbilder die Oberhand über die Freundschaftssymbolik der Gegenwart gewannen.

\subsubsection{SS-Kameradschaftsverbände: Hindernisse für ein freundschaftliches deutsch-französisches Verhältnis}

Im Juli 1976 sorgte der Tod des ehemaligen Oberst der Waffen-SS, Joachim Peiper ${ }^{485}$, in Frankreich wie in Westdeutschland für erhebliches Aufsehen. Peiper, der kurzzeitig Adjutant Heinrich Himmlers gewesen war und während des Zweiten Weltkriegs verschiedene Kampfverbände der SS-Panzerdivision »Leibstandarte Adolf Hitler« befehligt hatte ${ }^{486}$, war aufgrund seiner Beteiligung an der Erschießung von Kriegsgefangenen im Dezember 1944 bei Malmedy ${ }^{487}$ in den Dachauer Prozessen durch ein amerikanisches Militärgericht zum Tode verurteilt worden ${ }^{488}$. Nachdem er bereits sieben Jahre

485 Zur Biografie Peipers vgl. KLEE, Das Personenlexikon zum Dritten Reich, S. 453.

486 Vgl. hierzu ausführlich Bernd Wegner, Hitlers Politische Soldaten: Die Waffen-SS 1933-1945. Leitbild, Struktur und Funktion einer nationalsozialistischen Elite, Paderborn u. a. ${ }^{9} 2010$; René RohrKamp, »Weltanschaulich gefestigte Kämpfer«. Die Soldaten der Waffen-SS 1933-1945. Organisation - Personal - Sozialstrukturen, Paderborn u. a. 2010, hier zur »Leibstandarte Adolf Hitler« bes. S. 234.

487 Vgl. Volker Riess, Malmédy - Verbrechen, Justiz und Nachkriegspolitik, in: Wolfgang Wette, Gerd R. Ueberschär (Hg.), Kriegsverbrechen im 20. Jahrhundert, Darmstadt 2001, S. 247-258; Klaus-Dietmar Henke, Die amerikanische Besetzung Deutschlands, München ${ }^{2}$ 1996, S. 312-342; Peter M. Quadflieg, René Rohrkamp (Hg.), Das »Massaker von Malmedy«. Täter, Opfer, Forschungsperspektiven: Ein Werkbuch, Aachen 2010.

488 Vgl. Robert Sigel, Die Dachauer Prozesse, in: Norbert Göttler (Hg.), Nach der »Stunde Null«. Stadt und Landkreis Dachau 1945 bis 1949, München 2008, S. 178-193, hier 
in Haft gewesen war, wurde das Urteil 1951 in eine lebenslange Freiheitsstrafe umgewandelt. Wiederum sechs Jahre später wurde Peiper jedoch aus der Haft entlassen, lebte zunächst in der Bundesrepublik und siedelte im Jahr 1969 mit seiner Familie nach Frankreich über, wo er sich in dem westlich der Vogesen gelegenen Dorf Traves im Departement Haute-Saône niederließ ${ }^{489}$. Obwohl unter seinem richtigen Namen lebend, blieb Peipers Vergangenheit in Frankreich für lange Jahre unentdeckt. Erst im Sommer 1976, nun allerdings in großer Aufmachung, berichtete die französische Presse, insbesondere "L'Humanité «, über Peipers Karriere während der NS-Zeit ${ }^{490}$ und forderte vehement seine Ausweisung aus Frankreich und eine nachträgliche Bestrafung des ehemaligen SS-Offiziers für bis dahin ungesühnte Kriegsvergehen in Italien im Jahr $1943^{491}$.

Drei Wochen nach Beginn der Medienberichte verübten unbekannte Täter einen Brandanschlag auf das Haus Peipers, bei dem dieser ums Leben $\mathrm{kam}$. In einem Bekennerschreiben, das wenig später mehreren französischen Zeitungen zuging, übernahm eine Organisation des Namens Les vengeurs die Verantwortung für das Attentat und kündigte gleichzeitig die Ermordung weiterer strafloser deutscher Kriegsverbrecher $a^{492}$. Die westdeutsche Presse reagierte auf die Umstände der Gewalttat gegen Peiper mit Befremden. Dieser, so die weitgehend einhellige Meinung, habe schließlich im Gefängnis für seine Verbrechen während des Krieges gebüßt. Nun sei er, der doch nur seinen Lebensabend in Ruhe hatte beschließen wollen, einer infamen Hetzkampagne der französischen Kommunisten zum Opfer gefallen. "Die Welt« schrieb etwa: »Er überlebte als Panzeroffizier den Zweiten Weltkrieg, er überlebte sogar die Verurteilung zum Tode durch ein amerikanisches Kriegsgericht, aber er überlebte nicht mehr die `Humanität ‘ der französischen Kommunistenzeitung >Humanité««. Kaum jemand zweifele daran, wie

S. 187f.; Ludwig Eiber, Robert Sigel (Hg.), Dachauer Prozesse. NS-Verbrechen vor amerikanischen Militärgerichten in Dachau 1945-48. Verfahren, Ergebnisse, Nachwirkungen, Göttingen 2007.

489 Vgl. Brunner, Der Frankreich-Komplex, S. 325.

490 Vgl. PA-AA, Zwischenarchiv, Nr. 113544, Schreiben des deutschen Generalkonsulats Lyon an das Auswärtige Amt betreffend "Vermutliche Ermordung des ehemaligen Oberst der Waffen-SS Joachim Peiper« vom 19. Juli 1976; Früherer SS-Oberst vermutlich ermordet. Brandanschlag in Frankreich auf das Haus von Joachim Peiper, in: FAZ, 15.07.1976, S. 6; Untergrundorganisation droht mit Tötung deutscher Kriegsverbrecher, in: FAZ, 16.07.1976, S. 5 und 7.

491 Vgl. hierzu Gerhard Schreiber, Deutsche Kriegsverbrechen in Italien. Täter, Opfer, Strafverfolgung, München 1996, S. 127-135; Juliane WetzeL, Italien, in: Wolfgang Benz, Barbara Distel (Hg.), Der Ort des Terrors. Geschichte der nationalsozialistischen Konzentrationslager, Bd. 9: Arbeitserziehungslager, Ghettos, Jugendschutzlager, Polizeihaftlager, Sonderlager, Zigeunerlager, Zwangsarbeiterlager, München 2009, S. 292-312, hier S. 307.

492 Vgl. AMAE Paris-La Courneuve, Europe, RFA 1976-1980, Bd. 4000, Schreiben des französischen Außenministeriums an die französische Botschaft Bonn betreffend »Affaire Peiper« vom 16. Juli 1976. 
die Zeitung befand, dass diejenigen, die Peiper ermordet hätten, »den stark kommunistisch bestimmten Kreisen der französischen Résistance entstammten ${ }^{493}$. Der ehemalige SS-Oberst habe in Frankreich versucht, so berichtete "Die Zeit«, seine Vergangenheit hinter sich zu lassen. Er habe die französische Küche und Lebensart seit 1940 schätzen gelernt, habe die Menschen des Nachbarlandes geliebt und sei denn auch gut mit ihnen ausgekommen. »Er sah keinen Grund sich zu verstecken, [...] schließlich hatte er zwölf Jahre gebüßt. Aber aus dem erhofften ruhigen Lebensabend wurde nichts. In diesem Sommer ließen die Kommunisten ihre Kettenhunde los « ${ }^{494}$. Noch deutlicher zeichnete »Der Spiegel« das Bild eines Mannes, der sich auch im Krieg Anstand und Menschlichkeit bewahrt hatte: »Einer von der alten Garde« sei Peiper eben gewesen, »ein schneidiger Typ wie sein Oberbefehlshaber Sepp Dietrich ${ }^{495}$, mit dem zusammen sein Name immer in Kameradenmund war. Einer der >Indianergedanken ` in den Panzerschlachten hatte, und so, als shochdekorierten Mann obendrein, akzeptierten ihn auch die Bürger von Traves ${ }^{496}$. Nicht so sehr der Mord als solcher rief auf westdeutscher Seite Entrüstung hervor, als vielmehr das Empfinden, Peiper sei Opfer von Kräften geworden, welche den Deutschen ihre Vergangenheit, mochten sie hierfür auch noch so sehr Buße getan haben, mit dem erhobenen Zeigefinger eines immer währenden moralischen Triumphes vorhielten ${ }^{497}$.

Weitere Kreise zog die "Affäre Peiper«, als die rechtsextreme DVU im September 1976 in Köln und im November in Mannheim »Ehrenkundgebungen« für den Toten veranstaltete ${ }^{498}$, über welche die französischen

493 Günther Deschner, Ein Mord als Mittel zu einer Diffamierungs-Kampagne, in: Die Welt, 16.07.1976, S. 6.

${ }^{494}$ Karl-Heinz Janssen, Der Tod holte ihn ein. Warum ein Oberst der Waffen-SS seine Vergangenheit nicht abschütteln konnte, in: Die Zeit, 23.07.1976, S. 5.

495 Generaloberst der Waffen-SS Josef »Sepp« Dietrich (1892-1966) war Befehlshaber der »Leibstandarte Adolf Hitler « und wurde nach dem Krieg als Mitverantwortlicher für das "Massaker von Malmedy« zu lebenslänglicher Haft verurteilt, vgl. Christopher CLARK, Josef »Sepp« Dietrich - Landsknecht im Dienste Hitlers, in: Ronald SMELSER, Enrico Syring (Hg.), Die SS: Elite unter dem Totenkopf. 30 Lebensläufe, Paderborn u. a. 2000, S. 119-133; William T. Allbritton, Samuel W. Mitcham Jr., SS-Oberstgruppenführer und Generaloberst der Waffen-SS Joseph (Sepp) Dietrich, in: Gerd R. UeberschäR (Hg.), Hitlers militärische Elite, Bd. 2: Vom Kriegsbeginn bis zum Weltkriegsende, Darmstadt 1998, S. 37-44.

${ }^{496}$ Pech für ihn, in: Der Spiegel, 19.07.1976, S. 56f., Zitate S. 57.

497 Vgl. hierzu Daniel VERNET, Un journal allemand dénonce l'action des forces qui ne veulent pas oublier le passé, in: Le Monde, 16.07.1976, S. 22; AMAE Paris-La Courneuve, Europe, RFA 1976-1980, Bd. 4000, Schreiben der französischen Botschaft Bonn an das französische Außenministerium betreffend »Presse allemande du 16 juillet 1976« vom 16. Juli 1976.

498 Vgl. AMAE Paris-La Courneuve, Europe, RFA 1976-1980, Bd. 4000, Schreiben des französischen Botschafters in Bonn, Olivier Wormser, an das französische Außenministerium betreffend "Manifestation à la mémoire de Peiper " vom 13. September 1976; Schreiben der französischen Botschaft Bonn, Paul Henry, an das französische 
Medien breit berichteten ${ }^{499}$, sowie durch wiederholt öffentlich vorgetragene Solidaritätsbekundungen von Vereinigungen ehemaliger SS-Angehöriger. Die Existenz derartiger Verbände rückte im Zusammenhang mit dem Tod Peipers stärker ans Licht und führte auf Seiten der französischen Presse zu dem Verdacht, in der Bundesrepublik seien die Fahnenträger der nationalsozialistischen Ideologie wieder auf dem Vormarsch. Bereits im Mai 1976 hatte »Le Monde « konstatiert: "De fait, depuis quelques mois, des petits groupes ou des individus isolés se réclamant de l'idéologie nazie se manifestent ouvertement en République fédérale « ${ }^{500}$. Die öffentlichen Ehrbezeugungen für Peiper von Zusammenschlüssen ehemaliger Soldaten der SS verstärkten in Frankreich das Gefühl, die Geisteshaltung der ewig Gestrigen werde in Westdeutschland wieder zunehmend geduldet. Für mehrere französische Verfolgtenorganisationen waren die eingetretenen Entwicklungen jedenfalls Grund genug, um Anfang Oktober 1976 vor der deutschen Botschaft in Paris gegen die vermeintliche Zunahme rechtsradikaler Veranstaltungen in der Bundesrepublik zu demonstrieren und vor allem ein ihrer Auffassung nach lange überfälliges Verbot der SS-Kameradschaften zu reklamieren ${ }^{501}$.

Diese Forderung war indes nicht neu. Schon seit Beginn der 1970er Jahre hatte insbesondere das Bestehen der Vereinigung der Freunde der SS-Division "Das Reich", die im Oktober 1971 auf Betreiben des ehemaligen SSHauptsturmführers Hermann Buch im bayerischen Rosenheim gegründet worden war $^{502}$, in Frankreich immer wieder Proteste hervorgerufen. Die 2. SS-Panzerdivision "Das Reich « unter dem Kommando von Generalmajor Heinz Lammerding zeichnete 1944 für die Kriegsverbrechen in den französischen Orten Tulle und Oradour-sur-Glane verantwortlich, deren Namen sich gleichsam als Symbole nationalsozialistischer Gräueltaten in das kollektive Gedächtnis Frankreichs eingebrannt hatten. In Tulle, Hauptstadt des Depar-

Außenministerium betreffend "Manifestation d'extrême-droite« vom 8. November 1976; Vermerk betreffend "Activités des mouvements d'anciens nazis en RFA" vom 8. November 1976; PA-AA, Zwischenarchiv, Nr. 111202, Vermerk betreffend »Gedenkveranstaltungen der Deutschen Volksunion (DVU) für den ehemaligen SS-Offizier Peiper «, nicht datiert; PA-AA, Zwischenarchiv, Nr. 113544, Vermerk betreffend "Gedenkveranstaltung der rechtsextremen Deutschen Volksunion für den ehemaligen SSOberst Peiper« vom 10. September 1976.

499 Vgl. exemplarisch Les nazis de Cologne ont pleuré Peiper sous la protection de la police, in: France-Soir, 14.09.1976, S. 1.

500 Daniel Vernet, »Jamais depuis 1945 le nazisme n'a été aussi glorifié qu'aujourd'hui« constate le ministre de l'intérieur, in: Le Monde, 06.05.1976, S. 3.

501 Siehe PA-AA, Auslandsvertretungen, Botschaft Paris, Bd. 13523, Schreiben des deutschen Botschafters in Paris, Axel Herbst, an das Auswärtige Amt betreffend "Demonstration von französischen Verfolgten- und Résistanceorganisationen vor der Botschaft am 6.10.76« vom 7. Oktober 1976.

502 Siehe hierzu AMAE Paris-La Courneuve, Europe, RFA 1971-1976, Bd. 2952, Bericht des französischen Generalkonsuls in München, Charles de Bartillat, betreffend »Première réunion des anciens de la division SS >Das Reich«" vom 22. Oktober 1971. 
tements Corrèze, wurden im Juni 1944 als Repressalie für Partisanenangriffe auf deutsche Soldaten 99 willkürlich herausgegriffene männliche Einwohner in den Straßen der Stadt erhängt. Das nordwestlich von Limoges gelegene Oradour zerstörten SS-Soldaten der Panzerdivision Lammerdings vollständig. Nahezu alle Bewohner des Dorfes, 400 Erwachsene und 242 Kinder, wurden auf grausame Weise ermordet ${ }^{503}$. Eine Vereinigung, deren Name hiermit verbunden war, musste in Frankreich unweigerlich Erinnerungen an Besatzungszeit und deutsche Kriegsverbrechen wecken und die Tatsache, dass sie in der Bundesrepublik legal existierte, Unverständnis und Empörung hervorrufen.

Zahlreich waren denn auch die Proteste, welche französische Opferverbände öffentlich oder in Schreiben an Bonner und Pariser Regierungsstellen kundtaten. In der Erklärung einer nahe Bordeaux beheimateten Organisation vom Januar 1972 hieß es etwa:

Il est de notoriété publique que DAS REICH s'est rendu coupable de nombreux actes de terrorisme et de représailles à l'égard des populations civiles dans tous les pays occupés par l'Allemagne [...]. Aucun Français ne peut oublier les atroces massacres de femmes, d'enfants et d'hommes notamment à Oradour-sur-Glane, à Tulle et à la ferme de Richmond ${ }^{504}$.

Einhellig war daher die Forderung der Verfolgtenorganisationen, die genannte SS-Kameradschaft sowie sämtliche in der Bundesrepublik existierenden Vereinigungen ähnlichen Typs zu verbieten. Ein mit »Contre le réveil du nazisme en Allemagne« überschriebener Aufruf eines Veteranen- und Kriegsopferverbandes aus Grenoble formulierte: »Le Comité [...] demande au gouvernement français d'intervenir auprès du gouvernement de la République fédérale, afin de faire procéder à la dissolution de cette organisation et à l'interdiction de toutes les associations d'anciens SS ou nazis « ${ }^{505}$. Denn schließlich stellten das Vorhandensein derartiger Vereinigungen und ihre öffentlichen Auftritte nicht nur eine grobe Beleidung für die Opfer des $\mathrm{Na}$ tionalsozialismus dar, sondern ebenso ein schwerwiegendes Hindernis für freundschaftliche Beziehungen zwischen Deutschen und Franzosen: »Il nous

503 Vgl. zu den Massakern von Tulle und Oradour-sur-Glane Ahlrich Meyer, Die deutsche Besatzung in Frankreich 1940-1944. Widerstandsbekämpfung und Judenverfolgung, Darmstadt 2000, S. 149-170; Ders., Oradour 1944, in: Gerd R. Ueberschär (Hg.), Orte des Grauens - Verbrechen im Zweiten Weltkrieg, Darmstadt 2003, S. 176-185; Peter Lieb, Konventioneller Krieg oder Weltanschauungskrieg? Kriegführung und Partisanenbekämpfung in Frankreich 1943/44, München 2007, S. 360-376; Jean-Jacques Fouché, Oradour, Paris 2001; Ders., Oradour. La politique et la justice, Paris 2004; Ders., Tulle, nouveaux regards sur les pendaisons et les événements de juin 1944, Paris 2008.

504 AMAE Paris-La Courneuve, Europe, RFA 1971-1976, Bd. 2952, Erklärung des Comité d'entente des associations des anciens combattants et victimes de la guerre de Mérignac vom 15. Januar 1972.

505 AMAE Paris-La Courneuve, Europe, RFA 1971-1976, Bd. 2952, Aufruf »Contre le réveil du nazisme en Allemagne« des Comité départemental de liaison des associations d'anciens combattants et de victimes de guerre, Grenoble, Oktober 1971. 
paraît que de tels faits [...] constituent de graves obstacles tant à la nécessaire amitié entre les peuples français et allemand qu'à la détente en Europe. Seule la rupture totale et résolue avec le passé hitlérien peut ouvrir les perspectives nouvelles que nous souhaitons « ${ }^{506}$. Die Existenz der SS-Kameradschaften bildete somit einen potenziellen Störfaktor des deutsch-französischen Verhältnisses, der, wie sich im Falle der Ermordung Joachim Peipers zeigte, rasch virulent werden konnte.

In Anbetracht der Solidaritätsbekundungen verschiedener Verbände ehemaliger SS-Angehöriger nach dem Anschlag auf Peiper sowie der Aktivitäten der rechtsextremen DVU, die zeitweilig gar die Absicht bekundete, eine Stele für Peiper am Rande des Areals des früheren Konzentrationslagers Dachau errichten zu wollen ${ }^{507}$, sah »Le Figaro « im September 1976 bereits die »nostalgiques d'Hitler « aus ihrem bisherigen Schattendasein hervortreten ${ }^{508}$. Diverse französische Opferverbände warnten seit der »Affäre Peiper « verstärkt vor einer Wiederbelebung nationalsozialistischer Strömungen in der Bundesrepublik und sensibilisierten damit eine breitere Öffentlichkeit in Frankreich für das Thema. Das Comité international de Sachsenhausen beobachtete etwa, wie dessen Präsident im Oktober 1976 an Bundestagspräsidentin Annemarie Renger schrieb, "avec une profonde inquiétude les activités croissantes des anciennes formations SS [...] en République fédérale d'Allemagne « ${ }^{509}$. Die Fédération nationale des déportés et internés, résistants et patriotes fragte in einer Protestnote an den deutschen Botschafter in Paris: "Nous avons toujours su distinguer entre les Allemands et les nazis, nous avons toujours contribué à la réconciliation de nos deux peuples. Serions-nous des idéalistes? ${ }^{510}$ In der Bundesrepublik, diese Vorstellung fand hier immer mehr Verbreitung, konnten deutsche Kriegsverbrecher einen unangemessen breiten Raum im öffentlichen Leben einnehmen. Ungestraft waren sie für ihre Vergehen zwischen

506 AMAE Paris-La Courneuve, Europe, RFA 1971-1976, Bd. 2952, Schreiben des Mouvement contre le racisme, l'antisémitisme et pour la paix an den französischen Außenminister Maurice Schumann vom 21. Oktober 1971; vgl. auch ibid., Schreiben der Amicale des anciens détenues patriotes de la centrale d'Éysses an den französischen Premierminister Jacques Chaban-Delmas vom 15. Februar 1972 sowie zahlreiche Protestschreiben und Resolutionen weiterer französischer Opferverbände.

507 Vgl. hierzu PA-AA, Zwischenarchiv, Nr. 113544, Vermerk betreffend »Denkmal für Joachim Peiper in Dachau « vom 9. September 1976; AMAE Paris-La Courneuve, Europe, RFA 1976-1980, Bd. 4000, Vermerk für den Secrétaire d'État aux anciens combattants betreffend »Projet de manifestation à la mémoire de Peiper«, nicht datiert.

508 Siehe Baudouin BollaERT, RFA: les nostalgiques d'Hitler sortent de l'ombre, in: Le Figaro, 09.09.1976, S. 3 .

509 PA-AA, Auslandsvertretungen, Botschaft Paris, Bd. 13523, Schreiben des Comité international de Sachsenhausen an Bundestagspräsidentin Annemarie Renger vom 6. Oktober 1976.

510 PA-AA, Auslandsvertretungen, Botschaft Paris, Bd. 13523, Schreiben der Fédération nationale des déportés et internés, résistants et patriotes an den deutschen Botschafter in Paris vom 9. September 1976. 
1939 und 1945 geblieben, ungestraft konnten sie sich dreißig Jahre später der Pflege ihrer »militärischen Traditionen « widmen. Wie sollten Franzosen, so die Frage, die in den seit Sommer 1976 geführten Diskussionen immer wieder mitschwang, einem Land Sympathie entgegenbringen können, das dies duldete?

Die öffentliche Erregung, welche die legale Existenz von Organisationen ehemaliger SS-Soldaten und insbesondere der Vereinigung der Freunde der SS-Division "Das Reich « in Frankreich ausgelöst hatte, nahmen die Regierungsstellen derweil mit wachsender Sorge zur Kenntnis. Verstärkt durch das im Milieu der Opfer- und Veteranenverbände um sich greifende Gefühl, in Westdeutschland mehrten sich wieder nationalsozialistische Umtriebe, konnte sich, so die Befürchtung, das deutsch-französische Verhältnis leicht eintrüben. Bereits im Rahmen von Konsultationen der politischen Direktoren des Auswärtigen Amts und des Quai d'Orsay im Juni 1975 hatte die französische Seite ihre westdeutschen Gesprächspartner eindringlich darauf hingewiesen, dass Teile der französischen Öffentlichkeit und der Nationalversammlung insbesondere das Bestehen der SS-Truppenkameradschaft "Das Reich « für unvereinbar mit der Absicht Frankreichs hielten, ein enges Verhältnis zur Bundesrepublik zu entwickeln. Die französische Regierung könne ihre Politik der Aussöhnung mit Westdeutschland nur dann glaubwürdig im eigenen Lande vertreten, wenn diese Organisation von der Bundesregierung und der westdeutschen Öffentlichkeit nicht mehr toleriert werde ${ }^{511}$. Da, wie daraufhin die Diplomaten des Auswärtigen Amts festhielten, zu befürchten sei, »daß die guten deutsch-französischen Beziehungen durch das Verhalten der genannten Vereinigung Schaden nehmen könnten ${ }^{512}$, wurde über das Bundesministerium des Innern eine Überprüfung der Organisation angestrengt. Aus dortiger Sicht förderte diese jedoch keine stichhaltigen Gründe zu Tage, um ein Verbot zu erwirken. Seit ihrer Gründung 1971 habe die Vereinigung keine erkennbare Tätigkeit entfaltet, »die den Strafgesetzen zuwidergelaufen wäre oder sich gegen den Gedanken der verfassungsmäßigen Ordnung und der Völkerverständigung gerichtet hätte ${ }^{513}$. Die Mitglieder beschäftigten sich ausschließlich mit der Klärung der Schicksale von Vermissten und sozialen Aufgaben, Anhaltspunkte dafür, dass es sich um eine Nachfolgeorganisation der Waffen-SS handele, gebe es nicht. Die Bundesregierung habe, wie ein Schreiben des Auswärtigen Amts an die deutsche Botschaft in Paris formulierte, im Übrigen Verständnis für die Demarche

511 Siehe PA-AA, Zwischenarchiv, Nr. 109188, Vermerk betreffend »Vereinigung der Freunde der SS-Division >Das Reich « vom 4. Juli 1975.

512 PA-AA, Zwischenarchiv, Nr. 109188, Schreiben des Auswärtigen Amts an das Bundesministerium des Innern betreffend »Vereinigung der Freunde der SS-Division >Das Reich«" vom 7. Juli 1975.

513 PA-AA, Auslandsvertretungen, Botschaft Paris, Bd. 13523, Schreiben des Auswärtigen Amts betreffend »Truppenkameradschaft der 2. SS-Panzer-Division `Das Reich«"vom 28. Oktober 1975. 
der französischen Regierung und die Emotionen, welche die Existenz der Vereinigung in Frankreich hervorrufe, aus rechtlicher Sicht seien ihr jedoch die Hände gebunden ${ }^{514}$.

Auf Seiten der amtlichen französischen Stellen wurde diese Haltung als höchst unbefriedigend empfunden, hielten doch die Proteste der Verfolgtenorganisationen weiter an und war die Pariser Regierung nicht zuletzt auch aus den Reihen des Parlaments immer wieder mit Anfragen konfrontiert, die das Thema in steter Regelmäßigkeit auf die innenpolitische Agenda zurückbrachten $^{515}$. Das Unverständnis für die Duldung der SS-Kameradschaften durch die westdeutschen Behörden werde, wie der Quai d'Orsay gegenüber der deutschen Botschaft im Februar 1976 erklärte, von vielen Franzosen und partiell auch durch das französische Außenministerium selbst geteilt ${ }^{516}$. Die negativen Auswirkungen, welche gerade die Existenz der Vereinigung der ehemaligen Angehörigen der SS-Division "Das Reich" auf die französische Öffentlichkeit habe, seien schließlich nicht zu unterschätzen ${ }^{517}$. »Pour peu que les milieux hostiles à l'entente franco-allemande qui existent dans notre pays le veuillent, le thème de la création en Allemagne, aujourd'hui, d'une amicale des anciens d'une division d'aussi sinistre mémoire pourrait être aisément exploité «18. Zwar stand für die Verantwortlichen im französischen Außenministerium fest, dass es sehr viel schlechten Willen brauche, um aus den vorgefallenen Ereignissen den Schluss zu ziehen, in der Bundesrepublik komme es zu einem Wiedererwachen des Nationalsozialismus ${ }^{519}$. Jedoch bestünden in Frankreich gesellschaftliche Strömungen, welche diese Ansicht verbreiteten und nicht ohne Einfluss seien. Diese müsse man ernst nehmen und ihnen im Sinne einer Festigung der deutsch-französischen Freundschaft mäßigend entgegentreten. »Autrement, les adversaires de l'entente francoallemande auraient beau jeu $\ll^{520}$.

514 Siehe ibid.

515 Vgl. AMAE Paris-La Courneuve, Europe, RFA 1971-1976, Bd. 3120, Vermerk betreffend "Question écrite posée le 7 juin 1975 par M. Pranchère, député, au Premier ministre" vom 23. Juni 1975.

516 Siehe PA-AA, Auslandsvertretungen, Botschaft Paris, Bd. 13523, Schreiben des deutschen Botschafters in Paris, Sigismund von Braun, an das Auswärtige Amt vom 26. Februar 1976.

517 Siehe AMAE Paris-La Courneuve, Europe, RFA 1971-1976, Bd. 3120, Vermerk betreffend »Association des anciens de la division 〉Das Reich«« vom 4. März 1976.

518 AMAE Paris-La Courneuve, Europe, RFA 1971-1976, Bd. 3010, Vermerk betreffend »Protestations en France contre la constitution en RFA d'une association des anciens de la division SS >Das Reich`« vom 5. Februar 1976.

519 Siehe AMAE Paris-La Courneuve, Europe, RFA 1976-1980, Bd. 4000, Vermerk betreffend »Activités des mouvements d'anciens nazis en RFA« vom 8. November 1976.

520 AMAE Paris-La Courneuve, Europe, RFA 1976-1980, Bd. 4000, Schreiben des französischen Außenministeriums, Andreani, an die französische Botschaft Bonn betreffend »Manifestation à la mémoire de Peiper« vom 9. September 1976. 
Die Bonner Diplomaten stimmten hierin mit ihren französischen Gesprächspartnern voll und ganz überein. Man sei sich bewusst, wie eine Aufzeichnung des Auswärtigen Amts bezüglich des Deutschlandbildes in Frankreich konstatierte, »daß die Schatten der Vergangenheit noch lange über unseren beiden Ländern liegen werden und daß es immer wieder einmal zu einem Aufflammen von >Negativ-Stimmungen ${ }^{2}$ kommen kann $«^{521}$. In solchen Fällen seien all diejenigen politischen Kräfte, die an der Aussöhnung zwischen Deutschland und Frankreich festhielten, dazu aufgerufen, öffentlich ihre Solidarität zu bekunden und für die Verständigung einzustehen: „Wir sollten schließlich gemeinsam überlegen, wie wir die noch unzureichenden gegenseitigen Kenntnisse verbessern und die vielfachen Vorurteile der Deutschen über die Franzosen und der Franzosen über die Deutschen weiter abbauen können ${ }^{4522}$. Allerdings herrschte eine weitgehend illusionslose Klarheit darüber, dass ein solches Ziel nur durch äußerst langfristige und kontinuierliche Anstrengungen erreicht werden konnte. "La réconciliation est une œuvre continue et fragile; il faudra encore du temps pour que le cœur rejoigne la raison $"$ " 23 , wie im französischen Außenministerium im November 1976 bemerkt wurde. Gleichwohl sollte nichts unversucht gelassen werden.

Nach Ansicht des Quai d'Orsay zeigte die Aufregung um die "manifestations néo-nazies « ${ }^{524}$, welche zu einer wirklichen Gefahr überhaupt nur durch die sensationsheischende mediale Aufbereitung werden könnten, vor allem, wie übermäßig und irrational die Reaktionen in beiden Ländern noch immer ausfielen, wenn die deutsch-französische Vergangenheit im Spiel sei. Die Regierungen hätten daher vor allem darauf bedacht zu sein, die Öffentlichkeit diesseits und jenseits des Rheins für ihre Ziele zu gewinnen und sie von der unbedingten Notwendigkeit privilegierter deutsch-französischer Beziehungen zu überzeugen. Hierzu sollte, wie die französische Botschaft in Bonn vorschlug, die zwischenzeitlich aufgegebene Praxis der systematischen Einladung von Journalisten wieder aufgenommen werden. So könne die Presse einen offeneren Blick auf das Nachbarland erhalten, verständnisvoller hierüber berichten und somit in günstiger Weise Einfluss auch auf die Einstellung der Bevölkerungen ausüben ${ }^{525}$.

Des Weiteren sei es geboten, so auch schon die vermehrt gestellte Forderung der westdeutschen Stellen, auf die Programmgestaltung des

521 PA-AA, Auslandsvertretungen, Botschaft Paris, Bd. 13523, Aufzeichnung bezüglich des Deutschlandbildes in Frankreich vom 12. Oktober 1977, S. 1.

522 Ibid., S. 2.

523 AMAE Nantes, Bonn Ambassade, Bd. 340, Vermerk betreffend »Visite du Ministre à Bonn le 26 novembre« vom 15. November 1976, S. 3.

524 AMAE Nantes, Bonn Ambassade, Bd. 322, Aufzeichnung "La République fédérale d'Allemagne et sa politique extérieure au début de 1977 «vom 27. Januar 1977, S. 12.

525 Vgl. hierzu AMAE Paris-La Courneuve, Europe, RFA 1976-1980, Bd. 3962, Schreiben des französischen Botschafters in Bonn, Olivier Wormser, an die Direction des services d'information et de presse im französischen Außenministerium vom 8. Oktober 1976. 
französischen Fernsehens einzuwirken. Denn hier würden den Franzosen bald allabendlich Filme gezeigt, die das Bild des deutschen Besatzers nach wie vor pflegten und hierdurch die französischen Erinnerungen an den Zweiten Weltkrieg in unguter Weise wachhielten: »La télévision française [...] continue à donner à nos compatriotes [...] une image de l'Allemagne qui n'est pas de nature de créer un climat de compréhension pour les difficultés qui peuvent surgir entre Paris et Bonn ${ }^{526}$. Daher gelte es, die an der Kriegsvergangenheit orientierten Filme durch Dokumentationen zu ersetzen, die stärker das aktuelle Deutschland in den Fokus nähmen. Vor allem im Rahmen von deutschfranzösischen Fernsehkoproduktionen, deren Anzahl deutlich gesteigert werden müsse, könne dies erreicht werden ${ }^{527}$.

Für wesentlich, um die Voraussetzungen künftiger Verständigungsbereitschaft zwischen beiden Ländern zu schaffen, erachteten die Regierungen schließlich den Austausch von Jugendlichen. Gerade die jungen Generationen, die in ihrer Haltung zum jeweiligen Nachbarland nicht durch Kriegserfahrungen vorgeprägt waren, sollten dagegen gewappnet werden, sich die aus den blutigen Auseinandersetzungen zwischen Deutschen und Franzosen herrührenden Negativerzählungen zu eigen zu machen. Auf diese Weise würden die Bilder des anderen, welche sich aus Krieg und Besatzungszeit speisten, schrittweise den positiven Eindrücken der deutschfranzösischen Versöhnungsgeschichte der Nachkriegszeit Platz machen. Begegnungen im Rahmen von Schulpartnerschaften und die Programme des DFJW trügen dazu bei, persönliche Kontakte zu knüpfen, mit dem Nachbarland vertraut $\mathrm{zu}$ werden und eine unvoreingenommene Perspektive auf seine Menschen, seine Kultur und seine Geschichte zu entwickeln. Daher stellten sie nach einhelliger Auffassung der offiziellen Stellen unerlässliche Investitionen in die deutsch-französische Zukunft dar:

Tant dans les échanges de classes que dans les échanges de jeunes en formation professionnelle, l'action que mène l'OFAJ auprès de la jeunesse afin de lui permettre de parvenir à une meilleure connaissance du mode de vie, de pensée, et des aspirations des hommes du pays du partenaire dans le but d'une plus grande solidarité, est donc particulièrement efficace et précieuse $^{528}$.

526 AMAE Paris-La Courneuve, Europe, RFA 1971-1976, Bd. 2999, „Note pour le directeur d'Europe« bezüglich der deutsch-französischen Beziehungen vom 5. Juni 1976, S. 1; vgl. hierzu auch AMAE Paris-La Courneuve, Europe, RFA 1976-1980, Bd. 3999, „Note pour le cabinet du ministre «, 27. August 1976.

527 Siehe AN Fontainebleau, ministère de l'Éducation nationale, Bd. 900672/38, Protokoll der Sitzung der Interministeriellen Kommission für die deutsch-französische Zusammenarbeit am 29. Januar 1976, S. 22; BA, B 145, Bd. 11422, Vermerk des Presse- und Informationsamtes der Bundesregierung bezüglich des Vertrages über die deutsch-französische Zusammenarbeit vom 3. Januar 1977, S. If.

528 AN Fontainebleau, ministère de l'Éducation nationale, Bd. 840700/27, Vermerk zur Sitzung der deutsch-französischen Expertenkommission für das allgemeinbildende Schulwesen am 9. und 10. Dezember 1976 in Freiburg, Anlage: "Échanges franco-allemands d'élèves" vom 3. Dezember 1976, S. 2; vgl. auch AMAE Nantes, Bonn Ambassade, 
Ausgehend von den somit immer enger werdenden Beziehungen zwischen deutschen und französischen Jugendlichen entstünden, so eine Einschätzung des französischen Außenministeriums vom Januar 1977, die Grundlagen einer nachhaltigen Annäherung der Völker: »Sur ces bases nouvelles se construit un rapprochement réel des peuples qui correspond à l'imbrication des économies et à l'entente des gouvernements « ${ }^{529}$.

Dafür zu sorgen, dass die Nachwirkungen der Vergangenheit nicht $\mathrm{zu}$ Belastungen der gegenwärtigen und künftigen Beziehungen zwischen Frankreich und Westdeutschland führen konnten, machten sich neben den Regierungen zu gleicher Zeit auch die privaten Verständigungsorganisationen zur Aufgabe. So organisierte etwa das DFI in Kooperation mit der deutschen Botschaft in Paris im Februar 1977 eine Reise für die Delegation eines der größten französischen Kriegsopferverbände, die Union nationale des déportés, internés et victimes de guerre, nach Ludwigsburg. Die Teilnehmer besuchten dort die Zentrale Stelle zur Aufklärung nationalsozialistischer Verbrechen ${ }^{530}$ und konnten sich in einem Gespräch mit dem Leiter der Einrichtung, Adalbert Rückerl ${ }^{531}$, aus erster Hand über die Strafverfolgung nationalsozialistischer Verbrechen in der Bundesrepublik informieren. Den französischen Gästen sollte hierdurch vor Augen geführt werden, dass ihren westdeutschen Nachbarn ernsthaft daran lag, die Vergangenheit aufzuarbeiten, bislang nicht zur Rechenschaft gezogene NS-Täter zu bestrafen und dass der in den Kreisen der französischen Verfolgtenorganisationen aufgekommene Eindruck, nationalsozialistisch inspirierte Vereinigungen würden in der Bundesrepublik wieder salonfähig, unzutreffend sei ${ }^{532}$. Mit der Durchführung der Reise knüpfte das DFI an frühere Besuche französischer Kriegsopferverbände an. Zuletzt hatte im Mai 1971 mit der Amicale des anciens prisonniers de guerre des stalags ein Zusammenschluss ehemaliger Kriegsgefangener Ludwigsburg besucht, deren Aufenthalt den Beteiligten in guter Erinnerung geblieben war. So hatte ein Vertreter der Vereinigung in einer Dankesrede an die deutschen Gastgeber die Worte gefunden: »Gewiss, vor 30 Jahren war Krieg [...]. Wir haben gelitten, aber auch das deutsche Volk

Bd. 340, Vermerk betreffend »Visite du ministre à Bonn le 26 novembre« vom 15. November 1976, S. 4; BA, B 189, Bd. 26334, Schreiben des Bundesministeriums für Jugend, Familie und Gesundheit, Reinhard Wilke, an den Koordinator für die deutsch-französische Zusammenarbeit vom 11. Januar 1977.

529 AMAE Nantes, Bonn Ambassade, Bd. 322, Aufzeichnung "La République fédérale d'Allemagne et sa politique extérieure au début de 1977«vom 27. Januar 1977, S. 13.

530 Vgl. hierzu Annette WeINKE, Eine Gesellschaft ermittelt gegen sich selbst. Die Geschichte der Zentralen Stelle Ludwigsburg 1958-2008, Darmstadt ${ }^{2} 2009$.

531 Vgl. Adalbert RüCKERL, Die Strafverfolgung von NS-Verbrechen 1945-1978. Eine Dokumentation, Heidelberg u. a. 1979; Ders., NS-Verbrechen vor Gericht. Versuch einer Vergangenheitsbewältigung, Heidelberg 1982.

532 Siehe DFI-Archiv, Ordner Programme 1973-1987, Besuch einer Delegation der Union nationale des déportés, internés et victimes de guerre bei der Zentralen Stelle der Landesjustizverwaltungen in Ludwigsburg vom 23.-25. Februar 1977. 
hat gelitten und der Gedanke ist tröstlich, dass jene Jahre des Unglücks [...] es uns heute gestatten, uns besser zu verstehen, uns gegenseitig zu achten und einander näher zu kommen « ${ }^{533}$. Die menschlichen Verbindungen, welche durch derartige Besuche entstehen mussten, und die positiven Eindrücke, die die Franzosen aus dem Nachbarland mit in die Heimat nehmen würden, sollten, so die Intention der Verantwortlichen des DFI, letztlich einen Beitrag dazu leisten, dass die nachwirkenden Erfahrungen des Zweiten Weltkriegs das deutsch-französische Verhältnis nicht mehr beeinträchtigen konnten.

Selbiges Ziel gab auch dem ADFG eine Richtschnur für das Handeln zugunsten der Verständigung zwischen Deutschen und Franzosen vor. Noch immer, so klagte die Gründerin und Ehrenpräsidentin des Arbeitskreises, Elsie Kühn-Leitz, im Jahr 1977, komme es in den deutsch-französischen Beziehungen zu Rückschlägen und Krisen, die durch »verfälschte und einseitige Darstellungen in Presse, Radio und Fernsehen heraufbeschworen « würden. In Frankreich würden immer wieder »Filme der Hitlerzeit, der Konzentrationslager, des zweiten Weltkrieges im Fernsehen gezeigt und verdüstern das Bild des heutigen Deutschland. Es wird immer wieder behauptet, daß der Rechtsextremismus in Deutschland wieder zunimmt und noch viele schlimme Dinge mehr « ${ }^{534}$. Gerade angesichts dieser Belastungen des bilateralen Verhältnisses dürfe sich der ADFG, wie Kühn-Leitz ausführte, nicht von dem eingeschlagenen Weg abbringen lassen: „Wir glauben unerschütterlich an die wachsende Verständigung und Freundschaft zwischen unseren beiden Ländern. Wir bitten alle diejenigen, die eine Verantwortung in den Massenmedien haben, jede falsche Darstellung, sei es in Deutschland oder Frankreich, zu bekämpfen ${ }^{535}$. Neben solch öffentlichen Appellen betrachtete der ADFG es als seine vorrangige Aufgabe, die Menschen beiderseits des Rheins miteinander in Kontakt $\mathrm{zu}$ bringen. Hierdurch wollte er helfen, die fortbestehenden Ressentiments, die leicht wieder in Erscheinung treten könnten, zu überwinden und insbesondere der französischen Bevölkerung aufzuzeigen, dass die Bundesrepublik keine Brutstätte neu auflebender nationalsozialistischer Strömungen sei, die Deutschen in ihrer großen Mehrheit Gruppierungen wie den Vereinigungen ehemaliger SS-Angehöriger ablehnend gegenüber stünden ${ }^{536}$. Nicht zuletzt

533 DFI-Archiv, Ordner Besuch französischer Kriegsgefangener 1971, Übersetzung der Ansprache von Richard Gueutal aus Valentigney am 29. Mai 1971 im Rathaus Stuttgart, S. 2; vgl. auch ibid., Pressemitteilung des DFI »Ehemalige Kriegsgefangene kommen wieder « vom 16. April 1971; Nach 26 Jahren: Französische Kriegsgefangene kommen als Gäste, in: Ludwigsburger Kreiszeitung, 26.05.1971, S. 3.

534 VDFG-Archiv, Ansprache der Ehrenpräsidentin des ADFG, Elsie Kühn-Leitz, im Rahmen der 22. Jahrestagung der deutsch-französischen Gesellschaften in Montpellier am 11. September 1977, in: Mitteilungsblatt für die Deutsch-Französischen Gesellschaften 43 (1978), S. 116.

535 Ibid., S. $116 f$.

536 Vgl. VDFG-Archiv, Ordner Arbeitskreis Korrespondenz 1977-1979, Schreiben des Präsidenten des ADFG, Helmut Paetzold, an Bundeskanzler Helmut Schmidt vom 26. März 1977. 
sollten die politischen Verständigungsinitiativen auf diese Weise unterstützt werden. Der ADFG sei, wie sein Präsident Helmut Paetzold im März 1977 formulierte, »dazu berufen, von der unteren Ebene her die Kooperations- und Freundschaftspolitik der Regierungen beider Nationen mit Leben zu erfüllen, damit in diesem hochbedeutsamen Bereich zwischen Regierung und verständigungswilligen Staatsbürgern kein Vakuum klafft«537.

In den Reihen des BILD wurde konstatiert, dass die "Affäre Peiper « und ihre Begleiterscheinungen einmal mehr verdeutlicht hätten, wie krisenanfällig die deutsch-französischen Beziehungen noch immer seien, wenn es um Fragen des Zweiten Weltkriegs gehe. Dieser Tatsache dürfe man sich, wie der Präsident der Organisation, François Bourel, erklärte, keinesfalls verschließen, sondern müsse vielmehr stets wachsam bleiben und die eigene Informationsarbeit, sobald ähnliche Vorkommnisse am Horizont auftauchten, dementsprechend intensivieren. Vor allem den Franzosen wolle man es durch eine objektive Darstellung der Entwicklungen in Westdeutschland ermöglichen, sich jenseits der vielfach tendenziösen Pressekommentierung eine mehr an Fakten als an Polemiken orientierte Meinung zu bilden ${ }^{538}$. Eine besondere Bedeutung kam in diesem Zusammenhang den Jugendangeboten der Vereinigung zu, galten doch die Jugendlichen beider Länder als potenzielle Träger eines künftigen deutsch-französischen Dialogs. Damit dieser Dialog jedoch tatsächlich würde stattfinden können, der »l'esprit de réconciliation ${ }^{539}$ in den kommenden Generationen Widerhall fände, müsse die Saat der Verständigung immer wieder aufs Neue ausgebracht werden. Geschehen sollte dies in erster Linie im Rahmen von binationalen Seminaren zu gesellschaftspolitischen Themen, Jugendreisen mit Teilnehmern aus beiden Ländern und Austauschprogrammen für Schüler, die dazu angetan waren, negative Auswirkungen der deutsch-französischen Vergangenheit auf die gegenwärtigen und zukünftigen Beziehungen zu verhindern ${ }^{540}$.

Instanzen, welche ein solches Vorhaben unterstützten, fanden die privaten Assoziationen bei den Mittlerpersönlichkeiten des deutsch-französischen Kontextes. Insbesondere Joseph Rovan wandte sich wiederholt und mit allem Nachdruck gegen den sich in Frankreich verbreitenden Verdacht, die Entwicklungen in Westdeutschland deuteten auf ein Wiedererstarken des Nationalsozialismus hin. In seinem Werk »L'Allemagne n'est pas ce que vous croyez« führte er hierzu aus:

Le Démon a fait alliance avec l'Allemagne pendant un court instant, irréversible et inou-

537 Ibid.

538 Vgl. BILD-Archiv, Intervention du président François Bourel dans la cadre du rapport moral 1976-1977.

539 BILD-Archiv, Aufzeichnung »Le Bureau international de liaison et de documentation: présentation, structures, rapport d'activités«, 1977, S. 8.

540 Vgl. BILD-Archiv, Tätigkeitsbericht des Service des centres de jeunes des BILD und der GÜZ für die Jahre 1977 und 1978. 
bliable. Il n'est au pouvoir à personne d'affirmer que son règne est terminé à jamais, qu'il ne s'emparera plus d'aucun autre peuple, ni même qu'il ne reviendra pas un jour planter sa griffe dans le corps allemand. Mais il est possible d'affirmer que le nazisme ne règne pas actuellement sur l'Allemagne de l'Ouest, et qu'il n'a aucune chance prévisible d'y rétablir son règne ${ }^{541}$.

Westdeutschland sei, wie Rovan formulierte, aus französischer Sicht dazu verdammt, für alle Zeit das Kainsmal seiner Vergangenheit zu tragen. Weder gestehe man ihm das Recht des Vergessens zu, noch gelte beim Urteilen über das Nachbarland die Unschuldsvermutung. Vielmehr sei die französische Öffentlichkeit versucht, diese ins Gegenteil zu verkehren. Grundsätzlich unter Anklage stehend, müsse die Bundesrepublik selbst permanent ihre Unschuld beweisen. Hierzu, dessen war Rovan gewiss, reichten jedoch einige wenige Fakten. Durch den Nationalsozialismus inspirierten Parteien, Organisationen oder Publikationen komme schließlich in Westdeutschland kaum eine nennenswerte Bedeutung zu: »Sans avoir jamais atteint dans le passé $5 \%$ des voix sur le plan national, les partis qu'on peut appeler néonazis n'ont pas obtenu $0,5 \%$ à l'élection de 1976. [...] Les organisations néonazies ou d'extrême-droite sont peu nombreuses [...]. Leurs manifestations publiques sont rarissimes $«{ }^{542}$. Wenn sich vor dem Hintergrund dieser positiven Gesamtentwicklung hier oder dort ehemalige Angehörige der SS träfen, sei dies, so die Auffassung Rovans, kein Grund für eine tiefer reichende Beunruhigung. Die Mehrheit der französischen Zeitungen stelle derartige Vorkommnisse lediglich überproportioniert bedeutsam und angsteinflößend dar. Gerade jedoch diese übermäßige Aufmerksamkeit der Medien sei ein untrügliches Anzeichen dafür, wie gering die Gefahr des Wiedererstehens nationalsozialistischer Tendenzen in der Bundesrepublik tatsächlich einzuschätzen sei ${ }^{543}$.

Auch Alfred Grosser hielt die französischen Anschuldigungen für ebenso realitätsfern wie ungerecht. Wie bereits in den Jahren zuvor, betonte er vor allem, dass man in Frankreich bei der Beurteilung des Umgangs mit der NS-Zeit in der Bundesrepublik und der deutschen Kriegsverbrechen nicht die eigene Vergangenheit, und hier vor allem die Dekolonisierungskriege, aus dem Blick verlieren dürfe. Wenn man vollkommen ausblende, dass in Frankreich für Kriegsvergehen in Indochina und Algerien großzügig Amnestien gewährt worden seien und ansonsten über dieses Kapitel geschwiegen werde, falle es leicht, Westdeutschland der unzureichenden Aufarbeitung seiner Vergangenheit anzuklagen und sich über die Aktivitäten einiger weniger AltNazis und deren mangelhafte Sanktionierung zu ereifern: "nous passons notre temps à dire aux Allemands: >Attention à vos manuels scolaires, à vos discours politiques: parlez d'Hitler! N'esquivez rien!^ [...], alors que nous, nous

541 Joseph Rovan, L'Allemagne n'est pas ce que vous croyez, Paris 1978, S. 17 f.

542 Ibid., S. 18f.

${ }^{543}$ Siehe ibid., S. $19 f$. 
allons bien au-delà de la grâce, nous allons à l'amnistie « ${ }^{544}$. Die Franzosen, so der Appell Grossers, sollten sich dazu aufgefordert fühlen, nicht nur die dunklen Seiten der eigenen jüngsten Geschichte zu beleuchten, sondern auch die Anstrengungen anzuerkennen, die in dieser Hinsicht in der Bundesrepublik unternommen worden seien. Somit könne die Voraussetzung geschaffen werden, die unzutreffende französische Rede von der Renaissance des Nationalsozialismus in Westdeutschland wirkungsvoll zu entkräften.

Nach dem Prozess gegen Beate Klarsfeld zeigten die Todesumstände Joachim Peipers sowie die hierdurch angefachte Kontroverse um die legale Existenz von Verbänden ehemaliger SS-Soldaten in der Bundesrepublik erneut auf, dass die Nachwirkungen des Zweiten Weltkriegs in den deutschfranzösischen Beziehungen der 1970er Jahre nicht nur hintergründig präsent waren. Bei Vorhandensein eines entsprechenden Auslösers konnten sie vielmehr zu in hohem Maße emotionalisierten Konflikten führen, welche auch den verantwortlichen Regierungsstellen einmal mehr bewusst machten, dass die Aussöhnung zwischen Frankreich und Westdeutschland ein »fortwährendes und zerbrechliches Werk « war, wie die Diplomaten des Quai d'Orsay bemerkt hatten. Allein die Zeit schien das geeignete Mittel, um die Wunden, welche die Erfahrungen von Besatzung und Verfolgung in Frankreich gerissen hatten, zu heilen. Diesen natürlichen Prozess versuchte man staatlicherseits allerdings zu beschleunigen, etwa durch Einladungen von Journalisten in das jeweilige Nachbarland, um eine objektivere Presseberichterstattung zu erreichen oder durch Bemühungen, die Darstellung Deutschlands im französischen Fernsehen zu aktualisieren. Darüber hinaus sollten insbesondere die im Rahmen des DFJW durchgeführten Jugendbegegnungen dazu beitragen, dass die alten deutsch-französischen Feindbilder in der nächsten Generation keinen Nährboden mehr finden konnten. Im Zusammenwirken mit den Initiativen der privaten Organisationen, wie etwa den seitens des DFI organisierten Besuchen französischer Kriegsopferverbände oder der Informations- und Austauscharbeit des ADFG und des BILD sowie den öffentlichen Interventionen Joseph Rovans und Alfred Grossers würden die Regierungsbemühungen um die deutsch-französische Verständigung, dies die Hoffnung der beteiligten Protagonisten, schließlich helfen, die mentalen Folgen der Kriegsvergangenheit zu bewältigen. Dass dieses gemeinsame Engagement jedoch Erfolge nicht binnen Wochen oder Monaten, sondern allenfalls im Verlaufe von Jahren oder gar Jahrzehnten zeitigen würde, war für die Mehrheit der hier wirkenden Kräfte wohl ersichtlich. Konflikte, die sich

544 Alfred Grosser, La passion de comprendre. Noël Copin interroge Alfred Grosser, Paris 1977, S. 113; vgl. hierzu auch Ders., Introduction: l'interrogation sur le devenir allemand, in: Ders. (Hg.), Dix leçons sur le nazisme, Paris 1976, S.11-30; Ders., Was sollen Romanisten lehren?, in: Gisela Baumgratz, Robert Picht (Hg.), Perspektiven der Frankreichkunde, Bd. 2: Arbeitsansätze für Forschung und Unterricht, Tübingen 1978, S. 1-13, hier S. 9 f. 
aus den Erfahrungen des Zweiten Weltkriegs speisten, würden solange möglich bleiben, wie die Erinnerungen an das erfahrene Leid Identitäten prägen und Meinungen beeinflussen konnten. Die Verständigungsarbeit stieß hierin an eine Grenze, die zumindest auf mittlere Sicht kaum zu überwinden war.

\subsection{3 »Hitler-Nostalgie» und Kappler-Flucht: die Last der Vergangenheit bleibt}

Vor dem Hintergrund der anhaltenden Debatten um die mangelhafte Strafverfolgung von NS-Kriegsverbrechern und der nicht abreißenden Berichte über die Aktivitäten von ehemaligen SS-Angehörigen und Neo-Nazis in der Bundesrepublik sorgte im Juli 1977 der Kinostart von Joachim Fests Dokumentarfilm »Hitler - Eine Karriere « ${ }^{545}$ erneut für Konfliktstoff in den deutsch-französischen Beziehungen. Der sensibilisierten französischen Presselandschaft gab der Film einmal mehr Anlass zu der Vermutung, die deutschen Nachbarn könnten im Zuge einer durch den gewachsenen zeitlichen Abstand begünstigten Verklärung der NS-Zeit wieder Gefallen an »ihrem Führer « finden ${ }^{546}$. Insbesondere die wenig distanzierte Darstellung des deutschen Diktators in dem weitgehend auf Originalaufnahmen der Deutschen Wochenschau ${ }^{547}$ zurückgreifenden Streifen rief in Frankreich scharfe Kritik hervor. Die nationalsozialistischen Verbrechen würden dort bagatellisiert, wie »Le Nouvel Observateur« drei Wochen nach der Premiere des Films schrieb, und ein in unerträglichem Maße beschönigendes Bild eines »Hitler en rose« gezeichnet:

[C]ette nouvelle image du chancelier nazi fera le tour du monde. Image apaisée, dédramatisée. Pour les jeunes, ceux de la génération `Hitler, connais pas!‘, ce sera celle d'un chef à la présence fascinante, un surhomme qui, en douze ans, a su abolir le chômage, construire des autoroutes, s'opposer avec force à la `honte du traité de Versailles, rendre à un peuple désespéré la conscience d'une force nouvelle ${ }^{548}$.

»Le Monde« beurteilte das filmische Werk wenig später als »déformation particulièrement nocive, parce qu’insidieuse, de la vérité ${ }^{549}$. Der Zuschauer erfahre kaum etwas über die antisemitischen Exzesse im Deutschen Reich

545 Der Film orientierte sich inhaltlich im Wesentlichen an Fests Biografie über Hitler, die vier Jahre zuvor erschienen war, vgl. Joachim Fest, Hitler. Eine Biographie, Frankfurt a.M. 1973.

546 Vgl. hierzu Henri MÉnudier, Une revue de la presse française. »De quelle Allemagne parlez-vous? «, in: Documents 32/4 (1977), S. 14-42, hier S. $16 f$.

547 Vgl. Ulrike Bartels, Zwischen Anspruch und Wirklichkeit: Die Wochenschau als Propagandainstrument im Dritten Reich, in: Bernd Heidenreich, Sönke Neitzel (Hg.), Medien im Nationalsozialismus, Paderborn u. a. 2010, S. 161-202.

548 Gérard SANDOZ, Hitler en rose, in: Le Nouvel Observateur, 18.07.1977, S. 33.

549 Manuel Lucbert, Le III ${ }^{\mathrm{e}}$ Reich sans étoile jaune. »Hitler, une carrière«, in: Le Monde, 23.08.1977, S. 4. 
oder die Vorgänge in den Vernichtungslagern während des Krieges, werde dafür den ideologiegetränkten Reden Hitlers und der nationalsozialistischen Bildpropaganda nahezu kommentarlos gegenübergestellt. Für den Autor des Artikels stand fest: „C'est Hitler, sans l'hitlérisme. C'est le $\mathrm{III}^{\mathrm{e}}$ Reich sans étoiles jaunes ${ }^{550}$. In "L'Express « gelangte der Historiker Max Gallo gar zu der Einschätzung, man habe es bei Fests Film mit einer Mystifizierung der Person Hitlers und seines Handelns und daher mit einem handfesten Geschichtsskandal zu tun: "Jamais, peut-être, un film de documents n'a à ce point obscurci les réalités essentielles d'une Histoire proche et complexe mais bien connue ${ }^{551}$. Vielfach erschien $»$ Hitler - Eine Karriere« in der französischen Presseberichterstattung wenn nicht als Beweis, so doch als Indiz dafür, dass die Deutschen insgesamt von einer wahrhaftigen "HitlerNostalgie« befallen seien, welche die gefährliche Tendenz in sich barg, die nationalsozialistischen Verbrechen zu verharmlosen oder zu beschweigen. Dass der Film auch in Westdeutschland höchst umstritten war und nicht wenige Kritiker Fest vorwarfen, selbst der dämonischen Faszination seines Betrachtungsgegenstandes erlegen zu sein, wurde hier zumeist übersehen ${ }^{552}$.

Die Diskussionen um den Film Fests erzeugten demnach eine in hohem Maße spannungsgeladene Atmosphäre zwischen beiden Ländern, in welcher sich nur wenig später der »Fall Kappler « zu einer neuerlichen Belastungsprobe des deutsch-französischen Verhältnisses auswachsen konnte. Wie kam es hierzu? Im Sommer 1977 flüchtete der seit 1948 in italienischer Haft befindliche deutsche Kriegsverbrecher Herbert Kappler ${ }^{53}$ in die Bundesrepublik. Während des Zweiten Weltkriegs war Kappler als Chef der Sicherheitspolizei und des Sicherheitsdienstes in Rom verantwortlich für die Deportation der dort lebenden Juden gewesen. Im März 1944 hatte er zudem als Vergeltung für einen Bombenanschlag auf deutsche Soldaten die Ermordung von 335 Italienern in den Fosse Ardeatine befohlen. Nach Kriegsende wurde Kappler durch ein italienisches Militärgericht für seine Vergehen zu einer lebenslänglichen Freiheitsstrafe verurteilt ${ }^{554}$. Im August 1977 gelang dem ehemaligen SS-Offizier,

550 Ibid.

551 Max Gallo, C’était il y a mille ans, in: L’Express, 22.08.1977, S. 38.

552 Vgl. etwa die Kritik des Regisseurs Wim Wenders, That's entertainment: Hitler. Eine Polemik gegen Joachim C. Fests Film »Hitler - eine Karriere«, in: Die Zeit, 05.08.1977, S. 34; hierzu weiterführend Frank BöscH, Das »Dritte Reich« ferngesehen. Geschichtsvermittlung in der historischen Dokumentation, in: Geschichte in Wissenschaft und Unterricht 50/4 (1999), S. 204-220; Martina Thiele, Publizistische Kontroversen über den Holocaust im Film, Berlin ${ }^{2}$ 2007, S. 82f.; Brad Prager, The Haunted Screen (Again): The Historical Unconscious of Contemporary German Thrillers, in: Laurel CoHENPfister, Dagmar Wienroeder-Skinner (Hg.), Victims and Perpetrators: 1933-1945. (Re)Presenting the Past in Post-Unification Culture, Berlin 2006, S. 296-315, hier S. 297.

553 Zur Biografie Kapplers vgl. KLEE, Das Personenlexikon zum Dritten Reich, S. 299.

554 Vgl. zur Rolle Kapplers bei der Deportation der römischen Juden Richard BREITMAN, Dannecker und Kappler in Rom. Neue Quellen zur Oktober-Deportation 1943, in: Jürgen Matтhäus, Klaus-Michael Mallmann (Hg.), Deutsche, Juden, Völkermord. Der 
der aufgrund einer Krebserkrankung in ein römisches Militärhospital verlegt worden war, die Flucht nach Westdeutschland. Als die Bundesregierung daraufhin das Gesuch der italienischen Regierung, Kappler an Italien auszuliefern, unter Berufung auf das im Grundgesetz verankerte Auslieferungsverbot deutscher Staatsbürger ablehnte ${ }^{555}$, löste dies nicht nur in dem hiervon unmittelbar betroffenen Italien einen Sturm der Entrüstung aus, sondern ebenso in Frankreich. Begünstigt durch die Nachwirkungen der Debatten um »Hitler Eine Karriere« wurde dort in ähnlicher Form der Verdacht laut, die westdeutsche Regierung und Gesellschaft solidarisierten sich mit Kappler und machten sich damit in nicht hinnehmbarer Weise zu Komplizen von Alt- und NeoNazis ${ }^{556}$.

Die Deutschen, wie es in einem Kommentar in "Le Monde« hieß, versteckten sich hinter ihrer Verfassung, um die Ablehnung des italienischen Auslieferungsantrags zu rechtfertigen. Geradezu schockierend sei es, dass in der Bundesrepublik die Gräueltaten derer, die zwischen 1933 und 1945 die Gewährsmänner einer menschenverachtenden Ideologie und eines brutalen Repressionsapparates gewesen seien, offenbar als weniger verurteilungswürdig gälten als die Gewaltakte der RAF. Gegen deren Mitglieder, diese »enfants perdus des révoltes étudiantes de 1967-1968«, gehe der westdeutsche Staat schließlich auch mit unnachgiebiger Härte vor. Mehr und mehr dränge sich daher die Frage auf: „L'Allemagne de nos jours est-elle celle que les Alliés souhaitaient après l'effondrement du Reich hitlérien ${ }^{557}$ ? « "Le Nouvel Observateur « zeigte sich vor allem empört über das Gefühl des Triumphes, welches die westdeutsche Presse angesichts der gelungenen Flucht Kapplers ergriffen habe: "En Allemagne, au contraire, la jubilation est aussi générale qu'indécente. Pour la presse d'outre-Rhin, Kappler n'est qu'un sprétendu criminel de guerre`, et, en plus, >les Italiens n'ont qu'à s'occuper des crimes

Holocaust als Geschichte und Gegenwart, Darmstadt 2006, S. 191-203; zum Massaker in den Fosse Ardeatine vgl. Steffen Prauser, Mord in Rom? Der Anschlag in der Via Rasella und die deutsche Vergeltung in den Fosse Ardeatine im März 1944, in: Vierteljahrshefte für Zeitgeschichte 50/2 (2002), S. 269-301 sowie Joachim STARON, Fosse Ardeatine und Marzabotto: Deutsche Kriegsverbrechen und Resistenza. Geschichte und nationale Mythenbildung in Deutschland und Italien (1944-1999), Paderborn u. a. 2002.

555 Vgl. Aufzeichnung des Ministerialdirektors Ruhfus, Bundeskanzleramt, vom 6. September 1977, in: AAPD 1977, Bd. II, Dok. 236, hier bes. die Anmerkungen S. $1169 f$.

556 Vgl. hierzu Petra Terhoeven, Deutscher Herbst in Italien. Die italienische Linke und die "Todesnacht von Stammheim«, in: Dies. (Hg.), Italien, Blicke. Neue Perspektiven der italienischen Geschichte des 19. und 20. Jahrhunderts, Göttingen 2010, S. 185-208, hier S. 197; Hans Woller, Vom Mythos der schleichenden Entfremdung, in: Gian Enrico Rusconi, Thomas Schlemmer, Hans Woller (Hg.), Schleichende Entfremdung? Deutschland und Italien nach dem Fall der Mauer, München 2008, S. 17-24, hier S. 21; Schmitz, Zwischen Mythos und Aufklärung, S. 223-225.

${ }^{557}$ Le »scandale« Kappler, in: Le Monde, 18.08.1977, S. 1. 
fascistes dans leur propre pays $«^{558}$. Zwar versuchten einige Intellektuelle, wie etwa Heinrich Böll, sich dem kollektiven Schuldunbewusstsein ihrer Landsleute entgegenzustellen, doch gingen ihre Worte der Vernunft, wie es in dem Artikel hieß, im Strom der Gegenmeinungen völlig unter:

[N]e sont-ils pas désormais des `émigrés de l'intérieur`, totalement coupés de cette majorité pas du tout silencieuse qui prétend ignorer la gravité des crimes contre l'humanité commis par des milliers de Kappler dans d'innombrables 'grottes Ardéatines`, Marzabotto, Oradour, Lidice, partout où sont passés, pendant la Seconde Guerre mondiale, les troupes de la Wehrmacht et les $\mathrm{SS}^{559}$ ?

Offensichtlich, so das Urteil des Autors, bestehe in Westdeutschland Solidarität allein mit den ehemaligen Tätern, nicht jedoch mit deren Opfern. Eine Mehrheit der Deutschen, so schließlich auch eine Einschätzung in der Tageszeitung »Le Quotidien de Paris«, mache sich in skandalöser Weise zum Gehilfen eines nachweislichen NS-Täters, indem sie die Kriegsverbrechen Kapplers rundheraus in Abrede stelle. Diese Entwicklung sei in hohem Maße beunruhigend, denn sie zeige: »tout est encore possible dans l'Allemagne de 1977, tout peut recommencer ${ }^{560}$. Bedrohlich nahe gerückt war in den Augen der französischen Presseberichterstatter demnach im Sommer 1977 die Gefahr, in Westdeutschland könnten gesellschaftliche Strömungen wieder an Einfluss gewinnen, die eine »certaine nostalgie du nazisme ${ }^{561}$ pflegten. Wenn auch allem Anschein zum Trotz, wie der französische Journalist Gérard Sandoz formulierte, in der Bundesrepublik kein neuer Hitler an den Toren zur Macht stehe, so sei es doch offensichtlich, dass das Land Gefahr laufe, von einem "autoritarisme archi-conservateur" erfasst zu werden. Dies sei weder eine erfreuliche Perspektive für die Deutschen selbst noch für ihre Nachbarn ${ }^{562}$.

Die Welle der Kritik, welcher die Bundesrepublik seit Juli 1977 ausgesetzt war, nahm die westdeutsche Presse indessen keineswegs unwidersprochen hin. Der »hässliche Deutsche« sei in den Debatten um »Hitler-Nostalgie« und Kappler-Flucht wiedererstanden, wie die "Frankfurter Allgemeine Zeitung " beklagte, »der Nazi, der Kommißstiefel-und-Pickelhauben-Deutsche, der

${ }^{558}$ K. S. Karol, Tempête pour un nazi perdu, in: Le Nouvel Observateur, 22.08.1977, S. 37. 559 Ibid.

560 Zitiert nach Dans la presse parisienne, in: Le Monde, 18.08.1977, S. 4; vgl. hierzu auch Charles Moreau, Chronique des faits internationaux: Allemagne (RFA) et Italie, in: Revue générale de droit international public 82 (1978), S. 622-625, hier S. 625.

561 Vgl. K. S. KAROL, Réponse à des amis allemands, in: Le Nouvel Observateur, 26.09.1977, S. 56f., hier das angeführte Zitat; Manuel LuCBERT, La RFA malade de ses extrémistes II. - Fils de Wotan et guérilleros urbains, in: Le Monde, 08.09.1977, S. 2; MÉnudier, Die Deutschlandbilder der Franzosen, S. 138f.; Miard-Delacroix, Partenaires de choix?, S. 123; Susanne von Bassewitz, Stereotypen und Massenmedien. Zum Deutschlandbild in französischen Tageszeitungen, Wiesbaden 1990, S. 53f.; Bernard Trouillet, Das deutsch-französische Verhältnis im Spiegel von Kultur und Sprache, Weinheim, Basel 1981, S. 1-7.

562 Siehe Gérard Sandoz, Les derniers carrés de l'hitlérisme, in: Le Nouvel Observateur, 29.08.1977, S. 36. 
subalterne, obrigkeitsgläubige Untertan ${ } 563$. Die alten Vorbehalte, die seit Generationen weitergewälzt würden, kämen hier erneut zum Vorschein. Als unstet würden die Deutschen wahrgenommen, die Bundesrepublik als Staat ohne demokratische Traditionen. Noch immer wüssten die Nachbarn nicht, woran sie mit den Deutschen seien. Der positive Wandel, welcher die deutsche Entwicklung seit 1945 gekennzeichnet habe, werde hingegen kaum anerkannt. Niemand würdige in angemessener Weise, dass die Deutschen sich bis zur Unerkennbarkeit weit von ihrer Vergangenheit entfernt hätten. "Der große Vorgang der letzten Jahrzehnte ist, so entdecken wir plötzlich, gar nicht ins Bewußtsein der anderen gedrungen: jener Umbau der deutschen Innenwelt, der gewährleistet, daß Bonn in der Tat nicht Weimar ist « ${ }^{564}$.

Wenige Wochen später prangerte dasselbe Blatt vor allem die Rolle der französischen Presse an, welche maßgeblich zu der negativen Wahrnehmung Deutschlands in Frankreich beitrage. Eine Mehrheit der großen Presseorgane schüre den Verdacht, »in der Bundesrepublik wuchere wieder der Nazismus. Eine Hitlerwelle gehe durchs Land ${ }^{565}$. Gar die Rede von einem »neofaschistischen Regime", das sich in Bonn etabliert habe, gehe in Paris um. Zum Teil sei, wie der Autor der Ansicht war, die deutschfeindliche Berichterstattung auf eine fundamentale Schwäche des französischen Journalismus zurückzuführen, für den Behauptungen und Doktrinen mehr zählten als Tatsachen. Wesentlicher schien ihm jedoch, dass die Deutschen mit ihrem Aufstieg zur ersten Wirtschaftsmacht des Kontinents, zur stärksten Militärmacht und zum ersten politischen Gesprächspartner der Sowjetunion und der Vereinigten Staaten, "die Eitelkeit der Grande Nation schwer verletzt « hätten ${ }^{566}$. Die Deutschen könnten sich eben benehmen wie sie wollten, sie benähmen sich immer falsch: "Setzen sie sich mit ihrer Vergangenheit so wenig auseinander wie die Franzosen mit dem Pétain-Regime und der Kollaboration, so verdrängen sie Schuld und Verantwortung. Tun sie es aber, so werden sie der Rehabilitierung des Naziregimes bezichtigt « ${ }^{567}$. Halte dieser »neue Antigermanismus« in Frankreich weiter an, so stehe zumindest die Frage im Raum, ob die beiden Partnerländer sich gar »auf dem Wege zur deutsch-französischen Feindschaft« befänden.

War der Beitrag der »Frankfurter Allgemeinen Zeitung " zwar in seiner drastischen Zuspitzung nicht repräsentativ für die in der westdeutschen Presse vorherrschende Mehrheitsmeinung, hinsichtlich seiner Zielrichtung war er es allemal. Die »Frankfurter Rundschau« monierte etwa, dass Paris, vollkommen eingenommen von den medial produzierten negativen Deutsch-

${ }^{563}$ Hermann RudolPh, Währt die Pickelhaube ewig?, in: FAZ, 13.09.1977, S. 1.

564 Ibid.

${ }^{565}$ Karl Jetter, Auf dem Wege zur deutsch-französischen Feindschaft? Der neue Antigermanismus in Frankreich. Beobachtungen und Vermutungen über seine Ursachen, in: FAZ, 24.09.1977, S. 59.

566 Siehe ibid.

567 Ibid. 
landbildern, »nur noch braun« sehe ${ }^{568}$. »Die Welt« warf den Franzosen vor, sie badeten in der Genugtuung, sich wieder einmal in ihren Ansichten über den bösen Nachbarn bestätigt zu sehen ${ }^{569}$. "Der Spiegel « konstatierte, das französische Deutschlandbild vereine und vereinfache in unheilvoller Weise Geschichte und Gegenwart, helfe mithin, innenpolitische Kontroversen zu übertünchen und mache selbst Kollaborateure im Nachhinein zu Patrio$\operatorname{ten}^{570}$. Und Marion Gräfin Dönhoff verwies in »Die Zeit» die These von der "Renazifizierung in der Bundesrepublik " nachdrücklich in den Bereich des Absurden. Nationalsozialistische Ideologie habe in Westdeutschland keinen Platz mehr. Mit dem Wohlstand hätten vielmehr Selbstgefühl, Toleranz und pragmatisches Denken bei den Deutschen Einzug gehalten. Der Faszination Hitlers unterlägen sie jedenfalls nicht mehr ${ }^{571}$. Jenseits dieser mit Vehemenz und zum Teil Verärgerung vorgetragenen Plädoyers zugunsten des neuen Deutschland stimmte die Kommentatoren die Erkenntnis betroffen, dass bei den französischen Nachbarn ein leiser Verdacht oder eine bloße Vermutung ausreichten, um die Zeit des Nationalsozialismus in polemischer Weise aufzurühren. Die Franzosen, so zumindest die Wahrnehmung, hielten den Deutschen mit einem nicht zu verkennenden moralischen Unterton unablässig vor, dass sie weiterhin unter wachsamer Beobachtung stünden. Die Gefahr, »daß sich durch die Wiederbelebung der deutschen Vergangenheit eine kritische und in Ablehnung umkippende Distanz zur Bundesrepublik verfestigt $~^{572}$, schien vielen Beobachtern in besorgniserregender Weise real geworden zu sein.

Auch die Bonner Regierungsstellen maßen dieser Gefahr ob der anhaltenden öffentlichen Auseinandersetzungen eine nicht unerhebliche Bedeutung bei. So hieß es in einer Aufzeichnung des Auswärtigen Amts vom Herbst 1977: »Die antideutsche Stimmungsmache in Teilen der französischen Presse hat uns in letzter Zeit Sorgen gemacht, weil wir negative Auswirkungen auf die Beziehungen zwischen unseren beiden Ländern befürchten « 573 . Die Berichte über die angebliche Hitler-Nostalgie in der Bundesrepublik sowie über den Fall Kappler hätten dazu beigetragen, dass der französische Leser den Eindruck gewinnen konnte, Westdeutschland "gleite wieder in einen autoritären Unrechtsstaat, in den Neonazismus ab ${ }{ }^{574}$. Jede sachliche Kritik befreundeter

${ }^{568}$ Lutz KrusChe, Paris sieht nur noch braun, in: FR, 09.09.1977, S. 4.

569 Siehe August von KagENECK, Frankreich: Widerspruch gegen linke Klischee-Produzenten, in: Die Welt, 16.09.1977, S. 5.

570 Siehe Helmut Sorge, Kappler is here, in: Der Spiegel, 29.08.1977, S. 54f.

571 Siehe Marion Gräfin DöNHOFf, Was bedeutet die Hitlerwelle? Ein Phänomen, gegen das wir uns nicht wehren können, in: Die Zeit, 02.09.1977, S. 1.

572 Kurt Becker, Ist Deutschland ein Alptraum? Der Fall Kappler: Eine unerwartete Lektion für die Bundesrepublik, in: Die Zeit, 26.08.1977, S. 1.

573 PA-AA, Auslandsvertretungen, Botschaft Paris, Bd. 13523, Gesprächsvorschlag betreffend »Deutschlandbild in Frankreich" vom 12. Oktober 1977, S. 1.

574 PA-AA, Auslandsvertretungen, Botschaft Paris, Bd. 13523, Vermerk betreffend »Deutschlandbild in Frankreich - Sachstand « vom 12. Oktober 1977, S. 1. 
Länder an den Verhältnissen in der Bundesrepublik nehme man zwar ernst, doch wolle man sich, wie die Bonner Diplomaten formulierten, die deutsche Demokratie nicht zerreden lassen.

Die Motive für das Wiederaufleben deutschfeindlicher Tendenzen seien indes unterschiedlicher Natur. Die "geschichtliche Erfahrung mit den Deutschen, insbesondere mit dem nazistischen Deutschland « sowie »Rivalität und Neid angesichts der wirtschaftlichen und politischen Stabilität in der Bundesrepublik « ${ }^{575}$ spielten in diesem Zusammenhang eine wesentliche Rolle. Daneben falle die Deutschland-Berichterstattung des französischen Fernsehens nachteilig ins Gewicht, da dort antideutsche Vorurteile bewusst oder unbewusst aufrecht erhalten würden: »Negative psychologische Folgen für das gegenseitige Verständnis beider Völker, aber auch das politische Verhältnis beider Länder dürften - wenn sich diese Tendenz in der Berichterstattung fortsetzt - nicht ausbleiben ${ }^{576}$. Die Franzosen sollten daher, wie das Auswärtige Amt bereits im Sommer 1977 angemerkt hatte, darauf hingewiesen werden, dass die an der Vergangenheit orientierte Berichterstattung über Deutschland mit einer engen und freundschaftlichen Zusammenarbeit nicht vereinbar sei ${ }^{577}$. Aus Sicht der deutschen Botschaft in Paris deuteten die deutsch-französischen Spannungen, die sich seit der Flucht Kapplers entwickelt hatten, darauf hin, »wie sehr die Vergangenheit auch heute noch das Bewußtsein der französischen Öffentlichkeit bestimmt und welch große Lücken in der Kenntnis voneinander noch klaffen « ${ }^{578}$.

Auf französischer Seite zeigten sich die Verantwortlichen angesichts der jüngst aufgetretenen Ereignisse in ähnlicher Weise beunruhigt. Im Pariser Außenministerium gelangte man gar zu der Auffassung, dass die Erschütterungen, zu welchen es im Gefolge der Flucht Kapplers gekommen war, die schwerste "crise sentimentale « des deutsch-französischen Verhältnisses seit langer Zeit ausgelöst hätten: »Elle a montré combien la réconciliation restait fragile, surtout de notre côté comme il était naturel « ${ }^{579}$. Die Deutschen seien insbesondere von der Mühelosigkeit getroffen gewesen, mit welcher man sie unter Anklage gestellt habe, zumal im Freundesland Frankreich. Die Attacken der französischen Presse führten sie, wie die Diplomaten des Quai d'Orsay berichteten, vornehmlich auf die Missgunst der Franzosen gegenüber dem

575 Ibid., S. 1f.

576 PA-AA, Zwischenarchiv, Nr. 111203, Vermerk bezüglich der Gesprächsthemen des Bundespräsidenten im Rahmen der deutsch-französischen Gipfelkonsultationen in Bonn vom 13. Juni 1977, Anlage: Sachstand zum Deutschlandbild im französischen Fernsehen, S. 1.

577 Siehe ibid., S. 2.

578 PA-AA, Zwischenarchiv, Nr. 113561, Politischer Halbjahresbericht der deutschen Botschaft Paris vom 16. Januar 1978, S. 6 .

579 AMAE Paris-La Courneuve, Europe, RFA 1976-1980, Bd. 4011, Vermerk betreffend »La République fédérale d'Allemagne au début de 1978« vom 31. Januar 1978, S. 5. 
Wohlstand und den wirtschaftlichen Erfolgen der Bundesrepublik zurück und empfänden diese in ihrem Inhalt und ihrer Schärfe als zutiefst ungerecht: »les accusations portant sur la `renaissance du nazisme s sont ressenties comme des attaques injustes et destinées >à salir l'Allemagne « ${ }^{580}$.

Das aus dieser Verbitterung hervorgehende Gefühl, durch die Nachbarn unberechtigterweise in eine Art "moralische Quarantäne " genommen zu werden, so warnte der französische Botschafter Jean-Pierre Brunet, berge indes nicht zu unterschätzende Gefahren: "Cela risque de provoquer un repliement sur soi-même, une renaissance de tendances nationalistes que les campagnes de dénigrement de l'étranger sont susceptibles de renforcer « ${ }^{581}$. Gerade die von offener Feindseligkeit zeugenden Berichte einiger französischer Kommentatoren hätten die Deutschen in hohem Maße gekränkt, mehr noch als die Anschuldigungen der italienischen Presse. Bundeskanzler Schmidt selbst habe sich, wie Brunet nach Paris schrieb, äußerst irritiert über die Haltung der französischen Informationsmedien gegenüber der Bundesrepublik gezeigt. Insbesondere von einer Sendung des Fernsehsenders »TF 1«, die den Zuschauern Schmidt als »Hitler von 1977« präsentiert habe, sei er zutiefst schockiert gewesen ${ }^{582}$. Nach Auffassung des französischen Außenministeriums zeigten derart heftige Reaktionen auf die angebliche "HitlerNostalgie« und die »Affäre Kappler« in Frankreich, welches Gewicht der Vergangenheit in den deutsch-französischen Beziehungen noch immer zukam und dass in der französischen Öffentlichkeit eine Strömung überdauert hatte, für die Deutschland der »Erbfeind « geblieben sei: »Plus important est le poids psychologique du passé. Sans prétendre approfondir l'analyse morale des rapports franco-allemands il faut tenir compte de la survivance d'un courant d'opinion pour lequel l'Allemagne reste l'ennemi héréditaire « ${ }^{583}$.

Diese bestürzende Erkenntnis war es nicht zuletzt, welche die französische Regierung mehrfach dazu veranlasste, in den öffentlichen Diskussionen zu intervenieren und damit zu versuchen, die Verdächtigungen, denen das Partnerland in Frankreich ausgesetzt war, zu entkräften. So erklärte Außenminister Louis de Guiringaud in einem Interview mit »Le Monde« Mitte September 1977: "Il serait extrêmement regrettable de mettre en danger

580 AMAE Nantes, Bonn Ambassade, Bd. 318, Vermerk betreffend »L'opinion allemande et la France«, September 1977, S. 5; siehe auch AN Paris, 5 AG 3, Bd. 937, Vermerk des außenpolitischen Beraters Staatspräsident Giscard d'Estaings, Gabriel Robin, vom 2. Februar 1978, S. 7f.

581 AMAE Nantes, Bonn Ambassade, Bd. 318, Schreiben des französischen Botschafters in Bonn, Jean-Pierre Brunet, an das französische Außenministerium betreffend "L'Allemagne et les médias français" vom 10. September 1977, S. 2.

582 AMAE Paris-La Courneuve, Europe, RFA 1976-1980, Bd. 4000, Bericht des französischen Botschafters in Bonn, Jean-Pierre Brunet, über ein Gespräch mit Bundeskanzler Schmidt vom 11. November 1977, S. 2.

583 AMAE Paris-La Courneuve, Europe, RFA 1976-1980, Bd. 3999, Vermerk betreffend »Les relations franco-allemandes« vom 14. Oktober 1977, S. 3f. 
l'acquis extraordinaire que représente la réconciliation franco-allemande. Les incidents actuels sont parfois grossis, et les conclusions que certains en tirent sur l'évolution politique de l'Allemagne ne me paraissent pas justifiées ${ }^{584}$. Rechtsextreme Parteien seien schließlich bei Wahlen in der Bundesrepublik nie über ein Prozent der Stimmen hinaus gekommen. Von einem Wiedererwachen nationalsozialistisch inspirierter Tendenzen zu sprechen, sei daher in keiner Weise angemessen. Im Nachbarland gebe es, wie Guiringaud bekräftigte, keine Entwicklungen, die in Frankreich zu Beunruhigung führen müssten.

Diese Worte zur deutsch-französischen Aussöhnung kamen, wie Bundesaußenminister Genscher seinem Amtskollegen wenige Tage nach dem Interview mitteilte, "zur richtigen Zeit«: "Sie werden von uns als Hilfe des befreundeten Frankreichs gewertet und hoch geschätzt ${ }^{585}$. Derweil war die Bundesregierung ebenso bestrebt, zu versichern, dass die im Zuge der Kappler-Flucht aufgekommenen Vorwürfe haltlos seien, dass in der Frage der Auslieferung die durch das Grundgesetz vorgegebenen rechtsstaatlichen Prinzipien nicht verletzt werden könnten und dass insbesondere Vermutungen über eine Komplizenschaft zwischen bundesdeutschen Behörden und Alt-Nazis oder neo-nazistischen Gruppierungen jedweder Grundlage entbehrten ${ }^{586}$. Dass die nationalsozialistische Vergangenheit Deutschlands immer wieder Anlass zu Vorurteilen und Verdachtsmomenten gebe, so erklärte Bundespräsident Walter Scheel, sei zwar verständlich, doch hätten die Deutschen die notwendigen Lehren aus ihrer Geschichte gezogen. Darüber dürften die Nachbarn keine Zweifel hegen ${ }^{587}$.

Diese in offiziellen Stellungnahmen zum Ausdruck kommenden Bemühungen um Ausgleich und Verständigung konnten in den Augen der Regierenden allerdings nur dann Früchte tragen, wenn sie von den Menschen beiderseits des Rheins Unterstützung erfuhren. Dies wiederum sei, wie der französische Botschafter Jean-Pierre Brunet im November 1977 formulierte, nur möglich, wenn man den Partner und Nachbarn auch dem Wortsinn nach gut verstehe. "Auf eine kurze Formel gebracht: um sich besser zu verstehen,

584 Zitiert nach Jacques Amalric, Jacques Decornoy, Les vues du PCF et de Moscou sur la défense coïncident objectivement nous déclare le ministre français des affaires étrangères, in: Le Monde, 15.09.1977, S. 3.

585 AMAE Nantes, Bonn Ambassade, Bd. 342, Telegramm Bundesaußenminister HansDietrich Genschers an den französischen Außenminister Louis de Guiringaud vom 21. September 1977.

586 Vgl. hierzu die Erklärung des Regierungssprechers Armin Grünewald vom 23. August 1977, in: Bulletin des Presse- und Informationsamtes der Bundesregierung 80 (1977), S. 764 sowie die Erklärung Bundeskanzler Helmut Schmidts vor dem Bundestag am 15. September 1977, in: Bulletin des Presse- und Informationsamtes der Bundesregierung 86 (1977), S. 807.

587 Vgl. die Ansprache Walter Scheels zur Eröffnung des XXIII. Weltkongresses des Internationalen Gemeindeverbandes am 19. September 1977 in Hamburg, in: Ders., Reden und Interviews, Bd. 4: 1. Juli 1977-30. Juni 1978, Bonn 1978, S. 24 f. 
müssen sich Deutsche und Franzosen noch besser kennenlernen. Das setzt voraus, daß sie mit der Sprache und Kultur des anderen besser vertraut gemacht werden ${ }^{588}$.

Ein Hauptanliegen der Regierungen beider Länder, dies kam insbesondere in den regelmäßigen Gesprächen zwischen dem französischen Bildungsminister und dem Bevollmächtigten der Bundesrepublik zum Ausdruck, war es daher, das Erlernen der Sprache des Nachbarn weiterhin intensiv zu fördern. Dies sollte nicht nur im Rahmen des allgemeinbildenden Schulunterrichts geschehen, sondern ebenso mittels der Sprachkurse des DFJW und der jeweiligen Kulturinstitute sowie mithilfe des Austauschs von Studierenden ${ }^{589}$. Darüber hinaus galten die deutsch-französischen Gymnasien den amtlichen Stellen in Bonn und Paris als wertvolle Pflanzstätten des Freundschaftsgedankens. In den drei bis 1977 gegründeten binationalen Bildungseinrichtungen in Saarbrücken, Freiburg und Versailles besuchten immerhin tagtäglich mehrere hundert Kinder gemeinsam einen zweisprachigen Schulunterricht. Hier sollten die Voraussetzungen dafür geschaffen werden, dass künftige Verwaltungsbeamte, Journalisten, Unternehmer oder Politiker beider Länder Verständnis für die Probleme und Belange des Nachbarlandes aufbringen und damit auf lange Sicht einen Beitrag zur Festigung der deutsch-französischen Beziehungen leisten würden ${ }^{590}$. Wenn es gelänge, so die Einschätzung des französischen Botschafters, all diese Kontakte zwischen Deutschen und Franzosen beständig zu mehren, "wird es einmal möglich sein, die Vorurteile endgültig abzubauen, Fehlurteile zu vermeiden und das falsche Bild, das die Medien sehr oft vom Nachbarland zeichnen, zu korrigieren ${ }{ }^{591}$. Zumindest auf die politisch-administrative Kooperation habe die verzerrte Deutschlandberichterstattung der französischen Medien keine negativen Auswirkungen entfaltet, wie der westdeutsche Koordinator für die bilaterale Zusammenarbeit mit Frankreich, Carlo Schmid, in seinem Jahresbericht für 1977 konstatierte. Dies allein müsse bereits als Erfolg der Verständigungsbestrebungen gewertet werden ${ }^{592}$.

Jenseits der Regierungsebene waren indessen die verschiedenen privaten

588 PA-AA, Zwischenarchiv, Nr. 113555, Vortrag des französischen Botschafters Jean-Pierre Brunet vor dem Deutsch-Französischen Kreis in Düsseldorf am 17. November 1977.

589 Vgl. hierzu BA, B 304, Bd. 2562, Ergebnisprotokoll der Gespräche zwischen dem Bevollmächtigten und dem französischen Bildungsminister im Rahmen der deutschfranzösischen Gipfelkonsultationen am 16./17. Juni 1977; AN Fontainebleau, ministère de l'Éducation nationale, Bd. 900672/38, Protokoll der Sitzung der Interministeriellen Kommission für die deutsch-französische Zusammenarbeit vom 26. Januar 1978, S. 12-15.

${ }^{590}$ Vgl. AN Fontainebleau, ministère de l'Éducation nationale, Bd. 900672/38, »Note sur les lycées franco-allemands«, 24. Januar 1977.

591 PA-AA, Zwischenarchiv, Nr. 113555, Vortrag des französischen Botschafters Jean-Pierre Brunet vor dem Deutsch-Französischen Kreis in Düsseldorf am 17. November 1977.

592 Vgl. BA, B 189, Bd. 26334, 20. Bericht der Interministeriellen Kommission der Bundesregierung für die deutsch-französische Zusammenarbeit, März 1978, S. $15 f$. 
deutsch-französischen Organisationen darum bemüht zu verhindern, dass die öffentlichen Auseinandersetzungen des Sommers 1977 die Einstellung der Bevölkerungen zum jeweiligen Nachbarland in unheilvoller Weise beeinflussen konnten. Ausgehend von der Flucht Kapplers in die Bundesrepublik seien, wie die Verantwortlichen des BILD festhielten, die deutsch-französischen Beziehungen in besonderem Maße belastet gewesen. Vor allem die französischen Reaktionen hätten dazu beigetragen, einen Konflikt zwischen beiden Ländern heraufzubeschwören ${ }^{593}$. Wenn man in Frankreich von der Bundesrepublik spreche, werde, wie ein Tätigkeitsbericht der Vereinigung ausführte, gewöhnlich ihre politische und soziale Stabilität gelobt und die beispielhafte Übereinstimmung der Sozialpartner zitiert. In Krisenzeiten jedoch schlage diese Anerkennung nicht selten in harsche Kritik um. Misstrauen, Neid und Aggressionen beherrschten dann die Sicht auf den Nachbarn und führten bei vielen Franzosen zu dem Verdacht: »Die Deutschen werden sich niemals ändern - überall gibt es noch Nazis; wenn man sie gewähren ließe, dominierten sie in Europa; sie sind für uns eine nicht-loyale Konkurrenz « ${ }^{594}$. Diese Haltung in der französischen Bevölkerung nicht die Oberhand gewinnen zu lassen, war eines der wesentlichen Ziele der Informations- und Öffentlichkeitsarbeit des BILD seit Herbst 1977. Unter Bezugnahme auf die jüngsten Kontroversen hieß es in einem redaktionellen Vorwort der "Documents«:

Il n'y a pas d'événement qui ne permette, à ceux qui le veulent, d'entretenir le malentendu franco-allemand, voire de le gonfler, de l'exacerber, à la faveur des maladresses et des erreurs commises. Il ne s'agit nullement pour nous de nier que ces maladresses et que ces erreurs existent. Il faut qu'elles soient prises en compte, non pour prendre l'histoire à témoin, mais pour que la communauté franco-allemande [...] se construise sur la vérité ${ }^{595}$.

Um demgemäß für mehr Sachlichkeit und Objektivität in den deutschfranzösischen Beziehungen zu sorgen, brachte die Zeitschrift in derselben Ausgabe einen Beitrag des französischen Koordinators für die Zusammenarbeit zwischen Frankreich und Westdeutschland, Jean Laloy. Dieser verurteilte die tendenziöse Berichterstattung der französischen Presse ausdrücklich und rief seine Landsleute dazu auf, sich die medial verbreiteten Vorurteile nicht zu eigen zu machen: "Interrogez à l'automne de 1977 un Français sur la République fédérale, il vous répondra: renaissance du nazisme! C'est du moins ce qu'on pourrait croire en lisant les journaux, en regardant la télévision ${ }^{596}$. Wenn diese Zerrbilder sich erst fest in der französischen Gedankenwelt verankerten, würde dies, so Laloy, einen herben Rückschlag

593 Vgl. BILD-Archiv, Aufzeichnung zum Jahresbericht 1977 des Bureau international de liaison et de documentation, S. 2.

${ }^{594}$ BILD-Archiv, Tätigkeitsbericht 1979 der Gesellschaft für übernationale Zusammenarbeit und des Bureau international de liaison et de documentation, S. 5.

595 Avant-propos, in: Documents 32/4 (1977), S. 3f.

596 Jean LALOY, Les relations franco-allemandes. Mythes ou réalités, in: Documents 32/4 (1977), S. 43-51, hier S. 43. 
für das deutsch-französische Verhältnis bedeuten. Statt die falsche und gefährliche Vorstellung einer der nationalsozialistischen Ideologie Tür und Tor öffnenden Bundesrepublik zu befördern, sollten die Medien es sich daher zur Aufgabe machen, die Franzosen von der "post-totalitären Weisheit" in Kenntnis zu setzen, welche Nachkriegsdeutschland in weiten Zügen charakterisiere. Nur durch objektive Informationen könne das Bewusstsein für die deutsch-französischen Gemeinsamkeiten und damit die Einsicht in die Notwendigkeit einer engen Gemeinschaft von Deutschen und Franzosen entscheidend gestärkt werden ${ }^{597}$.

Einen ähnlichen Appell sandte der deutsche Botschafter in Paris, Axel Herbst, im September 1977 im Rahmen einer Grußbotschaft an die in Montpellier versammelten Mitglieder des ADFG: »En lisant toute la publicité [...] au sujet du spectre d'une récrudescence du néonazisme, un lecteur nonaverti pourrait être porté à croire, que l'Allemagne serait en train de devenir un État policier répressif et nostalgique du nazisme «598. Eine intensive Informationsarbeit sei daher vonnöten, um die auf französischer Seite noch immer bestehenden Klischeevorstellungen über Deutschland aus der Welt zu schaffen: "C'est là dans le domaine de l'information et dans celui de l'approfondissement de la connaissance que je vois une grande tâche pour les associations franco-allemandes, bref, il nous faut `l'Aufklärung` dans tout le sens du mot et d'une manière continue ${ }^{599}$.

Für die anlässlich des Jahreskongresses der deutsch-französischen Gesellschaften zusammengekommenen Delegierten bedeuteten die Worte des Botschafters Lob und Ansporn gleichermaßen. Lob für ihren bisherigen Einsatz im Dienste der Annäherung, Ansporn für ihr künftiges Engagement, zumal in Zeiten, in denen »das Verhältnis zwischen unseren beiden Völkern sich zu trüben scheint ${ }^{600}$, wie der Präsident des ADFG im Oktober 1977 feststellte. Zwar gehe diese Trübung im Wesentlichen von den französischen Medien aus und es sei nicht bewiesen, dass sie die Stimmung der französischen Bevölkerung in ihrer Gesamtheit widerspiegele, doch müsse allein die Tatsache, dass eine derartige Situation auftreten konnte, nachdenklich stimmen: »Vielleicht hat unsere Arbeit doch noch nicht die Effizienz erreicht, die wir wünschen oder die wir glauben schon erreicht zu haben « ${ }^{601}$. Die einzelnen Mitgliedsgesellschaften, insbesondere die französischen, sollten sich vor dem Hintergrund der eingetretenen Verstimmungen in jedem Falle dazu ermutigt sehen, in ihrem jeweiligen Umfeld, wie von Botschafter

597 Siehe ibid.

598 VDFG-Archiv, Rede von Botschaftsrat Wolfgang Bente im Rahmen der 22. Jahrestagung der deutsch-französischen Gesellschaften in Montpellier im September 1977, in: Mitteilungsblatt für die Deutsch-Französischen Gesellschaften 43 (1978), S. 136.

599 Ibid.

600 VDFG-Archiv, Ordner Arbeitskreis Korrespondenz 1977-1979, Überlegungen von ADFG-Präsident Alfred Borgmann zur Kuratoriumssitzung am 28. Oktober 1977.

601 Ibid. 
Herbst angeregt, Aufklärungsarbeit zu leisten und mithelfen, Schaden von der Freundschaft zwischen Frankreich und Westdeutschland abzuwenden.

Auch die Mitglieder der IBU sahen schließlich in den deutsch-französischen Disharmonien des Sommers 1977 einen Anlass zu verstärktem Handeln. In einer Sitzung des Verwaltungsausschusses im Oktober des Jahres wies der Vizepräsident der Vereinigung angesichts der verschiedenen "antideutschen Demonstrationen" und "tendenziösen Reportagen" der französischen Medien, »die geeignet waren, die neue Generation zu beeinflussen«, ausdrücklich auf die Notwendigkeit »der Neuerung der Bande zwischen unseren beiden Völkern " hin ${ }^{602}$. Man wolle, so die Beschlussfassung der Anwesenden, die Tätigkeit der IBU intensivieren, um »den derzeitigen Anfeindungen, denen Deutsche auch in Frankreich in den Massenmedien ausgesetzt sind, entgegenzuwirken ${ }^{603}$. Vor allem der Kongress der Bürgermeister-Union im April des Folgejahres sollte dazu dienen, die Vertreter von westdeutschen und französischen Städten und Gemeinden darauf einzuschwören, die im Zuge der Kommunalpartnerschaften stattfindenden Austauschaktivitäten weiter voranzutreiben. Schließlich war nach Auffassung der Verantwortlichen der IBU gerade durch die zahlreichen Begegnungen zwischen Deutschen und Franzosen aus partnerschaftlich verbundenen Städten eine Breitenwirkung zu erzielen, welche die Verständigung auf Ebene der Bevölkerungen überhaupt erst möglich machte. In dieser Auffassung wurden sie nicht zuletzt auch von Seiten der staatlichen Stellen bestärkt: »Les jumelages complètent et donnent un sens concret et humain aux relations officielles entre États, certes nécessaires, mais non suffisantes « ${ }^{604}$, wie der französische Generalkonsul in München, Gérard de la Villesbrunne, Botschafter Wormser auf Anfrage mitteilte. Die Städtepartnerschaften würden, so hoffte man, menschliche Bindungen herstellen, die Amtszeiten von Regierungen überdauern und Erschütterungen der politischen oder öffentlichen Beziehungen unbeschadet überstehen können.

602 StASt, Bestand 1020, Bd. 13, Protokoll der Sitzung des Verwaltungsausschusses der IBU am 24. Oktober 1977 in Fontainebleau, S. 4.

${ }^{603}$ Ibid., S. 3.

604 AMAE Paris-La Courneuve, Europe, RFA 1976-1980, Bd. 4010, Schreiben des französischen Generalkonsuls in München, Gérard de la Villesbrunne, an den französischen Botschafter in Bonn, Olivier Wormser, vom 2. März 1977; vgl. auch AMAE Nantes, Bonn Ambassade, Bd. 369, Schreiben des französischen Generalkonsuls in Saarbrücken, Étienne Coïdan, an den französischen Botschafter in Bonn, Olivier Wormser, vom 28. Januar 1977, wo es heißt: »la politique du jumelage [...] a appuyé utilement les efforts des deux gouvernements en faveur de la réconciliation et de la coopération entre les deux pays et à contribué à l'instauration d'une meilleure connaissance réciproque et d'une plus grande compréhension, voire de véritables liens d'amitié, entre villes et familles sarroises et françaises«. 
Bindungen dieser Art waren es auch, die deutsch-französische Mittlerpersönlichkeiten durch ihr Wirken zu schaffen oder zu festigen suchten. Joseph Rovan etwa erinnerte angesichts der französischen Proteste gegen die Entscheidung der Bundesregierung, den aus Italien geflohenen Kappler nicht auszuliefern, seine Landsleute eindringlich daran, dass kein »zivilisiertes Land « der Welt seine Staatsangehörigen ausliefere ${ }^{605}$. Kappler habe zudem bereits über dreißig Jahre seiner Strafe verbüßt. Und schließlich seien durch Staatspräsident de Gaulle selbst schon Anfang der 1960er Jahre mit Helmut Knochen und Carl Oberg die letzten in französischem Gewahrsam befindlichen deutschen Kriegsverbrecher begnadigt worden ${ }^{606}$, welche sich schwererer Vergehen schuldig gemacht hätten als Kappler: »Mais comment résister au plaisir d'accuser de complicité avec un criminel de guerre nazi le chancelier social-démocrate d'un pays dont le système économique capitaliste bénéficie [...] de ce soutien populaire qu'aucun régime socialiste n'a jamais osé solliciter par la voie d'élections libres? ${ }^{607}$ Statt die Deutschen permanent zu verdächtigen, stünde es den Franzosen, wie Rovan urteilte, besser an, mit den Nachbarn Wege zu suchen, die gemeinsame Vergangenheit zu bewältigen und die Erinnerung hieran wachzuhalten. Die zwischen beiden Ländern eingetretene »Vertrauens- und Verständniskrise« mache einmal mehr deutlich, wie grundlegend notwendig es auch jetzt noch sei, die 1945 begonnene politische wie gesellschaftliche Versöhnungsarbeit mit allen verfügbaren Mitteln fortzusetzen $^{608}$.

Für Alfred Grosser zeugten die öffentlichen Auseinandersetzungen des Sommers 1977 vor allem davon, wie sehr das Denken der Franzosen über Deutschland noch immer durch die Zeit des Nationalsozialismus bestimmt war, wie sehr die französischen Reaktionen auf verdächtige Entwicklungen im Nachbarland noch immer Angst und Ablehnung widerspiegelten. Dies habe die Aufregung um Joachim Fests Film »Hitler - Eine Karriere« ebenso erkennen lassen wie diejenige um die Flucht Herbert Kapplers. Jegliches Indiz, das Anlass zu der Vermutung nationalsozialistischer Umtriebe in der Bundesrepublik gebe, sei es in seiner Bedeutung auch noch so gering, werde durch die französische Presse begierig aufgenommen und vor den französischen Lesern ausgebreitet, die somit ihre alten Vorurteile über die Deutschen auf bequeme Weise bestätigt finden könnten. Auch das französische Fernse-

605 Siehe Rovan, L'Allemagne n'est pas ce que vous croyez, S. 20.

606 Vgl. hierzu Moisel, Frankreich und die deutschen Kriegsverbrecher, S. 7; Ulrich LAPPENKÜPER, Der »Schlächter von Paris«: Carl-Albrecht Oberg als höherer SS- und Polizeiführer in Frankreich 1942-1944, in: Stefan Martens, Maurice VÄ̈sse (Hg.), Frankreich und Deutschland im Krieg (November 1942-Herbst 1944). Okkupation, Kollaboration, Résistance, Bonn 2000, S. 129-143; Paul SANDERs, Anatomie d'une implantation SS: Helmut Knochen et la police nazie en France 1940-1944, in: Revue d'histoire de la Shoa 165 (1999), S. 111-145.

607 Siehe Rovan, L'Allemagne n'est pas ce que vous croyez, S. 20.

608 Siehe Ders., Deutsch-französische Zusammenarbeit, S. 278f. 
hen, welches ein nahezu ausschließlich an der Zeit des Zweiten Weltkriegs orientiertes Deutschlandbild zeige, habe dazu beigetragen, eine öffentliche Stimmung zu erzeugen, in der es möglich geworden sei, die Bonner Regierung der Komplizenschaft mit Alt- und Neo-Nazis zu bezichtigen ${ }^{609}$. Als absurd wie skandalös gleichermaßen empfand Grosser es insbesondere, dass seriöse französische Wochenzeitungen wie »Le Point« ihren Lesern das rechtsextreme Wochenblatt »Deutsche National-Zeitung « ${ }^{610}$ als repräsentatives Organ der westdeutschen Öffentlichkeit präsentierten. Angesichts des Fortbestehens dieser französischen Trugbilder des »ewigen Deutschlands" sei, wie Grosser in einem Artikel für »Le Monde« ernüchtert konstatierte, für jemanden wie ihn, der seit Jahrzehnten hiergegen ankämpfe, ein Gefühl der Entmutigung nicht zu verhehlen:

[Q]uand on essaie, depuis une trentaine d'années, de lutter contre les phantasmes, de faire connaître et de faire réfléchir, on ne peut s'empêcher d'éprouver un sentiment de découragement. En octobre 1953, au lendemain d'une victoire électorale d'Adenauer, j'avais écrit dans ce journal un article intitulé `Que vouliez-vous qu'ils fissent? ${ }^{611}$. J'y cherchais à montrer que les commentaires français parlant d'inquiétudes, s'interrogeant sur l'Allemagne par rapport à son passé et à son avenir, auraient été les mêmes quels qu'eussent été les résultats. Vingt-quatre ans plus tard, l'article pourrait, hélas, être repris sans trop de modifications. Les phantasmes français seraient-ils indestructibles ${ }^{612}$ ?

Grossers Feststellung, die französische Haltung zu den deutschen Nachbarn und zu ihrem Umgang mit der nationalsozialistischen Vergangenheit habe sich binnen eines Zeitraums von mehr als zwei Jahrzehnten nicht wesentlich zum Besseren verändert, musste bei ihm und bei all denjenigen, die ihr Wirken nach 1945 in den Dienst der Verständigung gestellt hatten, in der Tat ein Gefühl der Resignation auslösen. Die Debatten um den Film Joachim Fests sowie den »Fall Kappler « ließen die Streiter für die deutsch-französische Freundschaft, welche der aggressiven Zuspitzung der öffentlichen Konfrontationen weitgehend hilflos hatten zusehen müssen, erneut gewahr werden, wie leicht die Brücken der Annäherung, um deren Erhalt und Ausbau sie Jahr um Jahr in bisweilen beschwerlicher Kleinarbeit bemüht waren, Risse erhalten oder gar zum Einsturz gebracht werden konnten.

In Frankreich, so schien es, predigten die Meinungsmacher unverdrossen die Botschaft von den »ewigen Deutschen«, von ihrem unheilbaren Hang

609 Vgl. Alfred Grosser, Federal Republic of Germany: from democratic showcase to party domination, in: Anthony Smith (Hg.), Television and Political Life. Studies in Six European Countries, New York 1979, S. 114-141, hier S. 115f.; Alfred Grosser, Cessons de craindre et de condamner, in: Le Point, 17.10.1977, S. 89-91.

${ }^{610}$ Die »Deutsche National-Zeitung « war ein Nachfolgeorgan der 1951 durch den ehemaligen SS-Offizier Joachim Ruoff gegründeten »Deutschen Soldaten-Zeitung«, vgl. Uwe BACKes, Eckhard Jesse, Politischer Extremismus in der Bundesrepublik Deutschland, Berlin 1993, S. 87.

611 Vgl. Alfred Grosser, Que vouliez-vous qu'ils fissent?, in: Le Monde, 01.10.1953, S. 5.

612 Ders., Les phantasmes français, in: Le Monde, 09.09.1977, S. 2; vgl. auch Ders., Le criminel, le châtiment et la mémoire, in: Ouest-France, 24.08.1977, S. 1. 
zu obrigkeitsstaatlichen Gesellschaftsmodellen und von der Gefahr einer Wiederkehr des Nationalsozialismus. Währenddessen schrieben die westdeutschen Zeitungen die medialen Angriffe von jenseits des Rheins vor allem dem Neid der Franzosen auf die wirtschaftlich erfolgreiche und international angesehene Bundesrepublik zu. Misstrauen hier, Indignation dort - die Nachwirkungen des Zweiten Weltkriegs belasteten das deutsch-französische Verhältnis auch noch am Ende der 1970er Jahre.

Auf Ebene der Regierungen mochte die "Bonne Entente ${ }^{613}$ zwischen Frankreich und Westdeutschland mittlerweile Realität sein. Weite Teile der Presselandschaft waren jedoch von diesem deutsch-französischen Gemeinsinn nicht erfasst worden. Aus Sicht der Protagonisten der Annäherung stand zu befürchten, dass sich hieraus negative Folgen auch für die Beziehungen zwischen den Bevölkerungen ergeben konnten. Es blieb ihnen letztlich die Hoffnung, dass sich ihr Engagement auf die Generation der Nachgeborenen in günstigerer Weise auswirken würde, auf diejenigen, die im Rahmen von Jugendaustausch-Programmen oder Sprachausbildung das Nachbarland kennengelernt hatten, mit ihm positive Erfahrungen verbanden und daher gegen die medialen Zerrbilder der deutsch-französischen Konfliktgeschichte gefeit waren.

\subsection{Die westdeutsche Demokratie im Widerstreit}

War die Bundesrepublik drei Jahrzehnte nach dem Ende des Zweiten Weltkriegs ein gefestigter demokratischer Rechtsstaat? Hatten obrigkeitsstaatliches Denken und Autoritätshörigkeit einer liberalen Gesellschaftsform Platz gemacht? Verbunden mit der Frage, ob Reste nationalsozialistischen Gedankenguts in den Köpfen der Deutschen fortlebten, blieb für viele Menschen in den europäischen Nachbarländern vor allem die Sorge um die Entwicklung der westdeutschen Demokratie 614 .

Zwar hatte die Zeitspanne seit 1945 eine Vielzahl von Belegen hervorgebracht, die auf eine dauerhafte Verankerung rechtsstaatlicher Prinzipien und demokratischer Willensbildungsprozesse in der Bundesrepublik hindeu-

613 Siehe Helmut Schmidt, Menschen und Mächte, Bd. 2: Die Deutschen und ihre Nachbarn, Berlin 1990, S. 153.

${ }^{614}$ Vgl. Elke Bruck, Deutschland von außen, in: Werner Weidenfeld, Karl-Rudolf KorTE (Hg.), Handbuch zur deutschen Einheit 1949-1989-1999, Frankfurt a.M., New York 1999, S. 202-215; Paul Nolte, Was ist Demokratie? Geschichte und Gegenwart, München 2012, S. 332-348. 
teten $^{615}$, darauf, dass Bonn eben nicht Weimar war ${ }^{616}$. Doch letzte Zweifel an der Stabilität der politischen Kultur Westdeutschlands waren weiterhin vorhanden. Bestätigt fanden diese sich insbesondere dann, wenn Gesetzesinitiativen oder Regierungshandeln auf eine Einschränkung bürgerlicher Freiheiten beziehungsweise die Stärkung staatlicher Kontrollmechanismen abzuheben schienen. Rasch erwachte in derartigen Momenten die Befürchtung zu neuem Leben, auf deutschem Boden könnten sich wieder autoritäre Herrschaftspraktiken und justizielle Willkür ausbreiten. In den 1960er Jahren war dies etwa im Zusammenhang mit der Spiegel-Affäre und der Verabschiedung der Notstandsgesetze der Fall gewesen ${ }^{617}$. Mitte der 1970er Jahre gab vor allem der so genannte »Radikalenerlass«, der linksextremistischen Tendenzen im öffentlichen Dienst entgegenwirken sollte, Anlass zur Kritik an den inneren Verhältnissen der Bundesrepublik ${ }^{618}$. Die systematische Überprüfung der Verfassungstreue der westdeutschen Beamten kam auch aus Sicht eines Großteils der französischen Beobachter einer unlauteren Rechtspraxis gleich. Der Ausschluss von Bediensteten aufgrund ihrer politischen Einstellung rief die ungute Erinnerung an »Berufsverbote « wach, die es in der jüngeren deutschen Geschichte bereits gegeben hatte, und führte zu scharfen Verurteilungen der gesellschaftspolitischen Situation Westdeutschlands von Seiten der französischen Meinungsführer.

$\mathrm{Zu}$ noch stärkeren Verwerfungen in den deutsch-französischen Beziehungen kam es im Zuge der Ereignisse des "Deutschen Herbstes« 1977619. Während in Frankreich die Maßnahmen der bundesdeutschen Terrorismusbekämpfung vielfach als Fingerzeige für die schrittweise Etablierung eines westdeutschen Polizeistaates interpretiert und den Mitgliedern der RAF zum Teil offene Sympathien entgegengebracht wurden, ließen die Kommentatoren in der Bundesrepublik ihrem Ärger und ihrer Enttäuschung über die fehlende

615 Vgl. Manfred G. Sснмidt, Das politische System der Bundesrepublik Deutschland, München 2005, S. 10-15; Wolfrum, Die geglückte Demokratie, S. 43-186; Konrad H. Jarausch, Arnd Bauerkämper, Marcus M. Payk (Hg.), Demokratiewunder. Transatlantische Mittler und die kulturelle Öffnung Westdeutschlands 1945-1970, Göttingen 2005.

${ }^{616}$ So bereits der Titel des berühmt gewordenen Werkes des Schweizer Publizisten Fritz René AllemanN, Bonn ist nicht Weimar, Köln 1956.

617 Vgl. hierzu Jürgen Seifert (Hg.), Die Spiegel-Affäre, 2 Bde., Olten 1966; Boris Spernol, Notstand der Demokratie. Der Protest gegen die Notstandsgesetze und die Frage der NSVergangenheit, Essen 2008; Michael SchneIder, Demokratie in Gefahr? Der Konflikt um die Notstandsgesetze: Sozialdemokratie, Gewerkschaften und intellektueller Protest (1958-1968), Bonn 1986.

618 Vgl. Sven Reichardt, Große und Sozialliberale Koalition (1966-1974), in: Roth, Rucht (Hg.), Die sozialen Bewegungen in Deutschland seit 1945, S. 71-91; Marion Detjen, Stephan Detjen, Maximilian Steinbeis, Die Deutschen und das Grundgesetz. Geschichte und Grenzen unserer Verfassung, München 2009, S. 166-170.

619 Vgl. Wolfgang Benz, Der Aufbruch in die Moderne. Das 20. Jahrhundert, Stuttgart ${ }^{10} 2010$, S. $127 \mathrm{f}$. 
Solidarität der französischen Partner freien Lauf. Die hieraus entstehenden Auseinandersetzungen führten, wie die folgenden Kapitel aufzeigen, zu einer Krise des deutsch-französischen Verhältnisses, die in der Wahrnehmung zahlreicher Kräfte der Verständigung eine ernsthafte Gefahr für all das bis dahin zwischen Frankreich und Westdeutschland Erreichte darstellte. Umso mehr musste ihnen daran gelegen sein, ihrer Vermittlungsarbeit Nachdruck zu verleihen.

\subsection{1 "Chasse aux sorcières«: die Auseinandersetzungen um die "Berufsverbote»}

Seit Mitte der 1970er Jahre ließ der »Radikalenerlass« in Frankreich Befürchtungen aufkommen, die Bundesrepublik könne den Weg des freiheitlichen Rechtsstaates verlassen und in überwunden geglaubte antidemokratische und autoritäre Muster zurückfallen ${ }^{620}$. Die »Grundsätze zur Frage der verfassungsfeindlichen Kräfte im öffentlichen Dienst", im Sprachgebrauch »Radikalenerlass« oder »Extremistenbeschluss«, waren am 28. Januar 1972 von Bundeskanzler Brandt und den westdeutschen Ministerpräsidenten gemeinsam beschlossen worden. In ihrer Zielrichtung lassen sie sich den seit Anfang der 1970er Jahre forcierten Maßnahmen einer staatlichen »Gefahrenabwehr von links« zuordnen. Diese speisten sich zum einen aus der Angst, Linksextremisten könnten die Institutionen des Staates und insbesondere die Bildungseinrichtungen unterwandern. Zum anderen waren sie der Furcht der westdeutschen Sozialdemokratie geschuldet, im Vergleich mit der konservativen Opposition als zu nachgiebig gegenüber der kommunistischen

${ }^{620}$ Vgl. zur Wahrnehmung des Radikalenerlasses in Frankreich Dominik RigolL, »Herr Mitterrand versteht das nicht«. »Rechtsstaat« und »deutscher Sonderweg « in den deutsch-französischen Auseinandersetzungen um den Radikalenbeschluss 1975/76, in: Detlef Georgia Schulze, Sabine Berghahn, Frieder Otto Wolf, (Hg.), Rechtsstaat statt Revolution, Verrechtlichung statt Demokratie? Transdisziplinäre Analysen zum deutschen und spanischen Weg in die Moderne, Bd. 2: Die juristischen Konsequenzen, Münster 2010, S. 812-822; Dominik RigolL, »Was täten Sie, wenn quer durch Paris eine Mauer wäre?«. Der Radikalenbeschluss von 1972 und der Streit um die westdeutschen Berufsverbote. Deutsch-deutsch-französische Verflechtungen, in: Heiner Timmermann (Hg.), Historische Erinnerung im Wandel. Neuere Forschungen zur deutschen Zeitgeschichte unter besonderer Berücksichtigung der DDR-Forschung, Berlin 2007, S. 603-623; Hélène Miard-Delacroix, Libertés et droit dans le débat sur la législation contre l'extrémisme dans l'Allemagne fédérale des années 1970, in: Emmanuel Béhague, Denis Goeldel (Hg.), Une germanistique sans rivages. Mélanges en l'honneur de Frédéric Hartweg, Straßburg 2008, S. 388-397; Hélène Miard-DeLACROIX, Willy Brandt, Helmut Schmidt und François Mitterrand. Vom Komitee gegen "Berufsverbote" 1976 bis zum Streit um die Mittelstreckenraketen 1983, in: MöLLER, VAÏsse (Hg.), Willy Brandt und Frankreich, S. 231-246; PfeIL, Die »anderen« deutschfranzösischen Beziehungen, S. 480-494. 
Bedrohung zu erscheinen ${ }^{621}$. Schließlich kam auch der im Zuge der RAFAttentate entfachten Terrorismusdebatte, die in den Zeitungen nicht selten mit der Diskussion um die "Radikalenbekämpfung « verbunden wurde, hier eine ausschlaggebende Funktion $\mathrm{zu}^{622}$. Der Beschluss von 1972 sah im Einzelnen vor, dass im Beamtenverhältnis in der Bundesrepublik nur tätig sein konnte, wer die Gewähr bot, »daß er jederzeit für die freiheitlich-demokratische Grundordnung im Sinne des Grundgesetzes eintritt «623. Wenn ein Bewerber für den öffentlichen Dienst, wie es dort weiter hieß, jedoch verfassungsfeindliche Aktivitäten entwickele oder einer Organisation angehöre, die verfassungsfeindliche Ziele verfolge, begründe dies Zweifel daran, ob er die genannte Gewähr tatsächlich würde leisten können, und rechtfertige in der Regel eine Ablehnung seines Einstellungsantrags.

Die Überprüfung der Verfassungstreue erfolgte in der Praxis mittels einer Regelanfrage beim Verfassungsschutz, der allerdings nicht nach verfassungswidrigem Tun, sondern nach einer im Sinne des Beschlusses verdächtigen Gesinnung der betreffenden Personen forschte. Aufgrund des nicht eindeutigen Wortlauts des Beschlusstextes geriet die Frage, wer als »Verfassungsfeind " einzustufen war und wer nicht, schnell zur Auslegungssache und wurde dementsprechend von den Bundesländern in uneinheitlicher Weise gehandhabt. Nicht nur Bewerber, die Mitglied der 1968 legal gegründeten Deutschen Kommunistischen Partei waren, kamen hierbei in den Verdacht der Verfassungsfeindlichkeit. Es konnte schon ausreichen, in einer Organisation aktiv zu sein, in der auch Kommunisten mitarbeiteten, um entweder nicht zum öffentlichen Dienst zugelassen oder sogar hiervon ausgeschlossen zu werden. Seit 1972 wurden auf diese Weise über drei Millionen Bewerber oder bereits Bedienstete einer Überprüfung ihrer Treue zum Grundgesetz unterzogen. In mehreren Tausend Fällen wurde der Eintritt beziehungsweise der Verbleib der Betreffenden im öffentlichen Dienst untersagt. Mehrere Hundert Beschäftigte

621 Vgl. hierzu und zum folgenden Abschnitt Gerard Braunthal, Politische Loyalität und Öffentlicher Dienst. Der »Radikalenerlaß« von 1972 und die Folgen, Marburg 1992; Ralf Zoll, Der »Radikalenerlass«, in: Peter Imbusch, Ralf Zoll (Hg.), Friedens- und Konfliktforschung. Eine Einführung, Wiesbaden ${ }^{5} 2010$, S. 485-509; Gert-Joachim Glaessner, Politik in Deutschland, Wiesbaden ${ }^{2} 2006$, S. 131; Frank L. SchäFer, Wehrhafte Demokratie. Ein Vergleich zwischen Weimar und Bundesrepublik, in: Hartmut Brenneisen, Dirk Staack, Susanne Kischewski (Hg.), 60 Jahre Grundgesetz, Berlin 2010, S. 197-214, hier S. 209; Wolfgang FrindTe, Inszenierter Antisemitismus. Eine Streitschrift, Wiesbaden 2006, S. 110f., dort Anm. 33; Thomas KLeIn, SEW - Die Westberliner Einheitssozialisten. Eine »ostdeutsche« Partei als Stachel im Fleische der »Frontstadt«?, Berlin 2009, S. 50-54.

622 Vgl. Andreas Musolff, Die Terrorismus-Diskussion in Deutschland vom Ende der sechziger bis Anfang der neunziger Jahre, in: Georg Stötzel, Martin Wengeler, Kontroverse Begriffe. Geschichte des öffentlichen Sprachgebrauchs in der Bundesrepublik Deutschland, Berlin, New York 1995, S. 405-445, hier S. 416f.

${ }^{623}$ Wortlaut zitiert nach Gerhard Strauss, Ulrike Hass, Gisela Harras, Brisante Wörter von Agitation bis Zeitgeist, Berlin, New York 1989, S. 317. 
wurden als "Verfassungsfeinde» entlassen ${ }^{624}$. Aus rechtlicher Sicht stellte dies zwar kein Berufsverbot dar, doch hatte der Beschluss für bestimmte Bewerber, so zum Beispiel für Lehrer, die faktische Wirkung eines Verbots, ihren Beruf auszuüben. Da zahlreichen Zeitgenossen derartige Methoden in bedrohlicher Nähe zum nationalsozialistischen »Gesetz zur Wiederherstellung des Berufsbeamtentums « ${ }^{625}$ vom April 1933 zu stehen schienen, blieben öffentliche Proteste gegen die Verfahrenspraxis der Bundesregierung in Westdeutschland nicht aus ${ }^{626}$. In einem Urteil vom Mai 1975 erklärte das Bundesverfassungsgericht die umstrittene Handhabung unter Betonung der "politischen Treuepflicht« des Beamten für rechtens ${ }^{627}$ und weitete zudem die Einzelfallüberprüfung schrittweise auch auf Beschäftigte des mittleren Dienstes und technische Berufe aus. Hierdurch gelangte die Problematik des nunmehr als "Radikalenerlass" bekannten Beschlusses auch in den Fokus der internationalen Presse. Dort wurde Befremden darüber zum Ausdruck gebracht, dass die Bundesrepublik, so der immer wieder zu vernehmende Vorwurf, ihre Bürger ausspioniere und deren Rechte und Freiheiten einschränke ${ }^{628}$. Nicht zuletzt in Frankreich rief die innere Entwicklung des Nachbarlandes scharfe Kritik hervor ${ }^{629}$.

Bereits im Februar 1975 hatte der Deutschland-Korrespondent von "Le Monde«, Daniel Vernet, ohne in besonderem Maße auf die Proteste gegen den »Radikalenerlass« in der Bundesrepublik einzugehen, seinen französischen Lesern von einem fundamentalen Rechtsruck der westdeutschen Öffentlichkeit berichtet, welcher sich auch in der Politik der sozialliberalen Bonner

${ }^{624}$ Siehe zu den angeführten Größenordnungen Kai Artinger, »Radikalenerlaß«, in: Ders. (Hg.), Die Grundrechte im Spiegel des Plakats 1919 bis 1999, Berlin 2000, S. 144f., hier S. 144; die Zahlenangaben schwanken allerdings in der Forschung, vgl. KLEIN, SEW - Die Westberliner Einheitssozialisten, S. 51.

625 Vgl. zum Wortlaut des Gesetzes Götz Aly u.a. (Hg.), Die Verfolgung und Ermordung der europäischen Juden durch das nationalsozialistische Deutschland 1933-1945, Bd. 1: Deutsches Reich 1933-1937, bearb. v. Wolf GrUnER, München 2008, S. 130-134; hierzu weiterführend Angelika KöNIGSEDER, Art. »Gesetz zur Wiederherstellung des Berufsbeamtentums", in: Wolfgang Benz, Hermann Graml, Hermann Weiss (Hg.), Enzyklopädie des Nationalsozialismus, München ${ }^{5}$ 2007, S. 536f.

626 Vgl. Wolf-Dieter NARR, Bürger- und menschenrechtliches Engagement in der Bundesrepublik, in: Rотн, Rucht (Hg.), Die sozialen Bewegungen in Deutschland seit 1945, S. 347-362, hier S. 352-354.

627 Vgl. Tade Matthias Spranger, BVerfGE 39, 334ff. - Extremisten. Zur Einstellung von politisch Radikalen in den Öffentlichen Dienst, in: Jörg Menzel (Hg.), Verfassungsrechtsprechung. Hundert Entscheidungen des Bundesverfassungsgerichts in Retrospektive, Tübingen 2000, S. 254-259.

${ }^{628}$ Vgl. Dominik RigolL, Die Demokratie der anderen. Der Radikalenerlass von 1972 und die Debatte um die Berufsverbote. International vergleichende und transfergeschichtliche Aspekte, in: Jörg Calliess (Hg.), Die Geschichte des Erfolgsmodells BRD im internationalen Vergleich, Loccum 2006, S. 173-177.

${ }^{629}$ Vgl. hierzu SchmiTz, Zwischen Mythos und Aufklärung, S. 217-220. 
Regierung auf beunruhigende Weise widerspiegele ${ }^{630}$. Wenige Monate später stand angesichts der sich stetig potenzierenden Nachrichten über die seitens des westdeutschen Staates verhängten »Berufsverbote« nicht nur für die kommunistische Zeitung "L'Humanité fest, dass die Meinungsfreiheit in der Bundesrepublik massiv in Gefahr sei. Über eintausend Beamte seien, so wollte das Blatt in Erfahrung gebracht haben, aufgrund ihrer politischen Einstellung bereits aus dem öffentlichen Dienst entlassen worden. »Des centaines de milliers d'enquêtes policières" würden derzeit im Nachbarland gegen Kommunisten angestrengt ${ }^{631}$. Politische Repression und justizielle Willkür hielten in Westdeutschland Einzug, wie man lesen konnte ${ }^{632}$. Dabei sei, wie Daniel Vernet im Dezember 1975 schrieb, kaum nachvollziehbar, in welcher Form etwa ein kommunistischer Lokführer oder technischer Angestellter die demokratische Verfasstheit der Bundesrepublik bedrohe. Vielmehr brächten die inquisitorischen Methoden, mit denen der Staat gegen seine Bürger vorgehe, die liberale Ordnung der westdeutschen Gesellschaft in Gefahr. Eine besorgniserregende "nouvelle schasse aux sorcières « habe im Nachbarland begonnen ${ }^{633}$. Mehr und mehr entstehe dort, dies auch das Urteil in »Le Nouvel Observateur «, ein beängstigendes Klima allgemeiner Verdächtigung: »ce qui fait peur, c'est l'atmosphère qui s'est installée en Allemagne autour de ces affaires. Dans les universités, les ministères et les bureaux de poste, dans les écoles, les administrations régionales et municipales, la suspicion règne « ${ }^{634}$. Nachdenklich stimme insbesondere, dass von den staatlichen Überprüfungsmaßahmen, die doch den politischen Extremismus an sich in die Schranken weisen sollten, lediglich Linke betroffen seien, jedoch beispielsweise Mitglieder der NPD hiervon gänzlich verschont blieben. Es stelle sich die Frage, ob man nicht schlicht und einfach der Rückkehr alter deutscher Traditionen in die gegenwärtige politische Szenerie der Bundesrepublik beiwohne, nämlich »l'ordre, l'autorité, l'État«, welche es gegen reale oder auch nur vermutete Feinde zu verteidigen gelte ${ }^{635}$. Bestürzend sei allerdings, wie der französische Historiker Jacques Droz ${ }^{636}$ in einem Kommentar in "Le Monde" vom Mai 1976 konstatierte, dass gerade die Sozialdemokraten eine derartige Politik

630 Siehe Daniel Vernet, Le glissement à droite s'accentue dans l'opinion, in: Le Monde, 19.02.1975, S. 3 .

${ }^{631}$ Bonn: la liberté d'opinion en péril, in: L'Humanité, 20.10.1975, S. 1 und 3.

632 Vgl. François ScHLOSSER, Les sorcières de Helmut Schmidt, in: Le Nouvel Observateur, 15.09.1975, S. 39.

${ }^{633}$ Daniel Vernet, Nouvelle »chasse aux sorcières«. Les mesures d'interdiction d'accès à la fonction publique se multiplient à l'encontre des "extrémistes", in: Le Monde, 05.12.1975, S. 6; vgl. auch Ders., Il y a radicaux et radicaux..., in: Le Monde, 21./22.12.1975, S. 2.

${ }^{634}$ Gérard SANDOZ, Les broyeurs de »rouges«. Comment un innocent décret de 1972 est devenu une machine contre tous ceux qui se réclament de la gauche, in: Le Nouvel Observateur, 08.03.1976, S. 38.

635 Siehe ibid., S. 39.

${ }^{636}$ Vgl. Horst MöLLER, Jacques Droz (1909-1998), in: Francia 28/3 (2001), S. 195-198; Jac- 
der "Verfolgungen" autorisierten, zumal sie doch selbst in ihrer Geschichte, so etwa 1878 und 1933, wiederholt zum Opfer repressiver Maßnahmen geworden seien. Was also treibe sie um? Sei es, wie Droz fragte, ihr Machthunger, der sie dazu verleite, sich die Gunst der Nostalgiker eines "starken Staates « zu sichern? Sei es das mangelnde demokratische Bewusstsein ihrer Führungspersönlichkeiten, die ihre politische Sozialisation in der Zeit des Nationalsozialismus erfahren hätten? Oder, und dies wöge noch schwerer, sehe die westdeutsche Sozialdemokratie heute ihre Feinde nicht mehr bei den Anhängern Hitlers, sondern bei denen, die gegen das nationalsozialistische Regime gekämpft hatten? Wie die Antworten hierauf auch ausfielen: Kein Franzose, der sich der Stellung der Bundesrepublik in Europa bewusst sei, könne den beunruhigenden Entwicklungen jenseits des Rheins gleichgültig gegenüberstehen ${ }^{637}$.

Diese Maxime machten sich nicht zuletzt auch die französischen Sozialisten zu eigen, die auf ihrem Parteitag in Dijon Mitte Mai 1976 die "Berufsverbote« in der Bundesrepublik scharf attackierten. Zwei Wochen später gründete ihr Vorsitzender François Mitterrand, der erklärt hatte, der "Hexenjagd im öffentlichen Dienst « in Westdeutschland entgegenwirken zu wollen, gemeinsam mit weiteren führenden Persönlichkeiten der Sozialistischen Partei wie Jean-Pierre Chevènement, Michel Rocard und Lionel Jospin gar ein Comité pour la défense des droits civiques et professionnels en République fédérale ${ }^{638}$. Er wolle, so bekundete Mitterrand wenige Tage nach der Schaffung des Komitees, sich den Menschen anschließen, die sich, ganz gleich wo dies auch sei, durch die Einschränkung ihrer Freiheiten bedroht fühlten. Keineswegs richte sich sein Handeln gegen das deutsche Volk, sondern sei vielmehr als ein symbolischer Akt für die Wahrung der Menschen- und Bürgerrechte in der Bundesrepublik zu verstehen ${ }^{639}$. Die Reaktionen von deutscher Seite folgten prompt. Nicht nur Bundeskanzler Schmidt und Außenminister Genscher wiesen Mitterrands Initiative als nicht akzeptablen Angriff auf die Bundesrepublik zurück ${ }^{640}$, auch in der bundes-

ques BARIÉTY, Nekrolog Jacques Droz 1909-1998, in: Historische Zeitschrift 267 (1998), S. 827-829.

637 Siehe Jacques Droz, Questions aux socialistes allemands, in: Le Monde, 14.05.1976, S. 3.

638 Vgl. Miard-Delacroix, Willy Brandt, Helmut Schmidt und François Mitterrand, S. 236f.; Dies., Im Zeichen der europäischen Einigung, S. 185; PfeIL, Die »anderen" deutsch-französischen Beziehungen, S. 493.

639 Vgl. AMAE Paris-La Courneuve, Europe, RFA 1971-1976, Bd. 2949, AFP-Meldung "Après la création d'un comité français s pour la défense des droits civils et professionnels en RFA«« vom 3. Juni 1976.

${ }^{640}$ Siehe hierzu AMAE Paris-La Courneuve, Europe, RFA 1971-1976, Bd. 2949, Schreiben des französischen Botschafters in Bonn, Olivier Wormser, an das französische Außenministerium betreffend »Réactions de l'étranger à la législation concernant les rextrémistes«" vom 28. Mai 1976; Verschärfte Diskussion um Radikale im öffentlichen Dienst. Aktivitäten Mitterrands zurückgewiesen, in: FAZ, 31.05.1976, S. 3; So will Helmut Schmidt die Wahlen gewinnen. Stern-Gespräch mit dem Bundeskanzler, in: Stern, 
deutschen Presse wurde nun vielfach ein rauer Tonfall angeschlagen. Unter dem Titel »Wie Mitterrand deutsche Politik macht» verurteilte etwa »Die Welt« die Gründung des Komitees als unangebrachte und ungerechtfertigte Einmischung des sozialistischen Parteivorsitzenden in die inneren Belange der Bundesrepublik. »Die Aktion Mitterrands«, so die Auffassung des Blattes, »ist der einstweilige Höhepunkt einer seit Wochen andauernden Kampagne gegen die angeblichen Verletzungen der politischen Meinungsfreiheit in der >Muster-Demokratie< Bundesrepublik ${ }^{641}{ }^{61}$. Die "Süddeutsche Zeitung " stellte Ende Mai 1976 mit zynischem Unterton fest, dass »der häßliche Deutsche« wieder einmal bei den Nachbarn umhergeistere:

Die Bundesrepublik befindet sich offenbar in einer dramatischen Situation, vergleichbar nur noch mit dem Anfang der Hitlerzeit. [...] Studenten werden verhaftet, nur weil sie unerwünschte Fragen stellen. Massenhaft werden Menschen an der Ausübung ihres Berufes gehindert. Die Zugehörigkeit zu einer Gewerkschaft ist gefährlich. Spitzel verbreiten allenthalben Angst. Die Hexenjagd ist in vollem Gang und sogar Gasgeruch bereits wahrnehm$\operatorname{bar}^{642}$.

So primitiv und irrational die im Zusammenhang mit dem »Radikalenerlass" aufgekommenen Reaktionen in Frankreich und anderen europäischen Ländern seien, man müsse sie, wie der Autor befand, in der Bundesrepublik zur Kenntnis nehmen und einkalkulieren. Rasch das Büßergewand anziehen und beflissen auf die selbsternannten Zensoren schauen brauchten die Deutschen seiner Ansicht nach jedoch nicht. Wenn Mitterrand es künftig nur und ausschließlich mit den Kommunisten halten wolle, so werde man ihm sagen müssen, dass er seine Legitimation verloren habe, über bürgerliche Freiheiten in Deutschland zu räsonieren. »Diesseits des Rheins hat man jedenfalls recht eindeutige Erfahrungen mit Kommunisten sammeln können - im anderen Teil der Nation. Wir wünschen keinem Franzosen diese Erfahrung « ${ }^{643}$.

"Die Zeit» warf Mitterrand in einem Anfang Juni 1976 erschienenen Beitrag vor allem vor, es versäumt zu haben, sich über die Auswirkungen des "Radikalenerlasses" gründlich zu informieren. In der Sozialistischen Partei gebe es, wie der Verfasser urteilte, hierüber lediglich vage Vorstellungen, die nahezu ausschließlich auf den »übertrieben einseitigen Darstellungen der französischen Presse beruhen ${ }^{644}$. Einige Wochen zuvor hatte sich bereits

16.06.1976, S. 24, hier äußerte Schmidt: »Ich halte das von Herrn Mitterrand initiierte Komitee für eine böse Sache, weil es von Voraussetzungen ausgeht, die nicht stimmen. Dabei hätte Mitterrand die Tatsachen zum Extremistenproblem leicht nachprüfen können. Er war sogar bei Willy Brandt. Seine Angriffe auf die Bundesrepublik sollen offensichtlich innenpolitischen Zielen in Frankreich dienen. Das ist kein Verhalten, wie es unter Sozialdemokraten in der internationalen Zusammenarbeit üblich ist«.

${ }^{641}$ August von Kageneck, Wie Mitterrand deutsche Politik macht, in: Die Welt, 29./30.05.1976, S. 3.

${ }^{642}$ Hans Heigert, Der häßliche Deutsche, in: SZ, 29./30.05.1976, S. 4.

643 Ibid.

${ }^{644}$ Klaus-Peter Schmid, Keine überzeugende Kritik, in: Die Zeit, 04.06.1976, S. 8; vgl. auch 
die »Frankfurter Allgemeine Zeitung« kritisch mit der Deutschland-Berichterstattung der französischen Medien auseinandergesetzt. Dort glaube man in letzter Zeit vermehrt, »ein Abgleiten der Bundesrepublik in Praktiken der Unterdrückung von individuellen Freiheiten registrieren zu können « ${ }^{645}$. Nicht zuletzt die Phrase vom "Berufsverbot « diene immer wieder dazu, auf »angebliche Erbsünden« des Nachbarn hinzuweisen: »Der Deutsche ist diszipliniert bis zum Exzeß; Ordnung geht ihm vor Freiheit; die Rücksichtslosigkeit der Behörden zeigt den gering entwickelten Humanismus « ${ }^{646}$. Zwar seien aus den französischen Pressekommentaren bisweilen auch positivere Zwischentöne herauszuhören, doch stelle sich die Frage, ob nicht das stete Schüren alter Ressentiments im Verbund mit den neueren Ängsten vor der wirtschaftlichen Übermacht des Nachbarn auf lange Sicht negative Folgen für die Einstellung der Franzosen zu Deutschland zeitige.

Diese Frage trieb zu gleicher Zeit auch die bundesdeutschen Stellen um, welche die öffentlichen Reaktionen, die in Frankreich im Zusammenhang mit dem »Radikalenerlass « zu verzeichnen waren, aufmerksam beobachteten. Die deutsche Botschaft in Paris informierte seit Ende 1975 das Auswärtige Amt in steter Regelmäßigkeit über die Kritik der französischen Presse an den Verhältnissen in der Bundesrepublik. In vielfach sensationeller Aufmachung werde hier, wie die westdeutschen Diplomaten notierten, über die vermeintlich $» k a-$ tastrophalen Auswirkungen « der Politik der Bonner Regierung auf die liberale Gesellschaftsordnung der Bundesrepublik berichtet. Das politische Klima im Nachbarland, so sei den Zeitungen zu entnehmen, habe sich stark verschlechtert. Der Rechtsstaat werde durch zunehmend autoritär agierende Politiker in ein enges Korsett gezwängt. Die Beschränkungen der Grundrechte, die gegenwärtig in Westdeutschland vollzogen würden, seien in ihrer Rigidität einzigartig in Westeuropa. Die Demokratie in der Bundesrepublik, einen solchen Eindruck könne diese Art der Pressekommentierung in Frankreich hervorrufen, sei in akuter Gefahr ${ }^{647}$.

Daneben trugen auch öffentliche Protestkundgebungen einer Vielzahl kleinerer und zumeist der Kommunistischen Partei nahe stehender französischer Verbände und gesellschaftlicher Gruppierungen aus Sicht der Botschaft dazu bei, in Frankreich eine Stimmung zu erzeugen, welche der Haltung der französischen Bevölkerung zu Deutschland nur abträglich sein konnte. Mehrfach

Theo Sommer, Die Deutschen im Zerrspiegel. Radikalenerlaß als Stein des Anstoßes, in: Die Zeit, 04.06.1976, S. 1.

${ }^{645}$ Herbert Kaufmann, Frankreich sieht auf Deutschland, in: FAZ, 24.04.1976, S. 1; vgl. auch die Meldung Mitterrand will Bürgerrechte in der Bundesrepublik verteidigen, in: FAZ, 28.05.1976, S. 5.

${ }^{646}$ Ders., Frankreich sieht auf Deutschland, in: FAZ, 24.04.1976, S. 1.

${ }^{647}$ Vgl. BA, B 145, Bd. 9299, Schreiben der deutschen Botschaft Paris an das Auswärtige Amt vom 12. März 1976; BA, B 145, Bd. 9288, Schreiben der deutschen Botschaft Paris an das Auswärtige Amt betreffend "Deutschlandbild in der französischen Presse " vom 12. April 1976. 
wurden den diplomatischen Vertretungen der Bundesrepublik in Frankreich Unterschriftenlisten übergeben, die sich gegen die »Berufsverbote« richteten. So empfing etwa das deutsche Generalkonsulat in Marseille im Juli 1977 Repräsentanten des maßgeblich durch den ehemaligen Widerstandskämpfer und Rechtsanwalt Pierre Kaldor bestimmten Comité français pour la liberté d'expression et contre les interdictions professionnelles en République fédérale d'Allemagne. Der diesbezügliche Bericht des Generalkonsulats für das Auswärtige Amt hielt fest: "Gesprächsweise wurde immer wieder darauf hingewiesen, daß der Extremistenerlaß und das damit zusammenhängende sog. Berufsverbot Ausdruck eines wiederaufkommenden Rechtsextremismus à la Hitler in der Bundesrepublik Deutschland seien «" ${ }^{68}$. Solcherlei Kritik, welche, wie man in Bonn der Auffassung war, dazu führen könne, dass das Bild Westdeutschlands bei den Nachbarn negativ beeinträchtigt werde, gehe »in der Regel von irrtümlichen Voraussetzungen aus, in die zuweilen alte Vorurteile und Ressentiments einfließen ${ }^{649}$. Vor diesem Hintergrund müsse es insbesondere Aufgabe der bundesdeutschen Auslandsvertretungen sein, so wurde in den regierungsamtlichen "Hinweisen zur aktuellen Diskussion der $>$ Berufsverbote« « festgehalten, »unter Klarstellung der Fakten und unter Betonung der besonderen geschichtlichen Erfahrungen sowie der geografischen Lage der Bundesrepublik auf eine sachbezogene Argumentation « hinzuwirken. Dies könne helfen, den zu befürchtenden Schaden für das deutsch-französische Verhältnis zu verhindern.

Auch auf französischer Seite hielt man die im Zuge der Diskussionen um den »Radikalenerlass" aufgetretenen Spannungen zwischen beiden Ländern für bedenklich. Vor allem die Initiative François Mitterrands erwies sich in den Augen der Verantwortlichen als in hohem Maße kontraproduktiv für die freundschaftlichen Beziehungen zwischen Deutschen und Franzosen. In diesem Sinne schrieb Botschafter Olivier Wormser nach Paris: „Dans ce pays qui n'a jamais connu davantage de libertés qu'aujourd'hui et qui chaque jour est informé de l'absence des libertés en RDA et des coups de feu le long du Mur, la prise de position de M. Mitterrand a produit le plus mauvais effet « ${ }^{651}$. Sowohl die westdeutsche Presse als auch maßgebliche Politiker hätten auf Mitterrands

${ }^{648}$ BA, B 145, Bd. 9299, Schreiben des deutschen Generalkonsulats Marseille an das Auswärtige Amt betreffend »Französische Stellungnahme zum sog. Extremistenerlass « vom 8. Juli 1977; vgl. hierzu auch PA-AA, Auslandsvertretungen, Botschaft Paris, Bd. 13523, Schreiben des Comité français pour la liberté d'expression et contre les interdictions professionnelles en République fédérale d'Allemagne, Pierre Kaldor, an die deutsche Botschaft Paris, 1978.

649 BA, B 145, Bd. 9303, Aufzeichnung betreffend »Die Beschäftigung von Extremisten im öffentlichen Dienst - Hinweise zur aktuellen Diskussion der `Berufsverbote« vom 23. Juni 1976, S. 2.

650 Ibid.

651 AMAE Nantes, Bonn Ambassade, Bd. 318, Schreiben des französischen Botschafters in Bonn, Olivier Wormser, an das französische Außenministerium vom 31. Mai 1976, S. 1. 
Bestrebungen mit äußerstem Befremden reagiert. Gar von einer sich in Frankreich erneut Bahn brechenden Deutschfeindlichkeit sei die Rede gewesen ${ }^{652}$. Man müsse daher, wie der Botschafter empfahl, der westdeutschen Öffentlichkeit so rasch wie möglich verdeutlichen, dass die Aktion Mitterrands aus den Reihen der Opposition komme, die französische Regierung hierfür jedoch nicht verantwortlich gemacht werden könne.

Neben der öffentlichen Kampagne der Sozialistischen Partei galten den offiziellen französischen Stellen insbesondere die zum Teil stark ins Polemische abgleitenden Medienberichte über die vermeintliche Rückkehr des deutschen Obrigkeitsstaates als Ursache für die atmosphärischen Störungen zwischen Frankreich und Westdeutschland. Einmal mehr hätten sich die deutschen Nachbarn hierdurch unberechtigten Verdächtigungen ausgesetzt gesehen, wie einem Bericht des im Dienste des französischen Premierministers stehenden Secrétariat général de la défense nationale (SGDN) vom Juli $1976 \mathrm{zu}$ entnehmen ist: »Conscients de défendre l'ordre démocratique et libéral, nos voisins rejettent avec vigueur les accusations qui leur sont adressées d'attenter aux libertés. Ils les interprètent en même temps comme un phénomène antiallemand toujours vivace qui les déroute et les irrite «653. Die Reaktionen der bundesdeutschen Zeitungen seien von ausnehmender Schärfe gekennzeichnet gewesen. Die große Mehrheit der Kommentatoren habe das Wort von den »hässlichen Deutschen « zitiert und sich nach Kräften bemüht, aufzuzeigen, dass ihnen diese Bezeichnung seitens des Auslands völlig zu Unrecht attribuiert werde. $\mathrm{Zu}$ diesem Reflex der Selbstverteidigung habe sich, so die Einschätzung des SGDN, darüber hinaus "un certain masochisme traditionell« der Deutschen gesellt, die sich mitleidig beklagten, unverstanden, ungeliebt und viel beneidet zu sein. Der tief verwurzelten Angst der Nachbarn vor einer Wiederkehr des deutschen Autoritarismus oder gar nationalsozialistischer Strömungen entspreche das Gefühl der Deutschen, Gefangene des sie umgebenden Argwohns zu sein ${ }^{654}$. Die französischen Proteste gegen den »Radikalenerlass « hätten nach Ansicht der Diplomaten des Quai d'Orsay nur zu deutlich werden lassen, wie sehr die Franzosen in ihrer Beurteilung des Nachbarlandes noch immer von der Vergangenheit beeinflusst seien:

C'est en fait encore le poids du passé qui se fait sentir dans l'appréciation des Français sur des aspects de la politique intérieure allemande tels que l'extrémisme de gauche [...] et les réactions du gouvernement comme l'obligation de loyalisme des fonctionnaires, caricaturée

652 Vgl. AMAE Paris-La Courneuve, Europe, RFA 1971-1976, Bd. 2949, Schreiben des französischen Botschafters in Bonn, Olivier Wormser, an das französische Außenministerium vom 28. Mai 1976.

653 AMAE Paris-La Courneuve, Europe, RFA 1976-1980, Bd. 3955, Premier ministre, SGDN, Division du renseignement, Bulletin particulier de renseignement: »République fédérale d'Allemagne - Le poids du passé sur une récente polémique«, 9. Juli 1976, S. 1.

654 Siehe ibid., S. 2-4; vgl. des Weiteren AMAE Nantes, Bonn Ambassade, Bd. 318, Vermerk betreffend »L'opinion allemande et la France«, September 1977, S. 5. 
sous le nom d'interdictions professionnelles‘. Les réactions de certains milieux de l'opinion française seraient moins vives si ce n'était pas l'Allemagne qui était en cause ${ }^{655}$.

Einzig das Voranschreiten der Zeit könne auf lange Sicht dafür sorgen, dass sich die Last der Vergangenheit in den Beziehungen zwischen Franzosen und Deutschen verringere und öffentliche Auseinandersetzungen wie diejenigen um die »Berufsverbote« unmöglich würden ${ }^{656}$.

In Anbetracht des "grellen und verzerrten Bildes « ${ }^{657}$, welches nicht nur in Frankreich von der Bundesrepublik gezeichnet wurde, und vor allem der harschen Kritik an der vermeintlich zunehmenden Beschneidung von Rechten und Freiheiten der westdeutschen Bürger, sahen es die Bonner Verantwortlichen als unabdingbar an, ihre Bemühungen um eine Außendarstellung der Bundesrepublik als gefestigte Demokratie zu verstärken. Die auswärtige Kulturpolitik galt der westdeutschen Regierung in dieser Hinsicht einmal mehr als das geeignete Instrument ${ }^{658}$. In ihrer im September 1977 veröffentlichten Stellungnahme zum Bericht der Enquête-Kommission des Bundestages über die auswärtige Kulturpolitik hieß es, dem Ausland solle ein wirklichkeitsnahes und auch selbstkritisches Bild der Bundesrepublik vermittelt und dadurch für mehr Verständnis für den westdeutschen Staat geworben werden. »Der in letzter Zeit verschiedentlich feststellbaren Verzerrung des Deutschlandbildes muß durch eine ausgewogene Darstellung der tatsächlichen Verhältnisse entgegengewirkt werden ${ }^{659}$.

Die Instrumente, die hierzu eingesetzt werden sollten, boten indes kaum Neues. Zunächst setzte die Bonner Regierung auf eine intensivierte Förderung der deutschen Sprache. Noch mehr als zuvor müsse der Sprachunterricht dazu genutzt werden, zeitgemäße Informationen über die Bundesrepublik zu vermitteln und Klischeevorstellungen abzubauen. Mit besonderem Nachdruck sei künftig das Konzept der in das Bildungswesen des Gastlandes integrierten »bikulturellen Begegnungsschule« zu fördern. Daneben gelte die staatliche Aufmerksamkeit zum einen dem Bereich von Hochschulen und Wissenschaft, da hier Zielgruppen zusammengeführt würden, die in

655 AMAE Paris-La Courneuve, Europe, RFA 1976-1980, Bd. 3999, Vermerk betreffend »Les relations franco-allemandes« vom 14. Oktober 1977, S. 4.

656 Siehe AMAE Paris-La Courneuve, Europe, RFA 1976-1980, Bd. 3955, Premier ministre, SGDN, Division du renseignement, Bulletin particulier de renseignement: »République fédérale d'Allemagne - Le poids du passé sur une récente polémique«, 9. Juli 1976, S. 4.

657 PA-AA, Auslandsvertretungen, Botschaft Paris, Bd. 13523, Aufzeichnung bezüglich des Deutschlandbildes in Frankreich vom 12. Oktober 1977, S. 1.

658 Vgl. AMAE Nantes, Bonn Service culturel, Bd. 83, Schreiben des Kulturrats der französischen Botschaft Bonn, Maurice Descotes, an die Kulturabteilung des französischen Außenministeriums betreffend »Action culturelle de la République fédérale d'Allemagne à l'étranger « vom 17. Oktober 1977, S. 1.

659 Stellungnahme der Bundesregierung zum Bericht der Enquête-Kommission des Deutschen Bundestages zur Auswärtigen Kulturpolitik, in: Bulletin des Presse- und Informationsamtes der Bundesregierung 91 (1977), S. 841. 
entscheidenden Bereichen des Kulturlebens tätig seien und daher als Multiplikatoren für partnerschaftliche Beziehungen wirkten. Zum anderen müsse die Bundesregierung die Massenmedien stärker als bislang geschehen in den Blick nehmen, da gerade ihnen eine entscheidende Bedeutung zur »Objektivierung " des Deutschlandbildes zukomme. Jenseits der staatlichen Ebene sei der von gesellschaftlichen Organisationen durchgeführte Jugend- und Sportaustausch vermehrt zu unterstützen, da auf diese Weise jungen Menschen Kenntnisse und Verständnis anderer Völker in einer Lebensphase vermittelt würden, in welcher sie hierfür besonders aufnahmefähig und unvoreingenommen seien. Darüber hinaus wolle die Regierungspolitik »jede vernünftige, dem Ziel der Verständigung und des partnerschaftlichen Austauschs dienende nicht-staatliche Initiative « ermutigen ${ }^{660}$.

Die Aufgabe, die so formulierten Zielsetzungen zu realisieren, sollte insbesondere den beiden großen Mittlerorganisationen Goethe-Institut und DAAD zukommen. Vielfach mit Unterstützung der deutschen Botschaft in Paris organisierten sie die verständigungspolitische Feldarbeit, die als notwendig erachtet wurde, um die Folgen der Debatten um den »Radikalenerlass« abzumildern. Die von ihnen durchgeführten Austauschprogramme, Sprachkurse und kulturellen Veranstaltungen sollten helfen, den immer noch leicht mobilisierbaren Erinnerungen an das »hässliche Deutschland« Bilder entgegenzusetzen, welche die französische Wahrnehmung des Nachbarlandes zumindest in einer langfristigen Perspektive zum Positiveren wandeln würden. Im April 1976 veranstaltete etwa die Pariser DAAD-Zweigstelle gemeinsam mit dem Heinrich-Heine-Haus in der Cité universitaire eine öffentliche Diskussionsrunde zum Thema »Radikalenerlass«. Im Rahmen derer kamen deutsche und französische Gegner und Befürworter zusammen, darunter auch Alfred Grosser und der Deutschland-Korrespondent von »Le Monde«, Daniel Vernet, um über die möglichen Auswirkungen der westdeutschen Überprüfungspraxis auf das politische Klima und die demokratische Verfasstheit der Bundesrepublik zu streiten. Ein Botschaftsbericht hielt fest, die Reaktion des Publikums sei durchaus geteilt gewesen. Eine globale Verurteilung der deutschen Maßnahmen, wie sie auf kommunistischer und linksextremer Seite üblich sei, habe man jedenfalls nicht feststellen können. »Den meisten Teilnehmern dürfte doch klar geworden sein, daß die Dinge nicht so einfach liegen, wie die linke Anti-Berufsverbotskampagne sie darstellt $\aleph^{661}$.

Die Initiativen des staatlichen Bereichs konnten allerdings, auch wenn sie

${ }^{660}$ Siehe zu diesem Abschnitt ibid., S. 841f., hier die angeführten Zitate; vgl. auch SATtLER, Nationalkultur oder europäische Werte?, S. 67-74.

661 PA-AA, Zwischenarchiv, Nr. 109074, Schreiben der deutschen Botschaft Paris an das Auswärtige Amt betreffend »Öffentliche Diskussion über das Thema >Radikalenerlaß im Heinrich-Heine-Haus der Cité internationale universitaire in Paris« vom 1. Juni 1976, S. 3. 
in das halb-offizielle Gewand der kulturpolitischen Mittlerorganisationen gekleidet waren, leicht in Gefahr geraten, als Propagandamaßnahmen der Bonner Regierung abgetan zu werden. Aus Sicht der westdeutschen Verantwortlichen war es daher umso wünschenswerter - dies kam auch in der Stellungnahme der Bundesregierung zur Auswärtigen Kulturpolitik zum Ausdruck -, dass die staatlichen Verständigungsbemühungen Unterstützung seitens privat organisierter Kräfte erfuhren. Der ADFG etwa beschäftigte sich seit 1976 in Vorstandssitzungen und anlässlich seiner Jahrestagungen mehrfach mit der französischen Kritik an der inneren Entwicklung der Bundesrepublik und mit den möglichen negativen Auswirkungen auf das deutsch-französische Verhältnis. Der in der französischen Presse immer wieder geäußerte Verdacht, in Westdeutschland würden die Freiheiten der Bürger beschnitten und demokratische Grundprinzipien außer Kraft gesetzt, zeigte nach Auffassung der Verantwortlichen einmal mehr, wie hoch die Barrieren wechselseitigen Unverständnisses zwischen beiden Ländern immer noch waren ${ }^{662}$. Den deutsch-französischen Gesellschaften komme daher die Aufgabe zu, den Franzosen Deutschland und die Deutschen noch intensiver zu erklären und Brücken über die bestehenden mentalitätsbedingten Unterschiede zu schlagen. Die Einstellung zu den Menschen des Nachbarlandes müsse auf beiden Seiten von »einer echten Toleranz beherrscht sein ${ }^{663}$. Stärker als bislang sollten sich die Mitgliedsgesellschaften daher aufgefordert sehen, neben der Durchführung reiner Kulturveranstaltungen politische Informationsarbeit zu betreiben. Zudem müsse man sich vermehrt darum bemühen, dass die Sprache des Partners im jeweils anderen Land mehr Verbreitung finde. Denn nur durch eine »bessere Kenntnis der Lebens- und Wesensart des Nachbarn « ${ }^{664}$ könnten, wie im Arbeitskreis geurteilt wurde, die deutsch-französischen Beziehungen auf eine feste Grundlage gestellt werden. »Nur echtes Engagement, sorgfältige und hingebungsvolle Kleinarbeit [...] bringt uns auf dem Weg zu einer Verständigung und zu einem Verstehen zwischen unseren beiden Völkern weiter ${ }^{665}$.

Auch beim BILD wurden die öffentlichen Debatten um den »Radikalenerlass« mit einiger Besorgnis beobachtet. Vize-Präsident Joseph Rovan stellte

662 Vgl. VDFG-Archiv, Ordner Vorstandssitzungen 1974-1976, Bericht über die Klausurtagung des Vorstands des ADFG in Pont-à-Mousson im November 1976; VDFGArchiv, Ansprache der Ehrenpräsidentin des ADFG, Elsie Kühn-Leitz, im Rahmen der 22. Jahrestagung der deutsch-französischen Gesellschaften in Montpellier am 11. September 1977, in: Mitteilungsblatt für die Deutsch-Französischen Gesellschaften 43 (1978), S. 116f.

663 VDFG-Archiv, Ansprache des deutschen Präsidenten des ADFG, Alfred Borgmann, anlässlich der Jahrestagung der deutsch-französischen Gesellschaften im August 1978, in: Mitteilungsblatt für die Deutsch-Französischen Gesellschaften 44 (1979), S. 23.

664 VDFG-Archiv, Ordner Kongreß Braunschweig 1976, Pressenotiz "Deutsch-französische Partnerschaft in der Bewährung « vom 31. August 1976.

665 VDFG-Archiv, Ordner Vorstandssitzungen 1974-1976, Rundschreiben des deutschen Präsidenten des ADFG, Alfred Borgmann, vom Juli 1978, S. 2. 
im August 1976 fest: »La polémique récente soulevée par les mesures prises en République fédérale pour faire face aux agissements d'éléments extrémistes joue un rôle particulièrement négatif et trouble les esprits «666. Während man in weiten Teilen der französischen Öffentlichkeit, wie Rovan ausführte, die nahezu vollständige Abwesenheit von Freiheiten und Grundrechten in der DDR kaum zur Kenntnis nehme, verbreite sich in Frankreich derzeit mehr und mehr die Meinung, die Bundesrepublik sei auf dem besten Wege, ein Polizeistaat zu werden und sich dem Deutschland der Jahre 1933 bis 1945 anzunähern. Diese Ansicht werde bedauerlicherweise durch gezielte Pressekampagnen geschürt und sei umso verhängnisvoller für das deutschfranzösische Verhältnis, als sie mit den gegenwärtig wiedererstarkenden französischen Ängsten vor einer ökonomischen und politischen Dominanz Westdeutschlands zusammentreffe. Gerade derartige Rückschläge, derartige Enttäuschungen, seien jedoch dazu angetan, dem BILD als Impulse für eine Intensivierung seiner Verständigungsbemühungen zu dienen:

$[\mathrm{N}]$ ous devons agir au sein de nos deux sociétés comme de vrais militants, avec un très grand engagement personnel. Notre devoir est de convaincre et de prouver comme les encyclopédistes du XVIII ${ }^{e}$ siècle, d'agir au sein des réalités politiques, auprès des centres de décision comme de la grande masse des citoyens, d'être des éducateurs, des multplicateurs, des diffuseurs ${ }^{667}$.

Vor allem auf dem Gebiet der Austausch- und Begegnungsarbeit müsse die Organisation bestrebt sein, mehr junge Menschen dafür zu gewinnen, in persönlichen Kontakt mit dem jeweiligen Nachbarland zu treten. Schließlich entstünden auf diese Weise die Bindungen, von denen die deutsch-französischen Beziehungen künftig zehrten und die sie für Krisenerscheinungen unanfälliger machten. Darüber hinaus sei zu überlegen, wie es gelingen könnte, der Informationstätigkeit des BILD eine größere öffentliche Aufmerksamkeit zu sichern $^{668}$. Denn nur wenn die wohlmeinenden Appelle im Lärm der massenmedialen Wortgefechte Gehör fänden, diese Einsicht schien sich bei den Verantwortlichen der Vereinigung durchzusetzen, würden sich Dispute wie derjenige um den »Radikalenerlass« in einem verständigungsfördernden Sinne beeinflussen lassen.

Das Ludwigsburger DFI schließlich thematisierte die im Zuge der französischen Kritik an den »Berufsverboten" aufgetretenen Spannungen im deutsch-französischen Verhältnis anlässlich seiner Jahresversammlung im April 1976. Hier sollte Gastredner Alfred Grosser einem westdeutschen $\mathrm{Pu}$ blikum die in Frankreich bestehenden Befürchtungen erläutern und damit einen Beitrag zur Versachlichung der streckenweise hoch polemisch geführ-

${ }^{666}$ BILD-Archiv, Rede des Vize-Präsidenten des Bureau international de liaison et de documentation, Joseph Rovan, anlässlich der Feier zum dreißigjährigen Bestehen des BILD und der GÜZ am 20./21. August 1976 in Stuttgart, S. 2.

667 Ibid., S. 6.

668 Vgl. ibid., S. 6 f. 
ten Diskussionen leisten. In seinem mit dem Titel »Toleranz und Intoleranz in Deutschland und Frankreich « ${ }^{669}$ überschriebenen Vortrag legte Grosser dar, dass einer Mehrheit der Franzosen und auch ihm selbst, einem erklärten und langjährigen Freund Deutschlands, vollkommen unverständlich sei, aus welchem Grunde die Bundesrepublik, der Staat mit der stabilsten politischen Struktur in Europa, sich so sehr vor einer verschwindend geringen Anzahl an Kommunisten fürchte, dass eine intolerante Maßnahme wie der »Radikalenerlass" möglich werden könne. Dies habe die Bundesrepublik in keiner Weise nötig. Gewiss, so räumte Grosser ein, sei die besondere Wachsamkeit, welche kommunistischen Gruppierungen in Westdeutschland zuteil werde, mit der Existenz der DDR und auch mit dem Verhalten der KPD in der Weimarer Zeit zu erklären. Doch müsse man darauf Acht geben, dass das Pendel politischer Intoleranz nicht zu weit ausschlage, die Ablehnung von Bewerbern für den öffentlichen Dienst sich nicht auf Willkür gründe. Dies sei die Gefahr, die in Frankreich augenblicklich gesehen werde. Dass seinen Landsleuten jedoch der »Radikalenerlass« vielfach als Symptom einer fortschreitenden Negativentwicklung Westdeutschlands gelte und zu Zweifeln an der Demokratiefestigkeit des bundesdeutschen Staatswesens insgesamt führe, hielt Grosser andererseits für ein Zeichen mangelnden Verständnisses und mangelnden Vertrauens der Franzosen gegenüber ihren östlichen Nachbarn. Hierauf weise er in Frankreich allerdings regelmäßig hin. Auch die Kritik am »Radikalenerlass" müsse dem Geist der Toleranz entsprechen. Nur so könne man zu einer Entkrampfung des angespannten deutsch-französischen Verhältnisses kommen ${ }^{670}$.

Ähnlich wie im Rahmen seines Ludwigsburger Vortrags hatte Alfred Grosser bereits seit Anfang der 1970er Jahre vielfach in die Debatten um den »Radikalenerlass" eingegriffen. In Frankreich ging es ihm vornehmlich darum, mehr Verständnis für die besondere Lage Westdeutschlands als Frontstaat des Kalten Krieges zu wecken und zu verhindern, dass sich der Eindruck verfestigte, die Bundesrepublik würde zunehmend von antidemokratischen Tendenzen beherrscht. Mit seinen Reden in der Bundesrepublik

669 Vorträge desselben oder ähnlichen Titels hielt Alfred Grosser im Verlaufe des Jahres 1976 mehrfach in Westdeutschland, so etwa bereits Ende Januar 1976 auf Einladung der Deutsch-Französischen Gesellschaft Bremen, vgl. AMAE Nantes, Bonn Ambassade, Bd. 368, Schreiben des französischen Konsuls in Bremen, Louis Hirn, an den französischen Botschafter in Bonn, Olivier Wormser, betreffend »Conférence de M. Alfred Grosser« vom 3. Februar 1976; der Norddeutsche Rundfunk strahlte darüber hinaus im Februar 1976 die Aufzeichnung einer Podiumsdiskussion mit Grosser zu dem Thema aus, vgl. Diese Woche im Fernsehen, in: Der Spiegel, 09.02.1976, S. 159.

${ }^{670}$ Vgl. zu diesem Abschnitt Fridtjof Theegarten, »Sie ist der Untergang der Demokratie«. Professor Grosser warnt vor Intoleranz in der Politik, in: Stuttgarter Nachrichten, 12.04.1976, S. 8; Grosser erneuert seine Kritik am Radikalenerlaß, in: StZ, 12.04.1976, S. 2; »Toleranz und Intoleranz in Deutschland und Frankreich «. Ein kritischer Beitrag zur Jahresversammlung des Deutsch-Französischen Instituts, in: Ludwigsburger Kreiszeitung, 13.04.1976, S. 3. 
versuchte er vor allem, den westdeutschen Zuhörern die Hintergründe der französischen Kritik zu erläutern und machte auch selbst immer wieder auf die schädlichen Auswirkungen der Überprüfungspraxis aufmerksam. In einem 1974 veröffentlichten Beitrag zur kulturellen Identität der Bundesrepublik bekräftigte Grosser: »Die ganze Diskussion um die Maßnahmen zur Radikalen-Bekämpfung erfüllt den Beobachter von außen - sei er Franzose, Belgier oder Engländer - mit Unbehagen «671. Man stelle mit Sorge fest, so Grosser in seiner viel beachteten Rede anlässlich der Friedenspreisverleihung im Oktober $1975^{672}$, dass in Westdeutschland der Begriff der Sicherheit zunehmend mehr gelte als derjenige der Freiheit, die staatliche Regelsetzung mehr als politisch autonomes Denken und Handeln. Man müsse sich fragen, ob nicht manche Bürger der Bundesrepublik dem Staat mehr huldigten als dem Recht und ob sie die freiheitlich-demokratische Grundordnung nicht nur als eine Abwandlung der staatlichen Ordnung schlechthin auffassten, die ihren Vätern oder ihnen selbst im Kaiserreich oder im totalen Staat den täglichen biederen Frieden gesichert habe. »Vielleicht bin ich zu sehr Franzose oder denke ich zu sehr an 1933, aber es scheint mir doch, als ob in der Bundesrepublik immer mehr von der Verteidigung der Grundordnung durch den Staat die Rede sei und immer weniger von der Verteidigung der Grundfreiheiten gegen den Staat ${ }^{673}$. Vor allem der im Beschluss von 1972 verankerte Gedanke einer zukunftsbezogenen Verurteilung von Bewerbern für den öffentlichen Dienst erschien Grosser als geradezu absonderlich. Junge Leute würden vorsorglich vom Staatsdienst ausgeschlossen, weil sie ihre Weltanschauung nicht mehr ändern und möglicherweise ihre Pflichten gegenüber dem Rechtsstaat verletzen könnten. Andererseits habe es sich die Bundesrepublik aber leisten können, Männern wichtige staatliche Positionen anzuvertrauen, die während der NS-Zeit als Verteidiger des Rechtsstaats völlig versagt hätten. Wer die Nürnberger Judengesetze als normales Recht trocken ausgelegt habe, hätte im neuen Rechtsstaat immerhin Staatssekretär werden dürfen, wer die Gestapo polizeirechtlich gerechtfertigt habe, Rektor und Kultusminister. "Die Kriterien, die nun verbieten sollen, Zollbeamter oder Dorfschullehrer zu werden, scheinen mir wahrlich strenger zu sein ${ }^{674}$. Immer wieder wies Grosser auch in den folgenden Jahren mit ähnlicher Argumentation auf die genannten Missstände hin und riet den Deutschen, die französische Kritik nicht generalisierend als kommunistisch gesteuerte Kampagnen abzutun. Vielmehr seien sie gehalten, sich ernsthaft mit ihr auseinanderzusetzen und all denen, die in Frankreich in aufrichtiger Weise

${ }^{671}$ Grosser, Die kulturelle Identität der Bundesrepublik Deutschland, S. 206.

672 Vgl. Hans Schueler, Vom Staate, den wir wollen. Radikalen-Erlaß und innerer Friede:

Die Praxis unterspült die Theorie, in: Die Zeit, 17.10.1975, S. 1.

673 Grosser, Ansprachen anlässlich der Verleihung des Friedenspreises, S. 47.

${ }^{674}$ Ibid., S. 50. 
an den Entwicklungen im Nachbarland Anteil nähmen, mehr Verständnis entgegenzubringen ${ }^{675}$.

In Grossers Einmischungen auf französischer Seite trat hingegen seine eigene Kritik an der Anwendung des "Radikalenerlasses « weitgehend hinter sein Bestreben zurück, das in der Presseberichterstattung stark ins Negative verzerrte Deutschlandbild zu korrigieren. Wenn man den westdeutschen Staat kritisiere, wozu allemal eine Berechtigung bestünde, dürfe dies, wie Grosser Anfang Juni 1976 in "Le Monde« betonte, nicht mit einer sich auf Vorurteilen gründenden Feindseligkeit geschehen. Für die Franzosen müsse vielmehr der Grundsatz eines ehrlichen Mitfühlens mit den Nachbarn gelten. Es sei in Frankreich mehr Verständnis für die innerdeutsche Situation angebracht. Viele Westdeutsche sähen ihr Gemeinwesen, wie Grosser erläuterte, durch die Nachbarschaft zur DDR und zum sowjetischen Machtbereich permanent bedroht. Hieraus ließen sich auch die heftigen Reaktionen auf die Initiative François Mitterrands erklären. Die französischen Sozialisten seien schließlich selbst nie gewaltsam durch die Kommunistische Partei absorbiert worden, so wie die SPD nach 1945 in der sowjetischen Besatzungszone. Ebenso sei ihr Vorsitzender nie Bürgermeister einer Stadt gewesen, in der die Freiheit von mehr als zwei Millionen Menschen lediglich durch die Präsenz der alliierten Soldaten gewährleistet werde. Wenn man es sich daher in Frankreich zur Aufgabe mache, das Recht des westdeutschen Grundschullehrers zu verteidigen, Kommunist zu sein, so dürfe hierbei nicht verschwiegen werden, dass im anderen deutschen Staat ein von der offiziellen Meinung abweichender Lehrer in keinerlei Hinsicht Duldung erfahre, sondern dass dort der Lehrende grundsätzlich zur ideologischen Indoktrinierung seiner Schüler verpflichtet sei. Die Demokratie der Bundesrepublik habe, wie Grosser betonte, der französischen in verschiedenen Bereichen sogar einiges voraus: »À bien des égards, le respect du pluralisme, l'acceptation de la critique, la tolérance, sont autrement plus solides en République fédérale qu'en France. La télévision, l’armée, l’entreprise - l'énumération pourrait être allongée, les exemples multipliées « ${ }^{676}$.

In ähnlicher Weise wie Grosser beurteilte auch Joseph Rovan die seitens der bundesdeutschen Behörden angestrengten Überprüfungsmethoden als der extremistischen Bedrohung völlig unangemessen und zudem in ihren möglichen Auswirkungen auf die demokratische Kultur der Bundesrepublik als nicht ungefährlich:

675 Vgl. Ders., 30 Jahre Grundgesetz. Beobachtungen von außen, in: Politische Vierteljahresschrift 20/2 (1979), S. 190-197; DERS., Die äußere und die innere Sicherheit, in: Walter Scheel (Hg.), Nach dreißig Jahren. Die Bundesrepublik Deutschland - Vergangenheit, Gegenwart, Zukunft, Stuttgart 1979, S. 47-57; Alfred Grosser, Der Bürger seine Verwaltung und sein Staat in Frankreich und in der Bundesrepublik Deutschland - eine vergleichende Betrachtung, Düsseldorf 1980.

${ }^{676}$ Ders., La démocratie des autres, in: Le Monde, 01.06.1976, S. 8; vgl. hierzu auch Ders., La passion de comprendre, S. 118f. und S. 143-154; Ders., L'Allemagne de notre temps 1945-1978, S. 635-646. 
Elles [les enquêtes] peuvent ainsi aboutir à créer un climat de suspicion et de délation, où l'on objectera que, cinq ans plus tôt, on vous a vu à une manifestation extrémiste. Traitant de telle manière des gens jeunes, un tel système risque de supprimer le droit à l'erreur, et de développer, dans un peuple traditionnellement porté à la discipline sociale, une mentalité de conformisme tout à fait contraire à l'esprit démocratique. [...] En ce qui concerne l'accord de 1972 et ses effets, la République fédérale aurait intérêt à les soumettre à un nouvel examen ${ }^{677}$.

Auch wenn Kritik an dieser durchaus bedenklichen inneren Entwicklung der Bundesrepublik demnach auch ihre Berechtigung habe, so sei der in Frankreich oftmals bekundete Verdacht, im Nachbarland steige der traditionelle deutsche Autoritarismus wieder empor, vollkommen fern der Realität. Seit nunmehr dreißig Jahren verfüge die Bundesrepublik, wie Rovan bekräftigte, über eine funktionierende Demokratie, die sich durch ein stabiles politisches System, Meinungsvielfalt, eine demokratisch kontrollierte Armee, unabhängige Gerichte und ein starkes Parlament auszeichne. Gewiss sei der westdeutsche Staat nicht frei von Fehlern und Unzulänglichkeiten, doch wolle Rovan denjenigen, die in Frankreich der Bundesrepublik derzeit in ungerechter und maßloser Weise den Prozess machten, vor Augen führen, dass die Bonner Demokratie der französischen in vielerlei Hinsicht in nichts nachstehe. Im Gegenteil: Auf manchem Gebiet sei sie ihr sogar überlegen ${ }^{678}$. Seinen Landsleuten gegenüber ließ Rovan es daher an klaren Worten nicht fehlen: "la République fédérale dirigée par Helmut Schmidt reste, à mes yeux aussi, un pôle de fidélité à la démocratie et aux libertés « ${ }^{679}$.

Einmal mehr, dies wird anhand der öffentlichen Auseinandersetzungen um den »Radikalenerlass" deutlich, sahen sich die Kräfte der Verständigung einem Konflikt gegenüber, welcher in der raschen Mobilisierung alter Feindbilder, in den kaskadenartigen Folgen von Verdachtsmomenten und Verteidigungsreflexen, die Grenzen freundschaftlichen deutsch-französischen Einvernehmens in den 1970er Jahren offenbarten. Auf die seitens der französischen Presse ins Feld geführten Vermutungen, die Bundesrepublik gehe nach der schrittweisen Einschränkung der Freiheitsrechte ihrer Bürger sehenden Auges einem autoritären Regime entgegen, antworteten die westdeutschen Medienorgane mit zynischen Kommentaren. Kaum verhehlten sie die Verärgerung darüber, dass die Nachbarn den Deutschen auch nach mehr als drei Jahrzehnten nicht zugestehen wollten, sich zu verlässlichen Demokraten gewandelt zu haben.

Angesichts der anhaltenden medialen Verwerfungen zwischen beiden Ländern beabsichtigte die Bundesregierung im Rahmen ihrer Auswärtigen Kulturpolitik um mehr Verständnis für den westdeutschen Staat zu werben und das so festgestellte Bild des "hässlichen Deutschen" durch positivere und nicht von der Vergangenheit dominierte Eindrücke zu ersetzen. Hierzu

677 Rovan, L'Allemagne n'est pas ce que vous croyez, S. 94.

678 Vgl. ibid., S. 61-69.

679 Ders., Histoire de la social-démocratie allemande, S. 473. 
dienten ihr ausschließlich altbekannte Rezepte: Das Erlernern der deutschen Sprache sollte in Frankreich gefördert, zeitgemäße Informationen über Deutschland vermittelt, Hochschul- und Wissenschaftsbeziehungen intensiviert werden. Ähnliche Zielsetzungen waren auch auf Seiten der nichtstaatlichen Kräfte zu konstatieren: Gerade in schwierigen Zeiten sehe man sich aufgefordert, die eigene Verständigungsarbeit zu verstärken, politische Aufklärung zu betreiben, bilaterale Austauschprozesse zu forcieren. Bei aller Verurteilung der polemischen Färbung der Diskussionen um den "Radikalenerlass « und bei allem Anmahnen der möglichen negativen Folgen für das deutsch-französische Verhältnis wurden konkrete Initiativen jedoch, zumindest insofern dies festzustellen ist, nicht ergriffen. Die Pläne der kulturpolitischen Akteure wie auch der privaten Organisationen blieben vielmehr bloße Willensbekundungen. In den medialen Gefechten waren allenfalls die Stimmen Joseph Rovans und Alfred Grossers zu vernehmen, die sich vor allem durch das wechselseitige Darlegen der unterschiedlichen Problemlagen, Positionen und Perspektiven bemühten, grenzüberschreitende Vermittlungsarbeit zwischen beiden Ländern zu leisten. Ob dies allein am Ende ausreichte, um ein wirkungsvolles Gegenmodell zum Schlagwort der westdeutschen »Hexenjagden « und »Berufsverbote « zu etablieren, ist zumindest fraglich. Dass im Zusammenhang mit den Ereignissen des »Deutschen Herbstes« nur wenig später das Bild der brutalen, repressiv-polizeistaatlich agierenden Bundesrepublik erneut und um ein Vielfaches verstärkt in Frankreich hervortreten konnte, zeigt jedenfalls, dass alte Ängste, Misstrauen und Klischeevorstellungen fortlebten und ein Faktor blieben, der die Beziehungen zwischen Deutschen und Franzosen weiterhin belastete.

\subsubsection{Polemiken im "Deutschen Herbst" - die Bundesrepublik, ein Polizeistaat?}

In der Tat galt Teilen der französischen Presselandschaft neben dem »Radikalenerlass « insbesondere das Vorgehen der westdeutschen Behörden gegen die RAF als Indiz für die schrittweise Wiedererrichtung eines autoritären Polizeistaats im Nachbarland. Zielscheibe der französischen Kritik, die vor allem linksintellektueller Provenienz war, bildeten zum einen die zwischen 1974 und 1978 in der Bundesrepublik verabschiedeten so genannten »Anti-TerrorGesetze ${ }^{680}$, zum anderen die vermeintlich unmenschlichen Haftbedingun-

${ }^{680}$ Hierunter fielen zum einen das so genannte »Ergänzungsgesetz« vom 20. Dezember 1974, welches den Ausschluss des Strafverteidigers aus dem laufenden Verfahren regelte, wenn dieser im Tatverdacht stand, selbst an Straftaten seines Mandanten beteiligt zu sein oder die Begehung neuer Delikte zu fördern, zum anderen das Gesetz vom 18. August 1976, das die "Bildung terroristischer Vereinigungen " mit Strafe bedrohte, sowie das »Kontaktsperregesetz « vom 30. September 1977, welches Verbindungen der inhaftierten RAF-Mitglieder zu anderen Gefangenen und zur Außenwelt unterbrechen sollte, 
gen der gefangen genommenen RAF-Mitglieder. Bereits im Dezember 1974 hatte der Besuch des französischen Philosophen Jean-Paul Sartre bei dem in der Justizvollzugsanstalt Stuttgart-Stammheim einsitzenden Andreas Baader für einige Aufregung gesorgt ${ }^{681}$. Vor seiner Reise in die Bundesrepublik hatte Sartre in einem Interview erklärt, die Öffentlichkeit »über die schreckliche Situation dieser Leute in der Isolierhaft « informieren zu wollen ${ }^{682}$. In einer im Anschluss an sein Gespräch mit Baader veranstalteten Pressekonferenz rief er zur Gründung eines Komitees zur Verteidigung der RAF-Häftlinge auf und bezeichnete die Haftumstände der in Stammheim Inhaftierten als Folter ${ }^{683}$. Zwar distanzierte sich der Philosoph gleichzeitig von den gewaltsamen Methoden der RAF, doch reichte sein Auftritt aus, um nicht nur in der konservativ geprägten westdeutschen Presse Empörung hervorzurufen ${ }^{684}$. Indem etwa der baden-württembergische Ministerpräsident Hans Filbinger Sartre der Taktlosigkeit gegenüber den Opfern der RAF und gegenüber den Deutschen insgesamt bezichtigte, gab er nach Einschätzung des französischen Generalkonsulats in Stuttgart die Stimmung breiter Schichten der Bevölkerung wieder ${ }^{685}$. Die Kritik des französischen Philosophen sei, wie auch »Der Spiegel« urteilte, »fern von aller Wirklichkeit « ${ }^{686}$. Sartre, so der allenthalben $\mathrm{zu}$ vernehmende Vorwurf, lasse sich in unwürdiger Weise zum willfährigen Instrument von Terroristen machen.

Erneut, und nun in weitaus größerem Ausmaße, erlangte der Themen-

vgl. Hans-Dieter Schwind, Kriminologie. Eine praxisorientierte Einführung mit Beispielen, Heidelberg u. a. ${ }^{20}$ 2010, S. 661f.; Mark A. ZöLlER, Terrorismusstrafrecht. Ein Handbuch, Heidelberg u. a. 2009, S. 42-44 sowie ausführlich Philipp H. Schulte, Terrorismus und Anti-Terrorismusgesetzgebung. Eine rechtssoziologische Analyse, Münster 2008; Stephan SCHEIPER, Innere Sicherheit. Politische Anti-Terror-Konzepte in der Bundesrepublik Deutschland während der 1970er Jahre, Paderborn u. a. 2010.

${ }^{681}$ Der Besuch ging auf eine Initiative Ulrike Meinhofs zurück, die Sartre in einem Schreiben vom Oktober 1974 hierum gebeten hatte, siehe hierzu Nicole Colin, Mensch oder Schwein? Andreas Baader, Ulrike Meinhof und Gudrun Ensslin auf Besuch in Hamburg und Paris, in: Dies. u. a. (Hg.), Der »Deutsche Herbst« und die RAF in Politik, Medien und Kunst. Nationale und internationale Perspektiven, Bielefeld 2008, S. 67-82, hier S. 70f.; vgl. allgemein zu Sartres Besuch in Stammheim Jürg AltwEgG, Die Republik des Geistes. Frankreichs Intellektuelle zwischen Revolution und Reaktion, München, Zürich 1986, S. 126-131; Miard-DelaCroix, Im Zeichen der europäischen Einigung, S. 174176; BA, B 362, Bd. 3387, Antrag Jean-Paul Sartres bezüglich des Besuchs bei Andreas Baader in der Justizvollzugsanstalt Stuttgart-Stammheim vom 3. November 1974.

682 „Schreckliche Situation«. Interview mit Sartre über seinen Besuch bei Baader, in: Der Spiegel, 02.12.1974, S. 166.

${ }^{683}$ Vgl. Sartre spricht von Folter. Besuch des französischen Philosophen bei Andreas Baader, in: Die Zeit, 13.12.1974, S. 8.

${ }^{684}$ Vgl. Günter ZeHM, Sartre geht zu Baader, in: Die Welt, 04.12.1974, S. 1; Rolf R. BigLeR, Sartre inszenierte sein schlechtestes Stück, in: Die Welt, 06.12.1974, S. 3.

685 Vgl. AMAE Paris-La Courneuve, Europe, RFA 1971-1976, Bd. 2948, Schreiben des französischen Generalkonsulats Stuttgart an den französischen Botschafter in Bonn betreffend »Visite de M. Jean-Paul Sartre à Andreas Baader « vom 6. Dezember 1974.

${ }^{686}$ Baader-Meinhof: An der Brüstung, in: Der Spiegel, 09.12.1974, S. 27. 
komplex des Terrorismus seit Sommer 1977 Bedeutung für die deutschfranzösischen Beziehungen. Grund hierfür war die Flucht des Strafverteidigers von Andreas Baader im Stammheimer Prozess, Klaus Croissant, nach Frankreich. Gegen Croissant bestand bereits seit 1975 wegen des Tatbestandes der Komplizenschaft mit der RAF ein Haftbefehl, welcher jedoch gegen Zahlung einer Kaution und die Auflage, die Bundesrepublik nicht zu verlassen, zunächst ausgesetzt worden war. Anfang Juli 1977 passierte der Anwalt unerkannt die französische Grenze und beantragte nur wenig später in Paris politisches Asyl, um sich dem in Schwebe befindlichen Strafvollzug durch die bundesdeutschen Behörden zu entziehen ${ }^{687}$. Im Rahmen einer nach seiner Flucht rasch einberufenen Pressekonferenz im Hause des Anwalts Jean-Jacques de Félice erklärte Croissant, er wolle als in Westdeutschland politisch Verfolgter von nun an sein Schicksal in die Hände des französischen Volkes legen und von Frankreich aus die seiner Ansicht nach in der Bundesrepublik verlorene Sache der Menschenrechte verteidigen ${ }^{688}$. Der Zuspruch, den Croissant hierbei seitens verschiedener im linken politischen Spektrum $\mathrm{zu}$ verortender Organisationen wie der Ligue des droits de l'homme oder der Anwaltsvereinigung Syndicat des avocats de France erfuhr ${ }^{689}$, wurde auf westdeutscher Seite als Anzeichen einer unmoralischen Solidarisierung Frankreichs mit einem RAF-Sympathisanten und möglicherweise sogar Mittäter bei terroristischen Gewaltakten in der Bundesrepublik gedeutet. In einem in dieser Hinsicht bezeichnenden Kommentar, den »Die Zeit« Ende Juli 1977 veröffentlichte, hieß es, Klaus Croissant habe keine schlechten Aussichten, mit seinem Gesuch um Gewährung politischen Asyls in Frankreich durchzudringen. "Jedenfalls reitet er auf einer Welle alter Ressentiments und neuer Vorurteile. Sie läßt viele Franzosen - und nicht nur die Kommunisten unter ihnen - in der Bundesrepublik einen Polizeistaat sehen, der politisch mißliebige Bürger allein wegen ihrer Überzeugung verfolgt « ${ }^{690}$. Nicht zuletzt vor dem Hintergrund der Anschlagserie des Jahres $1977^{691}$, welche die west-

687 Vgl. Hanno Balz, Von Terroristen, Sympathisanten und dem starken Staat. Die öffentliche Debatte über die RAF in den 70er Jahren, Frankfurt a.M., New York 2008, S. 130135 und S. 310; Sarah Colvin, Ulrike Meinhof and West German Terrorism: Language, Violence and Identity, Rochester NY 2009, S. 163; Miard-Delacroix, Im Zeichen der europäischen Einigung, S. $176 f$.

${ }^{688}$ Vgl. BM-Anwälte: Schon wieder umdrehen, in: Der Spiegel, 18.07.1977, S. 74 und S. 79; Croissant: »Sache der Menschenrechte« von Paris aus verteidigen. Der Rechtsanwalt beantragt in Frankreich politisches Asyl, in: FAZ, 13.07.1977, S. 1.

689 Vgl. L'affaire Croissant, hg. v. Mouvement d'action judiciaire, Paris 1977; Georges MAMY, Le glas du droit d'asile. Un entretien sur l'affaire Croissant avec Henri Noguères, historien, avocat et président de la Ligue des droits de l'homme, in: Le Nouvel Observateur, 21.11.1977, S. 46f.; Gérard BossuAT, La France, terre d'asile: l'avenir brouillé d'un grand destin, in: Antoine Fleury, Carole Fink, Lubor Jílek (Hg.), Les droits de l'homme en Europe depuis 1945. Human Rights in Europe since 1945, Bern u. a. 2003, S. 107-134.

${ }^{690}$ H. ScH., Pariser Asyl?, in: Die Zeit, 15.07.1977, S. 1.

${ }^{691}$ Im Zuge derer ermordeten Mitglieder der »Zweiten Generation« der RAF General- 
deutsche Bevölkerung gleichermaßen erschüttert wie verunsichert hinterließ, galt die Vorstellung, dass Croissant »in Paris der rote Teppich ausgerollt wurde ${ }^{692}$, als Affront, der dem freundschaftlichen deutsch-französischen Verhältnis Schaden zufügte. In Frankreich mobilisierte hingegen zu gleicher Zeit das Bekanntwerden des Auslieferungsantrags, den die Bundesregierung inzwischen bei den französischen Stellen eingereicht hatte ${ }^{693}$, weitere Kreise der Öffentlichkeit zu Sympathiebekundungen mit dem, wie es vielen Beobachtern schien, zu Unrecht durch einen zunehmend repressiv agierenden westdeutschen Staat verfolgten Anwalt ${ }^{694}$.

Seit Juli 1977 entstand somit zwischen Frankreich und Westdeutschland eine Atmosphäre nahezu vollkommenen wechselseitigen Unverständnisses. Angesichts dessen konnte der Artikel, den der französische Schriftsteller Jean Genet Anfang September 1977 unter dem Titel »Violence et brutalité« in »Le Monde« veröffentlichte, zum Auslöser für öffentliche Auseinandersetzungen werden, welche das deutsch-französische Verhältnis über mehrere Wochen hinweg einer schweren Prüfung aussetzten ${ }^{695}$. Genet, der ganz offen Sympathie für die Ziele und das Handeln der RAF bekundete, bezog hierin Stellung gegen die seiner Ansicht nach unmenschliche Brutalität des "Systems Bundesrepublik«, welche die Freiheit der Menschen zerschlage und zwangsläufig in Maßnahmen der Gegengewalt münde. Je größer die Brutalität der Staatsmacht, so Genet, desto notwendiger die Gewalt der Gegenkräfte: "Nous devons à Andreas Baader, à Ulrike Meinhof, à Holger Meins, à la RAF en général, de nous avoir fait comprendre, non seulement par des mots, mais par leurs actions, hors de prison et dans les prisons, que la violence seule peut achever la brutalité des hommes « ${ }^{696}$. Bis zur Folter und zum Tod, wie der

bundesanwalt Siegfried Buback und den Vorstandssprecher der Dresdner Bank, Jürgen Ponto, vgl. zu den Attentaten der RAF im Jahr 1977 die Darstellungen von Butz Peters, Tödlicher Irrtum. Die Geschichte der RAF, Frankfurt a.M. ${ }^{3} 2007$ und Michael SonTHEIMER, »Natürlich kann geschossen werden«. Eine kurze Geschichte der Roten Armee Fraktion, München 2010; vgl. darüber hinaus die einschlägigen Sammelbände von Wolfgang Kraushaar (Hg.), Die RAF und der linke Terrorismus, 2 Bde., Hamburg 2006 sowie Klaus Weinhauer, Jörg Requate, Heinz-Gerhard Haupt (Hg.), Terrorismus in der Bundesrepublik. Medien, Staat und Subkulturen in den 1970er Jahren, Frankfurt a.M., New York 2006.

692 Miard-Delacroix, Willy Brandt, Helmut Schmidt und François Mitterrand, S. 238.

693 Vgl. hierzu das Gespräch zwischen Bundeskanzler Schmidt und Staatspräsident Giscard d’Estaing in Straßburg am 19. Juli 1977, in: AAPD 1977, Bd. 2, Dok. 198, hier bes. Anm. 31.

${ }^{694}$ Vgl. L'affaire Klaus Croissant, in: Le Nouvel Observateur, 08.08.1977, S. 30; MÉNUdieR, Une revue de la presse française, S. 31-33; Günter Grass, Alfred Grosser, Fritz J. RaDDATZ, Gespräch über eine schwierige Nachbarschaft, in: Freimut Duve, Heinrich BöLL, Klaus Staeck (Hg.), Briefe zur Verteidigung der Republik, Reinbek b. Hamburg 1977, S. 160-169; PA-AA, Zwischenarchiv, Nr. 113555, Aufzeichnung »Auflistung gegenwärtiger deutsch-französischer Irritationen " vom 16. August 1977, S. 1.

695 Vgl. hierzu Miard-Delacroix, Im Zeichen der europäischen Einigung, S. $172 \mathrm{f}$.

${ }^{696}$ Jean Genet, Violence et brutalité, in: Le Monde, 02.09.1977, S. 1. 
Schriftsteller formulierte, verstünden sich die Mitglieder der RAF als »Inseln der Freiheit" in diesem »westlichen Archipel Gulag" Bundesrepublik. Das Nachbarland, das die Todesstrafe zwar abgeschafft habe, treibe diejenigen, die sich gegen seine Unmenschlichkeit auflehnten, dennoch in den Tod, durch Hungerstreik, durch Isolationshaft. Schrecken erregend und monströs erscheine das Deutschland, das sich hier offenbare ${ }^{697}$. Genets Stilisierung der RAF-Mitglieder zu Freiheitskämpfern und die Pauschalverurteilung der Bundesrepublik als Staat der Unterdrückung löste in der westdeutschen Presse umso heftigere Reaktionen aus, als nur drei Tage nach Veröffentlichung dieses Kommentars der Vorsitzende des Bundes der Deutschen Industrie und des Bundes der Arbeitgeberverbände, Hanns Martin Schleyer, in Köln durch die RAF entführt und seine vier Begleiter ermordet wurden ${ }^{698}$.

Vor allem im Lichte dieser neuerlichen Bluttat erschien einer Mehrheit der westdeutschen Zeitungen Genets Beitrag, zu dem sich eine Reihe weiterer Artikel ähnlicher Zielrichtung gesellten, als zynisch und empörend. "Der Spiegel« druckte Mitte September 1977 Auszüge des »Le Monde«-Artikels in deutscher Übersetzung ab, brachte eine in deftigen Worten abgefasste Gegenrede und gab hiermit den Startschuss zum medialen Gegenangriff ${ }^{699}$. Mehr und mehr galt jedoch im Verlaufe der sich nun entspinnenden Kampagne die Meinung Genets als beredter Ausdruck eines in Frankreich auf breiter Front vorrückenden Antigermanismus und »Le Monde« als dessen Speerspitze ${ }^{700}$. Der Tatsache, dass in der französischen Presse, in »Le Monde « zumal, auch Gegenpositionen zu Genet vertreten wurden ${ }^{701}$, schenkten die bundesdeutschen Journalisten dabei nur wenig Beachtung. Schadenfreude und Chauvinismus seien in Frankreich die dominanten Reaktionen auf den Terrorismus in der Bundesrepublik, wie denn auch die »Frankfurter Allgemeine Zeitung « konstatierte. Geradezu genüsslich ergingen sich die Nachbarn über das augenblickliche Schicksal Westdeutschlands. Die »zahllosen antideutschen Ergüsse« der französischen Presse zeugten insbesondere von der Genugtuung darüber, dass die Bundesrepublik endlich die Quittung für ihre polizeistaatlichen Praktiken bekäme. Der Hohn über die »tüchtigen

${ }^{697}$ Siehe ibid., S. 1f.

698 Vgl. hierzu ausführlich Lutz Hachmeister, Schleyer. Eine deutsche Geschichte, München 2004.

699 Vgl. Schrecken erregendes Deutschland, in: Der Spiegel, 12.09.1977, S. 136 sowie Dieter WILD, Ihr Lieben von »Le Monde«, in: Der Spiegel, 12.09.1977, S. 138.

${ }^{700}$ Vgl. hierzu Bernard Brigouleix, La presse allemande accuse d'»antigermanisme« plusieurs journaux français dont »Le Monde«, in: Le Monde, 14.09.1977, S. 6; Klaus-Peter Schmid, Geht es um Bonn, ist »Le Monde" gallisch und gallig, in: Die Zeit, 16.12.1977, S. 3 .

701 Vgl. beispielsweise Pierre de BoIsDeffre, Comment faire face à la violence. Réponse à Jean Genet, in: Le Monde, 17.09.1977, S. 1 und S. 8. 
Deutschen mit ihrer harten Mark«, spiele, wie es in dem Artikel hieß, eine »wichtige Rolle im Seelenhaushalt der Franzosen ${ }^{702}$.

Wenige Wochen später veröffentlichte dasselbe Blatt unter dem Titel "Das ist der Beginn einer heimtückischen Kampagne« eine über zwei Seiten reichende Zusammenstellung ausgewählter Kommentare französischer Zeitungen zu den jüngsten Ereignissen in der Bundesrepublik. Die einleitenden Worte lauteten: "Selten ist die Bundesrepublik von einem großen Teil der französischen Presse mit so viel Feindseligkeit und Mangel an Verständnis bedacht worden wie in diesen Tagen der Herausforderung durch den Terrorismus ${ }^{703}$. In der zunehmenden Intoleranz, zu der die vom Terrorismus aufgeschreckte Bevölkerung und ihre Regierung angeblich neigten, sähen auch wohlmeinende Betrachter die Hinwendung zu einem autoritären, wenn nicht gar nazistischen Staatswesen. Die einhellige Ablehnung der RAF durch die Deutschen werde, so der Autor, in Frankreich nicht etwa als selbstverständlicher demokratischer Konsens, sondern vielmehr als "post- oder profaschistische Haltung" gedeutet. Die französischen Parteinahmen zugunsten der Terroristen gingen gar soweit, dass das Verhältnis von Täter und Opfer ins Gegenteil verkehrt werde. Vor diesem Hintergrund zu vermitteln, dass die Bundesrepublik auch angesichts der terroristischen Bedrohung ein Rechtsstaat bleibe, sei wahrlich keine leichte Aufgabe ${ }^{704}$. Ähnlich sah dies auch der Politologe Lothar Rühl, der Ende September 1977 den Lesern der "Zeit« erläuterte, »warum die Bundesrepublik vielen Franzosen ein Ärgernis ist «. Die Pariser Intelligentsia habe sich, wie Rühl befand, nie mit dem Erfolgsbeispiel, das ihnen die Nachbarn gaben, abfinden können. So stelle sie nun die Baader-Meinhof-Leute gegen das westdeutsche Modell. Die Deutschen seien in Frankreich von jeher als »dumm und diszipliniert« karikiert worden. Für die Franzosen sei es daher unerträglich, ihnen höhere Leistungen bei ebensoviel Freiheit und Menschlichkeit wie in Frankreich zuzubilligen. Wenn sie mehr leisteten, dann nur, weil sie sich noch immer unterdrücken ließen und in einem gut organisierten Kasernenbetrieb zur Arbeit marschierten. Es sei deshalb kein Zufall, dass in der französischen Presse, in »Le Monde« zumal, die deutsche Wirklichkeit weithin nur in ihren negativen Ausprägungen hervorgehoben werde ${ }^{705}$.

Angeheizt hatte die Debatten zu diesem Zeitpunkt neben dem Artikel Jean Genets vor allem ein Interview des flüchtigen und mittlerweile auch in

702 Andreas Razumovsky, Schadenfreude und Chauvinismus in Frankreich angesichts des Terrors in der Bundesrepublik. Seltsame Reaktionen nach der Schleyer-Entführung, in: FAZ, 12.09.1977, S. 3.

703 Thankmar von MüNCHHAusen, »Das ist der Beginn einer heimtückischen Kampagne«. Kommentare französischer Zeitungen zu den jüngsten Ereignissen in Deutschland, in: FAZ, 02.11.1977, S. 9.

704 Siehe ibid.

705 Siehe Lothar RüHL, Ein Popanz für die Linke. Warum die Bundesrepublik vielen Franzosen ein Ärgernis ist, in: Die Zeit, 23.09.1977, S. 11. 
Frankreich per Haftbefehl gesuchten Klaus Croissant am 7. September 1977 in den Abendnachrichten des staatlichen Fernsehsenders »Antenne 2«. Vier Minuten lang erklärte der Anwalt den französischen Zuschauern dort, dass angesichts eines auf dem Weg des Faschismus befindlichen westdeutschen Staates den »Kräften des Widerstandes«, namentlich der RAF, einzig der bewaffnete Kampf bleibe und die Entführung Schleyers eine legitime Methode sei, sich gegen das in der Bundesrepublik herrschende repressive "System" aufzulehnen ${ }^{706}$. In den westdeutschen Medien nährte der Auftritt Croissants den Verdacht einer unterschwelligen Komplizenschaft der französischen Behörden und Öffentlichkeit mit dem Gesuchten.

Vor dem Hintergrund einer in Frankreich tief verwurzelten Antipathie gegen die deutschen Begriffe von Recht und Ordnung sowie eingedenk der Parallelen, welche die französische Linke seit geraumer Zeit zwischen der bundesdeutschen Terrorismusabwehr und dem nationalsozialistischen Repressionsapparat ziehe, falle es Croissant leicht, wie die »Süddeutsche Zeitung" schrieb, »das bei Millionen Franzosen immer wache Mißtrauen gegen die Bundesrepublik neu zu schüren " ${ }^{707}$. Nicht zuletzt aus diesem Grunde habe die westdeutsche Bevölkerung das gute Recht, danach zu fragen, weshalb der seit zwei Monaten untergetauchte Anwalt von der französischen Polizei noch nicht gefasst worden sei. Und auch die Verwunderung darüber sei berechtigt, »daß die Leitung eines französischen Fernsehsenders es für vertretbar hält, dem einstigen Verteidiger der Terroristen die Bildschirme Frankreichs zur besten Sendezeit zu öffnen " ${ }^{708}$. Ähnlich lautete auch die Kritik in »Der Spiegel«. Croissant und seinen Parolen sei, wie hier geurteilt wurde, durch das Interview eine übermäßige öffentliche Aufmerksamkeit zuteil geworden: »In der Stunde der Not sah sich die Bundesrepublik allein im Kampf gegen die Anarchie, wähnte sich verhöhnt durch Croissants TV-Akt, mißverstanden von ausländischen Publizisten, die zwischen Faschismus und Anarchie inmitten Europas ein germanisches Monster auferstehen sahen ${ }^{709}$.

Auf Seiten der französischen Presse war demnach im Herbst 1977 erneut die Rede von einer Wiedererrichtung des deutschen Polizeistaates. Das Vorgehen gegen die RAF erinnerte zahlreiche Kommentatoren an die Verfolgungen des Nationalsozialismus. Aus den bundesdeutschen Zeitungen sprach hingegen einmal mehr das Gefühl, von den sich allzu rasch deutschfeindlichen Strömungen hingebenden französischen Nachbarn in ungerechter Weise an den Pranger gestellt und in schweren Zeiten im Stich gelassen zu werden. Un-

706 Vgl. Croissant zeigt Verständnis für Terroristen. Fernsehinterview mit dem nach Frankreich geflüchteten Strafverteidiger, in: Die Welt, 09.09.1977, S. 2; Miard-Delacroix, Partenaires de choix?, S. 124f.; AMAE Paris-La Courneuve, Europe, RFA 1976-1980, Bd. 3961, AFP-Meldung "Le gouvernement ouest-allemand `irrité ‘ par la diffusion d'une interview de $\mathrm{M}^{\mathrm{e}}$ Klaus Croissant « vom 9. September 1977.

707 Klaus Arnsperger, Frankreichs anderes Ordnungsdenken, in: SZ, 13.09.1977, S. 4.

708 Ibid.

709 Paris: »Wir jagen Croissant«, in: Der Spiegel, 19.09.1977, S. 127. 
heilvolle Schatten hatten die jüngsten Auseinandersetzungen auf den Rhein geworfen, wie »Le Monde« im November 1977 schrieb, welche nun drohten, die deutsch-französischen Beziehungen dauerhaft zu verfinstern ${ }^{710}$.

Diese Gefahr war auch von den Regierungsstellen beider Länder erkannt worden. Bereits nach der Flucht Croissants im Juli 1977 hatte der deutsche Botschafter in Paris, Axel Herbst, dem Auswärtigen Amt gegenüber auf die Risiken hingewiesen, welche aus dem Fall Croissant für das deutschfranzösische Verhältnis erwachsen könnten ${ }^{711}$. Im Zusammenhang mit der Pressepolemik, die der Artikel Jean Genets ausgelöst hatte, schien sich seine Prognose in beunruhigender Weise zu bestätigen. Ein Botschaftsbericht von Mitte September 1977 versuchte, die in Frankreich aufgekommene Kritik an der Bundesrepublik sowie insbesondere die zum Teil festzustellenden Sympathien der französischen Kommentatoren für die RAF zu erklären: Herrührend aus der französischen Revolution und bekräftigt durch die Erfahrungen der Résistance zwischen 1940 und 1944, finde individuelle Auflehnung gegen die Obrigkeit, auch unter Gewaltanwendung, in Frankreich eher ein positives Echo als in Deutschland, wo Ordnungs- und Gemeinsinn im Vordergrund stünden. Angesichts dieser grundlegenden Gegebenheiten habe es »der deutsche Terrorist « in Frankreich leichter als in anderen Ländern, auf Sympathie zu stoßen. Da sich zudem die Aktivisten der RAF von Beginn an als Linke präsentiert hätten, sei es ihnen, auch vor dem Hintergrund der Berichterstattung über die vermeintlich unmenschlichen Haftbedingungen in der Bundesrepublik, möglich gewesen, Verständnis vor allem in den linksintellektuellen Kreisen Frankreichs zu wecken. Diese dominierten weite Teile des kulturellen Lebens, des Schul- und Hochschulwesens sowie der Presse- und Fernsehlandschaft im Nachbarland. Was nun die Wirkungen des Terrorismus-Phänomens anbelangte, so seien hier in erster Linie die Besonderheiten des deutsch-französischen Verhältnisses zu berücksichtigen:

Ein Attentat wie das gegen Schleyer und seine Bewacher löst bei vielen Franzosen unausweichlich - oft wohl unterbewußt - bestimmte Assoziationen aus, wie Blutvergießen, äußerste Brutalität, Perfektion, Unmenschlichkeit, SS, Hitler, Wehrmacht, Deutsche, Krieg, Widerstand. Es geht davon eine Schockwirkung aus, die im ersten Augenblick weniger antiterroristisch als antideutsch sein mag. Ein solcher, aus Deutschland kommender Schock wirkt, wenn er - wie in diesem Fall - stark genug ist, weiter wie ein Katalysator. Wunden der Kriegs- und Nachkriegszeit beginnen wieder zu schmerzen ${ }^{712}$.

$\mathrm{Zu}$ hoffen sei, wie der Bericht formulierte, dass dieser Schockzustand der Franzosen alsbald der Besinnung weiche und hiervon ausgehend eine bessere Stimmungslage zwischen beiden Völkern eintrete. Voraussetzung dafür

710 Vgl. André Fontaine, Ombres sur le Rhin, in: Le Monde, 09.11.1977, S. 1 und S. 4.

711 Vgl. Botschafter Herbst, Paris, an das Auswärtige Amt, 26. Juli 1977, in: AAPD 1977, Bd. II, Dok. 205.

712 PA-AA, Auslandsvertretungen, Botschaft Paris, Bd. 13523, Schreiben der deutschen Botschaft Paris an das Auswärtige Amt betreffend "Frankreich und die Terroristen in der Bundesrepublik Deutschland« vom 14. September 1977, S. 4. 
sei allerdings, dass es gelinge, »bei der großen Mehrheit der französischen Bevölkerung - und nur bei dieser, denn bei manchen Franzosen wird uns dies nie gelingen! - alle denkbaren Assoziationen zwischen unserer Reaktion auf terroristische Verbrechen und einer Gewaltherrschaft wie wir sie früher hatten, zu vermeiden " $^{713}$.

In der französischen Vertretung in Bonn war man zu gleicher Zeit ebenso bestrebt, die möglichen Ursachen und Folgen der öffentlichen Kontroversen zwischen beiden Ländern näher zu bestimmen. Die seitens der französischen Presse erhobenen Vorwürfe gegen die Bundesrepublik würden, wie Botschafter Jean-Pierre Brunet am 10. September 1977 nach Paris schrieb, dort gegenwärtig umso stärker wahrgenommen, als die westdeutsche Öffentlichkeit infolge der jüngsten Gewaltakte der RAF desorientiert und zutiefst verunsichert sei. Dass verschiedene französische Kommentatoren Nachsicht gegenüber den Terroristen zeigten, sogar Sympathie für sie erkennen ließen und im selben Atemzuge die Bundesrepublik als Polizeistaat denunzierten, führe in Westdeutschland zu heftigen Gegenreaktionen. Insbesondere die Tatsache, dass "Le Monde" es Jean Genet an prominenter Stelle ermöglicht habe, gegen das »unmenschliche Deutschland « zu Felde zu ziehen, sowie das Interview Klaus Croissants im französischen Fernsehen hätten die Deutschen schockiert $^{714}$. Der instinktive und hoch emotionale Verteidigungsreflex, welcher das Verhalten eines Großteils der westdeutschen Presseorgane kennzeichne, verzerre allerdings deren Berichterstattung ganz erheblich: "La presse allemande $[. .$.$] consacre de longues colonnes à commenter ce qu'en$ disent les journalistes d'autres pays, au premier rang desquels le nôtre. Elle monte en épingle des interviews ou des articles qui sont passés à peu près inaperçus chez nous « ${ }^{715}$. In der westdeutschen Öffentlichkeit, vielleicht sogar im Regierungslager, greife, so die Auffassung von Brunet, mehr und mehr das Gefühl um sich, dass der Partner Frankreich in der schweren Krise, welche die Bundesrepublik zu bestehen habe, nicht an der Seite der Deutschen stehe. Wiederum offenbarten die zu Tage getretenen deutsch-französischen Spannungen, so das Urteil der Diplomaten des französischen Außenministeriums, wie zerbrechlich die Freundschaft beider Länder noch immer sei: »c'est une

713 Ibid., S. $5 f$.

714 Siehe AMAE Nantes, Bonn Ambassade, Bd. 318, Schreiben des französischen Botschafters in Bonn, Jean-Pierre Brunet, an das französische Außenministerium betreffend "L'Allemagne et les médias français" vom 10. September 1977.

715 AMAE Paris-La Courneuve, Europe, RFA 1976-1980, Bd. 3960, Schreiben des französischen Botschafters in Bonn, Jean-Pierre Brunet, an das französische Außenministerium vom 19. September 1977; siehe hierzu auch AMAE Nantes, Bonn Ambassade, Bd. 318, Schreiben des französischen Botschafters in Bonn, Jean-Pierre Brunet, an das französische Außenministerium betreffend »Relations franco-allemandes« vom 21. Oktober 1977. 
amitié récente, volontaire et fragile encore qu'il faut cultiver chaque jour par la pratique ${ }^{716}$.

$\mathrm{Zu}$ einer in diesem Sinne verstandenen Pflege der freundschaftlichen Bande sollten vor allem die wiederholten öffentlichen Solidaritätsbekundungen beitragen, welche die Pariser Regierung seit Zuspitzung des Konflikts über den Rhein sandte. So gab der Élysée-Palast am 13. September 1977 in einem Pressekommuniqué bekannt, dass Staatspräsident Giscard d'Estaing Bundeskanzler Schmidt angesichts der terroristischen Angriffe in Westdeutschland in einem Telefongespräch persönlich der Unterstützung des französischen Volkes und der Kooperationsbereitschaft der französischen Regierung und Behörden versichert habe. Beide erklärten hierin übereinstimmend, den Schaden, welche die seitens der Medien beider Länder ausgetragene Fehde in den deutsch-französischen Beziehungen anrichten könne, verhindern $\mathrm{zu}$ wollen ${ }^{717}$. Gut eine Woche später reiste der ehemalige französische Staatsminister Michel Poniatowski als Sonderbotschafter Giscards zu einem Gespräch mit Helmut Schmidt nach Bonn, um auf diesem Wege nicht nur der Bundesregierung, sondern auch der westdeutschen Bevölkerung die uneingeschränkte Solidarität Frankreichs im Kampf gegen den Terrorismus zu demonstrieren ${ }^{718}$. Vor der bundesdeutschen Presse erklärte Poniatowski:

[L]'immense majorité des Français partage l'émotion et comprend la répulsion du peuple allemand devant les événements récents. Les autorités françaises ont dès les premiers instants assuré le gouvernement allemand de leur entière solidarité et de leur complète coopération [...]. Le gouvernement français met tout en œuvre pour appuyer l'action des autorités allemandes ${ }^{719}$.

Am 26. September schließlich bekräftigte Innenminister Christian Bonnet in einem Interview mit dem »Spiegel «, dass es sich bei denjenigen, die in Frankreich derzeit die Bundesrepublik einen Polizeistaat schimpften, um eine Minderheit handele, welche mit ihrem Tun die freundschaftliche Verbun-

716 AMAE Paris-La Courneuve, Europe, RFA 1976-1980, Bd. 3999, Vermerk betreffend »Les relations franco-allemandes« vom 14. Oktober 1977, S. 5.

717 Vgl. M. Giscard d'Estaing s'entretient par téléphone avec le chancelier Schmidt, in: Le Monde, 15.09.1977, S. 6; Telefongespräch des Bundeskanzlers Schmidt mit Staatspräsident Giscard d'Estaing, 13. September 1977, in: AAPD 1977, Bd. II, Dok. 242; PA-AA, Auslandsvertretungen, Botschaft Paris, Bd. 13523, Schreiben der deutschen Botschaft Paris an das Auswärtige Amt betreffend »Deutsch-französische Beziehungen: Äußerungen der französischen Regierung zur jüngsten Pressepolemik « vom 16. September 1977.

718 Vgl. Dokumentation zu den Ereignissen und Entscheidungen im Zusammenhang mit der Entführung von Hanns Martin Schleyer und der Lufthansa-Maschine "Landshut", hg. v. Presse- und Informationsamt der Bundesregierung, Bonn ${ }^{2}$ 1977, S. 59 f.

719 AMAE Paris-La Courneuve, Europe, RFA 1976-1980, Bd. 3999, „Chronologie des déclarations relatives aux relations franco-allemandes durant l'été 1977 «, nicht datiert, S. 2f.; in ähnlicher Weise hatte sich kurz zuvor bereits der französische Botschafter in der westdeutschen Presse zu Wort gemeldet, vgl. AMAE Paris-La Courneuve, Europe, RFA 1976-1980, Bd. 3961, AFP-Meldung »Déclarations de l'Ambassadeur de France à Bonn « vom 20. September 1977. 
denheit der Franzosen mit den Deutschen in keiner Weise beeinträchtigen könne. Ein bedeutender Teil der französischen Polizeikräfte fahnde, anders als in den westdeutschen Medien berichtet, intensiv nach Klaus Croissant. Zudem gewähre die Pariser Regierung der Bundesrepublik jede erdenkliche Hilfe bei der strafrechtlichen Verfolgung der RAF-Mitglieder ${ }^{720}$. Im Gegenzug erhielt Bundeskanzler Schmidt Anfang Oktober 1977 seitens der nun um Ausgleich bemühten französischen Fernsehgesellschaft "Antenne 2«, welche für ihr Interview mit Klaus Croissant schwere Kritik hatte hinnehmen müssen, die Möglichkeit, sich im Rahmen der Sendung "Cartes sur table» zu der französischen Kritik am Vorgehen der bundesdeutschen Behörden gegen die RAF zu äußern ${ }^{721}$. Hier wurde Schmidt Gelegenheit gegeben, wie man in der westdeutschen Presse urteilte, "sich eine Stunde lang als bescheidener, nachdenklicher, mitunter gar humorvoller Mensch vorzuführen, der tabakschneuzend, überhaupt nicht wie `le Feldwebel` wirkte, als der er vielen Franzosen vorgesetzt worden war ${ }^{722}$.

Diese Form der Öffentlichkeitsarbeit auf höchster offizieller Ebene wurde von Bestrebungen der Regierenden begleitet, der tendenziösen Berichterstattung von Teilen der französischen Medien auch im Rahmen der kulturellen Verständigungspolitik mäßigend entgegenzutreten. Insbesondere die Bonner Verantwortlichen setzten es sich zum Ziel, hierdurch die befürchteten negativen Folgen für die Wahrnehmung der Bundesrepublik in Frankreich und die deutsch-französischen Beziehungen insgesamt abzuwenden. In dieser Hinsicht kam einer Ansprache Bundespräsident Walter Scheels, die dieser im Beisein des französischen Staatspräsidenten anlässlich der 500-JahrFeier der Universität Mainz im Sommer 1977 gehalten hatte, ein durchaus handlungsleitender Charakter $\mathrm{zu}^{723}$. Es wäre, wie Scheel dort ausführte, für Europa verhängnisvoll, wenn Deutsche und Franzosen wieder begännen, sich argwöhnisch zu belauern. Beide Länder sollten sich vielmehr einander zuwenden, aufeinander hören und eingehen. Um wirksam werden zu können, müsse diese Einigung jedoch seitens der Bevölkerungen bejaht und getragen werden. Wenn zwei Menschen sich zu einer dauernden Bindung entschlössen, so sei es unabdingbar, dass sie einander verstünden und schätzten. Bei Völkern sei dies nicht anders. »Deutschland und Frankreich

720 Vgl. »Wir wußten wirklich nicht, wo er war«. Der französische Innenminister Christian Bonnet über die Fahndung nach BM-Anwalt Croissant, in: Der Spiegel, 26.09.1977, S. 139-145.

721 Vgl. Henri MÉnudier, L’Allemagne à la télévision française en 1977, in: Documents 34 (1979), Sonderheft, S. 142-155.

722 Unmenschliches Deutschland?, in: Der Spiegel, 21.11.1977, S. 134.

${ }^{723}$ Bereits im Vorfeld der Zeremonie hatte Bundeskanzler Schmidt an Staatspräsident Giscard d'Estaing geschrieben, dass die Feierlichkeiten in Mainz eine besondere Gelegenheit bieten könnten, »die Verbundenheit unserer Länder, insbesondere auf kulturellem Gebiet, darzutun «, AN Paris, 5 AG 3, Bd. 936, Schreiben Bundeskanzler Helmut Schmidts an Staatspräsident Giscard d'Estaing vom 7. März 1977. 
brauchen Verständnis und Sympathie für einander. Deutsche und Franzosen müssen einander weit besser kennen und würdigen, als es bisher, trotz aller Anstrengungen, der Fall ist « ${ }^{724}$. Dabei, so die Worte des Bundespräsidenten, werde sich der einzelne kaum aus eigener Anschauung ein ausreichendes Bild von der Nachbarnation machen können. Er bedürfe hierbei der Vermittlung etwa von Journalisten, Wissenschaftlern oder Politikern, deren Aufgabe es sei, die »emotionellen Klischees" in den Vorstellungen der Nachbarn durch wirklichkeitsnahe Eindrücke zu ersetzen. Eines dieser überkommenen Klischees sah Scheel in der Kritik an der westdeutschen Demokratie. Die Bundesrepublik sei schließlich der freieste Staat in der deutschen Geschichte. Die Gewährleistung der Menschen- und Bürgerrechte in Westdeutschland stehe der keines anderen europäischen Staates nach. »Wer dieses Land als einen repressiven Polizeistaat verleumdet, kennt es nicht, oder er will es nicht kennen $\aleph^{725}$.

Bei der Abtragung des in solcherlei Anschuldigungen erkennbaren Argwohns maßen die Offiziellen nicht nur den von Scheel genannten Mittlerpersönlichkeiten aus Medien, Wissenschaft und Politik eine entscheidende Funktion zu. Punktuelle Verständigungsimpulse sollten daneben auch von kulturellen Großveranstaltungen ausgehen, im Rahmen derer breite Bevölkerungsschichten des Nachbarlandes in ihrer Wahrnehmung der Bundesrepublik, so hoffte man zumindest auf deutscher Seite, positiv gestimmt würden. Dies konnten Theateraufführungen bekannter westdeutscher Ensembles sein, ein Auftritt der Berliner Philharmoniker in Paris und insbesondere Ausstellungen. Unter den Medien der Auswärtigen Kulturpolitik, so die auf Seiten der Bonner Verantwortlichen diesbezüglich vertretene Auffassung, bleibe das der Ausstellung besonders geeignet, um »die Breite und den Reichtum der [...] kulturellen Aktivitäten darzustellen. Alle unsere Erfahrungen zeigen immer wieder, daß visuelle Ansprache auch dort zum Verstehen führen kann, wo andere Medien - aus welchen Gründen auch immer - nicht zum Zuge kommen " ${ }^{726}$. In diesem Sinne galten Ausstellungen nicht nur als hilfreiches Instrument, um das Deutschlandbild des Auslands in günstiger Weise zu beeinflussen und einen dauerhaften kulturellen Dialog mit den Nachbarn zu etablieren, sondern ebenso als Ausdruck einer Auswärtigen Kulturpolitik, die sich als Mittel der Vertrauensbildung verstand.

724 Ansprache Bundespräsident Walter Scheels anlässlich der 500-Jahr-Feier der Universität Mainz am 17. Juni 1977, in: Bulletin des Presse- und Informationsamtes der Bundesregierung 65 (1977), S. 610.

725 Ibid.

726 Rede des Staatssekretärs im Auswärtigen Amt, Hans Werner Lautenschlager, im Rahmen des internationalen Symposiums "Ausstellungen - Mittel der Politik» am 12. September 1980 in Berlin, in: Bulletin des Presse- und Informationsamtes der Bundesregierung 103 (1980), S. 875; vgl. hierzu auch Klaus Bleker, Andreas Grote (Hg.), Austellungen, Mittel der Politik? Internationales Symposium 10.9.-12.9.1980 in Berlin, Berlin 1981. 
Gerade in Frankreich erschienen nach den deutsch-französischen Auseinandersetzungen der Herbstmonate 1977 solch vertrauensbildende Maßnahmen notwendiger denn je. Die im Juli 1978 unter großer medialer Aufmerksamkeit im Pariser Centre Pompidou eröffnete Ausstellung »Paris-Berlin 1900-1933. Rapports et contrastes France-Allemagne « kam daher aus Sicht derer, die die Entwicklung des deutsch-französischen Verhältnisses mit Sorge verfolgt hatten, zur rechten Zeit. Kuratiert durch die Kunsthistoriker Werner Spies und Jean-Hubert Martin und maßgeblich seitens der deutschen Botschaft und des Goethe-Instituts gefördert, präsentierte die Exposition den Besuchern ein weites Panorama der Entwicklung Deutschlands im ersten Drittel des 20. Jahrhunderts. Dieses reichte von der expressionistischen Malerei des "Blauen Reiter" und der Bauhaus-Architektur über den Film, die Literatur und das Theater der 1920er Jahre bis hin zu den politischen Umwälzungen zwischen Kaiserreich und der nationalsozialistischen Machtübernahme von $1933^{727}$. Französische Stereotype von uniformierten, arbeitsamen Deutschen wollten die Ausstellungsmacher ins Wanken bringen, Voreingenommenheit, die den Blick auf das östliche Nachbarland verstelle, ausräumen, Zusammenhänge erklären. Mit diesen Zielen verbanden sie die Hoffnung, dass sich, wie Werner Spies im Vorwort zu der 1979 erschienenen deutschen Ausgabe des Ausstellungskatalogs formulierte, »dank einer ungeschminkten Darstellung der historischen und ästhetischen Realitäten in Deutschland bis zur Heraufkunft des Nationalsozialismus das Faszinationsgefälle zwischen beiden Ländern verringern möge « 228 .

Schenkt man den zahlreichen positiven Kommentaren aus Presse und Politik Glauben, schoss der Kurator mit seiner retrospektiven Einschätzung, es habe noch keine Begegnung der Franzosen mit Deutschland gegeben, »die eine derart tiefgreifende Auseinandersetzung zustande gebracht hätte « ${ }^{729}$, nicht gar so sehr über das Ziel hinaus, wie vielleicht zu vermuten wäre. So berichtete Ende August 1978 die deutsche Botschaft an das Auswärtige Amt: »Die 1977 zu verzeichnende Welle der Kritik an den deutschen Nachbarn ist abgeflaut. Erfreulich sind Anzeichen eines gewachsenen Interesses an Deutschland, für das etwa die täglich 3000 Besucher der am 13. Juli eröffneten Ausstellung Paris-Berlin zeugen " ${ }^{730}$. Nahezu überschwänglich hieß es in den Zeitungen, ein »Rauchvorhang von Mißverständnissen« zwischen beiden Ländern lich-

727 Vgl. den Ausstellungskatalog Paris-Berlin 1900-1933. Rapports et contrastes FranceAllemagne. Art, architecture, graphisme, littérature, objets industriels, cinéma, théâtre, musique. Centre national d'art et de culture Georges-Pompidou, 12 juillet-6 novembre 1978, Paris 1978.

728 Werner SPIEs, Zur deutschen Ausgabe, in: Paris-Berlin 1900-1933. Übereinstimmungen und Gegensätze Frankreich-Deutschland. Kunst, Architektur, Graphik, Literatur, Industriedesign, Film, Theater, Musik, München 1979, S. 3.

729 Ibid.

${ }^{730}$ PA-AA, Zwischenarchiv, Nr. 113561, Politischer Halbjahresbericht der deutschen Botschaft Paris vom 24. August 1978, S. 9. 
te sich ${ }^{731}$. Nie zuvor sei in Frankreich der »teutonische Nachbar und einstige Erbfeind « so differenziert zur Kenntnis genommen worden ${ }^{732}$. Der Erfolg von »Paris-Berlin« ändere das Deutschlandbild der Franzosen: »Es war in der Tat, als sentdeckten « die Franzosen ihre Nachbarn erst jetzt so recht, trotz eines seit 25 Jahren bestehenden Freundschaftspaktes, trotz Jugendaustausches und jährlicher Gipfeltreffen « ${ }^{733}$. Zumindest aus der Sicht der westdeutschen Presse trugen demnach die bislang ungekannten Eindrücke, welche der Gang durch die Ausstellung den rund 400000 überwiegend französischen Besuchern vermittelte ${ }^{734}$, dazu bei, mehr Verständnis für die Deutschen in Frankreich zu wecken und die deutsch-französische Krise des Herbstes 1977 vergessen zu machen. Der Gedanke, dass es mehr brauchen könnte, als eine viermonatige, wenngleich höchst bewegende Präsentation von »Bildern aus dem Drama der deutschen Seele ${ }^{735}$, um die Freundschaft zwischen Deutschen und Franzosen endgültig dingfest zu machen, wurde von manch einem Beobachter zwar vorsichtig formuliert. Doch gingen derartige Einwände im Enthusiasmus des Augenblicks, welcher die Reaktionen auf die gelungene Exposition beiderseits des Rheins kennzeichnete, nahezu vollständig unter. »Die Zeit« schrieb etwa:

Ein Besucher der Ausstellung >Paris-Berlin` fragte, wo eigentlich das Lachen sei in der deutschen Kunst. Man überlegte und stellte fest, daß das Lachen noch nie ein deutsches Thema war. [...] Zwischen Munchs \Schrei`, Ouvertüre zum deutschen Expressionismus, und Beckmanns `Abfahrt ` war kaum Raum für Freude. Die `Zerschleuderung der Welt ` - ist das eine deutsche Eigenart? Auf dem Weg zum Flughafen liest man an einer Mauer in Sprühdosenschrift `Schmidt assassin - solidarité avec Klaus Croissant $<$. Auch wenn man weiß, daß das die Wandmalerei einer Generation ist und nicht einer Nation, so begreift man doch auch, daß Deutschland immer noch und immer wieder der ethnologisch ferne Nachbar ist, als der er sich in dieser ebenso eindrucksvollen wie ehrlichen Ausstellung zeigt ${ }^{736}$.

731 Vgl. Andreas Razumovsky, Ein Rauchvorhang von Mißverständnissen lichtet sich. Die Ausstellung "Paris-Berlin" findet in Frankreich breite Anerkennung, in: FAZ, 02.09.1978, S. 19.

${ }^{732}$ Vgl. Jürgen Leinemann, Nur zum Schluß die vertraute Symbolik, in: Der Spiegel, 06.11.1978, S. 24f.

733 August von Kageneck, Der Erfolg von »Paris-Berlin« ändert das Deutschlandbild der Franzosen, in: Die Welt, 06.10.1978, S. 5.

734 Vgl. Ausstellung des Jahres, in: Die Zeit, 17.11.1978, S. 50, wo es heißt, dass die Ausstellung Paris-Berlin mit rund 406000 Besuchern sowohl im Hinblick auf die Publikumswirkung als auch die Resonanz der Presse die erfolgreichste Ausstellung genannt werden könne, die in Europa 1978 zu sehen gewesen sei.

735 Günther RüHLE, Bilder aus dem Drama der deutschen Seele. Paris-Berlin: Eine bedeutende Ausstellung für zwei Völker im Centre Pompidou in Paris, in: FAZ, 20.07.1978, S. 17.

${ }^{736}$ Petra Kipphoff, Die Zerschleuderung der Welt. Deutsch-französische Beziehungen und französisch-deutsche Nichtbeziehungen, in: Die Zeit, 21.07.1978, S. 34. 
War es das Ziel der staatlich protegierten Ausstellung »Paris-Berlin«, durch visuelle Effekte, einen publikumswirksamen Rahmen inmitten der französischen Hauptstadt und die hiermit einhergehende große öffentliche Aufmerksamkeit einen Beitrag zur Annäherung von Franzosen und Deutschen zu leisten, so fand die Verständigungsarbeit der verschiedenen privaten Kräfte des deutsch-französischen Milieus vergleichsweise im Verborgenen statt. Gleichwohl hatten auch sie es sich auf die Fahnen geschrieben, darauf hinzuwirken, negative Folgen der Krise des Herbstes 1977 für die Beziehungen zwischen Frankreich und Westdeutschland zu verhindern. Das Leitungsgremium der IBU diskutierte etwa im Rahmen einer Zusammenkunft in Fontainebleau im Oktober 1977 die angesichts der aufgetretenen öffentlichen Spannungen einzuleitenden Schritte. Den in jeder Hinsicht destruktiven Debatten um den Terrorismus sei, wie dort betont wurde, eine verstärkte deutsch-französische Zusammenarbeit entgegenzusetzen, vor allem "wenn man die Wiedergeburt eines schlechten Geistes vermeiden" wolle ${ }^{737}$. In einer durch die Delegierten gefassten Resolution hieß es, die wachsenden nationalen Spannungen, die sich als Folge der Terrorwelle zwischen Frankreich und Deutschland abzeichneten, seien in hohem Maße beunruhigend. Die seit Jahren bestehenden freundschaftlichen Beziehungen schienen erneut gefährdet. »Die IBU ruft deshalb alle Gemeinden, Städte und Landkreise in Frankreich und Deutschland auf, sich vermehrt für enge vertrauensvolle persönliche Kontakte, für eine herzliche Freundschaft zwischen den beiden Kulturen einzusetzen ${ }^{738}$. Diese Botschaft sollten die Mitglieder der Bürgermeister-Union in ihre Heimatorte mitnehmen, ihr dort Gehör verschaffen und vor allem im Rahmen der bestehenden kommunalen Partnerschaften dafür sorgen, dass das in den französischen Medien zuletzt beschworene Bild eines an die NS-Zeit erinnernden deutschen Polizeistaats sich in der Bevölkerung nicht dauerhaft festsetzte.

Stellungnahmen, die eine ähnliche Besorgnis dokumentieren wie die Resolution der IBU, lassen sich auch auf Seiten des BILD und des ADFG finden. Die Ereignisse des Herbstes 1977, welche einer schweren Erschütterung des deutsch-französischen Gefüges gleichgekommen seien, so die Ansicht der Verantwortlichen des ADFG, hätten gezeigt, dass die alten Ressentiments der Franzosen gegenüber den deutschen Partnern teilweise »nur hauchdünn überdeckt « seien und leicht wieder an die Oberfläche treten könnten. Die leidvolle Vergangenheit sei keineswegs bewältigt und auch deren »bewusstes

737 StASt, Bestand 1020, Bd. 13, Protokoll der Sitzung des Verwaltungsausschusses der IBU am 24. Oktober 1977 in Fontainebleau, S. 4.

738 DFI-Archiv, Ordner IBU bis 1993, Resolution des Verwaltungsausschusses der IBU zur aktuellen Situation im deutsch-französischen Verhältnis vom 31. Oktober 1977. 
Hochspielen « nicht auszuschließen ${ }^{739}$. Einer in dieselbe Richtung weisenden Aufzeichnung des BILD ist zu entnehmen:

La République fédérale d'Allemagne a été secouée par de graves événements à la fin de 1977: l'enlèvement et l'assassinat de Hanns Martin Schleyer et le suicide collectif des prisonniers de Stammheim. Les lecteurs de journaux français, prompts à s'émouvoir et à s'interroger sur les fondements de la démocratie allemande, étaient mal informés ou informés tendancieusement sur ce qui se passait outre- $\operatorname{Rhin}^{740}$.

So einhellig beide Vereinigungen in den Kontroversen um Terrorismus-Bekämpfung, Haftbedingungen der RAF-Aktivisten und die Flucht Croissants dem deutsch-französischen Verhältnis abträgliche Tendenzen erblickten, so einstimmig gelangten sie hiervon ausgehend zu dem Schluss, dass der festgestellten Misere entgegenzusteuern sei. Der Arbeitskreis wollte, wie man Bundesaußenminister Genscher in einem Schreiben mitteilte, insbesondere mithilfe seiner 1978 anstehenden Jahrestagung in Bonn die auf Frankreich gerichteten Verständigungsanstrengungen der Bundesregierung unterstützen. Es sollte der Beweis erbracht werden, »daß die private staatsbürgerliche Initiative unablässig bemüht ist, die gutnachbarlichen Beziehungen zwischen der Bundesrepublik Deutschland und der Französischen Republik von der unteren Ebene her zu fördern und auszubauen ${ }^{741}$. Von der Bonner Tagung erwarteten sich die Organisatoren in erster Linie Impulse für die Arbeit der Mitgliedsgesellschaften, welche durch ihr kontinuierliches Wirken den Geist der Freundschaft auch in künftigen schwierigen Phasen lebendig halten würden ${ }^{742}$.

Die Mitglieder des BILD sahen die vorrangige Aufgabe vor allem darin, den Franzosen eine Gegenperspektive zu der vielfach polemisierenden Berichterstattung der Tagespresse zu bieten. In den »Documents «ließ man daher "unverdächtige« Persönlichkeiten des westdeutschen öffentlichen Lebens wie Willy Brandt, Günter Grass und Heinrich Böll zu Wort kommen. Diese sollten den französischen Lesern die Hintergründe des "Deutschen Herbstes" erläutern und den Verdacht entkräften, die Bundesrepublik verlasse im Kampf

739 Vgl. VDFG-Archiv, Ansprache des deutschen Präsidenten des ADFG, Alfred Borgmann, anlässlich der Jahrestagung der deutsch-französischen Gesellschaften im August 1978, in: Mitteilungsblatt für die Deutsch-Französischen Gesellschaften 44 (1979), S. 19; VDFG-Archiv, Ordner Arbeitskreis Korrespondenz 1977-1979, Schreiben des Präsidenten des ADFG, Helmut Paetzold, an Bundeskanzler Helmut Schmidt vom 26. März 1977, S. 2; VDFG-Archiv, Ordner Pressestimmen 1978-1983, Rundschreiben an die Mitglieder des ADFG vom 15. Januar 1979.

740 BILD-Archiv, Aufzeichnung »Documents 1978«, nicht datiert, S. 1.

741 PA-AA, Zwischenarchiv, Nr. 113563, Schreiben des Präsidenten des ADFG, Helmut Paetzold, an Bundesaußenminister Hans-Dietrich Genscher vom 24. Januar 1978, S. 1.

742 Vgl. hierzu PA-AA, Zwischenarchiv, Nr. 113563, Vermerk betreffend »23. Jahreskongress des Arbeitskreises der Deutsch-Französischen Gesellschaften in Bonn vom 23.-27.8.78 « vom 24. Januar 1978 und Vermerk betreffend "Jahrestagung des Arbeitskreises DeutschFranzösischer Gesellschaften« vom 1. Februar 1978. 
gegen die RAF den Boden der Rechtsstaatlichkeit ${ }^{743}$. Aufklärungsarbeit dieser Art, so die in den Reihen des BILD vorherrschende Meinung, werde helfen, das deformierte Deutschlandbild der Franzosen zu wandeln und die notwendigen Voraussetzungen für ein tiefer reichendes Verständnis zwischen den Bevölkerungen beider Länder schaffen ${ }^{744}$.

Für das DFI in Ludwigsburg galt es in Reaktion auf die öffentlichen Konfrontationen des Herbstes 1977 vor allem die Rolle der Medien beiderseits des Rheins auf den Prüfstand zu stellen und auszuleuchten, in welcher Weise die als unzureichend empfundene Informationsvermittlung zwischen Frankreich und der Bundesrepublik verbessert werden könnte. Hierzu organisierte das Institut in Zusammenarbeit mit der Katholischen Akademie Hamburg, der Robert-Bosch-Stiftung und der Pariser Fondation nationale des sciences politiques Ende 1978 unter der wissenschaftlichen Leitung von Robert Picht und Henri Ménudier ein mehrtägiges Kolloquium. Die Teilnehmer sollten in einen offenen Austausch über die Frage gebracht werden, wie eine verantwortungsvolle Berichterstattung über das jeweilige Nachbarland auszusehen habe. Eine große Anzahl sowohl westdeutscher als auch französischer Korrespondenten und Redakteure aus Presse, Rundfunk und Fernsehen ${ }^{745}$ diskutierte hier über die Genese und das Vorhandensein nationaler Stereotype, die sachgerechte Präsentation von Informationen, kulturelle Unterschiede und ihre Auswirkungen, die Mittlerfunktion von Journalisten und die deutschfranzösische Kooperation im Medienbereich. Der Tagungsbericht hielt fest: "Auseinandersetzungen, wie sie im Herbst 1977 vor allem zwischen einzelnen Presseorganen, aber auch in der Öffentlichkeit, über das Bild des >hässlichen Deutschen geführt wurden, sollten nach Hamburg in dieser Form nicht mehr möglich sein ${ }^{746}$. Dies nicht nur deshalb, weil sich die Berichterstattung ihrer Verantwortung bewusster geworden sei, sondern auch, weil beide Seiten verstanden hätten, dass "europäische Innenpolitik« auch die kritische Auseinandersetzung mit inneren Vorgängen im Nachbarland einschließen müsse.

743 Vgl. Willy BRANDT, La »seconde démocratie allemande « face à l'épreuve, in: Documents 33/1 (1978), S. 43-52; Günter Grass, S'auto-détruire ou construire le socialisme, in: Documents 33/1 (1978), S. 53-64; Heinrich BöLL, Le passé terroriste de notre histoire, in: Documents 33/1 (1978), S. 65-71.

${ }^{74}$ Vgl. BILD-Archiv, Aufzeichnung »Documents 1978«, nicht datiert, S. 1; Tätigkeitsbericht 1977/78 der GÜZ und des BILD vom 3. Oktober 1979; Compte rendu des travaux de l'assemblée générale du BILD, 20 janvier 1979, annexe 4: Revue »Documents«.

745 Anwesend waren unter anderem Klaus Arnsperger (SZ), Otto R. Beger (ZDF), Bernard Brigouleix (Le Monde), Pierre Durand (L'Humanité), Heiko Engelkes (ARD), Karl Jetter (FAZ), Lutz Krusche (FR), Michel Meyer (Radio France), Jean-Paul Picaper (Le Figaro), vgl. DFI-Archiv, Ordner Kolloquium Hamburg 1978, Teilnehmerliste des Kolloquiums »Information und deutsch-französische Beziehungen« vom 23.-25. November 1978 in Hamburg.

746 DFI-Archiv, Ordner Kolloquium Hamburg 1978, Bericht Robert Pichts zu Ergebnissen und Perspektiven des Kolloquiums »Information und deutsch-französische Beziehungen« vom 23.-25. November 1978 in Hamburg vom 9. Mai 1979, S. 1. 
Das Aufbrechen von Spannungen zwischen Frankreich und Westdeutschland sei, wie es weiter hieß, allerdings auch in Zukunft immer möglich. Die mediale Berichterstattung dürfe diese weder verschleiern noch allerdings sie forcieren wie im Verlaufe der Krise von 1977. Sie habe vielmehr die Aufgabe, Konfliktsituationen über die Irritationen des Tages hinaus auf ihre Ursachen hin zu analysieren und den Menschen beider Länder verständlich zu machen. Die Frage, ob die im Rahmen des Hamburger Kolloquiums versammelten Journalisten in ihrer künftigen Arbeit etwaige Vorurteile tatsächlich ausblendeten, mehr Wert auf sachliche Informationen als auf eine der Auflagenhöhe zuträglichere Freund-Feind-Geschichte legten und die Notwendigkeit einer engen deutsch-französischen Zusammenarbeit als Leitidee akzeptierten, muss zwar unbeantwortet bleiben. Doch die Veranstalter der Tagung konnten es allemal als Erfolg verbuchen, nach den verbalen Gefechten des Jahres 1977 ein derart breites Feld an Medienrepräsentanten beider Seiten miteinander ins Gespräch gebracht zu haben.

In der Rolle von Vermittlern zwischen den verhärteten Fronten der veröffentlichten Meinung in Frankreich und der Bundesrepublik sahen sich auch Alfred Grosser und Joseph Rovan. Sie wurden nicht müde, beruhigend, mahnend oder klagend in die deutsch-französischen Debatten einzugreifen, welche sich an der Frage des bundesdeutschen Vorgehens gegen die RAF entzündet hatten. Rovans Buch "L'Allemagne n'est pas ce que vous croyez«, erschienen 1978, ist als eine direkte Replik auf die ungerechten Anfeindungen $\mathrm{zu}$ verstehen, denen die Bundesrepublik in der zweiten Jahreshälfte 1977 seiner Auffassung nach ausgesetzt war $^{747}$. In der Einleitung konstatierte der Autor:

Bien que l'Allemagne soit depuis plus de vingt ans notre alliée politique et militaire, les Français dans leur grande majorité l'ignorent ou l'imaginent autre qu'elle n'est. [L']Allemagne voisine déconcerte, irrite et inquiète beaucoup de Français, à tel point qu'une large partie de l'opinion a présentement l'impression qu'en République fédérale d'Allemagne ce sont les démocrates qui menacent la démocratie et que les terroristes extrémistes la défendent ${ }^{748}$.

Allzu leicht ließen sich die Franzosen, wie Rovan urteilte, vor dem Hintergrund ihrer noch immer vorhandenen althergebrachten Ängste und klischeehaften Vorstellungen dazu verleiten, Deutschland und die Deutschen nicht so zu sehen, wie sie seien, sondern so, wie die Kampagnen linker Meinungsmacher es ihnen vorgäben. Hiergegen wolle er mit seinem Buch ankämpfen: "'écris ce petit livre pour lutter contre l'ignorance, l'aveuglement plus ou moins volontaire et la propagande mensongère dont l'Allemagne est aujourd'hui l'objet ${ }^{749}$. Mehr als einmal bekräftigte Rovan auf den folgenden

747 Vgl. hierzu Henri Ménudier, L’Allemagne à laquelle il croit, in: Hartweg (Hg.), À Joseph Rovan, S. 95-101.

748 Rovan, L'Allemagne n'est pas ce que vous croyez, S. 7.

749 Ibid., S. 9. 
rund einhundert Seiten, dass der in den französischen Zeitungen kolportierte Vorwurf, die in Stammheim inhaftierten RAF-Mitglieder würden einer "Isolationsfolter « ausgesetzt, vollkommen haltlos sei. Darüber hinaus griffen die bundesdeutschen Behörden trotz der Schwere der terroristischen Bedrohung zu moderaten Gegenmaßnahmen. Der in Frankreich umhergehende Verdacht, die westdeutsche Demokratie bewege sich in Richtung eines autoritären Regimes, könne daher nicht nur als absurd, sondern nahezu als beleidigend bezeichnet werden: „Ce qui s'est passé sur ce point en France [...] dans un grand nombre d'organes de la presse, n'est pas loin de ressembler à une véritable agression contre la démocratie allemande, dont on s'efforce trop souvent d'accroître les difficultés au lieu de lui manifester compréhension et solidarité « ${ }^{750}$. Die demokratische Entwicklung der Bundesrepublik während der vergangenen Jahrzehnte habe, wie Rovan schrieb, Respekt verdient. Dessen sollten seine Landsleute sich bewusst werden.

Um seinen Positionen öffentliche Aufmerksamkeit zu sichern, brachte Rovan sein Buch im Verlaufe des Jahres 1978 dem französischen Publikum im Rahmen zahlreicher Vorträge nahe ${ }^{751}$, so etwa im Dezember 1978 im Goethe-Institut in Lyon. Einem diesbezüglichen Bericht des dortigen Generalkonsulats für das Auswärtige Amt ist zu entnehmen, dass aus dem Diskussionsabend mit Rovan unter dem Gesichtspunkt der bundesdeutschen politischen Öffentlichkeitsarbeit eine äußerst positive Darstellung der politischen Verhältnisse in der Bundesrepublik resultiert habe. "Davon ausgehend, daß der Durchschnittsfranzose über die deutschen Realitäten schlecht unterrichtet ist, betonte Rovan die Stabilität der Demokratie seit der Gründung der Bundesrepublik «752. Für Rovan leitete sich aus den öffentlichen Konfrontationen des Jahres 1977 einmal mehr die Verpflichtung ab, Deutsche und Franzosen auf die unbedingte Notwendigkeit einer engen Partnerschaft hinzuweisen. In Anbetracht der Tatsache, dass Elemente der Krise zwischen beiden Ländern weiter schwelten, sah er sich gehalten, »immer wieder warnend oder vorschlagend daran zu erinnern, daß für die europäischen Völker eine Existenz in Freiheit und Unabhängigkeit nur gemeinsam in einem um die deutsch-französische Säule organisierten Europa zu behaupten ist « ${ }^{753}$.

750 Ibid., S. 99.

751 Vgl. hierzu IMEC, Fonds Joseph Rovan, Schreiben des Goethe-Instituts Marseille an Joseph Rovan vom 12. Juli 1978; Schreiben des Publizisten Jean Toulat an Joseph Rovan vom 31. Oktober 1978; Schreiben des Deutsch-Französischen Kreises Düsseldorf an Joseph Rovan vom 9. November 1978; Schreiben des Germanisten Philippe Lasserre an Joseph Rovan vom 6. April 1979; AMAE Nantes, Bonn Ambassade, Bd. 368, Vermerk der Direction générale des relations culturelles, scientifiques et techniques betreffend "Les études d'allemand en France" vom 4. Juli 1978, S. 8f.

752 PA-AA, Zwischenarchiv, Nr. 117461, Schreiben des deutschen Generalkonsulats Lyon, Harder, an das Auswärtige Amt betreffend »Vortrag von Professor Rovan, Universität Paris-Vincennes, in Lyon" vom 5. Dezember 1978, S. 1.

753 Joseph Rovan, Die deutsch-französische Diskussion, in: Dokumente 34/3 (1978), S. 187-189, hier S. 189. 
Ähnlich dem Ansinnen seines Mitstreiters Rovan war auch Alfred Grosser daran gelegen, um mehr Verständnis für das bei allzu vielen Franzosen in Verruf geratene Nachbarland zu werben. Bereits nach der Verstärkung der bundesdeutschen Anti-Terror-Maßnahmen im Gefolge der tödlichen Anschläge der RAF auf Siegfried Buback und Jürgen Ponto im Frühjahr und Sommer 1977 hatte Grosser in »Le Monde« eindringlich davor gewarnt, die Bundesrepublik als Polizeistaat zu diffamieren. Vielmehr seien die Franzosen zur Solidarität mit den Deutschen angehalten, die sich angesichts der schweren Zeit, die sie durchlebten, von ihren Partnern nicht allein gelassen wähnen dürften. Es sei, wie Grosser ausführte, in hohem Maße bedauernswert, wenn die französische Haltung zu Deutschland weiterhin auf verzerrten Visionen der westdeutschen Realität, auf Mythen und falschen Vorstellungen beruhe $^{754}$. Das sich im September 1977 ausgehend von dem Artikel Jean Genets in den französischen Medien entfaltende Bild des brutalen deutschen Staates musste Grosser einerseits schmerzlich ins Bewusstsein rufen, dass sein Appell kaum Wirkung erzielt hatte, ihn andererseits jedoch in der Ansicht bestärken, dass seine Mittlertätigkeit unverzichtbarer war denn je. In wiederholten öffentlichen Stellungnahmen kritisierte er daher in den folgenden Wochen mit allem Nachdruck die Deutschland-Berichterstattung von weiten Teilen der französischen Presse als einseitig, klischeehaft und aggressiv ${ }^{755}$.

Deutliche Worte fand er insbesondere in einem Interview mit "Le Nouvel Observateur « Ende Oktober 1977. Schenke der Leser, wie Grosser hier anführte, gegenwärtig den französischen Zeitungen Glauben, so müsse bei ihm zwangsläufig der Eindruck entstehen, Westdeutschland sei von Alt-Nazis und linksextremen Terroristen bevölkert. Derartige Zuspitzungen seien ebenso ungerecht wie falsch: »la société d'aujourd'hui est la plus démocratique que l'Allemagne ait jamais connue, et elle l'est au moins autant, si ce n'est plus, que la France d'aujourd'hui. Alors, il serait peut-être temps de voir ce pays comme il est, non comme on l'imagine « ${ }^{756}$. Die Franzosen, so Grosser, neigten dazu, das Nachbarland vorzuverurteilen, ohne sich jedoch die Mühe zu machen, ihre Meinung auf mehr als eine oberflächliche und sich zumeist ausschließlich an Negativbeispielen orientierende Wahrnehmung zu stützen. Da werde Artikel um Artikel über die »Hexenjagden« in der Bundesrepublik veröffentlicht. Der Leser erhalte aber im Gegenzug keinerlei Informationen darüber, dass die Meinungsfreiheit und -vielfalt dort ausgeprägter sei als in Frankreich. Da werde über jeden einzelnen Prozentpunkt, den neo-nazistische Parteien bei Wahlen erhielten, ausführlich berichtet und die Gefahr eines

754 Vgl. Alfred Grosser, Les malaises allemands, in: Le Monde, 07.08.1977, S. 1 und S. 3.

755 Vgl. hierzu Ders., Les phantasmes français, in: Le Monde, 09.09.1977, S. 1f.; Ders., Cessons de craindre et de condamner, in: Le Point, 17.10.1977, S. 89-91; Ders., Contre le terrorisme, in: Le Monde, 18.10.1977, S. 1 und S. 5.

756 Josette AlıA, Alfred Grosser: »La société allemande est plus démocratique que la française«, in: Le Nouvel Observateur, 31.10.1977, S. 42f. 
Wiedererwachens nationalsozialistischer Strömungen beschworen. Dass jedoch ein Großteil der Bundesbürger 1969 mit Willy Brandt einen Exilanten, Sozialisten und Widerständler an die Spitze der Regierung gewählt hätte, sei kaum der Rede wert.

»Les Français«, so Grossers ernüchternde Feststellung, »en arrivent toujours aux stéréotypes quand il s'agit de l'Allemagne «757. Dies führe in der Konsequenz dazu, dass man in Frankreich die Mär von den unmenschlichen Haftbedingungen in Stammheim genauso glaube wie an die Rechtschaffenheit Klaus Croissants. Vor diesem Hintergrund geriet die deutsch-französische Verständigungsarbeit im Jahr 1977, wie Grosser in einem Vortrag in Straßburg bekundete, zu einer höchst mühseligen, gar entmutigenden Angelegenheit: »je dois dire que pour quelqu'un comme moi, qui, depuis maintenant un peu plus de 30 ans, s'occupe de problèmes franco-allemands il y a eu peu de périodes aussi profondément décourageantes que la période actuelle ${ }^{758}$.

Nicht nur Alfred Grosser erkannte derweil in den Auseinandersetzungen, welche ausgehend von der Flucht Croissants im Juli 1977 nach Frankreich die Gemüter diesseits und jenseits des Rheins über mehrere Monate hinweg erhitzt hatten, eine Krise, die tiefer zu reichen schien, als frühere deutschfranzösische Konflikte. Die geradezu bestürzende Verständnislosigkeit für die Belange des Nachbarlandes, die in den Debatten zu Tage getreten war, der anklagende und streckenweise sogar feindselige Tonfall, welcher die Berichte zahlreicher Presseorgane gekennzeichnet hatte und nicht zuletzt das vielfach festzustellende bewusste Inkaufnehmen eines dauerhaften öffentlichen Zerwürfnisses zwischen beiden Ländern ließen zahlreiche Verfechter der deutsch-französischen Freundschaft aufschrecken. Sah man in Frankreich bereits ein unmenschliches Deutschland dräuen, das selbst vor Folter nicht zurückschreckte, einen "westlichen Archipel Gulag", sprach aus den westdeutschen Entgegnungen das Gefühl, von schadenfrohen Nachbarn, die doch Freunde hatten sein sollen, in der Stunde der Not nicht nur allein gelassen, sondern gar angefeindet zu werden. Mit welchen Mitteln konnten diese Gegensätze, so mochte sich mancher fragen, der für die Aussöhnung eingetreten war, noch überbrückt werden? Waren dies nicht erste Anzeichen dafür, dass die Bereitschaft zur Verständigung hüben wie drüben zusehends geringer wurde und sich die nach dem Zweiten Weltkrieg in so hoffnungsvoller Zweisamkeit verbundenen Partner zunehmend auseinanderentwickelten?

Gewiss: Auf der Habenseite standen diesen Vorahnungen die fortwährenden Bemühungen der Regierungen um Ausgleich entgegen, effektvolle auswärtige Repräsentationen wie die Ausstellung »Paris-Berlin«, Initiativen und Appelle aus dem Milieu der privaten Organisationen und die Vernunft einfordernden Stimmen von Mittlerpersönlichkeiten wie Grosser und Rovan. Doch vermochten es die in solcherlei Gestalt geschaffenen menschlichen

757 Ibid., S. 43.

758 Grosser, Convergences et divergences franco-allemandes, S. 26. 
Bindungen allem Anschein nach nicht, die Entfaltung der zentrifugalen Kräfte, welche die deutsch-französischen Beziehungen nicht nur 1977, sondern während des gesamten Jahrzehnts immer wieder ernstlichen Zerreißproben aussetzten, zu verhindern. Wie oft schon hatten die Protagonisten der Annäherung in den vorangegangenen Jahren nach jüngst aufgetretenen Spannungen den Vorsatz bekundet, künftige Vertrauenskrisen schon in der Entstehungsphase unterbinden zu wollen. Wie oft waren sie trotz erheblicher Anstrengungen, die sie anschließend unternommen hatten, nur wenig später in enttäuschender Weise eines Besseren belehrt worden. Ostpolitik und deutsche Frage, Agrarpreiserhöhung und Europa-Wahl, Klarsfeld-Prozess und "Hitler-Nostalgie«, »Radikalenerlass" und Terrorismus - der Blick auf die Schlagworte, in denen sich die deutsch-französischen Auseinandersetzungen der 1970er Jahre widerspiegelten, brachte den verschiedenen Akteuren der Verständigung gegen Ende der Dekade ins Bewusstsein, dass es ihnen kaum gelungen war, die Konflikte, die beiderseits des Rheins weite Kreise der Presselandschaft bewegt hatten, wirkungsvoll einzudämmen. Eine solche Bilanz musste beinahe zwangsläufig nicht nur eine genaue Analyse der möglichen Ursachen, sondern noch viel mehr neuerliche Initiativen der Verständigung herausfordern. 
